\title{
Environmental Effects of Fog Oil and CS Usage at the Combat Maneuver Training Center, Hohenfels, Germany
}

by K.L. Brubaker, D.H. Rosenblatt," and C.T. Snyder*

Energy Systems Division,

Argonne National Laboratory, 9700 South Cass Avenue, Argonne, Illinois 60439

March 1992

Work sponsored by United States Army,

7th Army Training Command, Grafenwoehr, Federal Republic of Germany

\footnotetext{
*Rosenblatt is affiliated with Argonne's Environmental Assessment and Information Sciences Division and Snyder with Argonne's Chemical Technology Division, Analytical Chemistry Laboratory.
} 


\section{Contents}

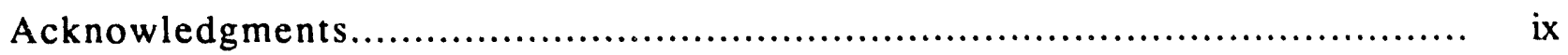

Abstract..............................................................................

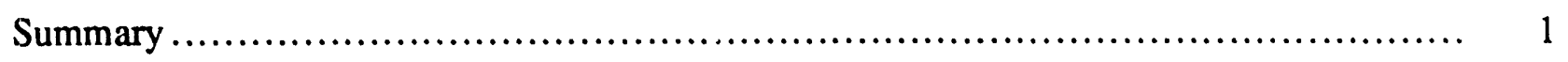

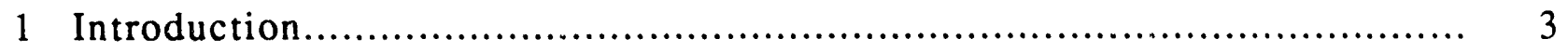

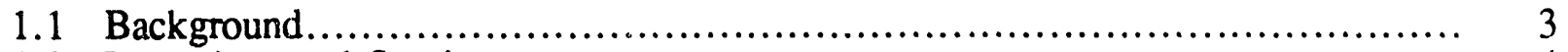

1.2 Location and Setting........................................................ 4

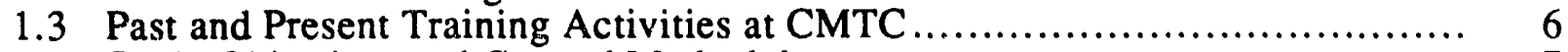

1.4 Study Objectives and General Methodology ................................ 7

2 Summary of Available Training Data .............................................. 9

3 Summary of Known Health and Environmental Effects................................. 12

3.1 Effects of CS............................................................... 12

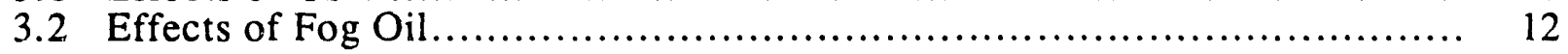

4 Field Sampling Program........................................................... 15

4.1 Site Location Selection Methodology ............................................ 15

4.2 Sampling Program Procedures.................................................. 19

4.2.1 Soil Sampling Procedure ............................................. 20

4.2.2 Vegetation Sampling Procedure.............................................. 24

4.2.3 Stainless-Steel Equipment Cleaning Procedure …............................ 26

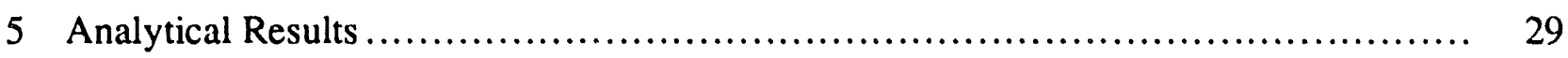

5.1 Fog Oil Samples .......................................................... 30

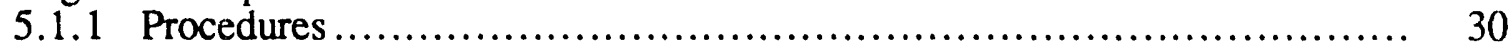

5.1 .2 Results ............................................................ 30

5.2 Environmental Samples....................................................... 34

5.2.1 Sample Workup Procedures............................................ 34

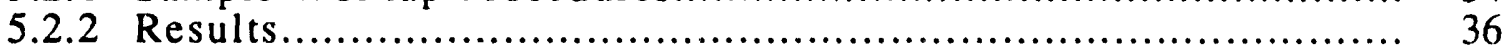

6 Discussion and Evaluation ......................................................... 58

6.1 Short-Term Health Effects...................................................... 58

6.2 Long-Term Health Effects............................................... 59

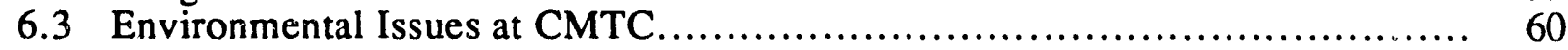

7 Conclusions and Recommendations ................................................ 63

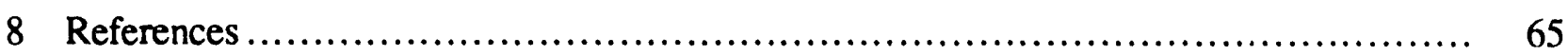

Appendix A: Nature and Effects of CS and Its Hydrolysis Products................. 67

Appendix B: Nature and Effects of Fog Oil Smoke .................................. 79 


\section{Contents (Cont.)}

Appendix C: Conversion of GPS Positions to Local Coordinates.................... 95

Appendix D: Data, Sample, and Document Management $\ldots \ldots \ldots \ldots \ldots \ldots \ldots \ldots \ldots \ldots \ldots .105$

Appendix E: Analytical Procedures ........................................... 111

Appendix F: Target List for U.S. Environmental Protection Agency Semivolatile Priority Pollutants

\section{Tables}

1 September 1990 CMTC Field Program Sampling Locations ................... 18

2 Sample ID Number Information Codes...................................... 19

3 September 1990 CMTC Sampling Program Chronology....................... 21

4 Environmental Samples Collected at CMTC ................................. 22

5 Tentative Identification of Substances in Fog Oil Sample HTA999999N03 ....... 32

6 Tentative Identification of Substances in Fog Oil Sample HTA975623N01 ....... 34

7 CMTC Soil and Sediment Samples Arranged by Sample Code.................... 37

8 CMTC Vegetation Samples Arranged by Sample Code ....................... 38

9 Environmental Samples Chosen for GC/MS Analysis ......................... 39

10 Tentative Identification of Substances in Environmental Sample HTA979682S01....... 48

11 Tentative Identification of Substances in Environmental Sample HTA019606S01 ....... 49

12 Tentative Identification of Substances in Environmental Sample HTA020603R01 ..... 50

13 Tentative Identification of Substances in Environmental Sample HTA037606S01 ....... 51

14 Tentative Identification of Substances in Environmental Sample HTA038601S01....... 53

15 Tentative Identification of Substances in Environmental Sample HTA056593SC1...... 54

16 Tentative Identification of Substances in Environmental Sample HTA056593S02....... 55

17 Tentative Identification of Substances in Environmental Sample HTA059601S02....... 56

18 CMTC Soil and Sediment Samples Arranged by Integrated Area ................ 62 


\section{Tables (Cont.)}

B.1 Percentages of Main Classes of "Old" Fog Oil Constituents ..................... 80

B.2 Carbon Numbers, Molecular Weights, Vapor Pressures, and Distribution of Fog Oil Constituents...................................................... 80

B.3 Physicochemical Requirements for Type SGF-2 Fog Oil...................... 81

B.4 Potencies of PAHs Relative to that of Benzo[a]pyrene.......................... 86

C.1 Linear Transformation Coefficients.......................................... 97

C.2 Nonlinear Parts of the MREs for Coordinate Conversions............................ 98

C.3 Parameters for the Conversion of WGS 84 to Local Coordinates ............... 100

C.4 Ellipsoid Parameter Values for Commonly Used Datums............................ 102

D.1 Sample ID Number Information Codes..................................... 106

D.2 Sample Label Information....................................................... 108

D.3 Sample Tag Information........................................................... 108

D.4 Documents Used by the Sampling and Analysis Team ......................... 109

E.1 CMTC GC/FID Analyses ................................................. 112

E.2 Sample Handling Chronology ................................................... 116

E.3 Matrix Spike and Matrix Spike Duplicate Comparison ......................... 122

E.4 Linearity Calibration Factors........................................................... 124

E.5 Calibration Standard Retention Times ......................................... 124

E.6 Calibration Standard Runs ................................................... 125

E.7 Percentage Differences in Soil Analysis Sequence Calibration Factors............. 127

F.1 EPA Semivolatile Priority Pollutants................................................. 172

\section{Figures}

1 Combat Maneuver Training Center..................................................... 5

2 Smoke Usage at CMTC, June-December, 1988.................................... 9 
Figures (Cont.)

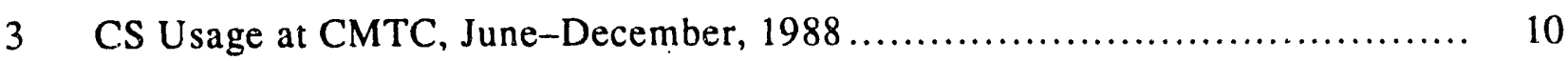

$4 \quad$ Smoke Usage at CMTC, June-August 7, 1990............................ 11

5 CMTC Fog Oil/CS Study Areas ............................................... 16

6 Total Ion Chromatogram of Fog Oil Sample HTA999999N03 .................. 31

7 Total Ion Chromatogram of Fog Oil Sample HTA975623N01 .................. 33

8 Total Ion Chromatogram of Sample HTA979682S01.............................. 40

9 Total Ion Chromatogram of Sample HTA019606S01.............................. 41

10 Total Ion Chromatogram of Sample HTA020603R01 ......................... 42

11 Total Ion Chromatogram of Sample HTA037606S01.............................. 43

12 Total Ion Chromatogram of Sample HTA038601S01............................... 44

13 Total Ion Chromatogram of Sample HTA056593S01.............................. 45

14 Total Ion Chromatogram of Sample HTA056593S02 ............................. 46

15 Total Ion Chromatogram of Sample HTA059601S02............................. 47

E.1 GC/FID Chromatogram of Fog Oil in Hexane .............................. 129

E.2 GC/FID Chromatogram of Sample HTA016616S01 ......................... 130

E.3 GC/FID Chromatogram of Sample HTA016616S02 ........................ 131

E.4 GC/FID Chromatogram of Sample HTA018597S01 .......................... 132

E.5 GC/FID Chromatogram of Sample HTA019606S01 ........................ 133

E.6 GC/FID Chromatogram of Sample HTA019606\$S02 ........................ 134

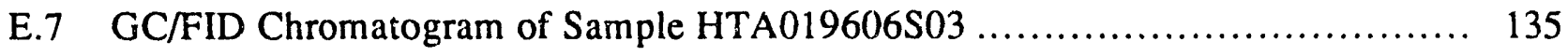

E.8 GC/FID Chromatogram of Sample HTA020603R01 ......................... 136

E.9 GC/FID Chromatogram of Sampie HTA020608R01 ........................ 137

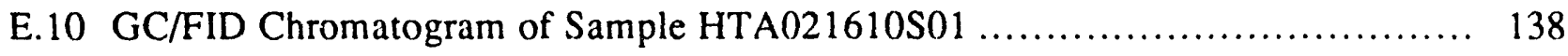

E.11 ,C/FID Chromatogram of Sample HTA023604S01 ......................... 139 
Figures (Cont.)

E.12 GC/FID Chromatogram of Sample HTA033606S01 .......................... 140

E.13 GC/FID Chromatogram of Sample HTA036605R01 .......................... 141

E.14 GC/FID Chromatogram of Sample HTA036605R02 ........................ 142

E.15 GC/FID Chromatogram of Sample HTA037606S01 ........................ 143

E.16 GC/FID Chromatogram of Sample HTA038601S01 ......................... 144

E.17 GC/FID Chromatogram of Sample HTA043597R01 ........................... 145

E.18 GC/FID Chromatogram of Sample HTA056593S01 ........................... 146

E.19 GC/FID Chromatogram of Sample HTA056593S02 ….................... 147

E.20 GC/FID Chromatogram of Sample HTA056603S01 ........................ 148

E.21 GC/FID Chromatogram of Sample HTA056625R01 .......................... 149

E.22 GC/FID Chromatogram of Sample HTA059601S01 ........................ 150

E.23 GC/FID Chromatogram of Sample HTA059601S02 ......................... 151

E.24 GC/FID Chromatogram of Sample HTA061596S01 ......................... 152

E.25 GC/FID Chromatogram of Sample HTA061596S02 ......................... 153

E.26 GC/FID Chromatogram of Sample HTA062592R01 .......................... 154

E.27 GC/FID Chromatogram of Sample HTA065585R01 ........................ 155

E.28 GC/FID Chromatogram of Sample HTA065598S01 ........................ 156

E.29 GC/FID Chromatogram of Sample HTA073624R01 ......................... 157

E.30 GC/FID Chromatogram of Sample HTA096600R01 ......................... 158

E.31 GC/FID Chromatogram of Sample HTA977673R01 .......................... 159

E.32 GC/FID Chromatogram of Sample HTA979679S01 ......................... 160

E.33 GC/FID Chromatogram of Sample HTA979682S01 ......................... 161 
Figures (Cont.)

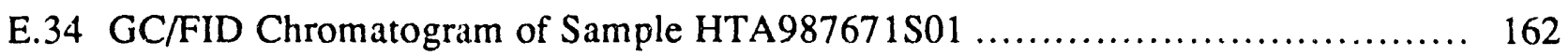

E.35 GC/FID Chromatogram of Sample HTA018597V01 .......................... 163

E.36 GC/FID Chromatogram of Sample HTA021610V01 .......................... 164

E.37 GC/FID Chromatogram of Sample HTA021610V02 …..................... 165

E.38 GC/FID Chromatogram of Sample HTA038601 V01 ......................... 166

E.39 GC/FID Chromatogram of Sample HTA056593V01 ......................... 167

E.40 GC/FID Chromatogram of Sample HTA056593V02 ........................ 168

E.41 GC/FID Chromatogram of Sample HTA056603V01 .......................... 169

E.42 GC/FID Chromatogram of Sample HTA979679V01 ........................ 170 


\section{Acknowledgments}

individuals:

The authors would like to acknowledge the invaluable assistance of the following

Mr. John Brent, Chief, Environmental Management Office, Directorate of Engineering and Housing (DEH) at the Combat Maneuver Training Center (CMTC), Hohenfels, Germany, for his interest, organizational support, and hospitality during the planning and execution of this program;

Mr. Bernd Weber, DEH, for his interest and participation as a member of the field sampling team;

Mr. Albert Böhm, DEH, for his unflagging efforts to make our visit a pleasant one in the Bavarian city of Regensburg;

Capt. Negron and the "6900 Smoke group" for valuable information about the training activities conducted at CMTC Hohenfels, and in particular about the past and present usage of fog oil obscurant and of CS compound;

Dr. Donald O. Johnson, Argonne National Laboratory/Energy Systems Division (ANL/ESD), Project Principal Investigator, for project management;

Mr. Stanley Zellmer, ANL/ESD, for arranging to obtain the necessary permits to import foreign soil samples into the United States and for serving as a member of the field sampling team;

Dr. Dorland Edgar, ANL/ESD, for serving as a member of the field sampling team; and

Drs. Amrit Boparai and Peter Aznavoorian, ANL Chemical Technology Division/Analytical Chemistry Laboratory, for providing high-quality analytical services in support of this program. 


\title{
Environmental Effects of Fog Oil and CS Usage at the Combat Maneuver Training Center, Hohenfels, Germany
}

by

\author{
K.L. Brubaker, D.H. Rosenblatt, and C.T. Snyder
}

\begin{abstract}
In response to environmental concerns at the Combat Maneuver Training Center (CMTC), Hohenfels, Germany, the U.S. Army 7th Army Training Command commissioned a scientific study by Argonne National Laboratory to investigate specific issues. The study involved three parts: (1) a field study to determine if fog oil and CS (a compound named after its discoverers, B.B. Carson and R.W. Stoughton) were accumulating in the CMTC environment, (2) a screening of selected soil samples for the presence of U.S. Environmental Protection Agency priority pollutants, and (3) a literature review of the health effects of fog oil and CS, as well as a review of training practices at CMTC. No fog oil or fog oil degradation products were detected in any soil, sediment, or vegetation sample collected at CMTC. Trace quantities of one or more priority pollutants were tentatively detected in three of eight soil and sediment samples. However, the priority pollutant concentrations are so low that they pose no environmental or health hazards. No evidence of widespread or significant contamination in the training areas was found. Crucial data needed to fully evaluate both acute and chronic health effects of civilian exposures to CS at CMTC are not available. On the basis of the available literature, long-term health effects in the civilian population near CMTC that could result from the use of fog oil and CS during training activities are believed to be negligible. Military fog oil is subjected to a refining process that removes carcinogens typically present in petroleum oils. At CMTC, diesel fuel is often mixed with fog oil in cold weather to facilitate the generation of fog. The health risk associated with this practice should be investigated. Operational restrictions currently in effect at CMTC are adequate to prevent short-term respiratory effects.
\end{abstract}

\section{Summary}

In recent years, the use of fog oil aerosol and CS during training activities at the U.S. Army Combat Maneuver Training Center (CMTC) in southern Germany has prompted complaints from civilians in the towns and villages surrounding CMTC. In addition, an extensive list of questions dealing with general environmental issues at CMTC was recently presented to the 
Minister for the Environment of the State of Bavaria, in which CMTC is Jxated. Because of these concerns, the U.S. Army 7 th Army Training Command commissioned a scientific study that would address some of these issues. This report describes the objectives, methodologies, results, conclusions, and recommendations of that study.

The emphasis of the study is on the potential health and environmental effects of the use of CS and fog oil aerosol at CMTC. The available literature on the health and environmental effects of these substances was reviewed and summarized. It was found that crucial data needed to estimate the threshold CS concentration, below which no respiratory effects would be seen even in sensitive individuals, are not available. Data on possible health effects of long-term, low-level exposures to CS are also not available.

Petroleum oils that contain polynuclear aromatic hydrocarbons (PAHs) are known to be carcinogenic upon repeated, long-term dermal exposure, but no evidence exists that inhalation of oil mists at typical occupational concentrations of up to $5 \mathrm{mg} / \mathrm{m}^{3}$ causes lung cancer. Because oils that contain PAHs are believed to be carcinogenic, military fog oil is subjected to an additional refining process to remove or chemically change any PAHs present. The common cold-weather practice of mixing diesel fuel with fog oil prior to use in the field appears to circumvent the special processing by reintroducing aromatic hydrocarbons from diesel fuel into the oil. However, this practice seems unlikely to pose significant health risks, and the practice should be allowed to continue until these risks are evaluated by a more thorough analysis.

On the basis of (1) the information available on the health effects of CS and fog oil and (2) a qualitative understandisg of atmospheric transport and dispersion in complex terrain, longterm health effects in the civilian population near CMTC are believed to be negligible. The potential exists for short-term respiratory effects to occur in sensitive individuals in off-post areas under some circumstances, but current operational restrictions on the quantities and locations of CS and fog oil aerosol usage are adequate to prevent such effects.

A field sampling program was undertaken to examine the possibility that fog oil, the CS degradation product o-chlorobenzaldehyde (OCB), or some other toxic or hazardous pollutant might be present in significant quantities in the soil at CMTC. No fog oil or OCB as detected in any soil, sediment, or vegetation sample taken as part of this program; to go undetected, the concentration of any fog oil present in the soil or sediments must have been below approximately 5-11 parts per million (ppm). Trace quantities of one or more of the substances classified as priority pollutants by the U.S. Environmental Protection Agency were tentatively detected in three of eight soil and sediment samples analyzed for the presence of priority pollutants. No evidence of widespread contamination in the CMTC training areas was found; the concentrations of the priority pollutants found are very low, and they present no environmental or health hazards at CMTC. 


\section{Introduction}

This report describes the results of a study of the potential environmental and health effects associated with the use of fog oil aerosol obscurant and $\mathrm{CS}^{*}$ during training activities at the U.S. Army Combat Maneuver Training Center (CMTC), Hohenfels, Germany.

\subsection{Background}

In recent years, the use of obscurants, primarily fog oil aerosol, and of CS during training activities at CMTC has prompted complaints from German citizens in the towns and villages surrounding CMTC. Citizens have complained directly to the CMTC public relations office or to local governmental officials. The complaints received by CMTC include symptoms, such as irritation of the eyes, nose, and throat, that might result from exposure to CS or to high levels of fog oil aerosol. The CMTC public relations office has kept a record of the complaints received since at least March 1985, but it is difficult to clearly associate specific complaints with specific training activities. The frequency and the location of the complaints are highly variable, although historically citizens in the town of Hohenburg and its environs seem to have complained more frequently than those elsewhere, and the available records of the use of smoke and CS are incomplete. For example, only two complaints have been recorded at CMTC that refer specifically to the use of CS, and one of these complaints is very ambiguous; both complaints came from the small town of Albertshofen, near the western edge of CMTC. Neither incident can be correlated with any data on known CS use. Furthermore, no documented or anecdotal evidence has been found that CS has ever been used anywhere within several kilometers of Albertshofen.

According to the results of a brief survey undertaken as part of the work described in this report, 62 complaints were received by CMTC between March 21, 1985, and August 1, 1990, an average rate of about one complaint per month. Of these complaints, by far the highest percentage (29.0\%) was for smoke drifting out of CMTC. The next highest categories were excessive noise, 21.0\%; window breakage and other damage, $14.6 \%$; and dust and dirt, mostly on the roads, $12.9 \%$. Of the 18 recorded complaints about smoke, 13 of them came from individuals in the towns of Hohenburg and Stettkirchen, two towns about one kilometer apart that lie very near a valley leading from the northern boundary of CMTC.

In response to these complaints, CMTC personnel have already curtailed some uses of CS and have instituted restrictions on the use of CS and fog oil aerosol at CMTC. To date, no credible scientific assessment of the health effects of the use of CS and fog oil aerosol at CMTC has been available.

\footnotetext{
"The compound CS is named after its discoverers, B.B. Carson and R.W. Stoughton. Sec Appendix A for more information about CS.
} 
In addition, general awareness about environmental issue 3 among citizens has been on the rise in Germany, and questions have been raised regarding the possible contamination of soil, surface water, and groundwater at U.S. Army training areas and other facilities in Germany. Just prior to the start of the discussions that led to the investigation described in this report, an extensive list of questions dealing with environmental issues at CMTC was presented to the Minister for the Environment of the State of Bavaria, in which CMTC is located. These questions were rather general in nature, but they demonstrated the increasing concern of the German people for environmental issues.

As a result of these concerns, the U.S. Army 7th Army Training Command (7th ATC), which has administrative oversight over CMTC, decided early in 1990 to undertake a scientific study that would address some of these issues. Argonne National Laboratory, one of several national laboratories under the administration of the U.S. Department of Energy, was contracted to carry out the investigation. This final report describes the objectives, methodologies, results, conclusions, and recommendations of that study.

The motivation for the work, a description of the setting, the past and present training activities, and the study objectives and methodologies are presented in Section 1. The results of a brief review of the available information about the locations and amounts of CS and fog oil used in recent training exercises are given in Section 2. Surr maries of the known health effects, as well as other properties, of fog oil and CS are given in Sec $: n$ 3; more detailed reviews of the current state of our knowledge in these areas are given in Appendix s A and B. Section 4 provides a detailed description of the field sampling program undertaken in this study. Section 5 presents the results of the chemical analyses that were done on the various environmental samples that were collected at C:ITC, as well as on the neat fog oil samples that were obtained. A discussion and an evaluation of the results of the study are given in Section 6, and the conclusions and recommendations are presented in Section 7. In addition to the fog oil and CS literature reviews, the appendixes contain descriptions of (1) the sample and document management procedures used, (2) the analytical procedures used, and (3) the procedures used to adjust the latitude and longitude of the sampling locations to the local geodetic system and to convert between the latitude/longitude and the corresponding local coordinates.

\subsection{Location and Setting}

The CMTC occupies an area of approximately 16,200 ha $(40,000$ acres) in Parsberg County, in the Upper Palatinate District of the state of Bavaria, Federal Republic of Germany, and is the largest maneuver area available to U.S. troops in Europe. The CMTC is located within a range of low mountains called the Franconian Jura, and the topography within CMTC is correspondingly complex, consisting primarily of forested mountains separated by grassy valleys. The name Hohenfels, literally transiated, means "high rock," in reference to the rock formations common in the area. 
. The CMTC is bordered on the north by the Lauterach River and on the east by the Vils River. The town of Hohenburg is located on the north bank of the Lauterach River, approximately in the middle of the northern edge of CMTC, and is we largest town immediately north of CMTC. The Lauterach River flows into the Vils River at the town of Schmidmuehlen, located at the northeastern corner of CMTC, near Gate 3. The eastern third of the southern boundary of CMTC is formed by the Forellenbach (Trout Brook), which originates within CMTC and exits CMTC near Gate 2 at the town of Hohenfels. The Forellenbach flows eastward into the Vils River at the town of Rohrbach, at the southeastern corner of CMTC. The western two-thirds of the southern boundary, as well as the western boundary of CMTC, is not defined by any particular topographic feature. The town of Velburg lies approximately $3 \mathrm{~km}$ southwest of the southwestern corner of CMTC.

Figure 1 shows a map of CMTC, the main roads, and the areas that are permanently offlimits for training activities (the hatched areas). The main gate is Gate 1, and the cantonment area is located in the immediate vicinity of that gate. The grid lines shown in Figure 1 are one kilometer

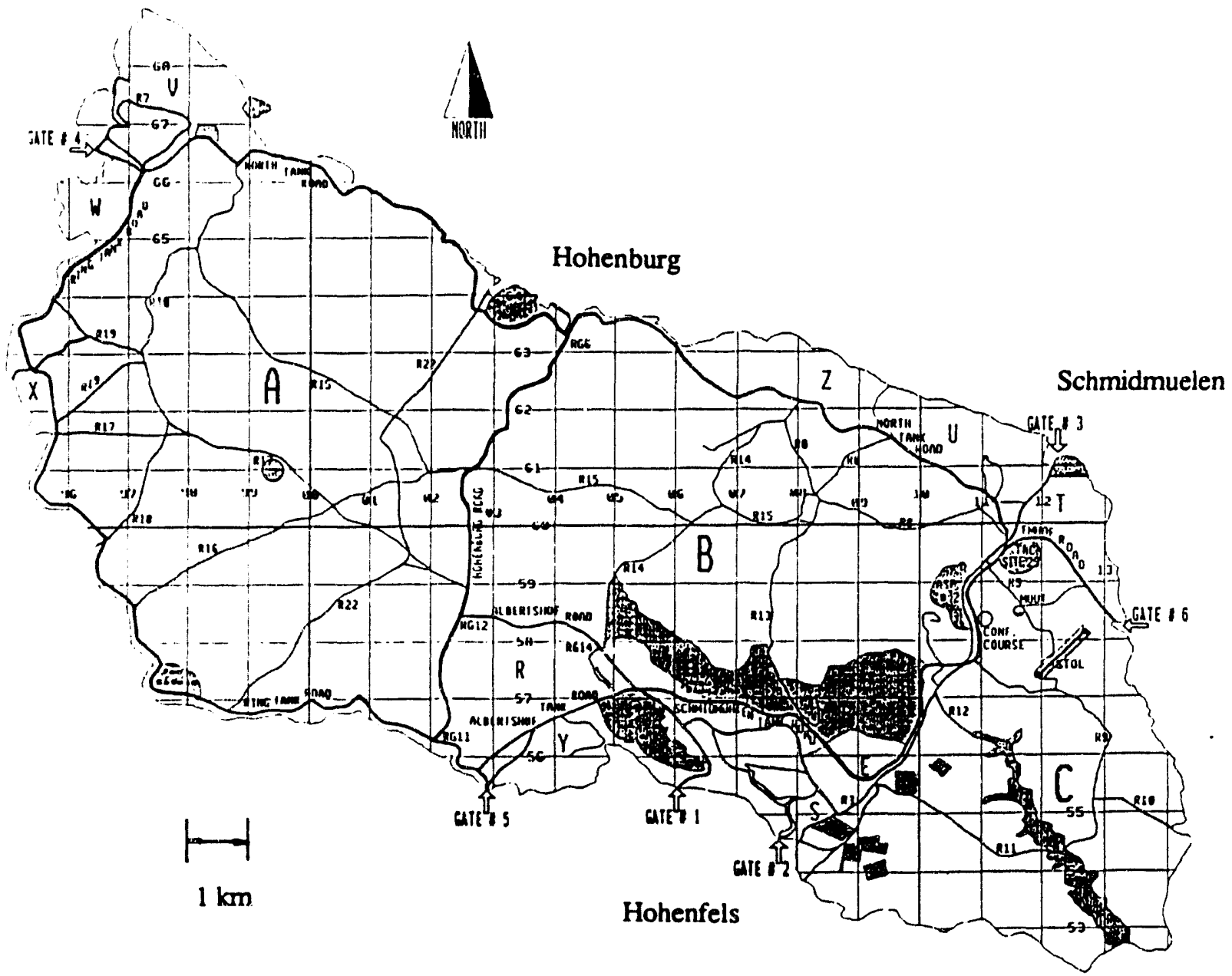

Rohrbach

FIGURE 1 Combat Maneuver Training Center 
apart, and they are numbered from 95 to 99 , then 00 through 14 from west to east, and from 52 to 68 from south to north. These designations are based on the Universal Transverse Mercator (UTM) system of coordinates. A specific location within CMTC is commonly specified by giving its grid reference with respect to this system. Thus, for example, the grid cell in Figure 1 containing the large letter $A$ is designated $9962 ; 99$ designates the column of cells just to the east of the line marked 99, and 62 designates the row of cells just to the north of the line marked 62 . A more specific point within a cell may be specified by giving more significant figures in each part of the grid specification; for example, 99756225 specifies a point located $0.75 \mathrm{~km}$ west of the line labeled 99 and $0.25 \mathrm{~km}$ north of the line labeled 62 . This point would be at the center of the southeast quadrant of cell 9962.

\section{i.3 Past and Present Training Activities at CMTC1,2}

In 1937, to provide troop training and firing areas for the VIIth Army Corps (VI, ) of the German Wehrmacht, a training area was set up between the Bavarian towns of Hohenfels, Rohrbach, Schmidmuehlen, Hohenburg, Martinsberg, Judeneidenfeid, Schmidheim, and Grossbissendorf and was named the "Hohenfels Troop Training Area." This early area occupied approximately the eastern three-fourths of the area currently used. The area was apparently used primarily for weapons firing practice, inciuding small arms, mortars, $20-\mathrm{mm}$ and $37-\mathrm{mm}$ antiaircraft guns, $75-\mathrm{mm}$ mountain guns, and 105- $\mathrm{mm}$ field artillery pieces (howitzers). Also in 1939-1940, in the Albertshof-Grossmittendorf area within CMTC, bunkers were constructea to provide training for an assault on the French Maginot Line. In late 1939, a prisoner-of-war camp was established in the former village of Unteroedenhart and was used throughout World War II. After the end of the war, several camps for displaced persons were established within the CMTC; the last of these camps was closed in the spring of 1949.

After 1946, German farmers were settled within the CMTC, assisted by the Military Government and later by the U.S. High Commissioner for Germany. By October 1951, most of ine former villages within CMTC had been resettled. At this time, the area was requisitioned as a training area by the U.S. Army, and it was agreed to extend the former training area westward to include an additional 4,125 ha, bringing the training area to its current boundaries. Since 1951 , extensive camp and road construction has taken place within the area. The German Bundeswehr has also used the area for training since approximately 1960.

The CMTC is currently used by the U.S. Army for training activities involving U.S. troops in Europe, as well as troops from European and other allied countries. Current training activities often involve the use sf "smoke," a very fine aerosol consisting of droplets of "fog oil," a lowviscosity, petroleum-based oil comparable with an $\mathrm{SAE}^{*} 10$ - or 20-weight lubricating oil. The smoke is generated to conceal the movements of the opposing (attacking) force (the OPFOR or the red force) from the view of the defending force (the blue force). Depending on the attack plan, one or more valleys within CMTC may be filled with smoke during the exercise. In addition, CS may be used during an exercise to simulate the use of chemical weapons by the OPFOR.

\footnotetext{
*SAE = Society of Automotive Engineers.
} 
A typical training exercise consists of the OPFOR attempting to advance from west to east along one or the other or both of the roads leading across the Hohenburg Road from area A to area B (Figure 1), although contact between the OPFOR and the BLUE force may take place anywhere within a rather broad area. Smoke generators are positioned prior to the start of the exercise and are operated only long enough to achieve the desired effects; typically, smoke generators are deployed in pairs and smoke is generated over a period lasting between 15 and $30 \mathrm{~min}$. Spotters observe the smoke during an exercise, and if smoke is seen to be blowing outside the CMTC area, the generators are stopped. Also, smoke is not generated within 1,250 m of the CMTC boundary, nor within an approximately 4- to 5- $\mathrm{km}^{2}$ area immediately south of the town of Hohenburg and the nearby village of Stettkirchen. At almost any time or place CS may be used, although CS is no longer used near the northern boundary, nor is it used anywhere within 1,250 $\mathrm{m}$ of the CMTC boundary. According to CMTC operations personnel, CS is not used in amounts greater than one CS grenade per square kilometer. The use of both smoke and CS tends to be concentrated in certain areas, as discussed in Section 2 . These areas coincide with tactically important areas along the most commonly used invasion routes, typically mountain passes, intersections of major roads, and large open areas through which the OPFOR must pass.

\subsection{Study Objuctives and General Methodology}

The overall objective of this study was to collect information sc that on-post and off-post environmental and health effects of fog oil and CS usage at CMTC could be assessed. Generally, such an assessment requires infonnation on the atmospheric concentrations of fog sil aerosol and $\mathrm{CS}$ in areas surrounding CMTC. Unfortunately, the nature of the terrain at CMTC is, from a meteorological perspective, extremely complex. Because of this constraint, current atmospheric transport and dispersion computer models are not capable of accurately describing the distribution of fog oil or CS over a long enough distance to be useful in assessing the impacts of a release on areas outside the CMTC boundaries. Therefore, the use of atmospheric models to assess the effects of the current fog oil and CS usage can currently be ruled out. Also, even if an adequate model did exist, such a model would certainly require very jetailed meteorological data for its operation, and such meteorological data are not available for CMTC and the surrounding area.

Another consequence of the complex terrain at CMTC is that a detailed field atmospheric transport study, while within the current state of the art, would be very time-consuming and expensive. Moreover, such a study may not be possible under the present access restrictions in effect during training exercises. A field study of atmospheric transport was therefore also ruled out as a source of the necessary information, given the time, resource, and access constraints imposed on this program.

If, however, the available data on health effects indicate that no health effects are produced at concentrations equal to or higher than any that are realistically expected off-post, then a credible argument can be made for the likely absence of health effects due to atmospheric releases of fog oil aerosol and/or CS. Two tasks that were therefore undertaken as part of this study were to

1) eview the available literature on the health effects and other properties of fog oil and CS and 
(2) determine, if possible, threshold concentrations below which no effects are expected. Summaries of the results of these reviews are given in Sections 3.1 and 3.2, and more detailed discussions, including references, are provided in Appendixıs A and B.

It was also felt that useful information regarding poiential long-term effects of the use of smoke and CS might be obtained by determining the extent to which fog oil and the CS degradation product $\mathrm{OCB}$ are present in the oil and on the vegetation within the CMTC boundaries. (CS itself is not expected to $\mathrm{F}:$ ist long in the environment.) Such information would be essential to an assessment of on-post ecological effects of fog oil and CS usage. The third major task undertaken was therefore to conduct a field study to cletermine the extent of such contamination. This study focused only on the more intensively used areas within CMTC, as indicated by a survey of recent training and planning documents. The training arcas that are subject to the most intense usage are the most likely places in which accumulations of these substances can be found. If they are not detected in these areas or are detected only in environmentally insignificant amounts, the rest of the training area may also be assumed to be relatively free from contamination. On the other hand, if surface soils in these areas are found to be significantly contaminated, the possibility of soil contamination over a much wider spatial extent might need to be considered, especially in view $c^{\mathfrak{f}}$ the airborne nature of the releases.

The field sampling effort was timed to coincide with a period during which training activities at CMTC were at a minimum so that access to the desired training areas was possible. No CS was used anywhere on-siie during this period, and the minimal use of smoke was restricted to an area several kilometers from the study areas used in this investigation.

A.ccumilated fog oil, CS, and/or CS degradation products are removed by various physical and/or chemical processes. The level present at any one time is determined by (1) the deposition history and (2) the total rate of removal. A comparison of the results from samples taken at different times and subject to no additional deposition during the sampling period might allow an estimate to be made of the total rate at which the contaminants are being removed, or, if no significant difference is seen in contaminant levels, an upper bound to the removal rate can be obtained. To begin to address the need for such comparisons, duplicate soil and vegetation samples were taken on different days during the sampling period from two study areas.

In addition, it was thought that contaminants in the surface soil might accumulate in and along the natural drainage channels that carry surface runoff to the waterways that border CMTC. A determination of contaminant levels in these drainage channels would provide evidence regarding the possible contamination of these waterways by activities within CMTC. The fourth principal task that was undertaken in this study was therefore to collect suitable samples from these runoff channels with which to examine these possibilities. 


\section{Summary of Available Training Data}

During a visit to CMTC by ANL personnel on August 6-10, 1990, two sources of information were identified that provide data concerning the recent historical usage of both smoke and CS. This section presents a summary of the information obtained at that time. This information was crucial for the selection of sampling locations.

The first source of data was the set of planning documents covering each day's training activity. Documents spanning the period from June to December 1988 (a total of 214 days) were available. Earlier records have been either discarded or stored elsewhere, and because of a change in format, later records are not helpful in determining smoke or CS usage. Figures 2 and 3 depict the content of these records.

Figure 2 shows the total number of days within the given period in which smoke was scheduled to be used in each one-kilometer-square grid cell. The total number of days within this

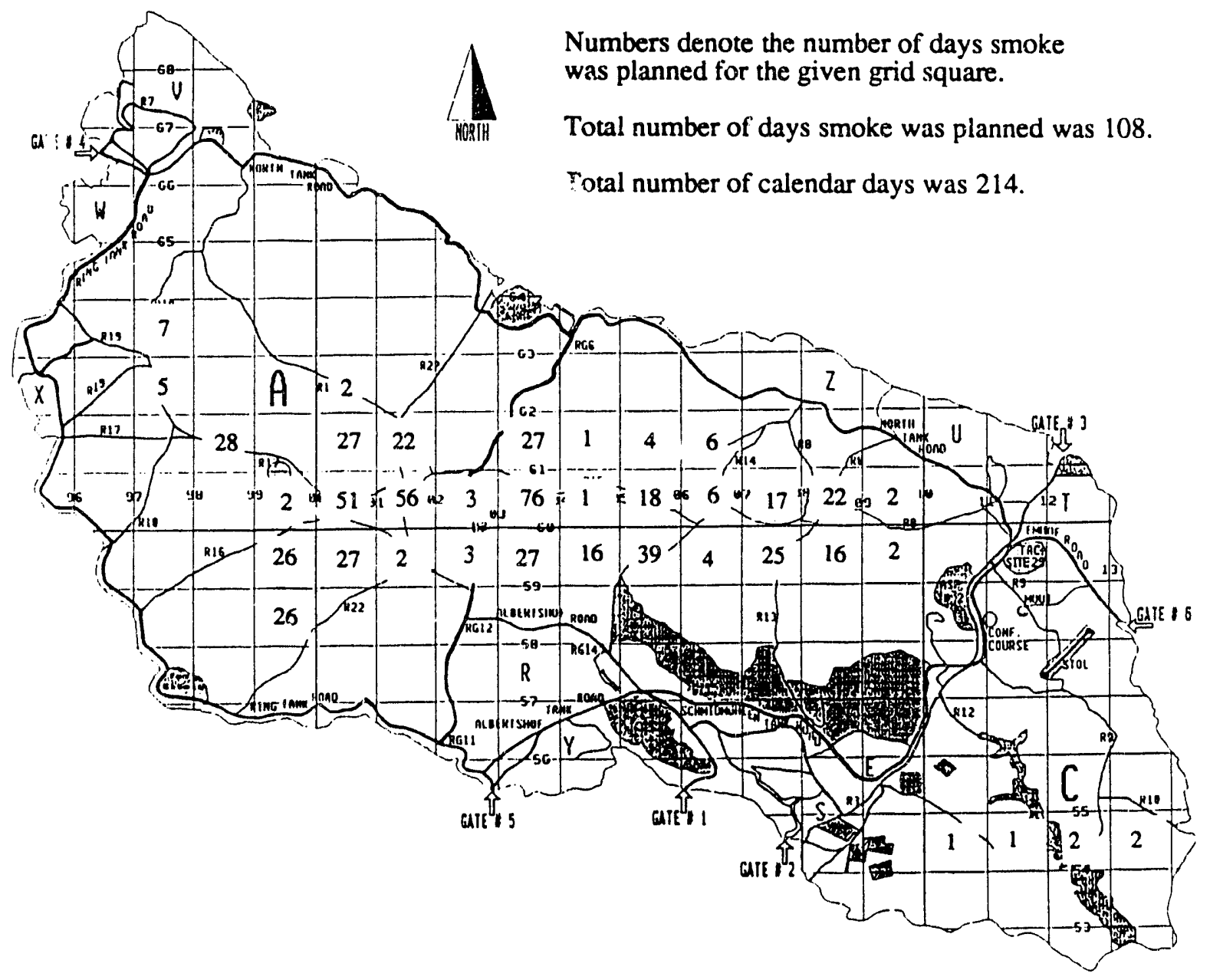

FIGURE 2 Smoke Usage at CMTC, June-December, 1988 


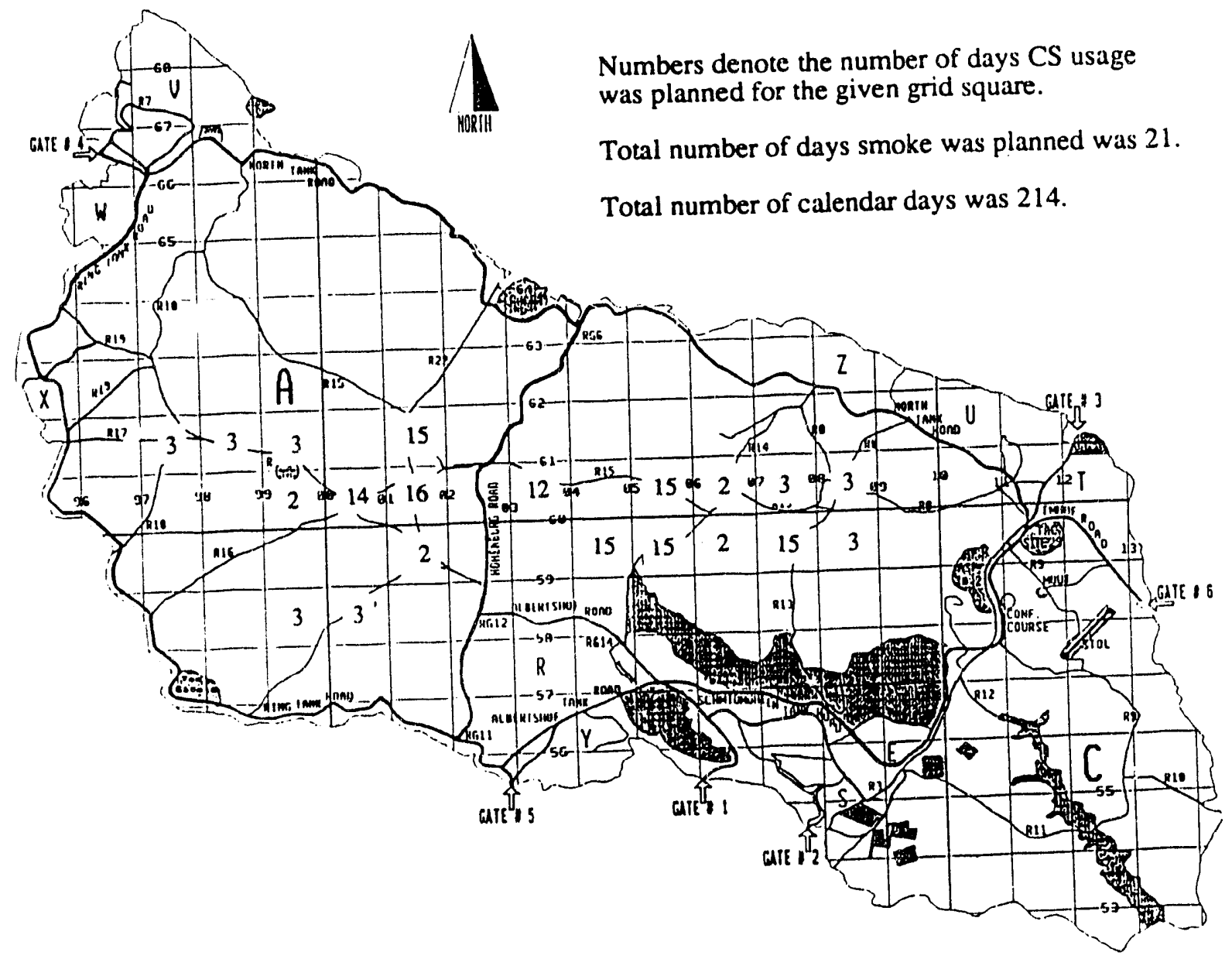

FIGURE 3 CS Usage at CMTC, June-December, 1988

period during which smoke was scheduled for use was 108. The concentration of smoke in just a few areas can be clearly seen in the figure. On the basis of these records, the four grid cells that seem to have received the greatest dose of smoke over this period are cells 0360 (76 days), 0160 (56 days), 0060 (51 days), and 0559 (39 days). These four cells lie within three valleys in the center of CMTC, along which the OPFOR often advances. The overall distribution of smoke usage corresponds to a wide band running from west to east and lying in areas $\mathrm{A}$ and $\mathrm{B}$, as shown in Figure 2; note that smoke is occasionally used in area $\mathrm{C}$ as well.

Figure 3 shows the corresponding results for CS usage. The total number of days within this period during which CS was scheduled for use was 21. Although CS seems to have been used much less frequently, the overall distribution for CS is roughly similar to that for smoke. The same three valleys that received the most intense smoke usage also received the most intense CS usage. These records do not indicate any CS usage in area C. No records are currently being kept by any CMTC personnel on the locations and amounts of CS that are used during the training 
exercises. Interviews with CMTC personnel indicate that the overall CS distribution should continue to be rather similar to the overall smoke distribution, as in the 1988 data.

The second source of data on smoke usage was a set of records currently kept by the "6900 Smoke" group, the people actually responsible for planning and executing the smoke operations. These records only date back to April 1990, but they give the grid coordinates of each target area, the number of generators used, and the period over which they were operated for each day smoke was used. Unfortunately, the early part of these records was difticult to interpret, and dates were not always given for each exercise. Figure 4 summarizes the smoke usage as documented in these records for the period from June through August 7, 1990. The target point for each release was plotted and a circle drawn around the target point; the size of the drawn circle indicates the number of generators used. The overall distribution of smoke usage is roughly similar to that shown in Figure 2. The same three valleys that are heavily used for training activities show up even more clearly in this rigure.

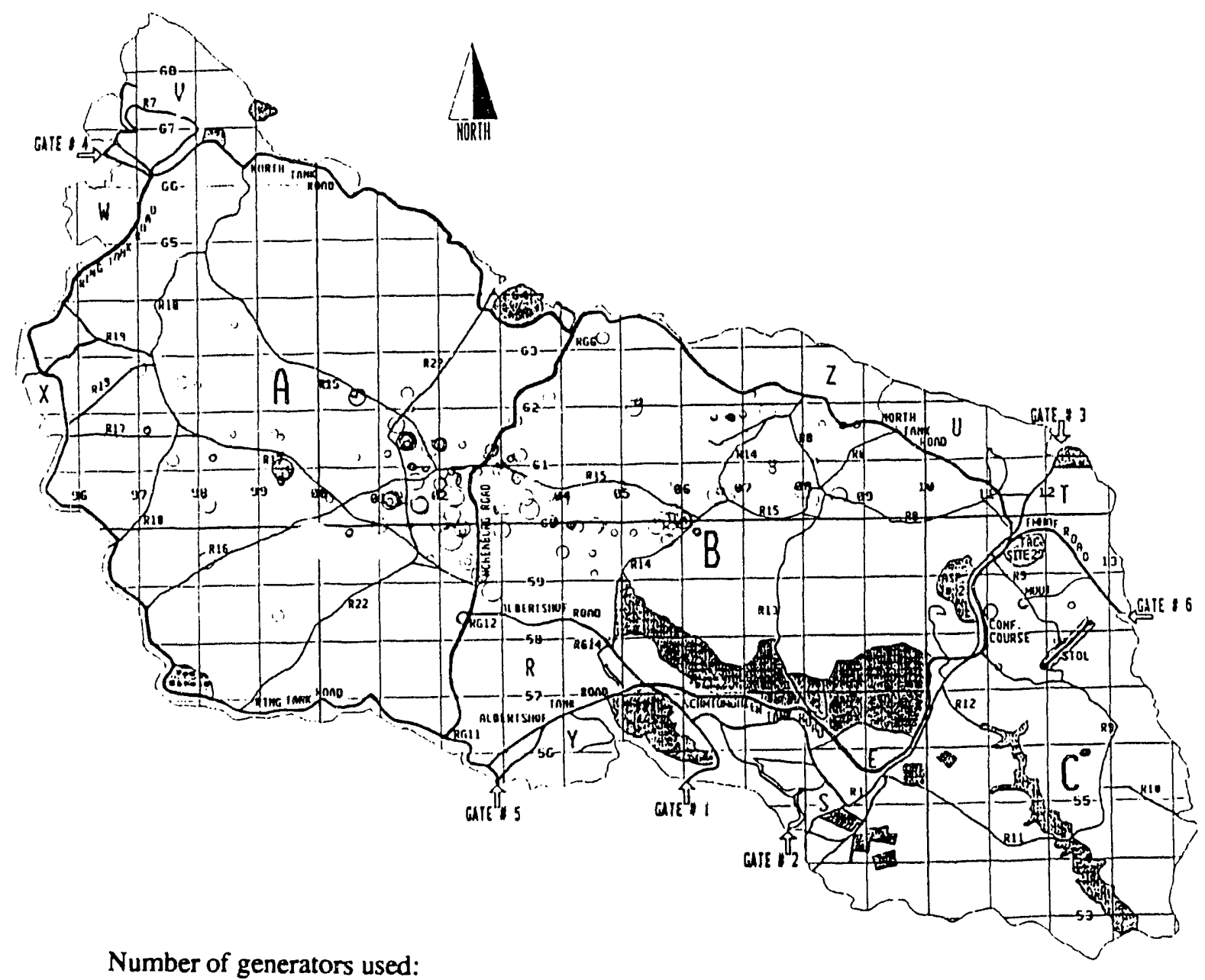

$1=0 \quad 2=0 \quad 3=0 \quad 4=0 \quad 5=0$

FIGURE 4 Smoke Usage at CMTC, June-August 7, 1990 


\section{Summary of Known Health and Environmental Effects}

This section contains summaries of the known health and environmental effects of fog oil and CS. More detailed descriptions, including references, of the available information on these effects and other properties are given in Appendixes A and B.

\subsection{Effects of CS}

Upon exposure to CS, sensory nerves in the skin and mucosa are irritated. The substance causes tearing, pain and conjunctivitis in the eyes, irritation in the respiratory passages and lungs, burning sensations and congestion in the nose and throat, runny nose, sneezing, coughing, salivation, chest constriction, and a feeling of suffocation. Within minutes of the cessation of CS exposure, there is relief from all major effects; after ton minutes, only moderate weeping and some redness of the eyes remain.

All studies of the effects on humans upon exposure to CS reviewed in this study involved CS concentrations at or above $0.1 \mathrm{mg} / \mathrm{m}^{3}$ and the participation of healthy male volunteers. Even at this concentration, the effects were quite unpleasant, and many subjects left the exposure chamber before the scheduled termination of the test. Some indication exists that humans develop a limited tolerance of the symptoms after several minutes of exposure. No studies have been identified that describe the effects of CS on potentially sensitive individuals, such as the young, the elderly, and people already suffering from a respiratory ailment. Even for healthy adults, no information is available that determines the threshold concentration (below which no symptoms are observable), and this information is certainly lacking for sensitive individuals.

Animal toxicity studies in which higher levels of CS were used indicate that $\mathrm{C} \delta$ is relatively nontoxic. For example, the oral $\mathrm{LD}_{50}{ }^{*}$ in rabbits, guinea pigs, and rats ranged from 143 to $1,366 \mathrm{mg} / \mathrm{kg}$. Biochemical studies suggest that the cause of death in studies of animals to determine the oral $\mathrm{LD}_{50}$ was cyanide poisoning that resulted from the chemical breakdown of CS within the body. The limited amount of toxicity data available on fish indicates that toxic effects occur only at relatively high CS concentrations, far above any that would be expected in the environmental setting at CMTC. No information is available on the effects of CS on reptiles, amphibians, birds, or invertebrates.

\subsection{Effects of Fog Oil}

Studies of human and mammalian toxicology 3 associated with petroleum-based (or mineral) oils such as fog oil have focused on two types of effects: (1) respiratory effects due

\footnotetext{
* Median lethal dose $=\mathrm{LD}_{50}$.
} 
specifically to the inhalation of oil mists and (2) other physiological effects due to repeated dermal (skin) contact with the oil. In addition, respiratory effects may be expected from the inhalation of fog oil aerosol simply because the inhalation of particulate matter of any sort at sufficiently high levels can cause symptoms. A review of respiratory effects caused by general particulate matter was outside the scope of this study.

Respiratory effects of mineral oils in humans occur primarily as two types of lipoid pneumonia: lipoid granulomas and diffuse pneumonitis. Mineral oils do not produce pulmonary necrosis, but they are taken up by macrophages that remain within the alveolar spaces. There is very little indication that workplace exposure to mineral oil mists causes lung cancer. Although lipord pneumonia is uncommon even in areas where oil mist concentrations exceed $50 \mathrm{mg} / \mathrm{m}^{3}$, worker discomfort occurs at levels greater than about $5 \mathrm{mg} / \mathrm{m}^{3}$. The U.S. Occupational Safety and Health Administration (OSHA) has therefore established $5 \mathrm{mg} / \mathrm{m}^{3}$ as the time-weighted average oil mist permissible exposure level (PEL) for the 8-h day, 5-day per week occupational setting. The same value has been set by the American Conference of Governmental Industria! Hygienists (ACGIH) as the airborne mineral oil Threshold Limit Value (TLV). The ACGIH is currently reviewing the mineral oil TLV and may reduce the TLV for oils that contain PAHs to $0.2 \mathrm{mg} / \mathrm{m}^{3}$.

The significance of PAHs and of other aromatic hydrocarbons, such as substituted benzenes, is that the degree of carcinogenicity associated with petroleum oils and fuels is believed to be directly related to the aromatic content of the oil or fuel. Dermal studies on animals and epidemiological studies have shown that the higher the aromatic content, the greater the carcinogenicity. In 1986, the military specification MIL-F-12070C was amended to require the elimination of the aromatic content of fog oil; this change requires that the oil to undergo an additional refining step. Prior to 1986 , the aromatic content of conventionally refined fog oil had ranged between 40 and $50 \%$.

Repeated dermal contact with conventionally refined lubricating oils or oil mists causes inflammation, dermatitis, folliculitis, acne, eczema, and contact sensitivity in humans. Although there is no evidence that the inhalation of oil mists causes lung cancer, malignant and premalignant skin changes may be caused by dermal exposure to lubricating oils. These effects are believed to be caused by the aromatic (primarily PAH) content of the oils. An association between squamouscell skin cancer of the hand, arm, and especially the scrotum, as well as exposures to conventionally refined oils, is overwhelmingly supported by the available evidence. The International Agency for Research on Cancer (IARC) has concluded that the mineral oils used in a variety of occupations are carcinogenic to humans. This epidemiological evidence is supported by the results of dermal studies using mice; these studies also show that tumo.s will not develop from oil from which the aromatic substances have been removed.

The effects of fog oil on plants have been investigated to a limited ex tent and only at fog oil aerosol concentrations approximately 100 to 1000 times higher than cisncentrations that are expected at CMTC. Such effects as tip burn, needle dieback, chlorosis, and necrotic spotting of pine needles were observed. Differences in the resistance of various species were also seen. No 
effects of soil contamination on seed germination were observed. Also, fog oil is not a toxicant to the soil heterotrophic microbial activity, nor is it toxic to earthworms at concentrations below 285 $\mathrm{mg} / \mathrm{kg}(\mathrm{ppm})$. No information on the effects of fog oil on birds, reptiles, amphibians and other fauna was identified. 


\section{Field Sampling Program}

This section contains a detailed description of the methodologies used to select specific sampling sites, the sampling procedures used, the quality assurance and quality control measures adopted, and other details of the field program. Readers who do not require this information may wish to proceed to Sections 6 and 7.

\subsection{Site Location Selection Methodology}

The selection of specific sampling locations for the field sampling program proceeded in three stages: (1) a review was conducted of the available historical data on fog oil and CS usage; (2) on the basis of an analysis of the historical data, three general sampling areas and one control area were selected; and (3) specific sampling locations within each selected area were determined by using a stratified random-sampling procedure. The results of the historical review are given in Section 2. On the basis of this brief analysis, the three areas shown in Figure 5 were selected for study. These three areas represent the areas within CMTC that, on the basis of recent training practices, have received the most intense dosage of fog cil and CS. They are, therefore, the areas in which any accumulations of fog oil and/or CS and OCB would be expected to be the greatest. In addition, the area at the northwest corner of CMTC shown on Figure 5 was selected to serve as the control area for the study. No evidence was found that fog oil or CS was ever used in this area, and it was expected to be free from fog oil or CS/OCB contamination.

Specific target locations at which soil and vegetation samples were to be collected were chosen whinin each of the three siudy areas and within the control area. In each study area, both soil and vegstation samples were collected from the valley floor and from the neighboring forest margins. The number of samples collected was determined by two considerations: (1) the rather uniform spatial distribution expected for any residual contamination from fog oil usage and, to a lesser degree, from CS usage and (2) budgetary and resource constraints. Three valley and two forest sites were chosen in study areas 1 and 3, and two valley sites and one forest site were chosen in study area 2 and in the control area. Soil and vegetation samples were collected at each site.

To select suitable valley floor sites, a square grid was superimposed over a magnified topographic map of the study area; the standard CMTC topographic map was used as a basis. ${ }^{4}$ Each grid square was approximately $123 \mathrm{~m}$ on a side and occupied an area of approximately 1.5 ha. The map was then examined, and each grid square containing a road, a portion of a former village now in ruins, a stream, or other such feature was eliminated from further consideration. The area was divided up into two or three parts, depending on the number of sites to be selected, and the remaining grid cells located in each part were identified. This division was made on the basis of broad topographic features and from knowledge of the general direction of typical maneuvers. Thus, study area 1 was subdivided into three parts: north $(10$ cells), central 


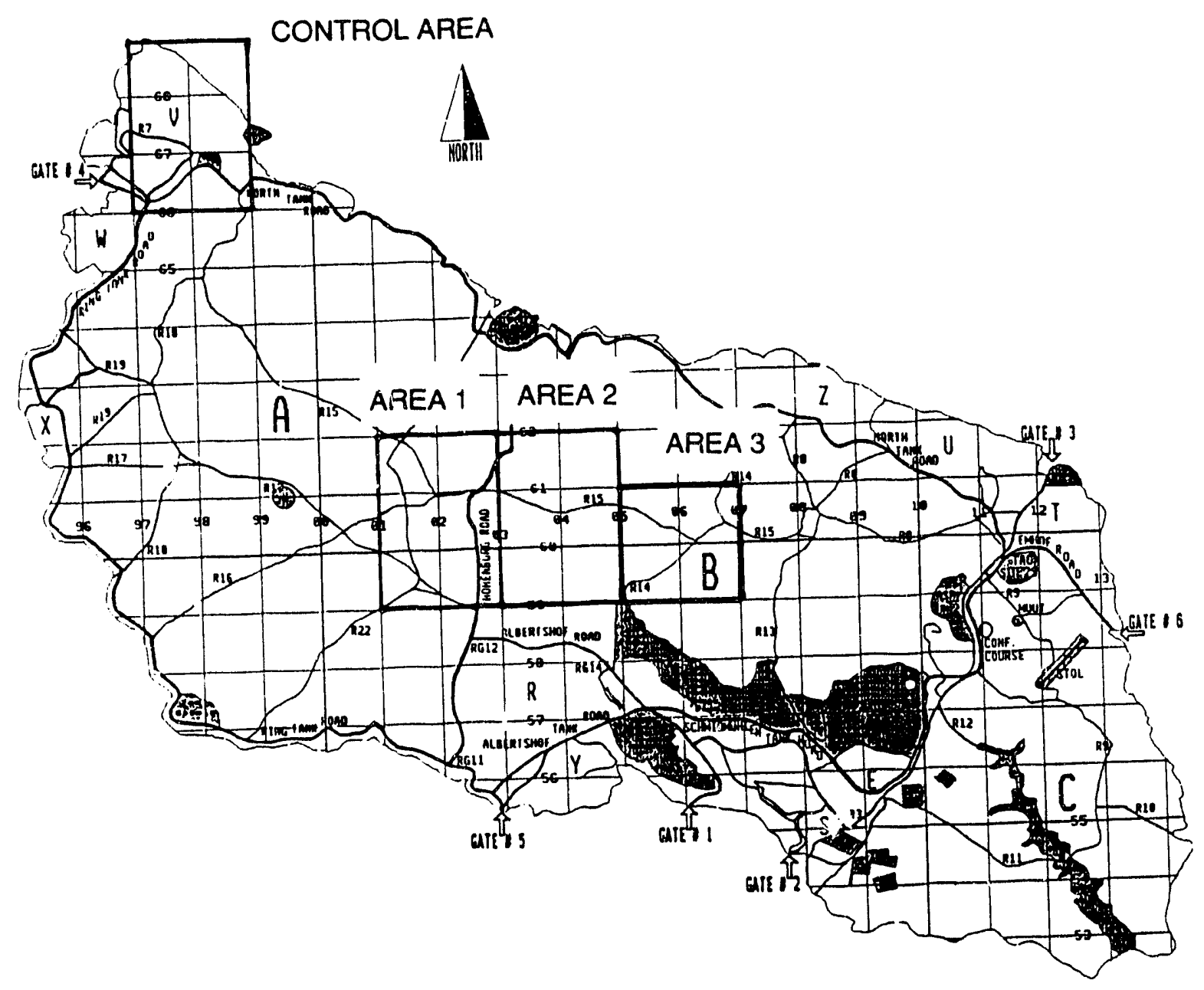

FIGURE 5 CMTC Fog OivCS Study Areas

( 25 cells), and south (11 cells). Study area 2 was divided into two parts: north (14 cells) and south ( 16 cells). Study area 3 was divided into three parts: north ( 8 cells), southwest ( 9 cells), and southeast ( 8 cells). The control area was divided into two parts: north ( 5 cells) and south ( 5 cells). A primary cell and a backup cell in each area was selected by using a random number generator, and the center of each chosen cell was adopted as a target sampling location.

Forest site locations in each area were selected by using a similar procedure. The forest margins surrounding the central valley in each area were divided into sections approximately $200 \mathrm{~m}$ long. Sections containing features such as roads were eliminated from consideration, and the desired number of forest sites was then randomly selected from the remaining sections by using a random number generator. The target sampling sites were taken to be at the middle of each section and approximately $50 \mathrm{~m}$ into the forest. 
In addition to soil and vegetation samples taken at the sites described above, sediment samples were also collected. The sampling locations for the sediment samples were selected so that sediments from surface water channels that drain the major training areas could be sampled.

Table 1 lists the actual sampling locations at which environmental samples were collected during the September 1990 field program at CMTC. The sample code denotes the targeted sampling site location, expressed as a three-significant-figure CMTC grid reference, and forms part of each individual sample identification number (ID), as explained in Section 4.2. The environment (valley, forest, or sediment) is given for each site and the associated study area. Each true site location is given as a four-significant-figure CMTC grid reference and is given therefore to the nearest $10 \mathrm{~m}$. In some cases, the actual sampling locations may differ significantly from the targeted locations, usually because it was impossible to collect the desired sample(s) as planned. For example, a valley site devoid of grass or other vegetation was unsuitable for the collection of a vegetation sample. In such a situation, the nearest suitable location was used instead. Also, the two sample codes 056593 and 066598 were inadvertently switched in assigning sample IDs in the field; accordingly, these two sample codes do not denote approximate site locations but must be considered as merely parts of the unique sample ID numbers.

The true sampling locations were determined by using a Global Positioning System (GPS) receiver. The GPS system determines absolute locations by triangulation, whereby a system of Earth satellites transmits specially coded signals that contain information about the precise time of transmission and the exact location of the satellite in orbit at the time of signal transmission. To prevent unauthorized foreign powers from using this system during wartime, the U.S. Department of Defense (DoD) has the ability to adjust the signals in such a way that civilian receivers cannot obtain the same positional accuracy as military receivers can. This capability is called "selective availability." During the actual field sampling work, the DoD had turned off the selective availability feature because of the imminent war in the Persian Gulf and because U.S. military forces needed to use civilian receivers (there was a severe shortage of the military version). As a result, the GPS positions obtained during the September 1990 field program have the full positional accuracy available to single-receiver systems. According to the manufacturer's literature, the accuracy of the positions correspond to a root-mean-square (RMS) positional precision of approximately $25-30 \mathrm{~m}$. An independent check of this precision was available for one site that was located near a surveyed marker (sample code 979679); the GPS position differed by only $10 \mathrm{~m}$ from the position derived from the known location of the marker and the measured distance and heading of the site from the marker. This positional error was certainly well within the expected uncertainty. In a few cases, the sampling site was located in a deep valley or on the slope of a steep hill, and the GPS receiver was unable to detect enough satellites to determine the position. In all but two of these cases, the GPS coordinates could be determined at a nearby but more exposed location; those coordinates were recorded, and the true sampling location was determined by using its measured distance and azimuth from the site at which the GPS position was known. In the remaining two cases, the sampling location could be determined to sufficient accuracy from the topographic map. 
TABLE 1 September 1990 CMTC Field Program Sampling Locations

\begin{tabular}{|c|c|c|c|c|}
\hline Sample Code & Environment & Area & CMTC Grid & Reference \\
\hline 977673 & Sediment & $\mathrm{Ca}^{\mathrm{a}}$ & 97756 & 6735 \\
\hline 979679 & Valley & C & $9797 \epsilon$ & 6795 \\
\hline 979682 & Forest & C & 9779 & 6820 \\
\hline 987671 & Valley & C & 9862 & 6721 \\
\hline 016616 & Valley & 1 & 0129 & 6158 \\
\hline 018597 & Valley & 1 & 0160 & 5975 \\
\hline 019606 & Valley & 1 & 0192 & 6067 \\
\hline 020603 & Sediment & 1 & 0208 & 6025 \\
\hline 020608 & Sediment & 1 & 0216 & 6061 \\
\hline 021610 & Forest & 1 & 0238 & 6112 \\
\hline 023604 & Forest & 1 & 0243 & 6039 \\
\hline 033606 & Valley & 2 & 0324 & 6055 \\
\hline 036605 & Sediment & 2 & 0356 & 6053 \\
\hline 037606 & Forest & 2 & 0354 & 6071 \\
\hline 038601 & Valley & 2 & 0387 & 6006 \\
\hline 043597 & Sediment & 2 & 0441 & 5974 \\
\hline 056593 & Forest & 3 & 0657 & 5977 \\
\hline 056603 & Valley & 3 & 0562 & 6031 \\
\hline 056624 & Sediment & $-b$ & 0551 & 6249 \\
\hline 059601 & Valley & 3 & 0595 & 6010 \\
\hline 061596 & Valley & 3 & 0625 & 5977 \\
\hline 062592 & Sediment & 3 & 0639 & 5918 \\
\hline 065585 & Sediment & 3 & 0658 & 5850 \\
\hline 066598 & Forest & 3 & 0616 & 5926 \\
\hline 073624 & Sediment & $-c^{c}$ & 0730 & 6240 \\
\hline 096600 & Sediment & $-d$ & 0964 & 6003 \\
\hline
\end{tabular}

a $\mathrm{C}$ denotes the control area.

b Selected so that drainage from the northern valley, south of Adertshausen, could be examined.

c Selected so that the drainage along the Lautertal Glen could be examined.

S Selected so that drainage from the large valley centered at approximate grid reference 0865 could be examined. 
The positions obtained from the GPS receiver were given in terms of the gesdetic latitude and longitude, on the basis of the WGS 84 geodetic system, which is used by the GPS system. To locate these positions on the standard CMTC topographic map and to determine the corresponding UTM coordinates (which form the basis for the grid reference system used on all military maps), the raw GPS coordinates had to be suitably converted. The CMTC topographic map is based on the International Ellipsoid and the European Datum 1950 (ED 50) horizontal geodetic datum, and GPS latitude and longitude had to be converted to this local geodetic system. Multiple-regression equations are available that can be used to achieve this conversion. ${ }^{5}$ After the latitude and longitude in the appropriate geodetic system had been obtained, the corresponding UTM coordinates were computed. ${ }^{6}$ A summary of these pr'sedures is given in Appendix C.

\subsection{Sampling Program Procedures}

The actual field sampling program was carried out during the last two weeks of September 1990. Standard sampling, sample management, and document management procedures were used. The sample and document management procedures are given in Appendix D, which is taken directly from the Sampling and Analysis Pları that was prepared prior to the field effort. This section summarizes the sample ID number convention adopted, the chronology of the sampling program, and the sampling procedures used, including QA/QC and chain-of-custody considerations.

Sample Identification Numbers. Sample identification numbers were assigned to each physical sample collected. A sample ID must be (1) unique so that it can be distinguished from other similar samples and (2) traceabie throughout the sampling and analysis process. To meet these two requirements, each sample ID contained (in 12-character coded form) the information provided in Table 2.

In this investigation, the Army facility was the CMTC (coded HTA for "Hohenfels Training Area"). The target sampling location code, consisting of characters 4-9, corresponded to

TABLE 2 Sample ID Number Information Codes

\begin{tabular}{llll}
\hline Character(s) & \multicolumn{1}{c}{ Definition } & Code Characteristic & \multicolumn{1}{c}{ Choices } \\
\hline & & & \\
1,2 , and 3 & Army Facility & Alphabetic & HTA only \\
4,5 and 6 & EAST Grid Reference & Numeric & $950-999$ or 000-149 \\
7,8 and 9 & NORTH Grid Reference & Numeric & $520-689$ \\
10 & Sample Type & Alphabetic & S, V, R, or N \\
11 and 12 & Sequential Sample & Numeric & $01-99$ \\
& Number & & \\
\hline
\end{tabular}


approximate grid reference numbers. The sample type code corresponds to the different types of sample that were collected: (S) surface soil samples, (V) vegetation samples, (R) runoff sediment samples, and (N) neat fog oil samples. For example, the sample ID number HTA015603S01 indicates the following:

- The Army facility at which the sample was collected is the CMTC (or Hohenfels Training Area), Germany.

- The sampling point (location) within CMTC was at approximate grid reference 015603 (subject to reinterpretation as described in Section 4.1).

- The sample was a surface soil sample.

- The sample was the first surface-soil sample collected at that point.

Sampling Program Chronology. The chronology of the sampling program is presented in Table 3, and a list of the environmental samples collected with the dates and times of collection is given in Table 4.

Sampling Procedures. The procedures used for the collection of soil and sediment samples are relatively standard and are summarized below. The project Health and Safety Plan required that a metal detector be used to check the sampling area for unexploded ordnance near the surface prior to the collection of surface soil samples.

\subsubsection{Soil Sampling Procedure}

1. Mark out a square approximately $10 \mathrm{~m}$ on a side and centered on the desired sampling location.

2. At each corner and at the center of the square, remove any grass (including roots), leaves, or other cover from an area sufficiently large to permit excavation of the soil from a square $8 \mathrm{~cm}$ on a side.

3. At each corner and in the center of the sample area, use a precleaned stainlesssteel spoon to excavate the soil from a square area $8 \mathrm{~cm}$ on a side to a depth of $4 \mathrm{~cm}$ and place the excavated soil into a stainless-steel tray lined with aluminum foil. This tray will be used to mix the samples. The sampling team member who is responsible for doing the actual excavating and sample mixing must wear disposable vinyl gloves. 
TABLE 3 September 1990 CMTC Sampling Program Chronology

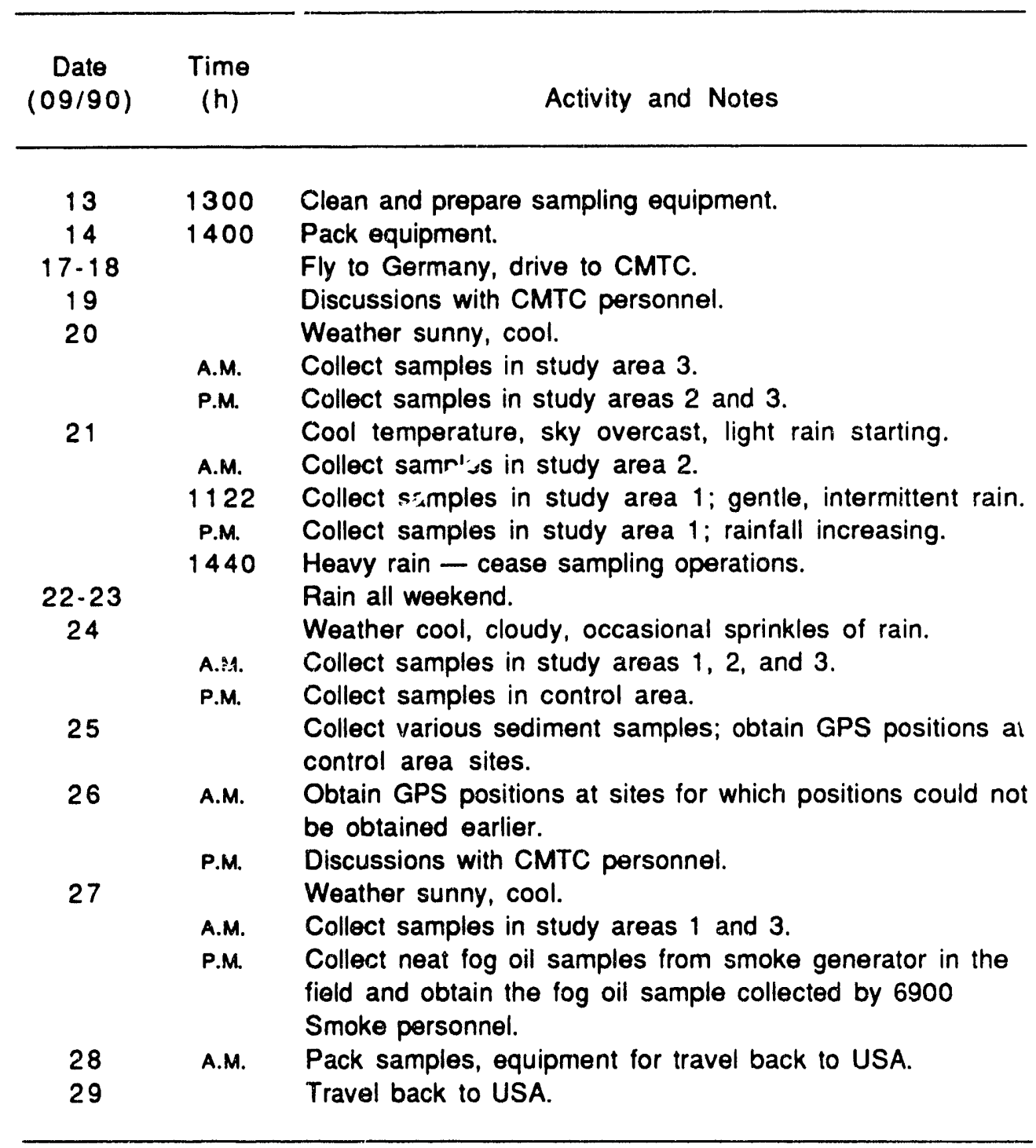

4. After all five grab samples have been collected and placed into the tray, mix them until they are homogeneous and transfer the mixed sample into a precleaned, $250-\mathrm{mL}$ sample bottle until it is full. Discard the remainder of the sample.

5. Wipe the sample container clean.

6. Fill out the sample label and attach it to the sample container.

7. Fill out the sample tag and attach it to the sample container. 
TABLE 4 Environmental Samples Collected at CMTC

\begin{tabular}{|c|c|c|c|c|}
\hline Sample ID & Environment & Area & $\begin{array}{c}\text { Date } \\
(09 / 90)\end{array}$ & $\begin{array}{c}\text { Time } \\
\text { Collected } \\
\text { (h) }\end{array}$ \\
\hline HTA977673R01 & Sediment & C & 24 & 1430 \\
\hline HTA979679S01 & Valley & C & 24 & 1320 \\
\hline HTA979679V01 & & & 24 & 1320 \\
\hline HTA979682S01 & Forest & C & 24 & 1250 \\
\hline HTA979682V01 & & & 24 & 1250 \\
\hline HTA979682V02 & & & 24 & 1250 \\
\hline HTA987671S01 & Valley & C & 24 & 1350 \\
\hline HTA987671V01 & & & 24 & 1350 \\
\hline HTA016616S01 & Valley & 1 & 24 & 1100 \\
\hline HTA016616V01 & & & 24 & 1100 \\
\hline HTA016616S02 & & & 27 & 1230 \\
\hline HTA018597S01 & Valley & 1 & 24 & 0917 \\
\hline HTA018597V01 & & & 24 & 0917 \\
\hline HTA019606S01 & Valley & 1 & 24 & 0950 \\
\hline HTA019606V01 & & & 24 & 0950 \\
\hline HTA019606S02 & & & 27 & 1150 \\
\hline HTA019606S03 & & & 27 & 1150 \\
\hline HTA020603R01 & Sediment & 1 & 21 & 1350 \\
\hline HTA020608R01 & Sediment & 1 & 21 & 1415 \\
\hline HTA021610S01 & Forest & 1 & 21 & 1122 \\
\hline HTA021610V01 & & & 21 & 1122 \\
\hline HTA021610V02 & & & 21 & 1122 \\
\hline HTA023604S01 & Forest & 1 & 21 & 1315 \\
\hline HTA023604V01 & & & 21 & 1315 \\
\hline HTA023604V02 & & & 21 & 1315 \\
\hline HTA033606S01 & Valley & 2 & 21 & 0928 \\
\hline HTA033606V01 & & & 21 & 0928 \\
\hline HTA036605R01 & Sediment & 2 & 20 & 1510 \\
\hline HTA036605R02 & & & 20 & 1510 \\
\hline HTA037606S01 & Forest & 2 & 21 & 0950 \\
\hline HTA037606V01 & & & 21 & 0950 \\
\hline HTA037606V02 & & & 21 & 0950 \\
\hline HTA038601SO1 & Valley & 2 & 21 & 0900 \\
\hline HTA038601V01 & & & 21 & 0900 \\
\hline HTA043597R01 & Sediment & 2 & 20 & 1440 \\
\hline HTA056593SO1 & Forest & 3 & 20 & 1110 \\
\hline HTA056593V01 & & & 20 & 1110 \\
\hline HTA056593V02 & & & 20 & 1110 \\
\hline HTA056593SO2 & & & 27 & 1100 \\
\hline HTA056593V03 & & & 27 & 1100 \\
\hline HTA056593V04 & & & 27 & 1100 \\
\hline HTA056603S01 & Valley & 3 & 20 & 0906 \\
\hline HTA056603V01 & & & 20 & 0906 \\
\hline HTA056624R01 & Sediment & - & 25 & 1124 \\
\hline
\end{tabular}


TABLE 4 (Cont.)

\begin{tabular}{llllc}
\hline Sample ID & Environment & Area & $\begin{array}{c}\text { Date } \\
(09 / 90)\end{array}$ & $\begin{array}{c}\text { Time } \\
\text { Collected } \\
(\mathrm{h})\end{array}$ \\
\hline HTA059601S01 & Valley & 3 & 20 & 0950 \\
HTA059601V01 & & & 20 & 0950 \\
HTA059601S02 & & & 27 & 0930 \\
HTA059601V02 & & & 27 & 0930 \\
HTA059601V03 & & & 27 & 0930 \\
HTA061596S01 & Valley & 3 & 20 & 1020 \\
HTA061596V01 & & & 20 & 1020 \\
HTA061596S02 & & & 27 & 1015 \\
HTA061596V02 & & 27 & 1015 \\
HTA062592R01 & Sediment & 3 & 20 & 1210 \\
HTA065585R01 & Sediment & 3 & 20 & 1230 \\
HTA066598S01 & Forest & 3 & 20 & 1412 \\
HTA066598V01 & & & 20 & 1412 \\
HTA066598V02 & & & 20 & 1412 \\
HTA073624R01 & Sediment & - & 25 & 1145 \\
HTA096600R01 & Sediment & - & 25 & 1330 \\
\hline
\end{tabular}

8. Place the aluminum-foil liner from the mixing tray and the used vinyl gloves into a trash bag for later disposal. Place the used spoon into a plastic bag for later decontamination.

9. Complete all chain-of-custody documents and field logbook entries.

In the case of sediment samples, a $10-\mathrm{m}$ square could not generally be laid out, and composite samples that were made up of four to five grab samples from clearly identifiable sediment near the desired sampling location were taken. Otherwise, the sediment sampling procedure was identical to that used for soil.

Only general guidelines for collecting vegetation samples are available, and these guidelines deal primarily with the possibility of contamination within plant tissues. Uptake by plants of various substances can be extremely plant-specific, and plant species populations may vary significantly over small spatial and temporal scales. For these reasons, the collection of representative vegetation samples presents particular difficulties, and the sampling objectives often require the collection and analysis of a large number of samples. This type of investigation was beyond the scope of this program. The main objective, however, in this study was to determine if fog oil was present on the surface of the vegetation, and there was no need for the collection of species-specific samples. Two samples were collected at each forest location, the first consisting of leaves and/or needles collected from four to seven feet off the ground and the second consisting 
of grass and/or other very low vegetative cover collected from or very near the forest floor. One sample was collected at each valley floor site, where the vegetation consisted almost entirely of grass and other small plants. Each sample was a spatial composite as well as a composite sample of potentially several plant species. Each sample was collected by using the procedure described below.

\subsubsection{Vegetation Sampling Procedure}

1. Mark out a circle approximately $10 \mathrm{~m}$ in diameter, centered on the point specified as the sampling location.

2. Collect eight to ten grab samples of vegetation equally spaced around the circle and place the samples into a stainless-steel tray lined with aluminum foil. Collect only blades of grass (no roots), leaves of trees or shrubs (no stems, twigs, or larger diameter pieces), or needles (from conifers; again, no twigs, etc.). The total amount collected should be sufficient to fill a $250-\mathrm{mL}$ sample bottle.

3. The sampling team member who is responsible for the actual collection must wear disposable vinyl gloves during sample collection.

4. Sample collection tools may consist only of precleaned stainless-steel scissors; uncleaned shears or clippers may be used to de:ach small boughs from trees or shrubs to facilitate the collection of the associated leaves or needles, as long as none of the actual sample comes into contact with the shears.

5. After placing all of the samples into the tray, mix them until they are homogeneous and transfer the mixed sample into a precleaned, $250-\mathrm{mL}$ sample bottle until it is full. Discard the remainder of the sample.

6. Wipe the sample container clean.

7. Fill out the sample label and attach it to the sample container.

8. Fill out the sample tag and attach it to the sample container.

9. Place the container into a plastic bag and store the bag in a cool container (for example, a cooler) for transportation. 
10. Place the aluminum-foil liner from the mixing tray and the used vinyl gloves into a trash bag for later disposal. Place the used scissors into a plastic bag for later decontamination.

11. Complete all chain-of-custody documents and field logbook entries.

In addition to the environmental samples, three neat fog oil samples were obtained on September 27, 1990. Two of these samples, sample IDs HTA975623N01 and HTA975623N02, were obtained from the oil tank on a smoke generator vehicle in the field; these two samples are duplicaites. The samples were collected from a plug valve near the bottom of the tank, and some sediment/residue was seen in each sample. According to the personnel operating the generator, the oil in the tank contained approximately $25 \%$ diesel fuel. The diesel fuel had been added to lower the viscosity of the oil, since the ambient temperature that morning had been low enough to affect the operation of the smoke generator. The practice of adding diesel fuel to the oil in this manner is quite common, and up to $50 \%$ diesel fuel may be used on the coldest days, according to the smoke generator personnel. The sample containers used were specially precleaned $50-\mathrm{mL}$ glass screw-top bottles purchased for the purpose. The third neat fog oil sample, ID number HTA999999N03, was collected for us by one of the smoke generator operators from fog oil stocks. No diesel fuel had been added to this sample. The sample was collected in a 250 -mL mouthwash bottle that had been washed with soap and water, then rinsed with hot water before the sample was collected. (The code N03 should have been N01 since only one such sample was taken.)

Quality Assurance/Quality Control Considerations. Quality assurance and quality control (QA/QC) issues are important for the scientific and legal defensibility of the work done in any scientific study. Quality assurance and quality control issues relevant to the type of field investigation carried out in this study include the need for specially cleaned equipment and sample containers; the use of blank, duplicate, and other types of control samples; the question of sample preservation and general integrity between collection and analysis; and the need to ensure that the sampling and analysis program is capable of achieving the desired results.

As indicated above, all of the sampling procedures used in this study required the use of precleaned sampling equipment; this requirement is imposed to prevent cross-contamination between different samples. It implies that a fresh piece of equipment must be used for each new sample or be cleaned according to specified protocols prior to reuse. In addition, the use of stainless-steel equipment is generally desirable in most environmental sampling efforts because it is easy to clean and/or decontaminate and has no potential for introducing unwanted contaminants into the sample. The use of precleaned equipment was also highly desirable from a logistic point of view, because the equipment could not be cleaned as effectively in the field. The following equipment cleaning procedure, used in this study, is based on that required by the U.S. Environmental Protection Agency (EPA). 


\subsubsection{Stainless-Steel Equipment Cleaning Procedure}

1. Wash and scrub the equipment thoroughly with detergent.

2. Wash and scrub the equipment thoroughly with tap water.

3. Check the equipment for adhered soils and other material; use a brush to dislodge any particles.

4. Rinse the equipment thoroughly with $10 \mathrm{~N}$ nitric acid.

5. Rinse the equipment thoroughly with tap water.

6. Double rinse the equipment with water that meets ASTM Type II purity specifications.

7. Using Teflon ${ }^{\mathrm{TM}}$ wash bottles, spray-rinse all surfaces with pesticide-grade methanol. Pour ASTM Type II waier and methanol over the surfaces of all the tools, bowls, and other sampling equipment. Collect the methanol in a container for disposal. One effective collection technique is to place a large glass or stainless-steel funnel below the tools during rinsing. Allow waste to flow into 1-L bottles for later disposal. If a rinsate sample is required for $\mathrm{QA}$, make an additional final rinse of the item (using ASTM Type II water) and collect it for analysis.

8. Allow the equipment to air-dry.

9. Carefully store dried equipment in aluminum foil (for samples requiring organic analysis) or plastic wrap or bags (for sample requiring only inorganic analysis).

Sample containers used for soil, vegetation, and sediment samples were commercially available precleaned (U.S. EPA cleaning protocol A), clear-glass 250 -mL screw-top jars with Teflon ${ }^{\mathrm{TM}}$ closures.

Data quality objectives were formulated to reflect the level of quality necessary for the intended use of the data obtained. As discussed earlier, this field sampling study was intended to be an exploratory investigation. If the results of the study had shown substantial, widespread contamination at CMTC, a subsequent, more elaborate and rigorous field study would have been undertaken to determine more accurately the nature, level, and extent of any contamination present. 
Accordingly, the data quality requirements in this investigation corresponded to EPA data quality level III. The EPA Contract Laboratory Program (CLP) data quality levels are defined as follows:

Level I: Field screening or analysis using portable instruments. Results often are not compound-specific and are not quantitative. Results are generally available immediately.

Level II: Field screening or analysis using more sophisticated portable instruments. The quality of data generated in this way is highly variable. Results are generally available immediately.

Level III: All analyses performed in an off-site laboratory that may or may not follow CLP procedures. QA/QC and documentation are less rigorous than for CLP. Results are delayed.

Level IV: CLP Routine Analytical Services. All analyses are performed in an offsite CLP laboratory following CLP procedures. QA/QC procedures and documentation are rigorous. Results are delayed.

Level V: Analysis by nonstandard methods. All analyses are performed in an off-site laboratory that may or may not be CLP certified. CLP Special Analytical Services are Level V. Results are delayed.

The sampling and analysis procedures used in this study are considered to be compatible with the data quality objectives described above and are capable of yielding data at the desired level of accuracy. The sampling locations selected provide a representative distribution at the site and are consistent with generally accepted sampling design principles. The collection of duplicate samples (as well as samples at several locations within the same general area) provides adequate checks and assists in the interpretation of the results. Results from analyses on the samples collected are comparable only with other results from samples taken at CMTC during the same period.

Because of the nature of the samples collected, the use of blank samples for internal quality control was precluded. Instead, as discussed earlier, the identification of a control area and collection of samples from that area, in addition to the study area samples, provides the same type of quality control.

One duplicate sample was taken for each type of sample collected. This number was considered adequate in view of the data quality objectives discussed above.

After collection, all samples were kept in a cool environment while at CMTC; some were kept refrigerated, but because of limited space, not all of the samples could be refrigerated. Upon 
delivery to the ANL Analytical Chemistry Laboratory (ACL), the samples were kept in locked, refrigerated storage at $4^{\circ} \mathrm{C}$ until they are removed for workup and analysis. No additional sample preservation measures were considered necessary.

Chain of Custody. To maintain legal defensibility of the results of a sampling and analysis program, it is necessary to follow strict chain-of-custody procedures. In particular, it is necessary to demonstrate that a sample is the same sample that was collected at the site and that it has not been altered since collection. A written record is kept for this purpose, and such a record unambiguously shows that the sample was in someone's custody every step of the way. A sample is in someone's "custody" if it meets one or more of the following criteria:

- It is in one's actual physical possession;

- It is in one's sight, after being in one's possession;

- It is in one's physical possession and then locked up so that no one can tamper with it; or

- It is kept in a secure area, restricted to authorized personnel only.

A chain-of-custody record for each sample collected was initiated by the person collecting the samples. These samples were transported back to ANL in the custody of a member of the sampling team. Custody seals were used as appropriate. The samples were tumed directly over to $\mathrm{ACL}$ personnel upon return to $\mathrm{ANL}$, and the chain-of-custody records were appropriately completed. 


\section{Analytical Results}

This section describes the sample workup and analysis procedures used in the analysis of the fog oil and the environmental samples collected at CMTC and presents the results of those analyses. Readers not requiring this information should proceed to Sections 6 and 7.

To clarify for nontechnical readers the meaning of the figures presented in this section, brief discussions of the methods of gas chromatography (GC) and mass spectrometry (MS) are given.

Gas chromatography usually involves the injection of a small amount $(1-3 \mu \mathrm{L})$ of suitably prepared liquid sample into a long, thin column through which a gas (the carrier gas) is flowing. The purpose of sample workup procedures is to produce a suitable liquid sample that contains all the substances of interest that were present in the original environmental sample. The injected liquid sample is vaporized and carried along through the column by the carrier gas. The different chemical substances present interact to varying degrees with a special coating present on the inside of the column. As a result, as the sample is carried through the column, the sample constituents are separated from each other. As they flow out of the other end of the column, they are detected by a suitable detector, which generates a voltage proportional to the amount of substance being detected. The length of time that it takes a particular substance to pass through the column is called its retention time. The result of the analysis consists conceptually of a chart, called the chromatogram, giving the detector response as a function of time, and each separated substance appears on the chromatogram as a separate peak at a specific retention time. The area under the peak is proportional to the total amount of that substance present in the original sample.

A mass spectrometer may be thought of as a particular type of detector in which the vaporized material is ionized in a particular way and the electrical current generated is detected; when used in this manner as a GC detector, the output from the mass spectrometer is called the total ion chromatogram, in which the total ion current is plotted as a function of time. In practice the ion current is usually scaled in such a way that the maximum has a specified arbitrary value, such as 100 , and the plot is called the Reconstructed Ion Chromatogram (RIC). However, unlike other GC detectors, the mass spectrometer allows the chemical identity of each substance to be determined, in principle. The molecular ion generated by ionizing a molecule of some substance fragments into smaller ions to a degree that depends on the substance. The particular ions produced and their relative amounts are together uniquely characteristic of the original material. The masses and relative numbers of these ions are typically determined by the mass spectrometer (one says that a "scan" is made) at least once every second, and this "mass spectrum" can therefore be obtained for each substance separated by the GC. The identity of the substance is determined in principle by comparing its mass spectrum with the mass spectra of known substances and finding one that matches. This procedure may not always work because (1) the mass spectra of similar compounds are similar to each other and the differences may be masked by instrumental effects and (2) the mass spectrum of the substance may not be in the library of mass spectra being searched. To a trained analyst, however, the mass spectrum can often be used to determine the type of compound present, if not its exact identity, even if a good match cannot be obtained. 


\subsection{Fog Oil Samples}

\subsubsection{Procedures}

Because of the nature of the samples, no special sample workup procedure was necessary other than to dilute aliquots from the oil samples by a factor of 50 with methylene chloride prior to analysis. The analysis was carried out by using a Finnegan Model 4021 Gas Chromatograph/Mass Spectrometer (GC/MS). The GC oven temperature program was as follows: the injection port temperature was $280^{\circ} \mathrm{C}$; the initial oven temperature was $35^{\circ} \mathrm{C}$ and was held for $2 \mathrm{~min}$; the oven temperature was increased at a rate of $6^{\circ} \mathrm{C} / \mathrm{min}$ to a temperature of $200^{\circ} \mathrm{C}$ and then increased to $280^{\circ} \mathrm{C}$ at a rate of $10^{\circ} \mathrm{C} / \mathrm{min}$; the final temperature of $280^{\circ} \mathrm{C}$ was held for $20 \mathrm{~min}$. The GC column used was a $30-\mathrm{m} \times 0.25-\mathrm{mm}$ DB-5 column with a $0.25-\mu \mathrm{m}$ film thickness. The sample size was 1 $\mu \mathrm{L}$. The mass spectrometer used electron impact ionization with an electron energy of $70 \mathrm{eV}$, and the mass spectra covered the range from 35 to 500 atomic mass units (amu). A mass spectrum scan was made once every second so that the scan number for a peak is equal to the retention time in seconds. This system is typical of those used for analyses of environmental samples for organic substances in the United States. The library of known mass spectra that was used is the NIST/EPA/MSDC library, ${ }^{7}$ with approximately 50,000 entries.

\subsubsection{Results}

Figure 6 shows the total ion chromatogram for the fog oil sample HTA999999N03. This sample was taken from fog oil supplies and does not have diesel fuel mixed with it. Fog oil, like most other petroleum oils, is an extremely complex mixture of literally thousands of different organic compounds, and the chromatographic system used in this work was not capable of resolving all of these constituents. As shown in the figure, the total ion chromatogram consists of a large, broad hump upon which is superimposed many sharp peaks that correspond to individual substances present in relatively larger amounts. The fact that the individual constituents of fog oil could not be separated means that the concentration of some particular substance, for example a PAH such as benzo[a]pyrene, cannot be determined in this way unless it is present in sufficient quantity to appear as a separate peak superimposed on the hump.

An attempt was made to identify the substances corresponding to the most prominent peaks from their mass spectra. To do this, the mass spectrum taken at the base of each peak was subtracted from the mass spectrum from the top of the peak to obtain an approximate mass spectrum for the peak itself without contamination from the substances constituting the hump. Mass spectra obtained in this way are not as reliable as those obtained from single, resolved peaks. Nevertheless, the tentative identities of several individual peaks in the chromatogram of Figure 6 are given in Table 5. No substance known to be hazardous or toxic was found. The scan numbers are shown on Figure 6, as is the corresponding retention time in minutes and seconds; one scan is taken every second. The "purity" value given in Table 5 is a measure of the degree to which the 


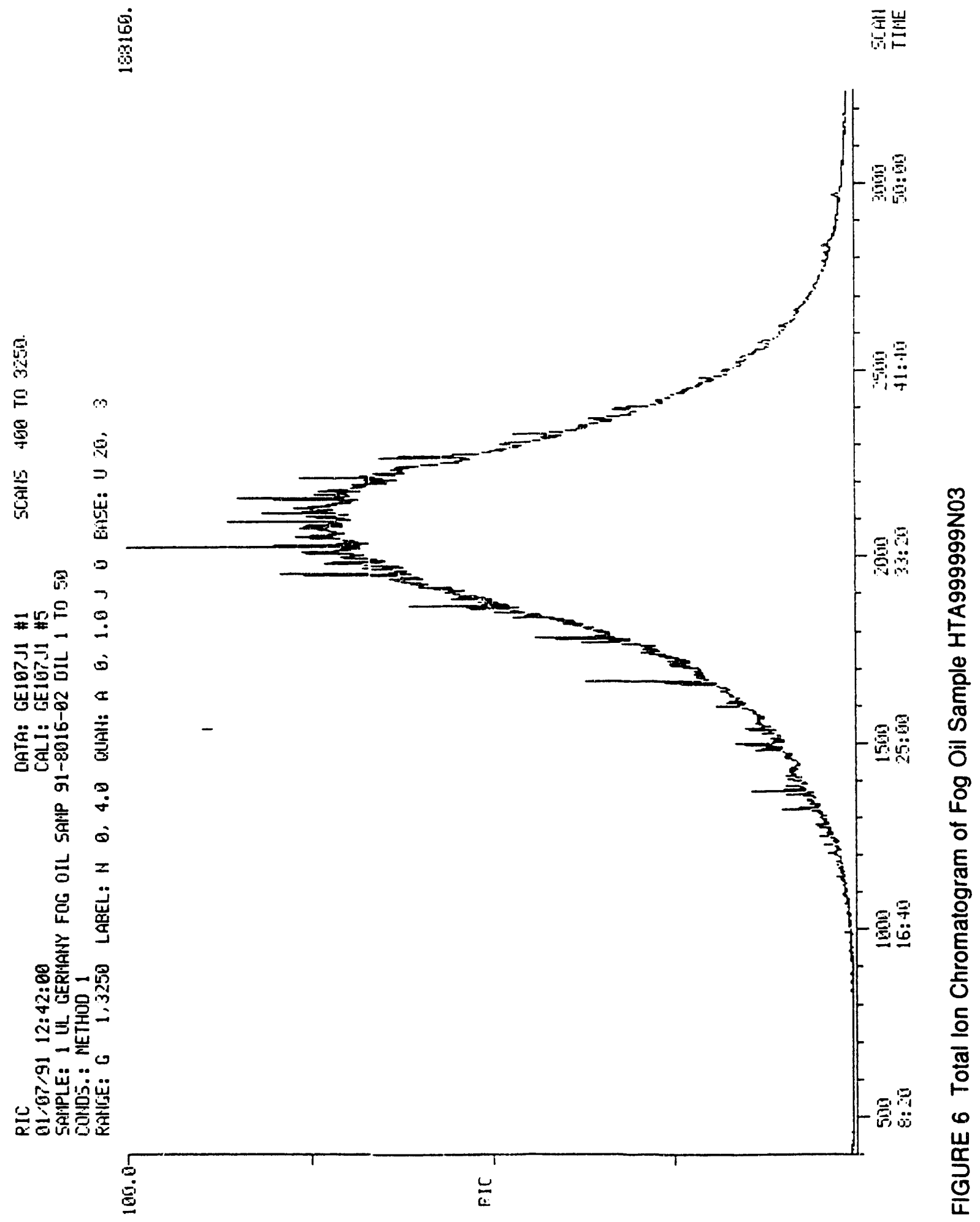


TABLE 5 Tentative Identification of Substances in Fog Oil Sampie HTA999999N03

\begin{tabular}{|c|c|c|}
\hline Tentative Identification & $\begin{array}{l}\text { Scan } \\
\text { Number }\end{array}$ & Purity \\
\hline 1H-indene, octahydro-2,2,4,4,7,7-hexamethyl-, trans ${ }^{a}$ & 1253 & 767 \\
\hline 1H-indene, octahydro-2,2,4,4,7,7-hexamethyl-, trans ${ }^{a}$ & 1376 & 771 \\
\hline 1H-indene, octahydro-2,2,4,4,7,7-hexamethyl-, trans ${ }^{a}$ & 1485 & 789 \\
\hline Pentadecane, 2,6,10,14-tetramethyl & 1668 & 902 \\
\hline Dodecane, $2,7,10$-trimethyl & 1785 & 863 \\
\hline Cyclohexane, 1-(1,5-dimethylhexyl)-4-(4-methylpentyl) & 2070 & 784 \\
\hline Long-chain aliphatic hydrocarbon ${ }^{b}$ & 1300 & - \\
\hline Long-chain aliphatic hydrocarbon ${ }^{b}$ & 1450 & - \\
\hline Long-chain aliphatic hydrocarbon ${ }^{b}$ & 1810 & - \\
\hline Long-chain aliphatic hydrocarbonb & 1873 & - \\
\hline Long-chain aliphatic hydrocarbonb & 1957 & - \\
\hline Long-chain aliphatic hydrocarbon b & 2032 & - \\
\hline Long-chain aliphatic hydrocarbonb & 2099 & - \\
\hline Long-chain aliphatic hydrocarbonb & 2160 & - \\
\hline Long-chain aliphatic hydrocarbon ${ }^{b}$ & 2217 & - \\
\hline
\end{tabular}

\footnotetext{
actual substance is chemically similar, but not identical, to the listed substance.

b Individual substances not identified; chemical class identified from examination of the mass spectrum.
}

observed mass spectrum agrees with that of the identified compound; this measure is given on a scale from 0 (complete disagreement) to 1000 (complete agreement).

Figure 7 shows the total ion chromatogram for fog oil sample HTA975623N01, taken from the oil tank of a smoke generator in the field. According to CMTC personnel, this sample contains approximately $25 \%$ diesel fuel and $75 \%$ fog oil. The chromatograms do not appear to be very different, but several individual peaks may be seen at relatively short retention times that do not appear in Figure 6. These peaks are undoubtedly due to the diesel fuel, but a substantial part of the diesel fuel is buried beneath the fog oil hump; in fact, diesel fuel itself generally shows a low hump of its own and cannot be resolved chromatographically without going to extreme measures. Again, an attempt was made to identify many of the individual peaks that appear by using the methods described above. The results are given in Table 6. Again, no hazardous or toxic material was identified from among these larger individual peaks. 


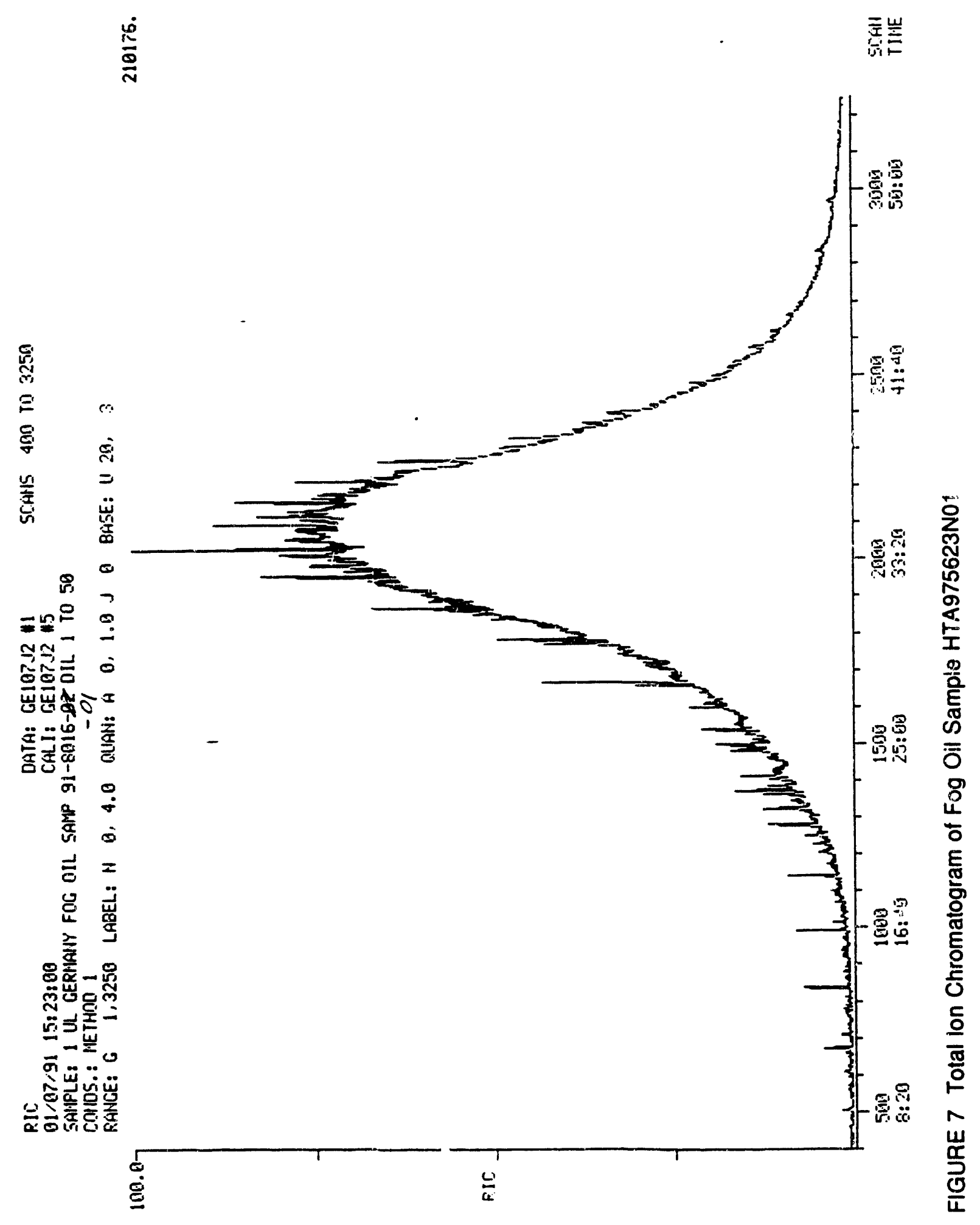


TABLE 6 Tentative Identification of Substances in Fog Oil Sample HTA975623N01

\begin{tabular}{|c|c|c|}
\hline Tentative Identification & $\begin{array}{c}\text { Scan } \\
\text { Number }\end{array}$ & Purity \\
\hline Nonane & 506 & 940 \\
\hline Dodecane & 996 & 933 \\
\hline $1 \mathrm{H}$-indene, octahydro-2,2,4,4,7,7-hexamethyl-, trans & 1326 & 853 \\
\hline Undecane, 4,6-dimethyl & 1416 & 830 \\
\hline Long-chain aliphatic hydrocarbon ${ }^{a}$ & 674 & - \\
\hline Long-chain aliphatic hydrocarbon ${ }^{a}$ & 839 & - \\
\hline Long $\rightarrow$. Iain aliphatic hydrocarbon ${ }^{a}$ & 1143 & - \\
\hline Long-chain aliphatic hydrocarbon & 1283 & - \\
\hline Long-chain aliphatic hydrocarbon ${ }^{a}$ & 1541 & - \\
\hline Long-chain aliphatic hydrocarbon ${ }^{\mathbf{a}}$ & 1669 & - \\
\hline Long-chain aliphatic hydrocarbon ${ }^{a}$ & 1786 & - \\
\hline Long-chain aliphatic hydrocarbon & 1873 & - \\
\hline Long-chain aliphatic hydrocarbon ${ }^{a}$ & 1957 & - \\
\hline Long-chain aliphatic hydrocarbon ${ }^{a}$ & 2032 & - \\
\hline Long-chain aliphatic hydrocarbon ${ }^{\mathbf{a}}$ & 2099 & - \\
\hline Long-chain aliphatic hydrocarbon ${ }^{a}$ & 2160 & - \\
\hline Long-chain aliphatic hydrocarbon ${ }^{a}$ & 2217 & - \\
\hline Long-chain aliphatic hydrocarbon ${ }^{a}$ & 2272 & - \\
\hline Long-chain aliphatic hydrocarbon ${ }^{a}$ & 2333 & - \\
\hline Long-chain aliphatic hydrocarbon ${ }^{a}$ & 2373 & - \\
\hline Long-chain aliptatic hydrocarbon ${ }^{a}$ & 2455 & - \\
\hline
\end{tabular}

a !rdividual substances not identified; chemical class identified from examination of the mass spectrum.

\subsection{Environmental Samples}

\subsubsection{Sample Workup Procedures}

In the case of typical environmental samples, such as those collected in this program, the sample workup procedure is intended to extract the substances of interest, in this case fog oil and $O C B$ at least, from the sample medium and to concentrate it in a solution suitable for injection into a GC or GC/MS. The U.S. EPA has developed standard workup procedures for use with samples collected as part of environmental investigations and restoration efforts in the United States and are documented in the U.S. EPA Contract Laboratory Program Statements of Work. ${ }^{8}$ The standard EPA workup procedure for semivolatile organic compounds was used as the workup procedure for the soil and sediment samples collected at CMTC. Briefly, the procedure involves the extraction of $30 \mathrm{~g}$ of sample, mixed with $60 \mathrm{~g}$ of anhydrous powdered sodium sulfate, in three successive 
100-mL portions of a 1-1 methylene chloride-acetone mixture. Each extraction is done by using an ultrasonic disruptor to ensure the breakup of soil particles and the maximum extraction efficiency. The extracts are then combined and concentrated to a final volume of $10 \mathrm{~mL}$.

In the case of the vegetation samples, no standard workup procedure is available. The situation is complicated by the possibility that natural organic substances, in addition to any contaminants present, will be extracted from the interior of the plant material. The sample workup procedure used in this study consisted of the extraction of the entire plant sample with hexane, without the use of ultrasound. The sample w/as not homogenized prior to the extraction. In effect, the surface of the sample was washed with hexane in an attempt to collect all organic matter that was on the plant surface while minimizing the collection of material from the plant interior. This procedure was not independently tested, but it is expected that all the fog oil and OCB that may have been present on the plant surface was collected by using this method. The results must be regarded as only semiquantitative without further testing of the procedure.

The analytical procedures used were the same for the soil, sediment, and vegetation samples. Analysis was done by using gas chromatography with a flame ionization detector (GC/FID). In this type of detector, the vaporized sample constituents are passed into a hydrogenair flame; as each peak elutes from the end of the column, any combustible material is burned and a large number of ions are formed. The current generated by these ions is detected by a pair of electrodes and is the basis for the detector response. This type of detector has a very high sensitivity, comparable with that of mass spectrometry, for combustible substances, such as the constituents of petroleum oils or fuels. The gas chromatograph used was a Hewlett-Packard Model $5990 \mathrm{GC}$ with an autosampler injection system. The column used was a J\&W DB-5 capillary column, $30 \mathrm{~m} \times 0.32 \mathrm{~mm}$ with a $0.25-\mu \mathrm{m}$ film thickness. The temperature was increased in the following way: the initial temperature was maintained at $100^{\circ} \mathrm{C}$ for $2 \mathrm{~min}$; then the temperature was increased to $120^{\circ} \mathrm{C}$ at a rate of $5^{\circ} \mathrm{C}$ per minute; then from $120^{\circ} \mathrm{C}$, the temperature was increased to $320^{\circ} \mathrm{C}$ at a rate of $12^{\circ} \mathrm{C}$ per minute until the temperature was $320^{\circ} \mathrm{C}$, which was maintained for $10 \mathrm{~min}$. The injector temperature was $270^{\circ} \mathrm{C}$, and the detector temperature was $290^{\circ} \mathrm{C}$. The carrier gas was helium and flowed at a rate of $19 \mathrm{~cm}^{3} / \mathrm{s}$. The injection volume was $3 \mu \mathrm{L}$ (splitless).

As in the GC/MS analyses, it was found to be impossible to separate the individual constituents of fog oil, and the chromatographic operating conditions were optimized to maximize the sensitivity of the method for the detection of fog oil itself. The analysis of fog oil samples at varying dilution was carried out so that a calibration curve could be prepared. Eight points were run (concentrations $0.576,5.76,11.52,28.8,57.6,115.2,288$, and $576 \mathrm{mg}$ fog oil/ $\mathrm{L}$ in hexane); the lowest detectable concentration was $11.52 \mathrm{mg} / \mathrm{L}$. See Appendix $\mathrm{E}$ for further details on calibration and other QA/QC issues.

Two data-processing techniques, the ratio and subtraction techniques, were applied to the GC/FID chromatograms of the environmental samples to improve the detection limit for fog oil, which elutes as a single, broad peak. The ratio technique calculates a point-by-point ratio of the sample chromatogram to a solvent blank chromatogram; this technique eliminates baseline drift that 
might mask a low, broad peak, such as that expected from a low fog oil concentration. The subtraction technique calculates a point-by-point difference between the sample chromatogram and a standard fog oil chromatogram. Sample peaks are reduced in size as chromatograms of increasing fog oil concentrations are used. If fog oil is not present in the sample, the baseline takes on a "bowl" shape. On the other hand, if fog oil is present, the eventual result will be a straight baseline where fog oil was present.

\subsubsection{Results}

No fog oil or OCB was detected in any environmental sample analyzed. The detection limit for fog oil varied with the sample, because the chromatograms from some samples were very complex and the detection of a low hump due to fog oil was more difficult than in a relatively clean sample. In the more complex samples, the fog oil detection limit was approximately 11 parts per million by weight (ppm), while in the relatively clean samples, the fog oil detection limit was approximately $5 \mathrm{ppm}$. In all samples, the OCB detection limit was approximately $33 \mathrm{ppm}$. Appendix E provides GC/FID chromatograms for all soil and sediment samples and selected vegetation samples.

Tables 7 and 8 summarize the results of the analyses of the soil and sediment samples and of the vegetation samples, respectively. In these tables, the entries are arranged by sample code for easy reference. The environment and the study area from which the sample was collected are also given, along with the rest of the sample ID ("S01," for example). The description provided for the soil and sediment samples includes a numerical value that will be explained shortly and the observed color of the extract after the sample workup procedure was completed. The analytical results for each sample consist not only of the chromatogram, but also of a printout of the retention time in minutes and the area in arbitrary units of each separate peak, as well as the total integrated area under all the peaks that appear. The numerical value given in the tables represents a measure, in arbitrary units, of the total integrated area in the chromatogram, excluding the solvent peak.

For the vegetation samples, the description includes a letter that indicates the height of the vegetation from which the sample was taken: " $L$ " for vegetation near the ground and " $H$ " for higher vegetation. Also given is the same numerical measure of the total integrated area under all peaks that appear, excluding the solvent peak. The sample extract color is not given; it was nearly the same (dark green to yellow-green) for all vegetation samples.

As indicated above, some soil samples gave rather complex chromatograms. Although neither fog oil nor OCB could be detected in any sample, it was desirable to determine what substances were present in the samples that gave rise to such complex chromatograms. Eight samples were selected from among the more complex ones for further analysis by using GC/MS techniques. Time and resource constraints precluded the further investigation of additional samples. The samples chosen are listed in Table 9, and their total ion chromatograms are shown in Figures 8 through 15. 
TABLE 7 CMTG Soil and Sediment Samples Arranged by Sample Code

\begin{tabular}{|c|c|c|c|c|c|}
\hline \multirow[b]{2}{*}{$\begin{array}{l}\text { Sample } \\
\text { Coode }\end{array}$} & \multirow[b]{2}{*}{ Environment } & \multirow[b]{2}{*}{$\begin{array}{l}\text { Study } \\
\text { Area }\end{array}$} & \multicolumn{3}{|c|}{ Description } \\
\hline & & & Sample & $\begin{array}{l}\text { Total } \\
\text { Area }\end{array}$ & $\begin{array}{c}\text { Extract } \\
\text { Color }\end{array}$ \\
\hline 977673 & Sediment & C & R01 & 1.80 & pale yel \\
\hline 979679 & Valley & C & $\mathrm{S} 01^{\mathrm{b}}$ & 7.27 & med yel \\
\hline 979682 & Forest & C & S01 & 7.24 & med yel \\
\hline 987671 & Valley & C & S01 & 5.17 & med yel \\
\hline \multirow[t]{2}{*}{016616} & Valley & 1 & So1c & 6.99 & med yel-grn \\
\hline & & & $S 02^{c}$ & 2.58 & med yel-grn \\
\hline 018597 & Valley & 1 & S01 & 6.37 & med yel-grn \\
\hline \multirow[t]{3}{*}{019606} & Valloy & 1 & So1b.d & 7.86 & med yel-grn \\
\hline & & & $S 02^{d, \theta}$ & 3.48 & med yel-grn \\
\hline & & & $\mathrm{SO}^{\circ}$ & 4.65 & med yel-grn \\
\hline 020603 & Sediment & 1 & $R 01^{b}$ & 1.64 & pale yel \\
\hline 020608 & Sediment & 1 & R01 & 0.167 & clear \\
\hline 021610 & Forest & 1 & S01 & 28.6 & deep yel-grn \\
\hline 1723604 & Forest & 1 & So1 & 10.6 & deep yel-grn \\
\hline 033606 & Valley & 2 & S01 & 3.17 & med yel-grn \\
\hline \multirow[t]{2}{*}{036605} & Sediment & 2 & $R 01^{f}$ & 8.38 & deep grn \\
\hline & & & $\mathrm{Ro2}$ & 8.82 & deөp yel-grn \\
\hline 037606 & Forest & 2 & S01b & 19.1 & med yel-grn \\
\hline 038601 & Valley & 2 & Solb & 11.5 & yel-grn \\
\hline 043597 & Sediment & 2 & R01 & 2.53 & med yel-grn \\
\hline \multirow[t]{2}{*}{056593} & Forest & 3 & So1b,g & 16.8 & med yel \\
\hline & & & $S 02^{b, g}$ & 11.4 & deep yel \\
\hline 056603 & Valley & 3 & S01 & 8.60 & deep yel-grn \\
\hline 056624 & Sediment & - & R01 & 0.415 & clear \\
\hline \multirow[t]{2}{*}{059601} & Valley & 3 & So1h & 8.87 & med yel \\
\hline & & & $\mathrm{SO} 2^{b, h}$ & 10.2 & deep yel-grn \\
\hline \multirow[t]{2}{*}{061596} & Valley & 3 & So1i & 3.99 & v. pale yel \\
\hline & & & $\mathrm{SO}^{i}$ & 2.49 & v. pale yel \\
\hline 062592 & Sediment & 3 & R01 & 1.01 & v. pale yel \\
\hline 065585 & Sediment & 3 & Ro1 & 1.58 & pale yel \\
\hline 066598 & Forest & 3 & S01 & 7.57 & med yel-grn \\
\hline 073624 & Sediment & - & R01 & 0.887 & clear \\
\hline 096600 & Sediment & - & R01 & 1.05 & pale yel \\
\hline
\end{tabular}

See text for definition.

b Samples chosen for GC/MS analysis.

c,d Samples taken three days apart at same location.

Q Duplicate soil samples.

'Duplicate sediment samples.

9.h,i Samples taken seven days apart at same location. 
TABLE 8 CMTC Vegetation Samples Arranged by Sample Code

\begin{tabular}{|c|c|c|c|c|c|}
\hline \multirow[b]{2}{*}{$\begin{array}{c}\text { Sample } \\
\text { Code }\end{array}$} & \multirow[b]{2}{*}{ Environment } & \multirow[b]{2}{*}{$\begin{array}{l}\text { Study } \\
\text { Area }\end{array}$} & \multicolumn{3}{|c|}{ Description } \\
\hline & & & Sample & Height & $\begin{array}{l}\text { Total } \\
\text { Area }\end{array}$ \\
\hline 979679 & Valley & C & v01 & - & 2.05 \\
\hline \multirow{2}{*}{979682} & Forest & C & V01 & Low & 1.40 \\
\hline & & & V02 & High & 2.39 \\
\hline 987671 & Valley & c & V01 & - & 2.69 \\
\hline 016616 & Valley & 1 & V01 & - & 1.55 \\
\hline 018597 & Valley & 1 & V01 & - & 1.38 \\
\hline 019606 & Valley & 1 & Vo1 & - & 1.15 \\
\hline \multirow[t]{2}{*}{021610} & Forest & 1 & Vo1 & Low & 2.18 \\
\hline & & & V02 & High & 1.18 \\
\hline \multirow[t]{2}{*}{023604} & Forest & 1 & V01 & Low & 1.70 \\
\hline & & & Vo2 & High & 2.12 \\
\hline 033606 & Valley & 2 & V01 & - & 2.21 \\
\hline \multirow[t]{2}{*}{037606} & Forest & 2 & V01 & Low & 3.13 \\
\hline & & & V02 & High & 1.86 \\
\hline 038601 & Valley & 2 & V01 & - & 1.83 \\
\hline \multirow{4}{*}{056593} & Forest & 3 & V01b & Low & 2.05 \\
\hline & & & $\mathrm{V}^{2} 2^{\mathrm{c}}$ & High & 2.60 \\
\hline & & & $\mathrm{V}^{0} 3^{\mathrm{b}}$ & Low & 1.70 \\
\hline & & & $\mathrm{VO} 4^{\mathrm{C}}$ & High & 1.72 \\
\hline 056603 & Valley & 3 & V01 & - & 1.64 \\
\hline \multirow[t]{3}{*}{059601} & Valley & 3 & Vo1d & - & 2.79 \\
\hline & & & $V 02^{d, e}$ & - & 1.38 \\
\hline & & & V03 ${ }^{\circ}$ & - & 1.62 \\
\hline \multirow[t]{2}{*}{061596} & Valley & 3 & vo1l & - & 2.41 \\
\hline & & & Vo $2^{\prime}$ & - & 2.32 \\
\hline \multirow[t]{2}{*}{066598} & Forest & 3 & V01 & Low & 3.13 \\
\hline & & & Vo2 & High & 1.61 \\
\hline
\end{tabular}

a See text for definition.

b,c,d,I Samples taken seven days apart at same location.

- Duplicate vegetation samples. 
The extracts from the eight selected samples were concentrated further by a factor of five and then analyzed by GC/MS under the same operating conditions as were used in the neat fog oil analyses described in Section 5.1. An examination was made of each scan, taken once every second by the mass spectrometer during the run, in an attempt to detect the presence of any U.S. EPA semivolatile priority pollutants. (These are substances that have been determined to pose a potential health hazard at hazardous waste sites in the United States.) The search for priority pollutants is made by searching each scan for the presence of key molecular ions, each associated with a specific priority pollutant. For example, the presence of molecular ions with a mass of 169 amu indicates the possible presence of $\mathrm{N}$-nitrosodiphenylamine in the sample. If a particular key ion is detected in any scan, a comparison is made of the complete mass spectrum with the known mass spectrum of the substance to try to confirm the identification. This comparison may fail, however, if the pollutant is present in only trace amounts, because the observed mass spectrum may not be very accurate in that case. Even if the comparison fails, the priority pollutant is considered to have been detected, although with much less certainty. A complete list of the priority pollutants considered in this work is given in Appendix F.

In addition to a search for priority pollutants, the mass spectra of the most significant peaks that appear in the total ion chromatogram were compared with those in the NIST/EPA/MSDC data base in an attempt to identify the corresponding substances; however, not all components could be identified in this way. Tables 10 through 17 list the substances tentatively identified by mass spectrometry in the samples listed in Table 9. Each table gives the name of the substance, the scan number at which it appeared, the purity value associated with the mass spectrum, and (except in Tables 10 and 16) an estimate of the concentration of that substance in the sample.

The concentration estimates given in these tables are based on the use of internal standards, which were specific compounds introduced into the sample extract in known concentrations. The concentration of a contaminant may be found by comparing the intensity of the principal ion in the mass spectrum with that of the nearest internal standard. In addition, other information is necessary, including knowledge of the concentration of the internal standard and, in the case of priority pollutants, knowledge of the sensitivity of the mass spectrometer to the contaminant compared with that of the internal standard. For substances not in the list of priority pollutants, the assumption was made that the responses of the mass spectrometer to the contaminant and to the internal standard used are identical. The concentrations in the tables are given in micrograms of substance per kilogram of dry sample; these units are equivalent to parts per $10^{9}$ (or parts per billion. American usage) by weight. Concentration estimates are not available for samples 


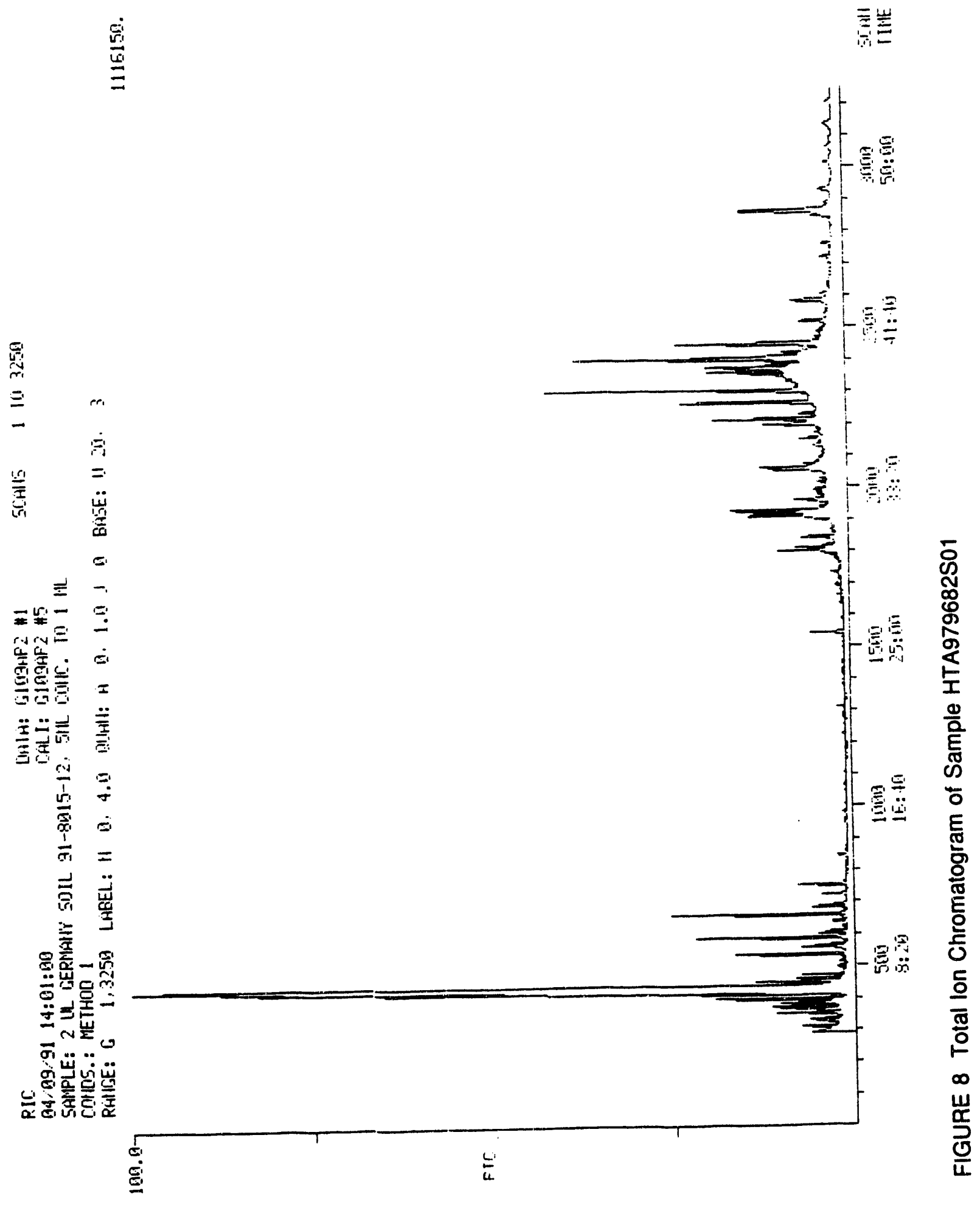




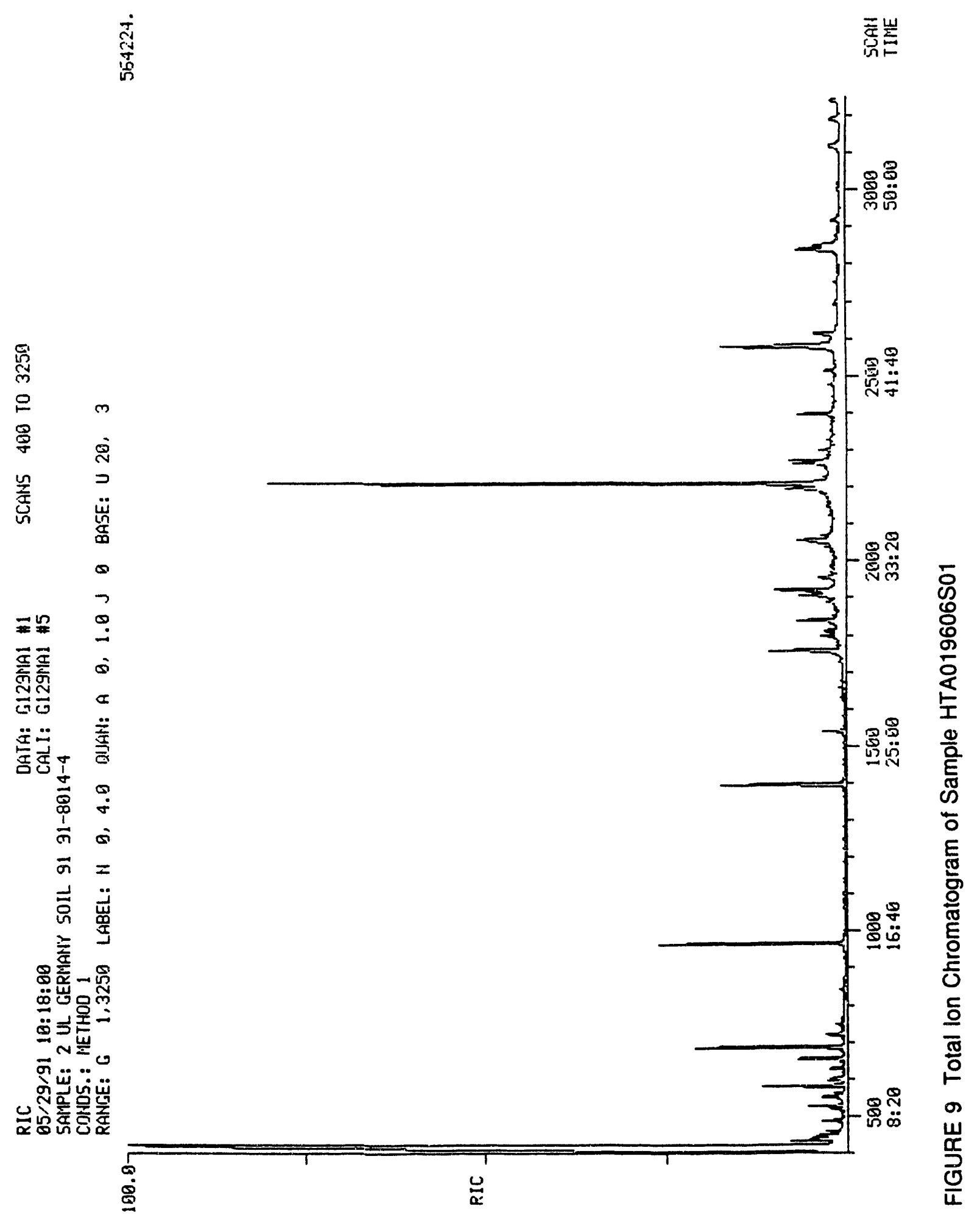




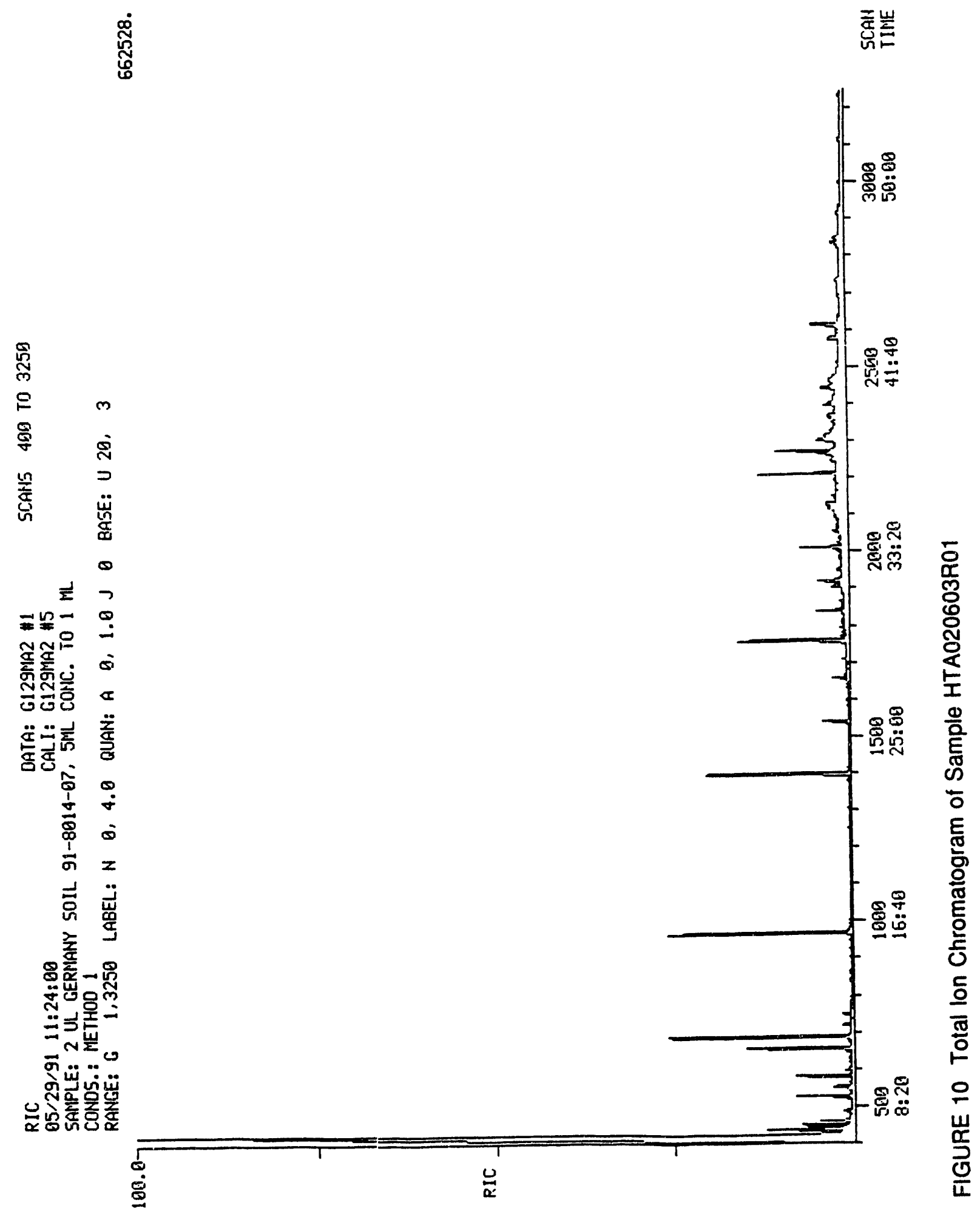




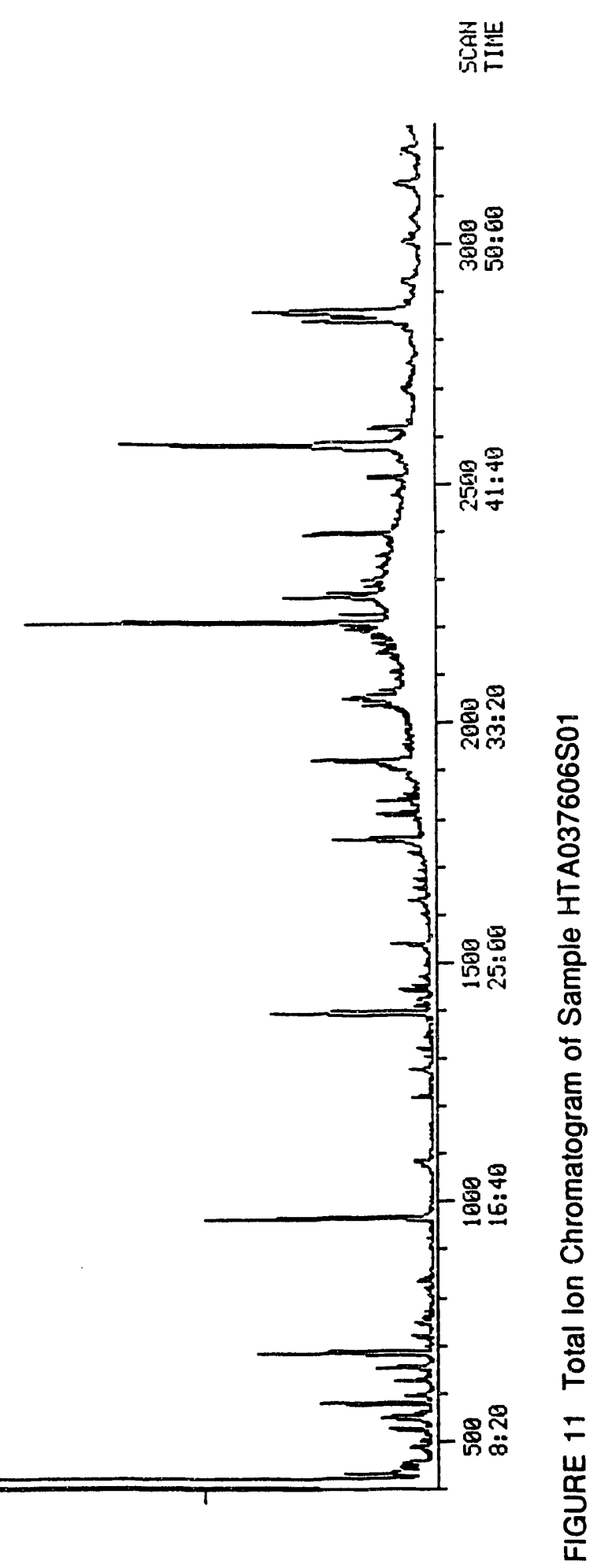




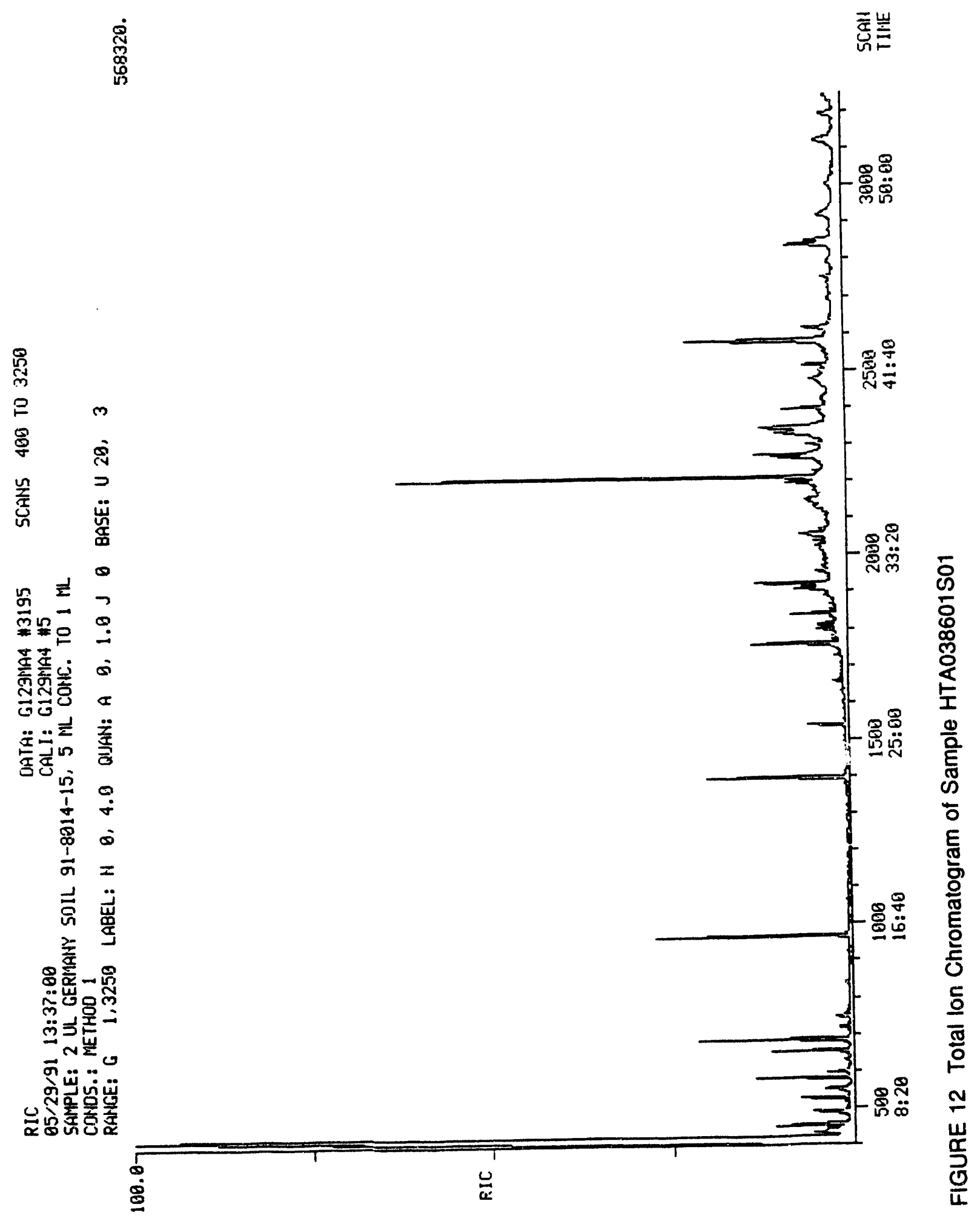


$\frac{\dot{0}}{\dot{*}}$

㗹崖
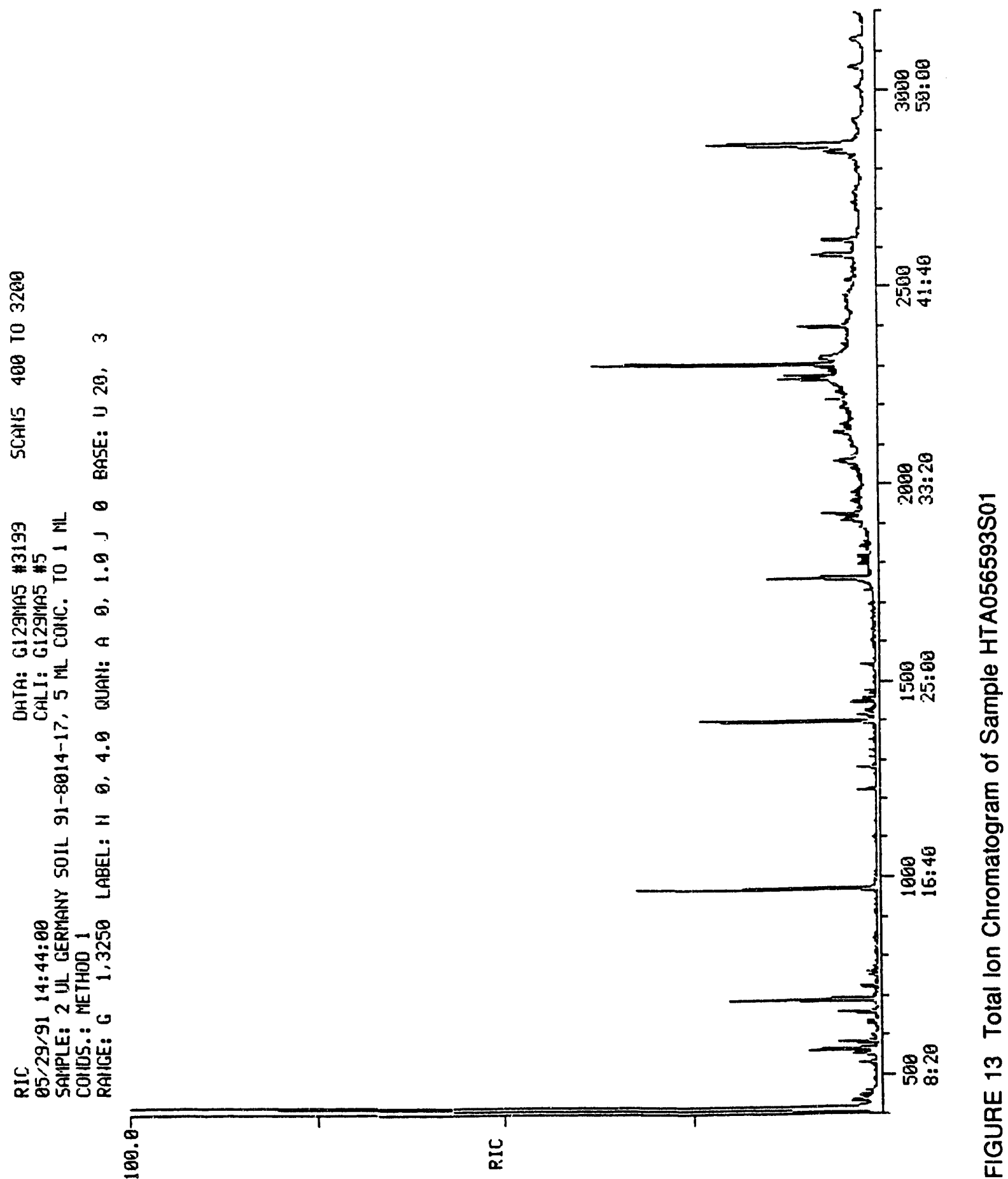


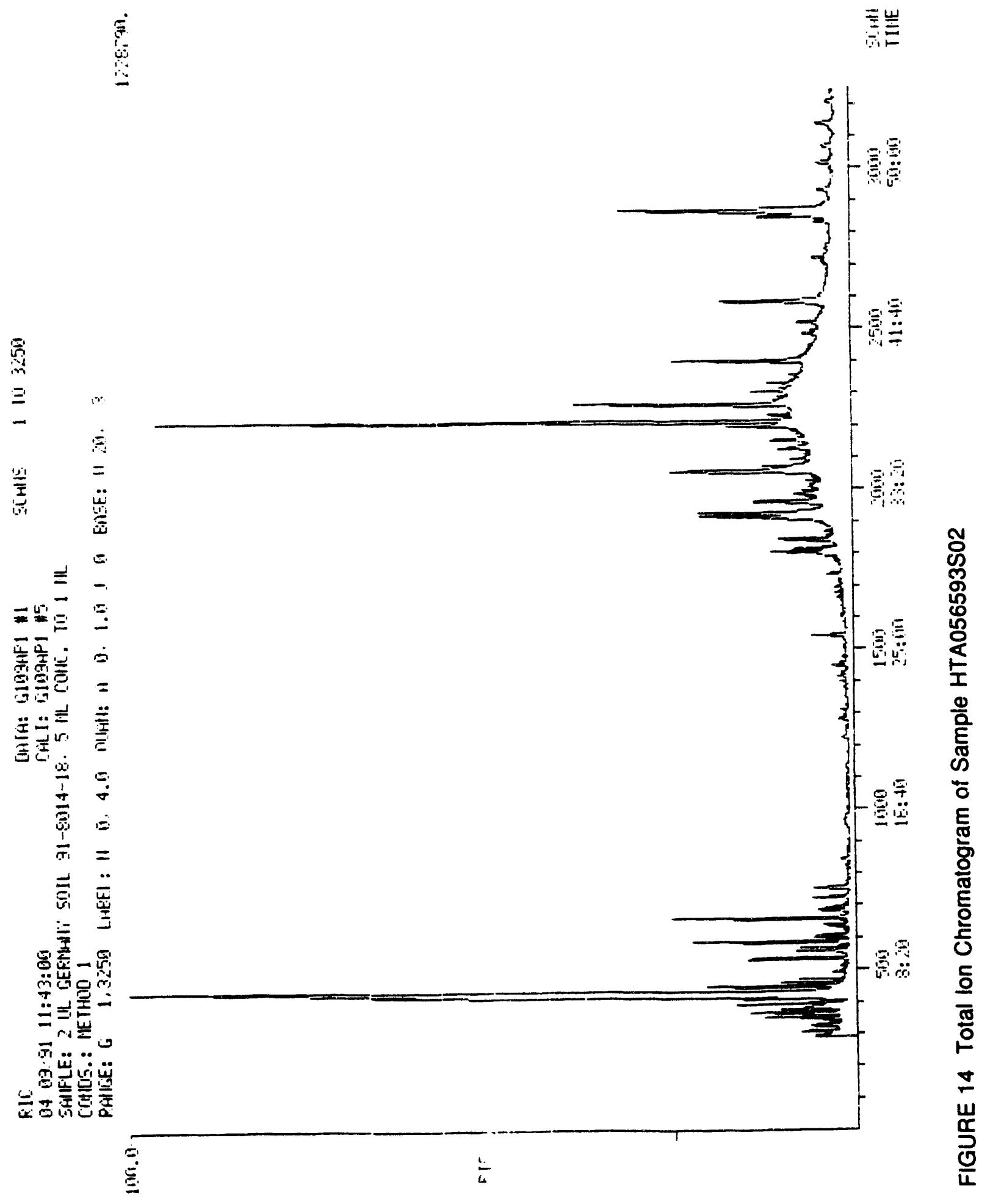


曽

站岕

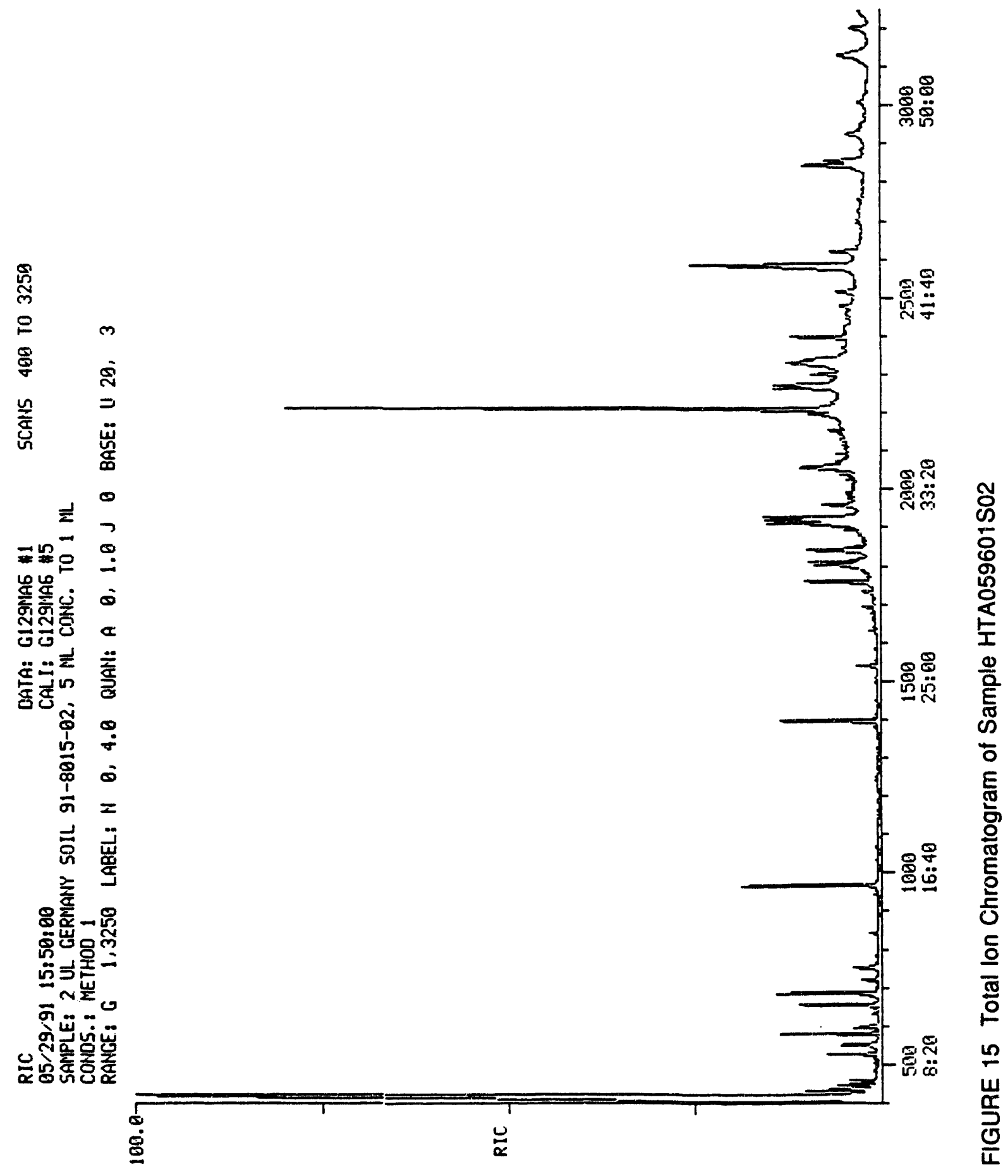


TABLE 10 Tentative Identification of Substances in Environmental Sample HTA979682S01a

\begin{tabular}{|c|c|c|}
\hline Tentative Identification & $\begin{array}{l}\text { Scan } \\
\text { Number }\end{array}$ & Purity \\
\hline 2-hexanone, 6-acetyloxyb & 537 & 695 \\
\hline 5-hexen-2-one, 5-methylb & 590 & 863 \\
\hline 3-heptanone, 2,4-dimethylb & 664 & 727 \\
\hline $\begin{array}{l}\text { 1,4-methaneazulene, decahydro-4,8,8-trimethyl-9-methylene-, } \\
\text { [1S-(1 alpha, 3a beta, } 4 \text { alpha, } 8 \text { a beta)]- }\end{array}$ & 1312 & 723 \\
\hline $\begin{array}{l}\text { Propanoic acid, 2-methyl-,1-(1,1-methylethyl)-2-methyl- } \\
\text { 1,3-propanediyl esterb }\end{array}$ & 1548 & 915 \\
\hline Tetradecanoic acid & 1735 & 810 \\
\hline Pentadecanoic acid & 1805 & 802 \\
\hline Unknown phthalate & 1847 & - \\
\hline 2-dodecenal & 1912 & 745 \\
\hline 9-octadecenal & 1919 & 715 \\
\hline Hexadecanoic acid & 1930 & 777 \\
\hline Long-chain hydrocarbon & 2065 & - \\
\hline 1-octadecanol & 2154 & 866 \\
\hline Hexanedioic acid, bis(2-ethylhexyl) esterb,c & 2217 & 871 \\
\hline Octadecane, $1 \cdot(\theta \text { thenyloxy })^{-c}$ & 2270 & 912 \\
\hline 1,2-benzenedicarboxylic acid, bis(2-ethylhexyl) ester & 2309 & 957 \\
\hline Long-chain hydrocarbond & 2406 & - \\
\hline Long-chain hydrocarbond & 2411 & - \\
\hline Long-chain hydrocarbond & 2452 & - \\
\hline Long-chain hydrocarbond & 2585 & - \\
\hline Long-chain hydrocarbond & 2849 & - \\
\hline
\end{tabular}

a Concentration estimates not available - see text.

b Known system contaminant.

c Substance is similar but not identical to the listed compound.

Background scans at 2106, 2342, and 2431 show the presence of long-chain hydrocarbons in the background "hump." 
TABLE 11 Tentative Identification of Substances in Environmental Sample HTA019606S01

\begin{tabular}{|c|c|c|c|}
\hline Tentative Identification & $\begin{array}{l}\text { Scan } \\
\text { Number }\end{array}$ & Purity & $\begin{array}{l}\text { Concentration } \\
(\mu \mathrm{g} / \mathrm{kg})^{\mathrm{a}}\end{array}$ \\
\hline 2-pentanone, 4-hydroxy-4-methy $\left.\right|^{b}$ & 423 & 898 & - \\
\hline $1,3,5,7$-cyclooctatetraene $\theta^{b}$ & 489 & 973 & - \\
\hline 2-hexanone, 6-acetyloxyb & 528 & 713 & - \\
\hline 5-hexene-2-one, 5-methylb & 583 & 881 & - \\
\hline 3-heptanone, 2,4-dimethylb & 657 & 798 & - \\
\hline 3-undecene, 6-methyl-,(E)- & 722 & 803 & 580 \\
\hline $\begin{array}{l}\text { Propanoic acid, 2-methyl-1,1-(1,1-dimethylethyl)-2- } \\
\text { Methyl-1,3-propanediyl esterb }\end{array}$ & 1542 & 993 & - \\
\hline Pentadecanoic acid & 1799 & 834 & 490 \\
\hline Butanoic acid, 3,7-dimethyl-6-octenyl ester & 1813 & 839 & 260 \\
\hline Long-chain hydrocarbon & 1818 & - & 140 \\
\hline 1,2-benzenedicarboxylic acid, butyl-8-methylnonyl ester & 1843 & 598 & 1640 \\
\hline 9-octadecenoic acid (Z)- & 1908 & 750 & 1800 \\
\hline Hexadecanoic acid & 1925 & 717 & 2700 \\
\hline Hexanedioic acid, bis(2-ethylhexyl) ester ${ }^{b}$ & 2215 & 877 & - \\
\hline Pctadecane, 1-(ethenyloxy)-c & 2265 & 913 & 3500 \\
\hline 1,2-benzenedicarboxylic acid, bis (2-ethylhexyl) ester & 2302 & 960 & 860 \\
\hline Long-chain hydrocarbon & 2399 & - & 2700 \\
\hline Octadecane, $1-(e$ thenyloxy)-c & 2583 & 843 & 18000 \\
\hline Long-chain hydrocarbon & 2842 & - & 6500 \\
\hline
\end{tabular}

a Rounded to two significant figures.

${ }^{b}$ Known system contaminant.

c Substance is similar but not identical to the listed compound. 
TABLE 12 Tentative Identification of Substances in Environmental Sample HTA020603R01

\begin{tabular}{|c|c|c|c|}
\hline Tentative Identification & $\begin{array}{l}\text { Scan } \\
\text { Number }\end{array}$ & Purity & $\begin{array}{l}\text { Concentration } \\
(\mu \mathrm{g} / \mathrm{kg})^{\mathrm{a}}\end{array}$ \\
\hline 2-pentanone, 4-hydroxy-4-methy $\left.\right|^{b}$ & 426 & 884 & - \\
\hline Heptane, 2,3-dimethyib & 437 & 947 & - \\
\hline Octane, 4-methy|b & 449 & 968 & - \\
\hline Heptane, 4-(1-methylethyl)-b & 460 & 908 & - \\
\hline 2-heptanol, acetateb & 528 & 690 & - \\
\hline 5-hexen-2-one, 5-methylb & 581 & 880 & - \\
\hline 3-heptanone, 2,4-dimethylb & 658 & 803 & - \\
\hline $\begin{array}{l}\text { Propanoic acid, 2-methyl-1-(1,1-dimethylethyl) } \\
\text {-2-methyl-1,3-propanediyl esterb }\end{array}$ & 1542 & 861 & - \\
\hline Long-chain hydrocarbon & 1659 & - & 370 \\
\hline 1,2-benzenedicarboxylic acid, butyl-2-methylpropyl ester & 1842 & 918 & 560 \\
\hline 2-dodecanal & 1906 & 786 & 320 \\
\hline Hexadecanoic acid & 1922 & 806 & 820 \\
\hline Long-chain hydrocarbon & 1952 & - & 230 \\
\hline Long-chain hydrocarbon & 2014 & - & 630 \\
\hline Hexanedioic acid, bis(2-ethylhexyl) ester & 2213 & 871 & 2200 \\
\hline Octadecane, 1 -(ethenyloxy)-c & 2264 & 843 & 870 \\
\hline 1,2-benzenedicarboxylic acid, bis(2-ethy|hexyl) ester & 2302 & 874 & 850 \\
\hline Long-chain hydrocarbon & 2368 & - & 780 \\
\hline Long-chain hydrocarbon & 2398 & - & 510 \\
\hline Long-chain hydrocarbon & 2576 & - & 1600 \\
\hline Long-chain hydrocarbon & 2838 & - & 1000 \\
\hline Long-chain hydrocarbon & 2849 & - & 820 \\
\hline Long-chain hydrocarbon & 3238 & - & 310 \\
\hline
\end{tabular}

a Rounded to two significant figures.

${ }^{b}$ Known system contaminant.

c Substance is similar but not identical to the listed compound. 
TABLE 13 Tentative Identification of Substances in Environmental Sample HTA037606S01

\begin{tabular}{|c|c|c|c|}
\hline $\begin{array}{l}\text { Tentative Identification } \\
\text { (priority pollutants in boldface) }\end{array}$ & $\begin{array}{l}\text { Scan } \\
\text { Number }\end{array}$ & Purity & $\begin{array}{l}\text { Concentration } \\
(\mu \mathrm{g} / \mathrm{kg})^{\mathrm{a}}\end{array}$ \\
\hline 2-pentanone, 4-hydroxy-4-methy $\left.\right|^{b}$ & 423 & 896 & - \\
\hline 2-heptanol, acetateb & 527 & 686 & - \\
\hline 5-hexene-2-one, 5-methylb & 582 & 878 & - \\
\hline Cyclohexene, 3-methylene-6-(1-methylethy 1$)$ - & 629 & 965 & 560 \\
\hline 3-heptanone, 2,4-dimethylb & 656 & 810 & - \\
\hline Benzolc acid & 959 & ع & 715 \\
\hline Benzeneacetic acid & 1089 & 937 & 550 \\
\hline $\begin{array}{l}\text { 1-H-cyclopenta[1,3]cyclopropa[1,2]benzene, 3a,3b,4,5,6,7- } \\
\text { hexahydro-3,7-dimethyl-4-(1-methylethyl-, } \\
\text { [3aS-(3a alpha, 3b beta, } 4 \text { beta, } 7 \text { gamma, 7aS*)]-(-)- }\end{array}$ & 1222 & 863 & 260 \\
\hline $\begin{array}{l}\text { 1-H-cyclopenta[1,3]cyclopropa[1,2]benzene, octahydro- } \\
\text { 7-methyl-3-methylene-4-(1-methylethyl)--, } \\
\left.\left.\text { [3aS-(3a alpha, 3b beta, } 4 \text { beta, } 7 \text { gamma, } 7 \mathrm{aS}^{*}\right)\right]-(-)-\end{array}$ & 1280 & 838 & 450 \\
\hline Bicyclo[7.2.0]undec-4-ene, 4,11,11-trimethyl-8-methylene- & 1323 & 790 & 190 \\
\hline $\begin{array}{l}\text { Naphthalene, decahydro-4a-methyl-1-methylene-7- } \\
\text { (1-methylethenyl)-, [4aR-trans]- }\end{array}$ & 1412 & 826 & 300 \\
\hline $\begin{array}{l}\text { Naphthalene, } 1,2,4 a, 5,6,8 \mathrm{a}-\text { hexahydro-4,7-dimethyl- } \\
1-(1-\text { methylethyl)-, (1 alpha, 4a alpha, 8a alpha)-d }\end{array}$ & 1425 & 823 & 290 \\
\hline $\begin{array}{l}\text { Naphthalene, } 1,2,3,4,4 a, 5,6,8 a-o c t a h y d r o-7-\text { methyl- } \\
\text { 4-methylene-1-(1-methylethyl)- (1 alpha, } 4 a \text { alpha, } \\
\text { 8a alpha)- }\end{array}$ & 1446 & 858 & 360 \\
\hline $\begin{array}{l}\text { Naphthalene, } 1,2,4 a, 5,8,8 a-h e x a h y d r o-4,7 \text {-dimethyl- } \\
1-(1-\text { methylethyl)-, (1 alpha, } 4 a \text { beta, } 8 a \text { alpha })-(+-)-\end{array}$ & 1455 & 874 & 340 \\
\hline $\begin{array}{l}\text { Naphthalene, } 1,2,4 a, 5,6,8 a-h e x a h y d r o-4,7-\text { dimethy!- } \\
\text { 1-(1-methylethyl)-, (1 alpha, } 4 \text { a alpha, } 8 \text { a alpha)-d }\end{array}$ & 1475 & 836 & 130 \\
\hline $\begin{array}{l}\text { Propanoic acid, 2-methyl-1-(1,1-dimethylethyl)-2- } \\
\text { methyl-1,3-propanediyl ester }\end{array}$ & 1542 & 932 & - \\
\hline Long-chain hydrocarbon & 1657 & - & 240 \\
\hline Tridecanal & 1675 & 813 & 210 \\
\hline Tetradecanoic acid & 1730 & 697 & 330 \\
\hline Unknown phthalate & 1842 & - & 723 \\
\hline Hexadecanoic acid & 1926 & 739 & 2900 \\
\hline 2-hexadecen-1-ol,3,7,11,15-tetramethyl-[R-[R,R-(E)]]- & 2039 & 762 & 840 \\
\hline 9,12-octadecadienoic acid $(Z, Z)$ - & 2054 & 921 & 2400 \\
\hline Octadecanoic acid & 2071 & 809 & 850 \\
\hline Octadecane, 1-(ethenyloxy)-d & 2150 & 858 & 1100 \\
\hline Long-chain hydrocarbon & 2155 & - & 770 \\
\hline
\end{tabular}


TABLE 13 (Cont.)

\begin{tabular}{lccr}
\hline \multicolumn{1}{c}{$\begin{array}{c}\text { Tentative Identification } \\
\text { (priority pollutants in boldface) }\end{array}$} & $\begin{array}{c}\text { Scan } \\
\text { Number }\end{array}$ & Purity & $\begin{array}{c}\text { Concentration } \\
(\mu \mathrm{g} / \mathrm{kg})^{\mathbf{a}}\end{array}$ \\
\hline Hexanedioic acid, bis(2-ethylhexyl) esterb & 2214 & 875 & - \\
Octadecanald & 2230 & 805 & 1300 \\
Octadecane, 1-(ethenyloxy)-d & 2266 & 921 & 5700 \\
Octadecanald & 2288 & 781 & 980 \\
Long-chain hydrocarbon & 2399 & - & 4100 \\
1-octadecanol & 2587 & 856 & 21000 \\
Long-chain hydrocarbon & 2844 & - & 7200 \\
Long-chain hydrocarbon & 2865 & - & 16000 \\
\hline
\end{tabular}

a Rounded to two significant figures.

b Known system contaminant.

cLow purity; substance detected only by single ion monitoring; see text.

d Substance is similar but not identical to the listed compound. 
TABLE 14 Tentative Identification of Substances in Environmental Sample HTA038601S01

\begin{tabular}{lrrr}
\hline \multicolumn{1}{c}{ Tentative Identification } & $\begin{array}{c}\text { Scan } \\
\text { Number }\end{array}$ & Purity & $\begin{array}{c}\text { Concentration } \\
(\mu \mathrm{g} / \mathrm{kg})^{\mathbf{a}}\end{array}$ \\
\hline & & & \\
2-pentanone, 4-hydroxy-4-methylb & 421 & 893 & - \\
2-heptanol, acetateb & 527 & 687 & - \\
5-hexene-2-one, 5-methylb & 583 & 877 & - \\
3-heptanone, 2,4-dimethylb & 656 & 788 & - \\
Propanoic acid, 2-methyl-1-(1,1-dimethylethyl)-2- & 1542 & 932 & - \\
$\quad$ methyl-1,3-propanediyl esterb & 1659 & - & 240 \\
Long-chain hydrocarbon & 1799 & 853 & 420 \\
Pentadecanoic acid & 1818 & 751 & 180 \\
2-pentadecanone, 6,10,14-trimethyl- & 1842 & - & 1100 \\
Unknown phthalate & 1908 & - & 1400 \\
Long-chain hydrocarbon & 1915 & - & 790 \\
Long-chain hydrocarbon & 1926 & 739 & 2000 \\
Hexadecanoic acid & 2214 & 876 & - \\
Hexanedioic acid, bis(2-ethylhexyl) ester ${ }^{b}$ & 2264 & 839 & 2200 \\
1-octadecanolc & 2398 & - & 1100 \\
Long-chain hydrocarbon & 2584 & 852 & 18000 \\
1-octadecanolc & 2843 & - & 6000 \\
Long-chain hydrocarbon & & & \\
\hline
\end{tabular}

a Rounded to two significant figures.

b Known system contaminant.

c Substance is similar but not identical to the listed compound. 
TABLE 15 Tentative Identification of Substances in Environmental Sample HTA056593S01

\begin{tabular}{|c|c|c|c|}
\hline Tentative Identification & $\begin{array}{l}\text { Scan } \\
\text { Number }\end{array}$ & Purity & $\begin{array}{l}\text { Concentration } \\
(\mu \mathrm{g} / \mathrm{kg})^{\mathrm{a}}\end{array}$ \\
\hline 2-pentanone, 4-hydroxy-4-methy $\left.\right|^{b}$ & 420 & 907 & - \\
\hline Heptane, 2,3-dimethyl.6 & 435 & 903 & - \\
\hline Octane, 4-methyl-b & 448 & 891 & - \\
\hline 2-hexanone, 6-(acetyloxy).b & 531 & 702 & - \\
\hline Bicyclo[3.1.1]hept-2-ene, 2,6,6-trimethyl & 564 & 980 & 1500 \\
\hline 5-hexene-2-one, 5-methylb & 584 & 855 & - \\
\hline 3-heptanone, 2,4-dimethylb & 659 & 787 & - \\
\hline $\begin{array}{l}\text { Propanoic acid, 2-methyl-1-(1,1-dimethylethyl)-2- } \\
\text { methyl-1,3-propanediyl esterb }\end{array}$ & 1542 & 932 & - \\
\hline $\begin{array}{l}\text { 1-H-cyclopenta[1,3]cyclopropa[1,2]benzene, 3a,3b,4,5,6,7- } \\
\text { hexahydro-3,7-dimethyl-4-(1-methylethyl-- } \\
\text { [3aS-(3a alpha, 3b beta, } 4 \text { beta, } 7 \text { gamma, } 7 \text { aS*)]-(-)- }\end{array}$ & 1225 & 903 & 350 \\
\hline $\begin{array}{l}\text { 1-H-cyclopenta[1,3]cyclopropa[1,2]benzene, octahydro- } \\
\text { 7-methyl-3-methylene-4-(1-methylethyl)-, } \\
\left.\left.\text { [3aS-(3a alpha, 3b beta, } 4 \text { beta, } 7 \text { gamma, } 7 a S^{*}\right)\right]-(-)-\end{array}$ & 1282 & 928 & 340 \\
\hline $\begin{array}{l}\text { Naphthalene, decahydro-4a-methyl-1-methylene-7- } \\
(1 \text {-methylethenyl)-, [4aR-trans]- }\end{array}$ & 1415 & 825 & 380 \\
\hline $\begin{array}{l}\text { Naphthalene, } 1,2,3,4,4 a, 5,6,8 a-o c t a h y d r o-7-\text { methyl- } \\
\text { 4-methylene-1-(1-methylethyl)- (1 alpha, 4a alpha, } \\
\text { 8a alpha)- }\end{array}$ & 1448 & 855 & 370 \\
\hline $\begin{array}{l}\text { Naphthalene, } 1,2,4 a, 5,6,8 \mathrm{a}-\mathrm{h} \theta \mathrm{xahydro}-4,7-\text { dimethyl- } \\
1-(1-\text { methylethyl)-, (1 alpha, } 4 \mathrm{a} \text { alpha, } 8 \mathrm{a} \text { alpha)-c }\end{array}$ & 1476 & 853 & 150 \\
\hline $\begin{array}{l}\text { Propanoic acid, } 2 \text {-methyl-1-(1,1-dimethylethyl })-2 \text { - } \\
\text { methyl-1,3-propanediyl ester }\end{array}$ & 1542 & 932 & - \\
\hline Pentadecanoic acid & 1800 & 823 & 290 \\
\hline 2-pentadecanone, 6,10,14-trimethyl. & 1820 & 778 & 180 \\
\hline Unknown phthalate & 1844 & - & 160 \\
\hline Hexadecanoic acid & 1926 & 781 & 710 \\
\hline Hexanedioic acid, bis(2-ethylhexyl) esterb & 2215 & 827 & - \\
\hline Octadecane, 1 -(ethenyloxy)-c & 2268 & 898 & 3500 \\
\hline Long-chain hydrocarbon & 2401 & - & 3600 \\
\hline 1-octadecanol & 2585 & 773 & 5100 \\
\hline Long-chain hydrocarbon & 2845 & - & 3000 \\
\hline Long-chain hydrocarbon & 2865 & - & 21000 \\
\hline
\end{tabular}

a Rounded to two significant figures.

${ }^{b}$ Known system contaminant.

c Substance is similar but not identical to the listed compound. 
TABLE 16 Tentative Identification of Substances in Environmental Sample HTA056593S02 ${ }^{a}$

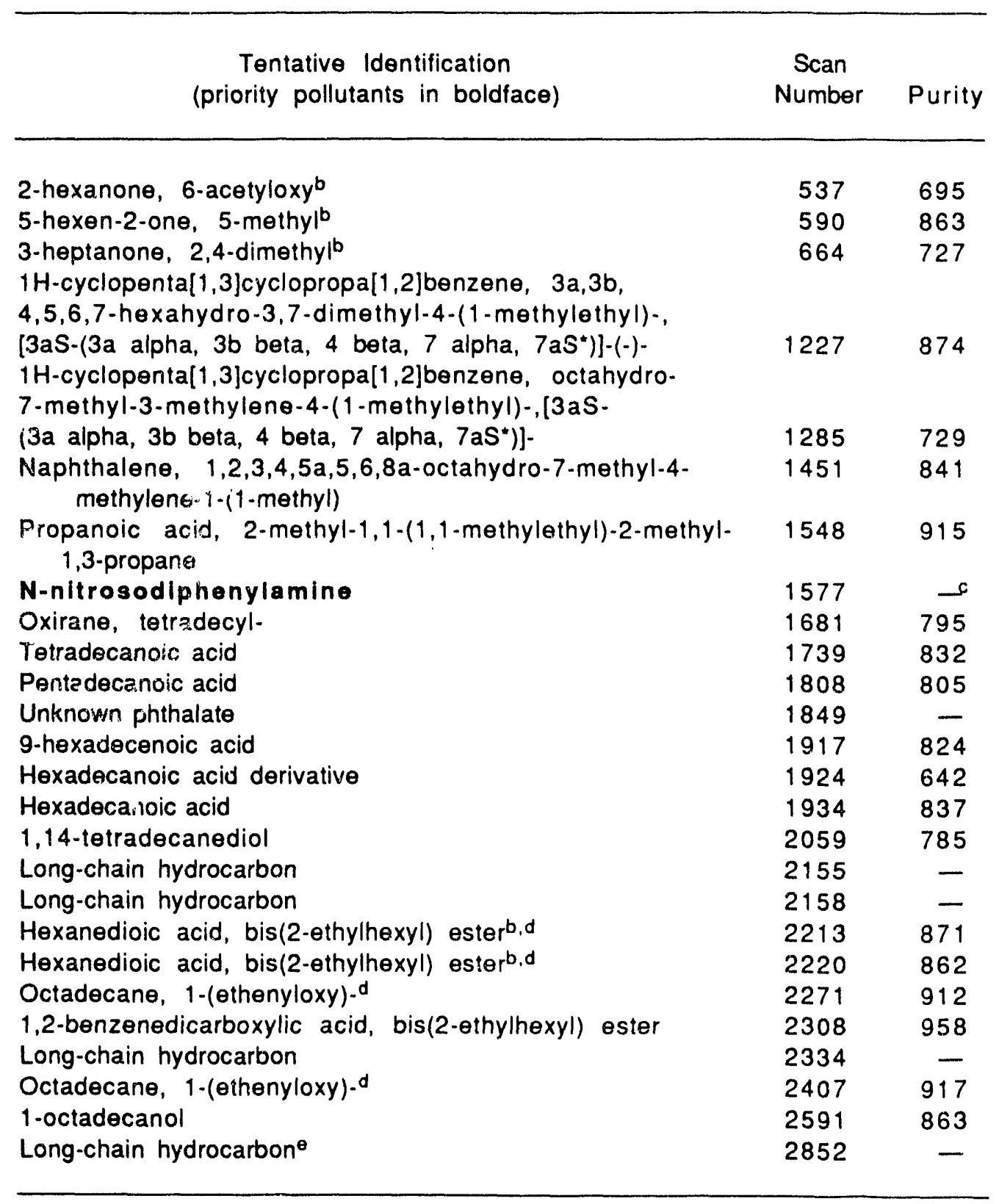

a Concentration estimates not available - see text.

b Known system contaminant.

cLow purity; substance detected only by single ion monitoring; see text.

d Substance is similar but not identical to the listed compound.

- Background spectra at scan numbers 2038 and 2439 show the presence of long chain hydrocarbons in the background "hump." 
TABLE 17 Tentative Identification of Substances in Environmental Sample HTA059601S02

\begin{tabular}{|c|c|c|c|}
\hline $\begin{array}{l}\text { Tentative Identification } \\
\text { (priority pollutants in boldface) }\end{array}$ & $\begin{array}{l}\text { Scan } \\
\text { Number }\end{array}$ & Purity & $\begin{array}{l}\text { Concentration } \\
(\mu \mathrm{g} / \mathrm{kg})^{\mathrm{a}}\end{array}$ \\
\hline 2-pentanone, 4-hydroxy-4-methy $\left.\right|^{b}$ & 426 & 891 & - \\
\hline Heptane, 2,3-dimethyl.b & 434 & 794 & - \\
\hline Octane, 4-methyl-b & 448 & 964 & - \\
\hline Heptane, 4-(1-methylethy I)-b & 459 & 908 & - \\
\hline 2-hexanone, 6-(acetyloxy)-b & 529 & 690 & - \\
\hline 5-hexene-2-one, 5-methylb & 533 & 876 & - \\
\hline 3-heptanone, 2,4-dimethyle & 658 & 799 & - \\
\hline Benzolc acid & 963 & عـ & 990 \\
\hline $\begin{array}{l}\text { Propanoic acid, } 2 \text {-methyl-1-(1,1-dimethylethyl)-2- } \\
\text { methyl-1,3-propanediyl ester }{ }^{b}\end{array}$ & 1543 & 725 & - \\
\hline Tetradecanoic acid & 1694 & 793 & 520 \\
\hline Phenanthrene & 1767 & عـ (l) (l) & 45 \\
\hline Pentadecanoic acid & 1805 & 825 & 1600 \\
\hline Unknown phthalate & 1842 & - & 2900 \\
\hline Long-chain hydrocarbon & 1915 & - & 5600 \\
\hline Long-chain hydrocarbon & 1922 & - & 4000 \\
\hline Hexadecanoic acid & 1930 & 780 & 4400 \\
\hline Fluoranthene & 2019 & عـ & 91 \\
\hline Pyrene & 2059 & عـ & 79 \\
\hline Hexanedioic acid, bis(2-ethylhexyl) esterb & 2216 & 874 & - \\
\hline Octadecane, 1 -(ethenyloxy)-d & 2266 & 901 & 2900 \\
\hline Long-chain hydrocarbon & 2400 & - & 1800 \\
\hline 1-octadecanol & 2588 & 875 & 23000 \\
\hline Long hain hydrocarbon & 2847 & - & 7800 \\
\hline Octadecane, 1 -(ethenyloxy).d & 2857 & 782 & 6300 \\
\hline
\end{tabular}

a Rounded to two significant figures.

b Known system contaminant.

' Low purity; substance detected only by single ion monitoring; see text.

' Substance is similar but not identical to the listed compound. 
HTA979682S01 and HTA056593S02 (Tables 10 and 16) because internal standards were not added to the sample extracts. These samples were the first two samples run, and it was feared that the addition of several internal standards might mask an important peak.

Trace amounts of one or more priority pollutants were detected in three of the eight samples examined. In no case did the detected priority pollutant correspond to an identifiable peak in the total ion chromatogram; all priority pollutant identifications were made solely on the basis of the detection of the corresponding key molecular ions in some scan during the analytical run through the use of a highly sensitive mass-spectrometric technique called "single-ion monitoring." The corresponding mass spectra were visually examined, and all were found to be inaccurate because of the very low concentrations involved. The spectra were visually compared with the authentic mass spectra, and in each case, it was considered likely that a trace amount of the contaminant was indeed present. These identifications must, however, be regarded as unconfirmed.

The distinct peaks in the total ion chromatograms that could be tentatively identified all corresponded to either high-molecular-weight organic compounds typical of those found in plant matter or known system contaminants. These system contaminants originate during the the presence of an intense ultrasonic field. The system contaminants are not present in the original sample and should be ignored. In some cases, the exact substance could not be identified, but the general chemical class to which it belongs could be found from the mass spectrum. For example, the mass spectra of long-chain hydrocarbons have very distinct characteristics, but it can be very difficult to distinguish one long-chain hydrocarbon from another, particularly if the unknown substance is present only in small amounts. 


\section{Discussion and Evaluation}

This section discusses the results obtained during this investigation. The results are evaluated with reference to the program objectives described in Section 1.4.

\subsection{Short-Term Health Effects}

The reviews of the available data on health effects revealed no information on the threshold concentrations of either CS or fog oil aerosol. The threshold concentration is the concentration below which no short-term health effects would be detectable even in sensitive individuals. The principal problem is that no experimental or epidemiological studies exist that examine effects on individuals who are not expected to be exposed under normal circumstances but who may be much more susceptible than those targeted in the existing studies. Individuals who might be more susceptible to respiratory effects from either CS or fog oil aerosol include the very young, the elderly, and people who already suffer from a respiratory problem (such as asthma or emphysema). Such individuals are present within the civilian population, but they are generally not found in the occupational settings that have been examined in the existing studies.

The lowest CS concentration used in tests, approximately $0.1 \mathrm{mg} / \mathrm{m}^{3}$, was still considered intolerable by some test subjects. The CS threshold concentration must be considerably lower than this value, perhaps by more than a factor of ten. It is possible to construct training scenarios involving the release of the CS contained in a single grenade that would produce CS concentrations of $0.1 \mathrm{mg} / \mathrm{m}^{3}$ in populated off-post areas. However, these scenarios all involve the use of CS within a valley having a direct exit to an off-post area and under meteorological conditions in which the dispersion of airborne contaminants is greatly reduced. These conditions occur during nighttime and early morning hours, particularly in the absence of cloud cover. The generation of drainage flows in mountain valleys under these conditions is a common occurrence. Such flows, in combination with suppressed vertical dispersion, could result in significant off-post concentrations of CS from a single grenade. However, if the CS cloud must be transported across a ridge or other elevated topographic feature, it must be carried by the general synoptic wind; a drainage flow will not cause this type of transport. The flow of wind over complex terrain (such as that at CMTC) is known to greatly enhance the dispersion of any airborne contaminant and to greatly reduce its concentration.

If the current operational guidelines for the use of CS are strictly followed, in particular if CS is not used within $1250 \mathrm{~m}$ of the post boundary and not in the vicinity of the town of Hohenburg, it does not seem likely that CS will be transported off-post in concentrations large enough to have adverse health effects in even the most sensitive individuals. This assessment cannot be supported, however, by either the necessary health effects data (which do not exist), by atmospheric modeling results (which cannot be produced at the current state-of-the-art), or by extensive atmospheric monitoring results (which have not yet been obtained). This assessment is based solely on the current qualitative understanding of atmospheric transport and dispersion 
processes in complex terrain and on the assumption that the CS threshold concentration is within perhaps a factor of 0.01 of the lowest concentration for which exposure tests have been carried out.

Under some circumstances, the potential exists for sensitive individuals in off-post areas to experience short-term respiratory effects as a result of exposure to fog oil aerosol. This assessment is based on a comparison of estimated fog oil concentrations generated within CMTC during training exercises with respect to ambient air quality and occupational exposure standards established in the United States. The current U.S. National Ambient Air Quality Standards for particulate matter less than $10 \mu \mathrm{m}$ in diameter are a 24-h average value of $0.150 \mathrm{mg} / \mathrm{m}^{3}$ and an annual average value of $0.05 \mathrm{mg} / \mathrm{m}^{3}$. These standards are intended to protect the public and are determined by the concentrations at which health effects are observed in sensitive individuals. The U.S. Occupational Safety and Health Administration 8-h standard for occupational oil mist exposure is $5 \mathrm{mg} / \mathrm{m}^{3}$, a level determined on the basis of reports of noticeable discomfort in some individuals at somewhat higher levels. Since this is an occupational exposure standard, it is not necessarily determined on the basis of effects seen in sensitive individuals, and such individuals might be expected to notice respiratory discomfort at levels lower than $5 \mathrm{mg} / \mathrm{m}^{3}$. Finally, estimates of the fog oil aerosol concentration within a targeted area in CMTC when the aerosol is uniformly distributed within the target valley range from 1 to $2 \mathrm{mg} / \mathrm{m}^{3}$ for a large training exercise.

On the basis of a comparison of these values, it appears that if fog oil is used near the CMTC boundaries, and in particular in a valley with a direct connection with off-post areas, then it is possible that civilian exposure to fog oil aerosol may result in noticeable short-term respiratory effects in sensitive individuals. However, as in the case of CS, if the current operating guidelines with respect to fog oil usage are strictly followed, it seems unlikely that fog oil aerosol will be transported off-post in high enough concentrations to produce noticeable respiratory effects. This assessment is based on the same type of considerations on which the CS assessment was based, specifically on the qualitative understanding of transport and dispersion in complex terrain and on the assumption that off-post fog oil aerosol concentrations will not exceed an assumed threshold value of approximately $0.1 \mathrm{mg} / \mathrm{m}^{3}$.

\subsection{Long-Term Health Effects}

As in the case of short-term health effects, the information necessary to make a direct assessment of the health effects in the local civilian population associated with long-term exposure to fog oil or CS aerosol is not currently available. In particular, an accurate measure of the population's exposure to these airborne substances is not available, and no information exists on the effects of long-term, low-level exposures to CS.

The exposure of the local civilian population to fog oil would take place entirely via the inhalation of airborne aerosol. However, on the basis of occupational exposures to oil mists at much higher concentrations, no epidemiological evidence exists that the inhalation of such aerosols over a long period causes lung $\operatorname{cancer}^{3}$ (see also Appendix B), even when the oils in question are 
believed to be carcinogenic upon long-term repeated dermal exposure. In addition, the fog oil currently used by the U.S. Army has been subjected to an additional refining step that removes the substances, primarily aromatic hydrocarbons, believed to be responsible for the carcinogenicity of petroleum oils. Because of this additional step, no long-term health effects should be expected, except that it is a common practice to mix diesel fuel with the fog oil prior to use so that its viscosity on cold days is reduced. This practice essentially circumvents the special processing of the fog oil by reintroducing aromatic hydrocarbons. Even with this practice, it seems unlikely that long-term exposure of the civilian population around CMTC would result in any noticeable health effects, but an evaluation of the potential health effects resulting from this practice has not yet been made.

Because of the nature of the oil, the analysis of the fog oil samples (including those which are believed to contain diesel fuel) for priority pollutants at low concentrations could not be carried out.

An alternative approach to assessing the likelihood of long-tern health effects is presented in Appendix B. In this approach, if the concentration of several polynuclear aromatic hydrocarbons in the oil being used is known or assumed, and if a long-term average exposure level to fog oil aerosol is also assumed, then the additional risk of cancer in the surrounding population may be estimated. Even on the basis of very conservative assumptions, the lifetime risk of someone contracting cancer from fog oil exposure is far below one part in a million, the threshold value frequently used in risk assessments in the United States. ${ }^{9}$

\subsection{Environmental Issues at CMTC}

On the basis of the detection limits associated with the analytical procedures used, any amount of fog oil or OCB present over a wide area must be present at concentrations less than approximately $11 \mathrm{ppm}$ in soils and $5 \mathrm{ppm}$ in sediments. No fog oil or OCB was detected in any environmental sample collected during the field sampling and analysis program. The absence of detectable amounts of fog oil can be attributed to a combination of the low deposition rate (see Appendix B) and the operation of various physical, chemical, and biological processes that would reduce further any already low environmental fog oil concentrations. On the basis of the measured deposition velocities for fog oil aerosol, it is clear that virtually all the fog oil that is emitted during training exercises remains airborne and is dispersed and transported downwind. Similar considerations indicate that the ultimate fate of CS aerosol emitted during training exercises is the same as that of fog oil. The extent to which CS aerosol can be removed from the air by water in the form of fog, mist, or rain is unknown.

The analysis of selected soil and sediment samples for priority pollutants also indicates that no widespread contamination exists within the training areas at CMTC. Trace amounts of one or more priority pollutants were found in three out of the eight samples examined (see Tables 10-17). Two of the samples were collected seven days apart at exactly the same location, as far as it was possible to determine. No priority pollutants were detected in the first sample, but a trace amount 
of N-nitrosodiphenylamine was detected with a reasonable level of confidence in the second sample. The origin of this material is obscure. Very small quantities of three PAHs (phenanthrene, fluoranthene, and pyrene) were detected in one sample (HTA059601S02; see Table 17). In this case, it is possible that the sampling site might coincide with an old spill of a minor amount of oil from a vehicle used during some exercise. Phenanthrene and fluoranthene are not considered to be carcinogenic, and pyrene is considered to be only weakly carcinogenic (see Table B.4, Appendix B).

In all cases, the priority pollutants detected did not form identifiable peaks in the gas chromatograms, but they were detected solely by the prese.ıce of certain key molecular ions in one of the mass spectra taken once a second during the analytical runs. The amounts of pollutants found are extremely small and present no environmental concerns, particularly since no evidence of widespread contamination was found. Two of the three samples were taken from study area 3, and the other from study area 2, but an insufficient number of samples were used to allow any conclusions to be made about the degree to which one area is contaminated relative to another.

Although no fog oil or OCB was found in the environmental samples, many of the chromatograms obtained during the analyses are rather complex, and a large number of substances are clearly present in those samples. In fact, the complexity of these chromatograms and the desire to try to identify the substances responsible were the original reasons for analyzing these samples using GC/MS methods. Evidence indicates that these substances may have originated from plant matter in the samples, not as a result of any anthropogenic activity. First, the chromatograms are visually similar to those obtained from plant samples, as can been seen by examining the chromatograms shown in Appendix E. Second, the chemical nature of those substances for which a tentative identification could be obtained is consistent with a plant origin. Many of the identified compounds are long-chain fatty acids of the type common to plants and that arise from plant lipid metabolism. ${ }^{10}$

Finaliy, there is a clear correlation between the complexity of the chromatogram and the sampling location, and this correlation is consistent with a plant origin for the bulk of the chromatographic peaks. Table 18 presents the same data provided in Trble 7 , but the data are arranged in order of decreasing total integrated area, which is taken as a measure of sample complexity as described in Section 5.2. The correlation of the sample complexity with the sample environment is obvious, as is the correlation of sample complexity with the color of the extract produced by the sample workup procedure. These correlations are confirmed to a very high level of confidence by the use of the Rank Sum statistical test. 11 Forest soil samples are systematically more complex than are valley soil samples, as expected, and sediment samples have apparently had mort of the plant matter washed out during rainfall events, also as expected. No statistically significant correlation exists between sample complexity and the study area in which the sample was collected. 
TABLE 18 CMTC Soil and Sediment Samples Arranged by Integrated Area

\begin{tabular}{|c|c|c|c|c|c|}
\hline \multirow[b]{2}{*}{$\begin{array}{l}\text { Sample } \\
\text { Code }\end{array}$} & \multirow[b]{2}{*}{ Environment } & \multirow[b]{2}{*}{$\begin{array}{l}\text { Study } \\
\text { Area }\end{array}$} & \multicolumn{3}{|c|}{ Description } \\
\hline & & & Sample & $\begin{array}{l}\text { Total } \\
\text { Area }\end{array}$ & Extract Color \\
\hline 021610 & Forest & 1 & So1 & 28.6 & deep yel-grn \\
\hline 037606 & Forest & 2 & So1b & 19.1 & med yel-grn \\
\hline 056593 & Forest & 3 & $S 01^{b, c}$ & 16.8 & med yel \\
\hline 038601 & Valley & 2 & So1b & 11.5 & $y e l-g r n$ \\
\hline 056593 & Forest & 3 & $\mathrm{SO} 2^{\mathrm{b}, c}$ & 11.4 & deep yel \\
\hline 023604 & Forest & 1 & So1 & 10.6 & deep yel-grn \\
\hline 059601 & Valley & 3 & $S 02^{b, d}$ & 10.2 & deep yel-grn \\
\hline 059601 & Valley & 3 & So1d & 8.87 & med yel \\
\hline 036605 & Sediment & 2 & $\mathrm{Ro2} 2^{\circ}$ & 8.82 & deep yel-grn \\
\hline 056603 & Valley & 3 & So1 & 8.60 & deep yel-grn \\
\hline 036605 & Sediment & 2 & Ro1e & 8.38 & deep grn \\
\hline 019606 & Valley & 1 & So1 ${ }^{b, 1}$ & 7.86 & med yel-grn \\
\hline 066598 & Forest & 3 & S01 & 7.57 & med yel-grn \\
\hline 979679 & Valley & C & $\mathrm{S} 01^{\mathrm{b}}$ & 7.27 & med yel \\
\hline 979682 & Forest & C & So1 & 7.24 & med yel \\
\hline 016616 & Valley & 1 & S019 & 6.99 & med yel-grn \\
\hline 018597 & Valley & 1 & So1 & 6.37 & med yel-grn \\
\hline 987671 & Valley & $C$ & so1 & 5.17 & med yel \\
\hline 019606 & Valley & 1 & $\mathrm{SO}^{h}$ & 4.65 & med yel-grn \\
\hline 061596 & Valley & 3 & So1i & 3.99 & v. pale yel \\
\hline 019606 & Valley & 1 & $\mathrm{SO} 2^{1, \mathrm{~h}}$ & 3.48 & med yel-grn \\
\hline 033606 & Valley & 2 & S01 & 3.17 & med yel-grn \\
\hline 016616 & Valley & 1 & So2g & 2.58 & med yel-grn \\
\hline 043597 & Sediment & 2 & Ro1 & 2.53 & med yel-grn \\
\hline 061596 & Valley & 3 & $\mathrm{SO}^{i}$ & 2.49 & v. pale yel \\
\hline 977673 & Sediment & C & R01 & 1.80 & pale yel \\
\hline 020603 & Sediment & 1 & Ro1b & 1.64 & pale yel \\
\hline 065585 & Sediment & 3 & Ro1 & 1.58 & pale yel \\
\hline 096600 & Sediment & - & Ro1 & 1.05 & pale "el \\
\hline 062592 & Sediment & 3 & Ro1 & 1.01 & v. pale yel \\
\hline 073624 & Sediment & - & R01 & 0.887 & clear \\
\hline 056624 & Sediment & - & R01 & 0.415 & clear \\
\hline 020608 & Sediment & 1 & R01 & 0.167 & clear \\
\hline
\end{tabular}

a See text for definition.

b Samples chosen for GC/MS analysis.

c,d,i Samples taken at same location seven days apart.

- Duplicate sediment samples.

9.' Samples taken at same location three days apart.

h Duplicate soil samples. 


\section{Conclusions and Recommendations}

The conclusions of the CMTC fog oil/CS study are as follows:

1. Short-term respiratory effects on the local civilian population due to exposure to CS aerosol are almost certainly negligible under current operating guidelines, but crucial health effects data (at low concentrations and for potentially sensitive individuals) are not available.

2. The potential may exist for short-term respiratory effects from exposure to fog oil aerosol to occur in sensitive individuals in off-post areas under extreme circumstances. The conditions under which this may occur involve the use of fog oil near the post boundary or in a valley having a direct topographic connection to off-post areas and under meteorological circumstances that favor the generation of drainage flows.

3. Health effects due to long-term exposure to fog oil aerosol are negligible, but the evaluation is complicated somewhat by the practice of mixing diesel fuel with the fog oil, thereby introducing varying amounts of aromatic hydrocarbons into the oil actually used in the field. It does not seem likely that this practice would produce noticeable health effects in the local civilian population, but this possibility has not been thoroughly evaluated.

4. No detectable amounts of fog oil or the CS degradation product OCB are present in the soils and sediments or on the vegetation within the heavily used training areas at CMTC; by implication, these substances are also not expected to be detectable in soils, sediments, or vegetation anywhere else, either on-post or off-post.

5. No widespread contamination exists in the soil within the training areas at CMTC by substances classified as semivolatile priority pollutants by the U.S. Environmental Protection Agency. Trace quantities of one or more priority pollutants were tentatively identified in three of eight samples, but the concentrations involved were very low and posed no environmental or health hazard.

On the basis of these conclusions, the following recommendations are made:

1. The risk to the health of local citizenry associated with the practice of mixing diesel fuel with fog oil prior to smoke generation should be evaluated. Because of the minimal risks to health that are expected on the basis of an initial evaluation, this practice can be ailowed to continue while the risk assessment is 
in progress. An alternative method of reducing the oil viscosity on cold days that does not introduce potentially toxic materials into the oil should be sought if the risk assessment shows that the risks from this use of diesel fuel are appreciable.

2. All valleys having a downward-sloping topographic connection with off-post areas should be identified and made off-limits for smoke generation and CS usage.

3. Current CS usage restrictions should be continued and strictly observed.

4. Current restrictions on the generation of fog oil smoke within $1,250 \mathrm{~m}$ of the post boundary and within a larger distance near the town of Hohenburg should be continued and strictly observed. 


\section{References}

1. Griesbach, E., Truppenübungsplatz "Hohenfels," Geschichte einer Landshaft, Eckehart Griesbach, Am Eichenrangen 52, 8501 Behringersdorf, Federal Republic of Germany (1988).

2. A History of Hohenfels, Hohenfels Training Area Office of Public Relations (undated).

3. Palmer, W.G., Exposure Standards for Fog Oil, Technical Report No. 9010, U.S. Army Biomedical Research and Development, Fort Detrick, Frederick, Md. (Nov. 15, 1990).

4. Militärgeographisches Amt Topographic Map Truppenübungsplatz Hohenfels, Scale 1:25000, Serie M 841-TR-Z 63 Hohenfels, Ausgabe 12-DMG (1986).

5. Defense Mapping Agency, Department of Defense World Geodetic System 1984, Its Definition and Relationships with Local Geodetic Systems, DMA Technical Report No. 8350.2, Washington, D.C., NTIS Ref. AD/A188 815 (Sept. 30, 1987).

6. Snyder, J.P., Map Projections - A Working Manual, U.S. Geological Survey Professional Paper No. 1395, U.S. Government Printing Office, Washington, D.C. (1987).

7. National Institute of Science and Technology/U.S. Environmental Protection Agency/Mass Spectrometry Data Centre (NIST/EPA/MSDC) Mass Spectral Database, 1990 Edition.

8. U.S. EPA Contract Laboratory Program Statement of Work for Organics Analysis, MultiMedia, Multi-Concentration, U.S. Environmental Protection Agency, Washington, D.C., Document Number OLM01.0 (undated).

9. Travis, C.C., et al., Cancer Risk Management, Environmental Science and Technology, $21: 415-420$ (1987).

10. Somerville, C., and J. Browse, Plant Lipids: Metabolism, Mutants, and Membranes, Science, 252:80-87 (1991).

11. Snedecor, G.W., and W.G. Cochran, Statistical Methods, 6th Ed., The Iowa State University Press, Ames, Iowa (1967). 


\section{Appendix A: Nature and Effects of CS and Its Hydrolysis Products}

\section{A.1 Introduction}

A highly irritating but not very lethal organic compound, CS was originally employed by the British as an antiriot agent in Cyprus in the late 1950s. It was adopted for similar purposes by the U.S. National Guard in the late 1960s and by the U.S. Army for tunnel denial during the Vietnamese War.

More recently, the U.S. Army has used CS as a training agent to enforce the use of gas masks. The compound, named after its discoverers, B.B. Corson and R.W. Stoughton, ${ }^{1}$ was first synthesized in 1928. It may be dispersed as a silanized powder (CS2) or more efficiently through thermal generation. In the latter case, hot CS vapor pressure rapidly condenses to particles of less than one micrometer in dianeter. ${ }^{2}$ The vapor pressure of CS is sufficiently low that, following thermal generation, clouds of the compound consist mainly of particulate matter, rather than vapor, until the particles have dispersed to a considerable extent.

In training exercises, CS is usually generated from a number of M7A3 grenades, each containing $4.5 \mathrm{oz}(127.6 \mathrm{~g})$ of pelletized CS and $7.35 \mathrm{oz}(208.4 \mathrm{~g})$ of burning mixture; ${ }^{3}$ the latter mixture supplies heat for vaporizing the CS. When the CS vapor cools, it condenses to an aerosol within $2-3 \mathrm{~cm}$ of the grenade's emission holes. ${ }^{4}$

\section{A.2 Structure, Nomenclature, and Registry Numbers}

The structure of CS is as follows:

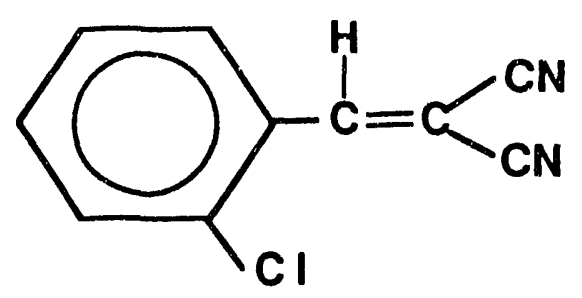

Molecular weight $=188.62$

Molecular formula $=\mathrm{C}_{10} \mathrm{H}_{5} \mathrm{Cl} \mathrm{N} 2$ 
The current Chemical Abstracts nomenclature for CS is propanedinitrile (2-chlorophenylmethylene). Several other names are to be found in the literature, including the following:

1, 1-dicyano-2-(2-chlorophenyl) ethylene,

ortho-chlorobenzylidenemalononitrile,

o-chlorobenzylidenemalononitrile,

2-chlorobenzylidenemalononitrile,

o-chlorobenzalmalononitrile,

2-chlorobenzalmalononitrile,

o-chlorobenzylidinemalonic nitrile, and

beta, beta-dicyano-o-chlorostyrene..$^{5}$

The Chemical Abstracts registry number for CS is 2698-41-1; that for propanedinitrile (chlorophenylmethlyene), namely the compound with the chlorine position unspecified, is 18270 61-6. There are no registry numbers for isotopically labeled CS. The number from the Registry of Toxic Effects of Chemical Substances, 1989 edition, ${ }^{6}$ is 003675000.

\section{A.3 Physicochemical Properties}

Physical form: ${ }^{5}$ colorless or slightly tinged solid

Melting point: ${ }^{5} 95-96^{\circ} \mathrm{C}$

Estimated $\log ($ octanol/water partition coefficient): 51.26

Estimated $\log$ (soil organic carbon/water partition coefficient) $: 5 \quad 1.20$

Estimated solubility in water: $5.4 \mathrm{~g} / \mathrm{L}$ at $25^{\circ} \mathrm{C}$ (CS is quite soluble in boiling solvents such as methanol [ $333 \mathrm{~g} / \mathrm{L}]$, isopropyl alcohol $[417 \mathrm{~g} / \mathrm{L}]$, or acetone [714 $\mathrm{g} / \mathrm{L}])$ 
Vapor pressure equation: ${ }^{7} \log _{10} \mathrm{P}(\mathrm{Pa})=16.692-5582.7 / \mathrm{T}(\mathrm{K})$

Vapor concentration equation: $\mathrm{C}\left(\mathrm{mg} / \mathrm{m}^{3}\right)=0.02269 \mathrm{P}(\mathrm{Pa}) / \mathrm{T}(\mathrm{K})$

Calculated saturated vapor concentration:

at $20^{\circ} \mathrm{C}: 0.347 \mathrm{mg} / \mathrm{m}^{3}$

at $25^{\circ} \mathrm{C}: 0.711 \mathrm{mg} / \mathrm{m}^{3}$

Wavelength of maximum absorbance in the ultraviolet region: ${ }^{2} 298 \mathrm{~nm}$

Molar absorptivity 2 at $298 \mathrm{~nm}: 1.86 \times 10^{4}$

Infrared and mass spectra of CS have been determined. ${ }^{5}$

\section{A.4 Synthesis and heactions of CS}

CS is best synthesized by condensing o-chlorobenzaldehyde with malononitrile in $30 \%$ aqueous ethanol or $30 \%$ aqueous isopropyl alcohol at $\mathrm{pH} 6.5$ and $50^{\circ} \mathrm{C} .5$ This condensation reaction is reversed when CS is put in dilute aqueous solution; that is, CS hydrolyzes readily to malononitrile and o-chlorobenzalciehyde. In seawater at $\mathrm{pH}$ 7.8-7.9, an experimental half-life of $14.5 \mathrm{~min}$ was observed. 6 A temperature-dependent rate equation was derived: 8 $\log k_{\text {obs }}\left(\mathrm{s}^{-1}\right)=12.31-4568 / \mathrm{T}$. This calculation gives half-lives of $21.6 \mathrm{~min}$ at $20^{\circ} \mathrm{C}$ and $11.8 \mathrm{~min}$ at $25^{\circ} \mathrm{C}$. Hydrolysis rates increase with increasing $\mathrm{pH} .{ }^{5}$ Nucleophilic reagents exhibit facile addition across the ethylenic bond; moreover, it has been suggested that the interaction of CS with amino and sulfhydryl functions (acting as nucleophiles) in proteins might be related to the compound's physiological activity. 5

\section{A.5 Sampling and Analysis of CS}

In the vapor state, CS could be analyzed by gas-liquid chromatography down to a detection limit of $0.01 \mathrm{mg} / \mathrm{m}^{3}$ with a tritium-source electron capture detector and (it would seem) a considerably lower detection limit with a flame ionization detector. A 5.5 - $\mathrm{ft} \times 0.25$-in. outsidediameter (o.d.) glass column packed with $10 \%$ QF-1 on 60/80 mesh Gas-Chrom Q was used. ${ }^{9}$

Near a CS aerosol generator, such as a grenade, particle concentrations of the solid compound are sufficiently high that relatively little is in vapor form, and relatively little would be lost by evaporation from a filter used to trap the particles. Thus, in such circumstances, collection 
from an air stream on a glass fiber filter mat followed by dissolution in a suitable solvent, such as absolute ethanol, is sufficient for sampling. 10 Sample collection in the vicinity of the Threshold Limit Value (TLV $=0.4 \mathrm{mg} / \mathrm{m}^{3}$, see below), however, must deal with both particles and vapor; for example, the saturated vapor concentration at $20^{\circ} \mathrm{C}$ is calculated as $0.347 \mathrm{mg} / \mathrm{m}^{3}$, so that air containing CS at the TLV would carry both vapor and particulate matter. For this reason, the National Institute of Occupational Safety and Health (NIOSHI) collection method" ${ }^{1}$ uses both a Teflon $^{\text {TM }}$ filter and Tenax-GC sorbent in its sampling train; these are extracted with a $20 \%$ solution of methylene chloride in hexane. The range of concentrations over which the NIOSH method was tested is 0.147 to $0.82 \mathrm{mg} / \mathrm{m}^{3}$. The detection limit was estimated to be at least $0.3 \mu \mathrm{g}$ per sample.

Analysis of such extracts can be carried out by gas-liquid chromatography (see above) with $0.1 \mathrm{mg}$ detectable by tritium-source electron capture and $0.002 \mathrm{mg}$ by flame ionization. ${ }^{9}$ Highperformance liquid chromatography (HPLC) with an ultraviolet absorption detector is used in the NIOSH method, ${ }^{11}$ which is applicable at least down to half the TLV (i.e., $0.2 \mathrm{mg} / \mathrm{m}^{3}$ ). CS in relatively clean extracts can be analyzed directly by using ultraviolet spectroscopy at the absorption maximum (about 298-302 nm). 2,5 Colorimetric methods for CS are less sensitive, but they may be of value in some situations. Useful colorimetric methods include color development with formaldehyde and sulfuric acid to produce a yellow color, ${ }^{5}$ treatment with benzofurazan oxide in alkaline solution to give a "distinct" violet absorption with a broad maximum at about $580 \mathrm{~nm}, 12$ and reaction with alkaline sodium 1,2-naphthoquinone-4-sulfonate to produce a violet-red absorption showing a maximum at about $525-550 \mathrm{~nm} .{ }^{10}$ The last two methods involve hydrolysis of $\mathrm{CS}$ and reaction of the resulting malononitrile with a chromogen.

Analysis of soil extracts for CS was carried out by HPLC ${ }^{13}$ in a manner similar to the NIOSH method. 11

\section{A.6 Mammilian Toxicology - Human Exposures}

In humans, 0 irritates sensory nerves in the skin and mucosa. It causes tearing, pain and conjunctivitis in the eyes, irritation in the respiratory passages and lungs, burning sensations and congestion in the nose and throat, runny nose, sneezing, coughing, salivation, chest constriction, and a feeling of suffocation. ${ }^{5}$ Within minutes following cessation of CS exposure, there is relief from all major effects, and after ten minutes, only moderate lacrimation (weeping), with some redness of the eyes, remains. 14

Exposure of male volunteers to $0.1-1.7 \mathrm{mg} / \mathrm{m}^{3}$ of $0.8-\mu \mathrm{m}$ diameter CS-2 (CS treated with Cab-o-sil 5 and hexamethyldisiloxane) for up to $10 \mathrm{~min}$ in a wind tunnel, or to $0.4-1.0 \mathrm{mg} / \mathrm{m}^{3}$ of $0.9-\mu \mathrm{m}$ diameter CS for up to $10 \mathrm{~min}$ in an exposure chamber, caused various degrees of respiratory and eye irritation in all of the subjects. ${ }^{15}$ Of seven volunteers exposed to $0.4 \mathrm{mg} / \mathrm{m}^{3}$ (the lowest level) of CS in the chamber, four remained in the chamber for the full $10 \mathrm{~min}$, while the other three "found the agent intolerable" and left after 135,420, and $435 \mathrm{~s}$, respectively. Half the subjects exposed to $0.1 \mathrm{mg} / \mathrm{m}^{3}$ of CS-2 left early. To the extent that they could open their eyes, even briefly, none of the subjects in these tests suffered loss of visual acuity. 
Thirty-five subjects were exposed in a chamber to level or increasing doses of CS. Initial doses ranged from 0.31 to $0.84 \mathrm{mg} / \mathrm{m}^{3}$, and final doses ranged from 0.74 to $2.30 \mathrm{mg} / \mathrm{m}^{3}$. Only one subject quit before $55 \mathrm{~min}$. The initial effects were very unpleasant, but after the first four or five minutes, most found the symptoms more tolerable. The increased tolerance was also demonstrated by the ability of the subjects to withstand increasing doses over time - from which they would probably have retreated had they been exposed to such levels initially. No abnormalities were noted in electrocardiograms, respiratory function, blood biochemistry, or hematology. It was concluded that "the true effects of CS are [apparently] due to local irritation of exposed nerve endings. Any systemic changes demonstrated are those due to stress and they cannot be regarded as specific to CS." 14

Men exposed to increasing levels of CS (in ranges between 0.16 and $4.4 \mathrm{mg} / \mathrm{m}^{3}$ ) were evaluated with respect to ventilation, cardiac frequency, and breathing pattern while performing exercise. All experienced intense discomfort on first exposure to the aerosol, including coughing, lacrimation, and substernal pain; in most instances, these effects wore off within a few minutes. Exercise cardiac frequency was no higher during exposure to CS than on the control days, once adjustment was made for temperature differences. On average, ventilation minute volume was reduced six percent by exposure to $\mathrm{CS}$. At low doses, the reduction in ventilation minute volume reflected diminished respiratory frequency; at higher doses, the reduction was attributable to a reduction in total volume, accompanied by tachypnea (rapid breathing). ${ }^{16}$

Human eyes are about an order of magnitude more sensitive to CS than those of guinea pigs and rabbits, as measures by blepharospasm (spasms of the orbital muscle of the eyelid). The saline solution concentration that will cause blepharospasm in half of human test subjects $\left(\mathrm{EC}_{50}\right)$ is $0.604 \mathrm{mg} / \mathrm{L} .5$ The $\mathrm{EC}_{50}$ for producing a stinging sensation in the cornea was over four times lower. 5 On initial exposures, CS irritates, stings, and reddens the skin. At high enough levels, it can also induce allergic sensitization to subsequent exposures. ${ }^{5}$

\section{A.7 Mammalian Toxicology - Experimental Animals}

Small mammals have been exposed to CS orally, by inhalation, intravenously, and intraperitoneally. Values of $\mathrm{LD}_{50}$ (the weight of CS per kilogram body weight that is lethal to half of the test animals) and $\mathrm{L}(\mathrm{Ct})_{50}$ (the product of $\mathrm{CS}$ aerosol concentration and time of exposure resulting in death of half the test animals) were all relatively high, indicating low toxicity: oral $\mathrm{LD}_{50}$ in rabbits, guinea pigs, and rats ranged from 143 to $1366 \mathrm{mg} / \mathrm{kg}$, while $\mathrm{L}(\mathrm{Ct})_{50}$ values in guinea pigs, dogs, rats, mice, and monkeys ranged from 25,000 to $165,000 \mathrm{mg}-\mathrm{min} / \mathrm{m}^{3}$. Results of biochemical studies suggest that the breakdown of a small fraction of the administered CS to cyanide, along with irritation, shock, and stress, may be responsible for the deaths. ${ }^{5}$ It appears that CS is not carcinogenic, embryolethal, or teratogenic. 


\section{A.8 Non-Mammalian Toxicology}

The acute toxicity of $\mathrm{CS}\left(\mathrm{LC}_{50}=\right.$ concentration lethal to half the animals in the specified time) to rainbow trout (Salmo gairdneri) at $15^{\circ}, \mathrm{pH} 7.1-7.4$, and $290 \mathrm{mg} / \mathrm{L}$ water hardness (as $\mathrm{CaCO}_{3}$ ) was determined in a constant-flow apparatus over exposure periods of 12-96 h. CS was added to the water as a stock solution in ethyl alcohol, with exposures shortly thereafter, to minimize hydrolysis. The $\mathrm{LC}_{50}$ values were $1.28 \mathrm{mg} / \mathrm{L}$ at $12 \mathrm{~h}, 0.45 \mathrm{mg} / \mathrm{L}$ at $24 \mathrm{~h}, 0.42 \mathrm{mg} / \mathrm{L}$ at $48 \mathrm{~h}$, and $0.22 \mathrm{mg} / \mathrm{L}$ at $96 \mathrm{~h}$. An equimolar mixture of the two hydrolysis products, malononitrite and o-chlorobenzaldehyde, gave an $\mathrm{LC}_{50}$ of $1.17 \mathrm{mg} / \mathrm{L}$ at $48 \mathrm{~h}$; this value was more than the additive toxicities of the individual components (see below). The concentration level at which these fish would tolerate CS for prolonged periods (one week or more) was estimated at $0.1 \mathrm{mg} / \mathrm{L} .17$

Static bioassays on mummichog (Fundulus heteroclitus [Linnaeus]), an estuarine fish, gave higher values of $\mathrm{LC}_{50}$ (e.g., $4.3 \mathrm{mg} / \mathrm{L}$ at $96 \mathrm{~h}$ ), but such values probably represent effects of the hydrolysis products of CS 18

No information has been found on the effects of CS on reptiles, amphibians, birds, or invertebrate animals.

CS phytotoxicity was tested on three species of duckweed, an aquatic plant. There were slight adverse effects in two of the species at an exposure concentration of $1 \mathrm{mg} / \mathrm{L}$ in water, and there were definite effects in all three at $5 \mathrm{mg} / \mathrm{L} .^{5}$

\section{A.9 Properties and Effects of CS Hydrolysis Products}

\section{A.9.1 Malononitrile}

Alternative name:5 Propanedinitrile

Chemical Abstracts registry number: 6 109-77-3

Number from the Registry of Toxic Effects of Chemical Substances: 6003150000

Structure: $\mathrm{NC}-\mathrm{CH}_{2}-\mathrm{CN}$

Molecular formula: $\mathrm{C}_{3} \mathrm{H}_{2} \mathrm{~N}_{2}$

Molecular weight: 66.07 
Physical form:5 colorless white solid

Melting point: $:^{5} 32^{\circ} \mathrm{C}$

Boiling point: $5218-219^{\circ} \mathrm{C}$

Estimated $\log \mathrm{K}_{\mathrm{ow}}$ (octanol/water partition coefficient): 50.079

Estimated $\log \mathrm{K}_{\mathrm{oc}}$ (soil organic carbon/water partition coefficient), method of Reference 19, Equation 4-11: 0.094

Solubility in water: $5130 \mathrm{~g} / \mathrm{L}$

Estimated vapor pressure at $25^{\circ} \mathrm{C}: 20.1 \mathrm{~Pa}(0.151 \mathrm{Torr})$

Estimated vapor concentration at $25^{\circ} \mathrm{C}: 53 \mathrm{mg} / \mathrm{m}^{3}$

Malononitrile, a pseudo acid, dissociates measurably in water. ${ }^{20}$ Through the anion thus produced, it dimerizes and trimerizes, in reactions accelerated by the presence of base, to the following:5

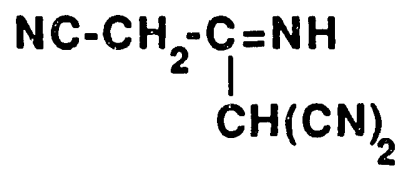

Dimer

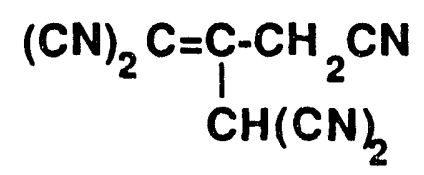

Trimer

Oral LD 50 , mouse: $619 \mathrm{mg} / \mathrm{kg}$

$\mathrm{LC}_{50}, 96$-h, flow-through bioassay, trout: ${ }^{17} 1.63 \mathrm{mg} / \mathrm{L}$

LC $_{50}, 96-\mathrm{h}$, static bioassay, mummichog: ${ }^{5} 1.7 \mathrm{mg} / \mathrm{L}$

The growth rate of the duckweed Lemna perpusilla, an aquatic plant, was reduced $10 \%$ by $1 \mathrm{mg} / \mathrm{L}$ of malononitrile, $59 \%$ by $5 \mathrm{mg} / \mathrm{L}$, and $76 \%$ by $10 \mathrm{mg} / \mathrm{L}$; concentrations of $50 \mathrm{mg} / \mathrm{L}$ or more killed the plants. 5 


\section{A.9.2 0-Chlorobenzaldehyde}

Alternative names: 6 benzaldehyde, o-chloro; benzaldehyde, 2-chloro; 2-chlorobenzaldehyde

Chemical Abstracts registry number:6 89-98-5

Number from the Registry of Toxic Effects of Chemical Substances: ${ }^{6}$ CU5075000

Structure:

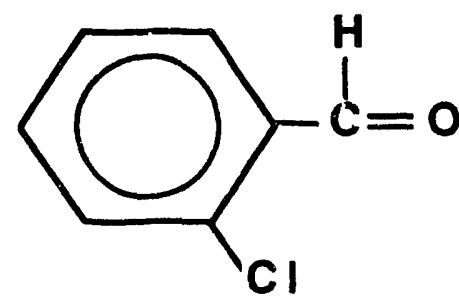

Molecular formula: $\mathrm{C}_{7} \mathrm{H}_{5} \mathrm{ClO}$

Molecular weight: 140.57

Physical form: liquid

Melting point: ${ }^{5} 12.39^{\circ} \mathrm{C}$

Boiling point: $5211.9^{\circ} \mathrm{C}, 84^{\circ} \mathrm{C} / 10$ Torr

Estimated $\log ($ octanol/water partition coefficient): 52.59

Estimated $\log$ (soi! urganic carbon/water partition coefficient): 52.45

Estimated solubility in water: $50.56 \mathrm{~g} / \mathrm{L}$

Vapor pressure at $25^{\circ} \mathrm{C}: 526.7 \mathrm{~Pa}(0.2 \mathrm{Torr})$

Saturated vapor concentration at $25^{\circ} \mathrm{C}: 1512 \mathrm{mg} / \mathrm{m}^{3}$ 
Although the environmental chemistry of o-chlorobenzaldehyde itself has not been studied, Berkowitz et al. have reasonably surmised that this compound should behave like benzaldehyde; like the latter, o-chlorobenzaldehyde should undergo photochemical air oxidation, proceeding through the peroxyacid to o-chlorobenzoic acid

Intraperitoneal $\mathrm{LD}_{50}$, mouse: $610 \mathrm{mg} / \mathrm{kg}$

Intravenous $\mathrm{LD}_{50}$, rabbit: $8.5 \mathrm{mg} / \mathrm{kg}$

LC $50,96-\mathrm{h}$ flow-through bioassay, trout: $172.45 \mathrm{mg} / \mathrm{L}$

Mummichogs (Fundulus heteroclitus [Linnaeus]) were unaffected by $35 \mathrm{mg} / \mathrm{L}$ of o-chlorobenzaldehyde. 5 The growth rate of the duckweed Lemna perpusilla, an aquatic plant, was reduced $7 \%$ by $1 \mathrm{mg} / \mathrm{L}$ or $5 \mathrm{mg} / \mathrm{L}$ o-chlorobenzaldehyde and $49 \%$ by $10 \mathrm{mg} / \mathrm{L}$. Concentrations of $50 \mathrm{mg} / \mathrm{L}$ or more killed the plant. ${ }^{5}$

\section{A.10 Standards}

The Occupational Safety and Health Administration standard for air exposure to $\mathrm{CS}^{21}$ is a Time Weighted Average (TWA) of $0.05 \mathrm{ppm}$ or $0.4 \mathrm{mg} / \mathrm{m}^{3}$.

\section{A.11 Significance and Fate of CS Aerosols}

CS is dispersed thermally from an M7A3 grenade over a period of approximately $30 \mathrm{~s}$ to provide particles of less than $1 \mu \mathrm{m}$ in diameter. Initially, these particles form a dense cloud that gradually grows in size as it travels downwind.

The particles are too small to settle out to any significant extent. If one assumes that all $127.6 \mathrm{~g}$ of the CS contained in a grenade are emitted, the compound must eventually be dispersed in $319,000 \mathrm{~m}^{3}$ of air - for example, in a cube $68 \mathrm{~m}$ on a side - to reach the TLV level of $0.4 \mathrm{mg} / \mathrm{m}^{3}$ for CS. Exposure to this level of CS would cause considerable discomfort to human populations downwind. On the basis of the human toxicological experiments reported above, it would appear that the sensation threshold is well below $0.1 \mathrm{mg} / \mathrm{m}^{3}$, particularly for sensitive individuals. It should be emphasized that concentrations far higher than the TLV would not cause systemic toxic effects, only extremely unpleasant temporary effects. Exposures of downwind populations are, in our opinion, most likely to occur under nighttime or early morning atmospheric inversion conditions. One may ask whether fog migh . absorb CS from a cloud; if so, the absorbed CS might be hydrolyzed. For aerosol clouds this is most unlikely, since it takes about an inch of rainfall to remove half the CS from an aerosol cloud. 5 It may be argued that the absorption of CS 
vapor (from low-concentration vapor plumes) by fog droplets could be a more rapid, more efficient, process; this idea has yet to be examined in detail.

The ultimate fate of CS clouds generated in a hilly, partially wooded area at times when such clouds may be affected by the presence of trees is not known. At least a portion of the CS could undergo impaction/interception by trees while some would settle out. Moisture on damp surfaces would dissolve some of that CS, which would then undergo hydrolysis. Analyses of soil in disposal areas at the Chemtronics industrial site near Ashland, North Carolina, ${ }^{22}$ indicated that intact CS can remain in the soil several years, accompanied by one of the hydrolysis products, o-chlorobenzaldehyde; the other product, malononitrile, was not present. The absence of malononitrile at that site could be due to its high water solubility or to its facile dimerization or trimerization.

\section{A.12 Data Gaps}

1. No information has been found from which the threshold concentration, below which no noticeable sensation is observed in even the most sensitive individuals, can be determined for CS. At the lowest concentrations used in tests examined in this study, approximately $0.1 \mathrm{mg} / \mathrm{m}^{3}$, the characteristic effects of CS on young, healthy human volunteers were not only clearly noticeable, but in some cases were still considered intolerable. No investigation was uncovered that examined the effects of CS on individuals that might be considered sensitive, such as the very young, the very old, or people suffering from various respiratory ailments. Such studies are essential before any assessment can be made of the effects of low levels of CS on civilian populations.

2. Nothing is known of the biological action of CS on microorganisms, reptiles, amphibians, birds, invertebrates, or terrestrial piants. Laboratory studies need to be carried our on representative species of the foregoing, both from the point of view of avoidance and of toxicity. The effects of CS and its breakdown products on foliage and seed germination are unknown.

\section{A.13 References}

1. Corson, B.B., and R.W. Stoughton, Reactions of Alpha, Beta-Unsaturated Dinitriles, Journal of the American Chemical Society, 50:2825-2837 (1928).

2. Milham, M.E., and A. Deiner, Measurement of the Particle-Size Distribution of Thermally Generated Smokes. II. CS Smoke, Edgewood Arsenal Technical Report No. 4292, Ground Munitions Laboratory, Edgewood Arsenal, Md. (May 1969). 
3. U.S. Department of the Army, TM 43-0001-29, Change 8, Grenade, Hand: Riot, CS M7A3, pp. 2-41 to 2-42 (1966).

4. Personal communication, Mitchell E. Penn, former employee of the U.S. Army Chemical Research, Development, and Engineering Center, Aberdeen Proving Ground, Md. (March 27, 1990).

5. Berkowitz, J.B., et al., Research and Development for Health and Environmental Hazard Assessment - Task Order 7: Assembly and Evaluation of Data Bases for Six Environmental Pollutants of Significance to the U.S. Army, Appendix F, Final Report, Contract No. DAMD17-79-C-9139, AD8098471, Arthur D. Little, Inc., Cambridge, Mass. (Nov. 1981).

6. Registry of Toxic Effects of Chemical Substances, 1989 Edition, U.S. Department of Health, Education, and Welfare, Rockville, Md. (1989).

7. Bryant, P.J.R., The Vapour Pressure, Volatility and Latent Heat of Solid o-Chlorobanzal Malononitrile (CS), Porton Note No. 225, Chemical Defense Establishment, Porton Down, Salisbury, Wilts. (Aug. 15, 1961).

8. Demek, M.M., et al., Behavior of Chemical Agents in Seawater, Edgewood Arsenal Technical Report No. 4417, Edgewood Arsenal Physical Research Laboratory, Edgewood Arsenal, Md. (Aug. 1970).

9. Sass, S., et al., Gas-Liquid Chromatography of Some Irritants at Various Concentrations, Analytical Chemistry, 43:462-464 (1971).

10. Deiner, A., and A. Koblin, Field Sampling and Analysis of CS (EA 1779), Chemical Welfare Laboratories Report No. 2277, Chemical Welfare Laboratories, Army Chemical Center, Md. (May 1959).

11. National Institutes of Occupational Safety and Health (NIOSH) Method No. P\&CAM 304, NIOSH Manual of Analytical Methods, Vol. 5, pp. 304-1 to 304-10 (April 1979).

12. Hladdadin, M., et al., Sensitive Test for Detection and Determination of Malononitrile and its Derivatives, Analytical Chemistry, 46: 2072 (1974).

13. Jones, C., and V. Grady, Analytical Methods Development and Analysis of Camp Simms Soil Samples for o-Chlorobenzylidenemalononitrile and o-Chlorobenzaldehyde, report by Arthur D. Little, Inc., under Contract DAAK 11-80-C-0010 to the U.S. Army Toxic and Hazardous Materials Agency (USATHAMA), USATHAMA Report No. DRXTH-TE-A-CR81113 (June 1981). 
14. Beswick, F.W., P. Holland, and K.H. Kemp, Acute Effects of Exposure to Orthochlorobenzylidene Malononitrile (CS) and the Development of Tolerance, British Journal of Industrial Medicine, 29:298-306 (1972).

15. Rengstorff, R.H., The Effects of the Riot Control Agent CS on Visual Activity, Military Medicine, 134(3):219-221 (1969).

16. Cole, T.J., et al., Ventilation, Cardiac Frequency, and Pattern of Breathing During Exercise in Men Exposed to o-Chlorobenzylidene Malononitrile (CS) and Ammonia Gas in Low Concentrations, Quarterly Journal of Experimental Physiology, 62:341-351 (1977).

17. Abram, F.S.H., and P. Wilson, The Acute Toxicity of CS to Rainbow Trout, Water Research, 13:631-635 (1979).

18. Pearson, J.G., and R.T. Renne, The Toxicity of the Riot Control Agent CS and its Hydrolysis Products to the Mummichog, Fundulus heteroclitus (Linnaeus), Report No. EBTR-740-95, Edgewood Arsenal, Aberdeen Proving Ground, DTIC AD A007 500 (1975).

19. Lyman, W.J., W.F. Reehl, and D.H. Rosenblatt, Handbook of Chemical Property Estimation Methods: Environmental Behavior of Organic Compounds, McGraw-Hill Book Co., New York, pp. 4-9 (1982).

20. Pearson, R.G., and R.L. Dillon, Journal of the Americal Chemical Society, 75:2439 (1953); R.G. Pearson and J.M. Mills, Journal of the Americal Chemical Society, 72:1692 (1950).

21. American Conference of Governmental Industrial Hygienists (ACGIH), TLVs: Threshold Limit Values and Biological Exposure Indicies for 1988-1989, ACGIH, Cincinnati, Ohio (1988).

22. U.S. Environmental Protection Agency (EPA), Region IV, Enforcement Record of Decision Remedial Alternative Selection, Chemtronics Site, Swannanoa, Buncomb County, N.C. U.S. EPA, Region IV, Atlanta, Ga. (1988). 


\section{Appendix B: Nature and Effects of Fog Oil Smoke}

\section{B.1 Introduction}

The purpose of this discussion is to provide background information on the properties, behavior, and health and environmental effects of fog oil. It is estimated that up to a maximum of approximately 200 gal $(757 \mathrm{~L}$ ) of fog oil is used daily for smoke (oil fog) generation.* Presumably, generation entails the use of U.S. Army M3A3 mechanical pulse jet smoke generators.

The M3A3 smoke generator consists of a small gasoline-powered ramjet engine. The fog oil is metered into the exhaust manifold of this engine at a predetermined rate partially controlled by a manually operated valve. The heat of the exhaust vaporizes the oil and ejects it through three nozzles into the atmosphere. As the vapor emerges from the nozzles at high velocity, large volumes of air are sucked into the vapor stream. The resulting dilution and cooling produces great numbers of condensation nuclei, arcund each of which a small droplet grows. Thus, a dense cloud of fog oil aerosol is formed. In the normal mode of operation, the generator uses about $40 \mathrm{gal} / \mathrm{h}$ (nominal rate of $48 \mathrm{gal} / \mathrm{h}$ ) of fog oil and $3 \mathrm{gal} / \mathrm{h}$ of gasoline. ${ }^{1-3}$

\section{B.2 Physical and Chemical Characteristics of Fog Oil}

Fog oil (SGF-2 oil) is similar to SAE No. 20 motor oil, but without additives, 3,4 its color varies from light yellow to almost black; its density is about $0.89-0.93 \mathrm{~g} / \mathrm{mL} .^{1}$ The performance characteristics of SGF-2 oil are presented in the military specification MIL-F-12070C, ${ }^{4}$ which was amended in 1986 to require the oil to be noncarcinogenic. The proportions of the main classes of constituents may vary to a considerable degree, as shown for an "old" (pre-1986) batch of fog oil in Table B.1. Treatment to remove carcinogens can change this picture radically, removing most or all of the aromatics.

Fog cil constituents may also be characterized by the number of carbon atoms they contain, molecular weights associated with those numbers, and vapor pressures, as provided in Table B.2.2 According to Katz et al., ${ }^{1}$ both the aliphatic and aromatic fractions are in the $\mathrm{C}_{12}-\mathrm{C}_{22}$ range of carbon numbers. Aliphatics may include cycloparaffins, ${ }^{3}$ also known as naphthenates. Aromatic fractions (present in "old" fog oil) contain a variety of species, such as substituted benzenes, naphthalenes, anthracenes, phenanthrenes, fluorenes, etc.; no cyclic structures beyond tetracylics were identified. ${ }^{1}$ Numerous nitrogen bases have been observed, including quinolines, indoles, and benzoquinolines. ${ }^{1}$ Metal analyses of "old" fog oils from three manufacturers indicated the presence of copper and zinc at levels up to about $100 \mathrm{ppb} .{ }^{1}$

\footnotetext{
* Estimate made on the basis of six smoke generators used during a large training exercisc.
}

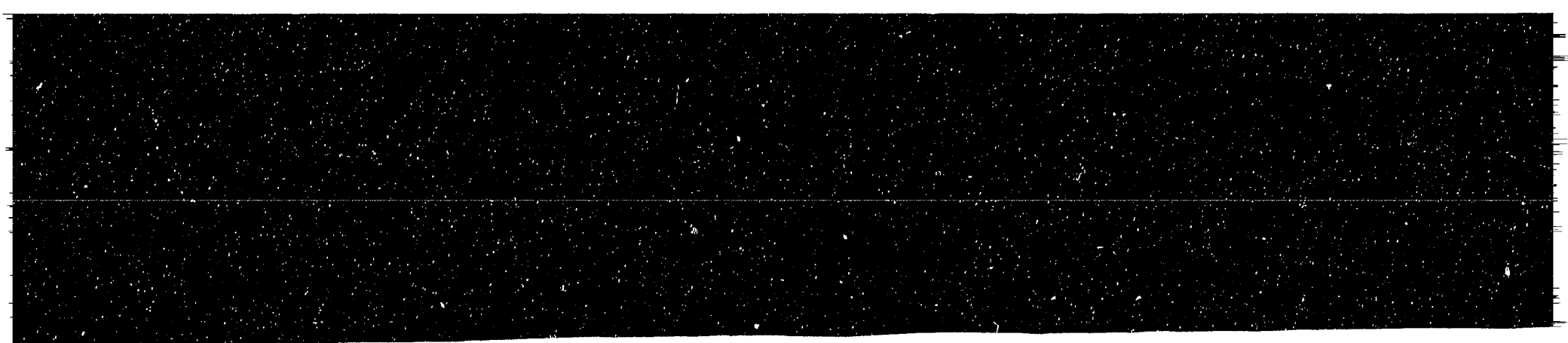


TABLE B.1 Percentages of Main Classes of "Old" Fog Oil Constituents

\begin{tabular}{llllll}
\hline $\begin{array}{c}\text { Fog Oil } \\
\text { Sample } \\
\text { Number }\end{array}$ & Aliphatics & Aromatics & Esters & Alcohols & Acids \\
\hline & & & & & \\
1 & 58.2 & 40.0 & 0.7 & 1.1 & 0.0 \\
2 & 42.7 & 50.0 & 4.1 & 2.7 & 0.5 \\
3 & 54.1 & 43.5 & 0.9 & 0.7 & 0.7 \\
\hline
\end{tabular}

TABLE B.2 Carbon Numbers, Molecular Weights, Vapor Pressures, and Distribution of Fog Oil Constituents

\begin{tabular}{lccr}
\hline $\begin{array}{c}\text { Carbon } \\
\text { Number }\end{array}$ & $\begin{array}{c}\text { Molecular } \\
\text { Weight }\end{array}$ & $\begin{array}{c}\text { Vapor } \\
\text { Pressure } \\
(\mathrm{kPa})\end{array}$ & $\begin{array}{c}\text { Fraction } \\
\text { in Fog Oil } \\
(\%)\end{array}$ \\
\hline & 198 & $7.24 \times 10^{-04}$ & 1.90 \\
14 & 212 & $1.89 \times 10^{-04}$ & 3.42 \\
15 & 226 & $4.62 \times 10^{-05}$ & 5.32 \\
16 & 240 & $1.27 \times 10^{-05}$ & 7.98 \\
17 & 254 & $3.15 \times 10^{-06}$ & 9.13 \\
18 & 268 & $7.76 \times 10^{-07}$ & 12.93 \\
19 & 282 & $1.49 \times 10^{-07}$ & 12.17 \\
20 & 296 & $4.21 \times 10^{-08}$ & 11.03 \\
21 & 310 & $1.04 \times 10^{-08}$ & 9.51 \\
22 & 324 & $2.59 \times 10^{-09}$ & 7.60 \\
23 & 338 & $6.68 \times 10^{-10}$ & 6.08 \\
24 & 352 & $1.78 \times 10^{-10}$ & 4.94 \\
25 & 366 & $4.99 \times 10^{-11}$ & 3.80 \\
26 & 380 & $1.48 \times 10^{-11}$ & 2.28 \\
27 & 395 & $4.73 \times 10^{-12}$ & 1.14 \\
28 & 409 & $1.64 \times 10^{-12}$ & 0.76 \\
29 & & & \\
\hline
\end{tabular}

Source: Reference 2.

a Number of carbon atoms per molecule.

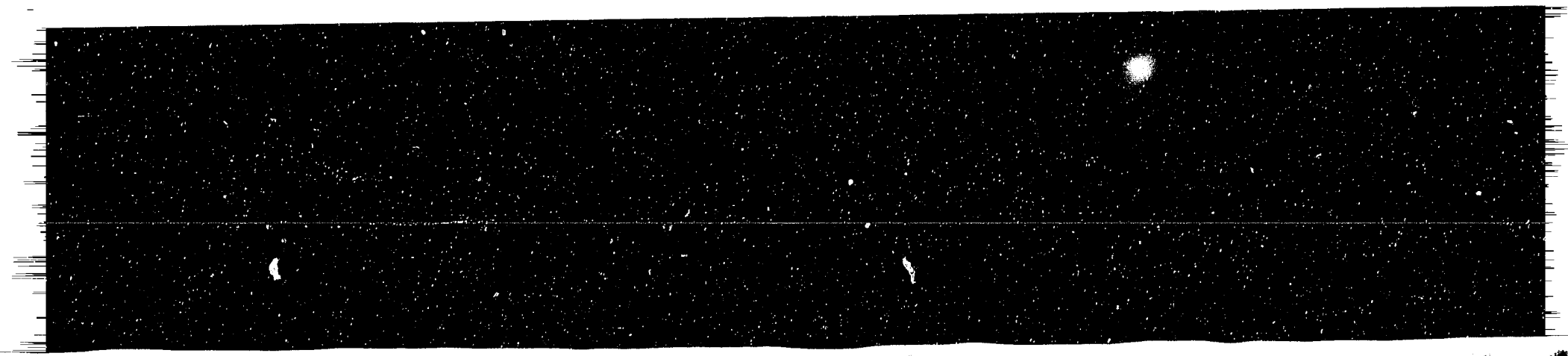


Fog oil is specified to consist of overhead petroleum fractions and not contain additives or rerefined oils. ${ }^{4}$ Chemical and physical standards for fog oil are given in Table B.3. ${ }^{4}$ To satisfy the pour point requirement, the oil must be derived from a primarily naphthenic stock. ${ }^{5}$ In addition to these requirements, the 1986 requirement that carcinogens or potential carcinogens be absent may necessitate that the oil have special treatment, typically severe hydrotreatment (i.e., catalytic hydrogenation) or severe solvent refinement. ${ }^{6-8}$ (Fog oil produced before the requirement for carcinogen removal is referred to as "old"; 5 that produced afterward is called "new"). In the first of the special treatments, carbon-carbon double bonds (including aromatic bonds) are hydrogenated and heterocylics undergo ring opening; in the second, polynuclear aromatic hydrocarbons (PAHs) and other aromatic compounds, as well as heterocylics, are removed by solvent extraction. 5 The mean vapor pressure of fog oil has been reported as $1.6 \times 10^{-5}$ Torr at $25^{\circ} \mathrm{C}$, and the mean boiling point has been reported as $371^{\circ} \mathrm{C} .10$

\section{B.3 Character of Fog Oil Aerosol}

The chemical composition of suspended fog oil aerosol is about the same as that of bulk material and does not change as the fog plume travels downwind. ${ }^{10,11}$ Particle diameters average approximately $1 \mu \mathrm{m}$, with various experiments yielding slightly different sizes, depending on the exact conditions of generation (see below). One-micrometer particles are quite respirable and wellretained by the lungs. In a cloud chamber, particles slowly coagulate, so that mean diameters tend to increase somewhat over time. ${ }^{1,12}$ The vapor pressure of fog oil is so low that less than $1 \%$ of a fog oil cloud is usually in the gaseous state. ${ }^{11}$ Thus, a cloud tends to persist until it is dispersed, and it may travel as much as $6.5 \mathrm{~km} .^{3}$ The aerosol particles are so small that the deposition velocities are quite low. Cataldo et al. ${ }^{12}$ reported deposition velocities for fog oil in wind tunnel

TABLE B.3 Physicochemical Requirements for Type SGF-2 Fog Oil

\begin{tabular}{lcc}
\hline Property & Maximum & Minimum \\
\hline $\begin{array}{l}\text { Flash point, }{ }^{\circ} \mathrm{C} \\
\text { Kinematic viscosity, } \\
\text { cSt at } 100^{\circ} \mathrm{C}\end{array}$ & 4.17 & 160 \\
$\begin{array}{l}\text { Ramsbottom carbon, } \\
\text { weight percent }\end{array}$ & 0.1 & 3.4 \\
$\begin{array}{l}\text { Neutralization number } \\
\text { Pour point, }{ }^{\circ} \mathrm{C}\end{array}$ & 0.1 & - \\
$\begin{array}{l}\text { Water and sediment, } \\
\text { volume percent }\end{array}$ & -40 & - \\
\hline
\end{tabular}

Source: Reference 4. 
tests between 0.024 and $0.030 \mathrm{~cm} / \mathrm{s}(0.027 \pm 0.003 \mathrm{~cm} / \mathrm{s})$. Liljegren et al..$^{2}$ estimates an even lower value, about $0.0031 \mathrm{~cm} / \mathrm{s}$. Policastro et al. ${ }^{13}$ observed no deposition from fog plumes beyond $20 \mathrm{~m}$ from the generators. ${ }^{14}$

Because the representative diameters of fog oil aerosol are expressed in varying ways and different kinds of instruments may not provide identical measurements for the same particles, exact comparisons cannot be easily made. Katz et al. ${ }^{1}$ reported average mass mean diameters ranging from 0.74 to $i .58 \mu \mathrm{m}(1.16 \pm 0.14 \mu \mathrm{m})$ when a piezoelectric particle impactor was used, whereas the values were consistently lower when an active scattering aerosol spectrometer was employed for the same experiments. Liljegren et al. ${ }^{10}$ reported mass mean diameters ranging from 0.61 to $1.35 \mu \mathrm{m}$ (average $1.0 \mu \mathrm{m}$ ) and mass median aerodynamic diameters of 0.34 to $1.31 \mu \mathrm{m}$ (average $0.74 \mu \mathrm{m}$ ) for the same raw data sets. Results of tests at Camp Atterbury ${ }^{2}$ were reported as mass mean diameters of $1.02 \pm 0.13,0.7 \pm 0.06$, and $1.07 \pm 0.09 \mu \mathrm{m}$, and geometric mass mean diameters were reported to be $0.91 \pm 0.10,0.60 \pm 0.03$, and $0.96 \pm 0.03 \mu \mathrm{m}$. Cataldo et al. 12 reported mass median aerodynamic diameters (particles generated in a small laboratory smoke generator) ranging from 1.22 to $2.40 \mu \mathrm{m}$ (average $1.60 \pm 0.15 \mu \mathrm{m}$ ) for one set of experiments and a range of 1.6 to $3.1 \mu \mathrm{m}$ for another set. These values all lie close to the optimal particle diameter range for obscuration, ${ }^{3}$ namely 0.5 to $1.0 \mu \mathrm{m}$. Data for a laboratory-generated fog oil smoke indicate that $99.9 \%$ of the mass is in particles of less than $5 \mu \mathrm{m}$ in diameter; 10 a field study showed $98 \%$ of the fog oil smoke to be between 0.3 and $3.0 \mu \mathrm{m}$ in diameter. ${ }^{2}$

\section{B.4 Analytical Methods}

The properties of lubricating oils can be determined by using various analytical methods, some applicable to fog oil; no attempt is made here to review that literature. Instead, key information will be used to illustrate the variety of approaches, especially as applied to fog oil itself and to the analysis of oil fogs.

As indicated above, some "old" fog oil samples have been characterized by Katz et al. ${ }^{1}$ through fractionation into classes of compounds, such as those listed in Table B.1, with highpressure liquid chromatography (HPLC). After preparative isolation of sufficiently large quantities of an individual fraction, more detailed high-resolution gas chromatographic analyses were performed, but it was impossible to identify most of the numerous individual components. Jenkins et al. ${ }^{15}$ performed a similar HPLC evaluation of largely aromatic (hence "old") fog oils and fogs, separating each sample into an aliphatic fraction, five aromatic fractions, and a semipolar fraction. The American Society for Testing and Materials (ASTM) ${ }^{16}$ issued a procedure that separates liquid petroleum on a silica gel column into three zones - saturated hydrocarbons, olefins, and aromatics - whose boundaries are marked by fluorescent dyes that can be visualized with ultraviolet light. Zone lengths are proportional to the concentrations of these classes of hydrocarbons in the oil. The foregoing analytical procedures would be useful in distinguishing between "old" and "new" fog oil, since the latter should contain only saturated hydrocarbons (aliphatic and cycloaliphatic). They would not, however, suffice to identify or quantify the 
compounds of greatest potential concern (polynuclear aromatic hydrocarbons [PAHs or PNAs]), some of them carcinogenic.

Concerned with PAHs, Lijinsky et al. ${ }^{17}$ laboriously isolated the PAH-rich aromatic fraction of mineral oil by column chromatography and selective liquid-liquid extraction. They separated PAHs by repeated filter paper chromatography until pure compounds were obtained and confirmed their identities from their fluorescence emission spectra. Absorption spectrophotometry was used to calculate the original concentrations. Although it represented real progress at the time it appeared, the procedure is far too time-consuming for general use. The following PAHs have been listed by the International Agency for Research on Cancer ${ }^{8}$ (IARC) as constituents of white oils, which resemble fog oil: fluoranthene, benzo[b]fluoranthene, benzo[k]fluoranthene, benzo[a]pyrene, benzo[ghi]perylene and indeno[1,2,3-cd]pyrene. NIOSH Method 5515,18 involving capillary gas chromatography, was developed for airborne PAH particulates and appears adaptable to the analysis of concentrates extracted from hydrotreated fog oil; it seems to be useful down to about $1 \mu \mathrm{g}$ of benzo[a]pyrene, the paradigm for PAHs. Hermann and coworkers 19,20 extracted PAHs selectively by means of a cyclohexane-dimethyl sulfoxide system, then separated and measured the individual compounds through HPLC. They compared the results for various petroleum products with those of mutagenicity tests and found good correlation. Haas et al. 21 were able to predict carcinogenicity and mutagenicity in petroleum oils empirically with an equation employing the viscosity of the oil and the ultraviolet absorbance at 280-290 nm (due to PAHs) of a dimethyl sulfoxide extract of the oil. For evaluating mutagenicity, these authors used an adaptation of the Ames mutagenicity assay reported by Blackburn et al.,22 which correlates well with mouse dermal bioassays.

Although the chemical constituents of oil fogs have been sorted into classes of compounds, fog analysis has been mainly concerned with quantifying total aerosol mass and determining particle size distribution. Airborne droplet sizes have been measured by light scattering or by frequency shifts in the output of a piezoelectric particle cascade impactor. ${ }^{1,2}$ Wagner et al. ${ }^{23}$ used electrostatic precipitation and gravimetry to obtain the mass concentrations of mineral oil mists. Glass fiber filters $2,4,11-13,15,18,24$ and mixed cellulose ester or polyvinyl chloride membrane filters 18 have also been used for collecting samples for gravimetric or chemical analysis; both particulates and any associated vapors have been absorbed in tubes filled with the polymer "Tenax" for elution and subsequent chemical analysis. $10,11,13$ Oil particles have also been collected in gas washing bottles for later analysis. ${ }^{3}$ Where particle sizing was desired, the diameters of fog particles have been collected and classified by means of cascade impactors and cyclone impingers; this process involved chemical analysis of the inertially separated material. $2,3,11,12$ Isolates have been analyzed by using ultraviolet absorption below $300 \mathrm{~nm}$, but such a method would have had to depend on the aromatic constituents, which would be present in varying proportions in "old" fog oil but should be essentially absent in "new" fog oil. ${ }^{3}$ Infrared absorption in the vicinity of $3 \mu \mathrm{m}$ has been similarly used for analyses; it is not recommended for plant tissue extracts because of interfering substances. 3,12 Low-resolution gas chromatography, with flame ionization detection, has been applied to quantifying isolates without any attempt to identify their constituents. $10,11,13,18,24$ Although low-resolution, high-pressure liquid chromatography has 
been used with both ultraviolet $(230 \mathrm{~nm})$ and refractive index detectors, $1,21,15$ the ultraviolet detector is probably a bad choice for "new" fog oil because saturated hydrocarbons absorb so poorly.

\section{B.5 Human and Mammalian Toxicology5}

A thorough and up-to-date literature summary and evaluation of the human and mammalian toxicology of fog oil has just been completed by Dr. Winifred G. Palnier of the U.S. Army Biomedical Research and Development Laboratory. ${ }^{5} \mathrm{~A}$ precis of the report is presented in this section without further mention of its origin; literature citations have been added to certain statements for emphasis of the original sources or to introduce an additional statement of possible significance, but this section essentially reflects a great amount of thought and effort (and in some instances the wording) by Dr. Palmer.

Experimental animals have been exposed to several types of mineral oils with diverse constituents, including additives, by different routes and under various time and dosage regimes. In only a few cases was military fog oil used, and then the fog oil was clearly of the "old" type, known to contain aromatics (and probably high PAH concentrations). Epidemiological studies hav'e been conducted on mineral oil exposures (but not exposures to fog oil) in a number of industries, and they tend to agree with the results obtained with laboratory animals. Thus, general conclusions have had to be pieced together from scattered and often indirect evidence.

Respiratory effects of conventionally refined mineral oils in humans have been reportedly related to oral administration of mineral oil, to oil-based nose drops, or to intralaryngeal injection of medicinal oil, thou not related to exposure to oil mists. These effects have been seen in humans as two types of ipoid pneumonias - lipoid granulomas and diffuse pneumonitis. Mineral oils do not produce pulmonary necrosis but are taken up by macrophages that remain within the alveolar spaces. There is very little indication that workplace exposure to mineral oil mists causes lung cancer. Indeed, pulmonary effects occur with exposure to highly refined mineral oils that lack PAHs. Wagner et al. ${ }^{23}$ exposed five animal species - dogs, rabbits, rats, hamsters, and mice to $5 \mathrm{mg} / \mathrm{m}^{3}$ of a "light" $\left(\mathrm{C}_{25}-\mathrm{C}_{30}\right)$ naphthene-based mineral oil six hours daily, five days a week for a year; no adverse effects were seen except for occasionally observed alveolar macrophages. However, repeated mineral oil mist exposures at considerably higher doses were shown by Wagner et al.23 and various other experimenters to cause adverse noncarcinogenic respiratory effects in mammals. Although lipoid pneumonia is uncommon in the workplace even in areas where oil mist concentrations exceed $50 \mathrm{mg} / \mathrm{m}^{3}$, complaints from surveyed workers indicated that discomfort occurs at oil mist levels greater than $5 \mathrm{rig} / \mathrm{m}^{3}$. On the basis of this information, the U.S. Occupational Safety and Health Administration (OSHA) established $5 \mathrm{mg} / \mathrm{m}^{3}$ as the timeweighted average permissible exposure level for the eight-hour-a-day, five-day-a-week occupational setting.

Whereas mists of the various grades of mineral oil do not appear to cause occupational lung cancer, repeated dermal contact with conventionally refined lubricating oils or oil mists does cause 
inflammation, dermatitis, folliculitis, acne, eczema, and contact sensitivity in humans. Malignant and premalignant skin changes (e.g., atrophy, hyperkeratosis, and benign papillomas) may be caused by exposure to poorly refined lubricating oils. Most of these effects have been attributed to the PAH content of the oils. Evidence for an association between squamous-cell skin cancer - of the hand, the arm, and especially the scrotum - and exposures to conventionally refined mineral oils is overwhelming. The IARC, ${ }^{8}$ having reviewed epidemiological studies, concluded that there is sufficient evidence "that mineral oils (containing various additives and impurities) that have been used in occupations such as [cotton] mulespinning, metal machining and jute processing are carcinogenic to humans." The epidemiological evidence is mirrored in mouse dermal bioassays ("skin painting studies") that have been used routinely for many years to evaluate the tumorigenicity of petroleum oil fractions. These experiments typically involve repeated application of measured quantities of test materials to shaven skin on the backs of mice. Such studies have demonstrated that conventionally refined mineral oils are carcinogenic, and that severe hydrotreatment or severe solvent extraction reduces or eliminates the tumorigenic activity.

It is widely accepted that the content of carcinogenic PAHs in mineral oils is responsible for the tumorgenicity of these oils. However, other factors also appear to be involved; for example, nitrosoamines in metal machining cutting oils are carcinogenic, and constituents may be tumor promoters or cocarcinogens but not initiators. There is evidence suggesting that solvent refining can remove tumor promoters and cocarcinogens from a lubricant base oil. The severity of refining does greatly influence the carcinogenicity of lubricating oils.

In-vitro screening (cytogenetic analysis of peripheral blood lymphocytes) was conducted on glass makers who had been exposed to less than $5 \mathrm{mg} / \mathrm{m}^{3}$ of high-PAH mineral oil mists. There were significant increases in the frequency of aberrant cells and in the numbers of chromosome breaks per cell, as compared with controls.

\section{B.6 Carcinogenicity of PAHs}

Neither the U.S. Environmental Protection Agency's "Health Effects Assessment Summary Tables" (HEAST) 25 nor its Integrated Risk Information System (IRIS) ${ }^{25}$ currently provide quantitative criteria for the carcinogencity of PAHs. The withdrawal from these official sources of a cancer slope factor (index of carcinogenic risk) for benzo[a]pyrene - and the failure to provide such expressions of risk for other PAHs - forces one to turn to other credible (but not yet widely recognized and possibly transient) sources of guidance. A draft report recently prepared for the U.S. Environmental Protection Agency Office of Health and Environmental Assessment by ICF-Clement Associates ${ }^{26}$ appears to be in this category and is used here. The value of the slope (or "carcinogenic potency") factor by the inhalation route for benzo[a]pyrene, $\mathrm{q}_{1}{ }^{*}$, is $0.453(\mathrm{mg} / \mathrm{kg} \text {.day })^{-1}$. Slope factors for the other PAHs are calculated by multiplying this value by the "relative potencies," which are presented in Table B.4. The use of these "relative potencies" will be illustrated below. 


\section{B.7 Terrestrial Ecological Effects of Fog Oil12}

Wind tunnel tests were carried out on a 1983 - hence "old" - lot of fog oil. About $80 \%$ of the oil deposited on foliar surfaces disappeared linearly over roughly four days, but the rest then lingered far longer. The oil was more persistent in soils.

Phytotoxicity was tested on two-yearold ponderosa pine, big sagebrush, and short needle pine seedlings, as well as on tall fescue grown from seed. In one test series, the plants were exposed to a fog oil mist of approximately $737 \mathrm{mg} / \mathrm{m}^{3}$ concentration at a wind speed of $0.73 \mathrm{~m} / \mathrm{s}$ for periods of 2,4 , 6 , and $8 \mathrm{~h}$ to give four mass loadings per species; these loadings varied according to exposure time and leaf and canopy structure over a range of 33 to $292 \mu \mathrm{g}$ fog oil $/ \mathrm{cm}^{2}$ of foliage. In other tests, higher wind speeds gave heavier loadings. The intensity and extent of damage to the plants caused by the oil increased with time over a three-week period following the exposures. While tip burn and needle dieback were prevalent symptoms, chlorosis and necrotic spotting of needles were apparent at the higher loadings. Ponderosa pine and sagebrush were substantially more susceptible to damage than was new growth. Although there were also longer term effects on the plants, no effects of soil contamination on seed germination were noted. There was no significant effect of fog oil contamination of a sandy loam on growth of tall fescue; but in silty clay, the first of three crops showed growth inhibition.

The influence of fog oil (concentrations not stated) on soil respiration, dehydrogenase activity, and nitrifying activity was measured as an indicator of the effects of the oil on the soil microbial population. There was no effect on soil respiration; both inhibitory and stimulatory effects on soil enzyme activities were observed. The results indicate that fog oil is probably not a toxicant to the soil heterotrophic microbial activity.

Earthworm mortality was determined in a series of soil tests. All wornis survived the 14-day test period at fog oil concentrations below $285 \mathrm{mg} / \mathrm{kg}$, corresponding to a surface loading of about $3.6 \mathrm{mg} / \mathrm{cm}^{2}$.
TABLE B.4 Potencies of PAHS

Relative to that of Benzo[a]pyrene

\begin{tabular}{ll}
\hline \multicolumn{1}{c}{ PAH } & $\begin{array}{l}\text { Relative } \\
\text { Potency }\end{array}$ \\
\hline & \\
\hline Anthracene & 0.032 \\
Benzo[a]pyrene & 1.000 \\
Benzo[e]pyrene & 0.004 \\
Benzo[a]anthracene & 0.145 \\
Benzo[b]fluoranthene & 0.140 \\
Benzo[j]fluoranthene & 0.061 \\
Benzo[k]fluoranthene & 0.066 \\
Benzo[ghi]perylene & 0.022 \\
Chrysene & 0.0044 \\
Cyclopentadieno[cd]pyrene & 0.023 \\
Dibenz[ah]anthracene & 1.11 \\
Indeno[1,2,3-cd]pyrene & 0.232 \\
Pyrene & 0.081 \\
\hline
\end{tabular}




\section{B.8 Current and Possible Future Standards}

An airborne mineral oil exposure Threshold Limit Value (TLV) 5,27 and an identical Permissible Exposure Level (PEL) ${ }^{5}$ have been established by the American Conference of Governmental Industrial Hygienists (ACGIH) and the U.S. Occupational Safety and Health Administration, respectively. This value is $5 \mathrm{mg} / \mathrm{m}^{3}$ as an eight-hour-a-day, five-day-a-week timeweighted average (TWA). The ACGIH short-term exposure limit (STEL) is $10 \mathrm{mg} / \mathrm{m}^{3}$. The ACGIH is currently revising the mineral oil TLV and may reduce the TLV for PAH-containing mineral oil to $0.2 \mathrm{mg} / \mathrm{m}^{3}$.

\section{B.9 Ensuring the Use of "Safe" Fog Oil}

It is assumed that only fog oil complying with the current military specification ${ }^{4}$ will be employed. This specification refers indirectly to the IARC monograph ${ }^{8}$ cited above; essentially it relies on the refining history of the oil. There is "sufficient" evidence that untreated (by either hydrotreatment or solvent refining), mildly hydrotreated, or mildly solvent-refined oils are carcinogenic; "no evidence" that severely solvent refined oils or oils that have undergone sequential mild hydrotreating and mild solvent refining are carcinogenic; and "inadequate evidence" that severely hydrotreated oils are carcinogenic. ${ }^{6-8}$ It is essential that military authorities at CMTC accept and permit only the use of oil stocks in compliance with the present specification, ${ }^{4}$ namely those with the proper refining history. Although no current requirements exist for the chemical or biological testing of fog oil, it may be prudent to consider one of the following, as discussed above: mouse dermal bioassay, 5,8,21,22 mutagenicity testing, 19,20,22 ultraviolet absorption/ viscosity testing, ${ }^{21}$ the ASTM fluorescent indicator adsorption test ${ }^{17}$ (which may be inadequate to identify oils low in other aromatics but high in PAHs), or analysis for carcinogenic PAHs. 19,20,28 The last of these tests deals with the cancer initiators believed to be responsible, in the absence of carcinogenic additives, for the major part of mineral oil carcinogenicity. Since refining should have removed most of the aromatics (and with them the promoters and cocarcinogens found in unrefined mineral oils), the PAH content should correlate well with carcinogenicity. If analyses are available for individual PAHs in fog oil used at CMTC, calculations such as those indicated below would be able to provide an estimate f incremental cancer risk to local residents in accordance with current risk assessment practice.

For the present exercise, the following assumptions and definitions are employed:

$$
\begin{aligned}
C_{\mathrm{PAH}}= & \begin{array}{l}
\text { acceptable concentration of PAHs, as benzo[a]pyrene equivalents, in } \\
\text { fog oil; }
\end{array} \\
\mathrm{R}= & \text { lifetime acceptable cancer risk of } 10^{-6} \text { (dimensionless); } \\
\mathrm{q}^{*} 1= & 0.453(\mathrm{mg} / \mathrm{kg} \cdot \text { day })^{-1} \text { for benzo[a]pyrene slope factor or for potency- } \\
& \text { adjusted equivalents (see below); }
\end{aligned}
$$




$$
\begin{aligned}
& \mathrm{L}=\text { human lifespan of } 70 \mathrm{yr} ; \\
& \mathrm{T}=\text { residence (exposure) time in Hohenfels, } 35 \mathrm{yr} \text {, } \\
& \mathrm{H}=\text { hours per day of resident exposure during training, } 1 \mathrm{~h} \text {; } \\
& \mathrm{D} \text { = days per week during training weeks, } 5 \text { days; } \\
& \mathrm{W}=\text { weeks of training per year, } 49 \text { weeks; } \\
& \text { dpy }=365 \text { days per year; } \\
& \mathrm{BW}=\text { adult body weight, } 70 \mathrm{~kg} \text {; } \\
& C_{\mathbf{f}}=\text { exposure concentration of fog oil, assumed to be } 1 \mathrm{mg} / \mathrm{m}^{3} \text { for the } \\
& \mathrm{K}=\text { factor to convert } \mathrm{mg} / \mathrm{mg} \text { to } \mathrm{mg} / \mathrm{kg}(\mathrm{ppm}), 10^{6} \text {. }
\end{aligned}
$$

The pertinent equation is:

$$
\mathrm{C}_{\mathrm{PAH}}=(\mathrm{R} \times \mathrm{L} \times \mathrm{dpy} \times \mathrm{BW} \times \mathrm{K}) /\left(\mathrm{q}_{1}{ }^{*} \times \mathrm{H} \times \mathrm{D} \times \mathrm{W} \times \mathrm{T} \times \mathrm{C}_{\mathrm{f}} \times \mathrm{F}\right)
$$

Inserting the above assumed values for the various parameters, one obtains

$$
\begin{aligned}
C_{\text {PAH }}= & 192 \mathrm{mg} / \mathrm{kg} \text { as benzo[a]pyrene, } \\
& \text { or } 192 \mathrm{ppm} \mathrm{BaP} \text { equivalent concentration. }
\end{aligned}
$$

As an example of a calculation of a benzo[a]pyrene (BaP) equivalent concentration, suppose a fog oil sample contains $80 \mathrm{ppm}$ fluoranthene, $45 \mathrm{ppm}$ benzo[b]fluoranthene, $60 \mathrm{ppm}$ benzo[a]pyrene, and $90 \mathrm{ppm}$ benzo[ghi]perylene. Multiply each concentration by the relative potency of that compound from Table B.4. Note that fluoranthene is not in the list; although 
fluoranthene is a PAH, fluoranthene is not a carcinogen, as evidenced by its appearance only among the noncarcinogens in HEAST. 25 Thus,

$$
\mathrm{BaP} \text { equivalent }=(45 \times 0.14)+(60 \times 1.0)+(90 \times 0.022)=68.28 \mathrm{ppm}
$$

Hence, the BaP equivalent is only $68 \mathrm{ppm}$, whereas the total PAH concentration is $275 \mathrm{ppm}$. In this example, the oil has a $\mathrm{BaP}$ equivalent concentration below the estimated maximum value computed above and would be considered safe to use.

\section{B.10 Discussion and Conclusions}

Occupational exposure of humans to mineral oil mists (of which fog oil mists are a subset) does not appear to cause respiratory illness, such as pneumonias or cancer, although concentrations above $5 \mathrm{mg} / \mathrm{m}^{3}$ have reportedly occasioned some pulmonary discomfort. Furthermore, $5 \mathrm{mg} / \mathrm{m}^{3}$ is a level at which no adverse effects have been observed in animals. Levels of workplace exposures to carcinogen-containing mineral oil mists have far exceeded any mineral oil fog concentrations that would be encountered in the vicinity of the CMTC (i.e., off-site) as a result of smoke training exercises. Since the U.S. Occupational Safety and Health Administration's permissible exposure level (time-weighted average) for mineral oil mists is $5 \mathrm{mg} / \mathrm{m}^{3}$, this number serves as a benchmark, at least as far as noncarcinogenic effects are concerned.

"Old" fog oil (i.e., that produced under pre-1986 military specifications) is assumed to contain carcinogens. The carcinogens occur at levels believed to be sufficient to cause skin cancer, especially squamous cell carcinomas of the scrotum, in individuals exposed repeatedly to high dermal doses. Exposure to such low-level "old" fog oil mists as might occasionally be experienced by residents of the area around the Hohenfels training site should pose no risk of skin cancer; not only is the mist concentration low, but the efficiency of deposition on skin may be considered miniscule. All evidence points to properly refined fog oil being carcinogen-free.

Out of extreme prudence, and to provide the utmost guarantee of safety to local residents, it is recommended that every effort be made by the U.S. military commander of the Hohenfels Training Area to assure that only "new" fog oil, documented to guarantes that it was treated in an approved manner to remove all carcinogens, be used for smoke training.

Although high levels of oil fogs in wind tunnel tests induced damage to plant species, it is extremely doubtful that U.S. Army-generated oil fogs would cause significant adverse effects on the environment (plants, microbiota, invertebrates) at Hohenfels (except, perhaps, very close to the smoke generators, the fog concentrations would be far too low). Because of the very small particle size of fog oil aerosol, the particle deposition rate would be low. 
It may be concluded that past and current use of fog oil in the CMTC represents minimal health risk to residents around the training area or to environmental biota within or outside the area.

\section{B.11 References}

1. Katz, S., et al., Physical and Chemical Characterization of Military Smokes - Part II: Final Report on Fog Oils and Oil Fogs, AD 093205, Illinois Institute of Technology Research Institute, Chicago, Ill., Contract No. DAMD17-78-C-8085 (1980).

2. Liljegren, J.C., et al., Field Measurement and Model Evaluation Program for Assessment of the Environmental Effects of Military Smokes: Final Report on the Atterbury-87 Field Study of Smoke Dispersion and a New Stochastic Dispersion Model, AD A212983, University of Illinois, Urbana, Ill., Contract No. 84PP4822 (1989).

3. Liss-Suter, D., and J.E. Villaume, Final Report on Occupational Health and Safety Aspects of the Fog Oils SGF No. 1 and SGF No. 2 and Smoke Screens Generated from Them, AD A055903, Franklin Institute Research Laboratories, Philadelphia, Penn., Contract No. DAMD17-77-C-7020 (1978).

4. Department of the Army, Fog Oil. Military Specification No. MIL-F-12070C with Amendment 2, U.S. Government Printing Office, Washington, D.C. (16 May 1984 with Amendment 2, 2 April 1986)

5. Palmer, W.G., Exposure Standards for Fog Oil, Technical Report No. 9010, U.S. Army Biomedical Research and Development, Fort Detrick, Frederick, Md. 21702 (Nov. 15, 1990).

6. Occupational Safety and Health Administration, U.S. Department of Labor, 29 CFR Part 1910, Hazard Communication; Interpretation Regarding Lubricating Oils, Federal Register, 50 FR 51852, Washington, D.C. (Dec. 20, 1985).

7. Occupational Safety and Health Administration, U.S. Department of Labor, Clarifications and Interpretations of the Hazard Communication Standard, Appendix A to OSHA Instruction CPL 2-2.38B, Washington, D.C. (Aug. 15, 1988).

8. International Agency for Research on Cancer, Mineral Oils, In Evaluation of the Carcinogenic Risk of Chemicals to Humans. Polynuclear Aromatic Hydrocarbons. Part 2. Carbon Blacks, Mineral Oils (Lubricant Base Oils and Derived Products) and Some Nitroarenes, International Agency for Research on Cancer (IARC) Monograph 33:87-168, World Health Organization, Lyon, France (1984). 
9. Criteria and Standards Division, Office of Drinking Water, Initial Draft of Toxicological Profile for Fog Oil, U.S. Environmental Protection Agency, Washington, D.C. (Aug. 1987).

10. Liljegren, J.C., et al., Field Measurement and Model Evaluation Program for Assessment of the Environmental Effects of Military Smokes: Field Study of Military Smokes, University of Illinois, Urbana, Ill., Contract No. 84PP4822 (1988).

11. DeVaull, G., et al., Field Measurement and Model Evaluation Program for Assessment of the Environmental Effects of Military Smokes: Final Report on Oil Analysis Method for Study of Atmospheric Dispersion of Military Fog Oil Smokes, AD A216049, University of Illinois, Urbana, Ill., Contract No. 84PP4822 (1989).

12. Cataldo, D.A., et al., Evaluate and Characterize Mechanisms Controlling Transport, Fate and Effects of Army Smokes in an Aerosol Wind Tunnel: Final Report on Transport, Tranformations, Fate and Terrestrial Ecological Effects on Fog Oil Obscurant Smokes, AD A204314, Pacific Northwest Laboratory, Richland, Wash., Contract No. 84 PP4819 (1989).

13. Policastro, A.J., et al., Field Measurement and Model Evaluation Program for Assessment of the Environmental Effects of Military Smokes: Annual Report, Argonne National Laboratory, Argonne, Ill., Contract No. 84PP4822 (1989).

14. Policastro, A.J., et al., Field Measurement and Model Evaluation Program for Assessment of Environmental Effects of Military Smokes: Evaluation of Atmospheric Dispersion Models for Fog-Oil Smoke Dispersion, AD 216055, Argonne National Laboratory, Argonne, Ill., Contract No. 84PP4822 (1989).

15. Jenkins, R.A., W.M. Caldwell, and J.E. Caton, Analysis of Fog Oil Smoke Particulate Samples: Post-Exposure Monitoring of HERL/EPA-RTP Inhalation Exposures, Oak Ridge National Laboratory, Oak Ridge, Tenn., Contract No. 82PP2802 (1987).

16. American Society for Testing and Materials (ASTM) Committee on Standards, Standard Test Method for Hydrocarbon Types in Liquid Petroleum Products by Fluorescent Indicator Adsorption, ASTM Standard D 1319-84, American Society for Testing and Materials, Philadelphia, Penn. (1984).

1\%. Lijinsky, W., et al., The Chromatograhic Determination of Trace Amounts of Polynuclear Hydrocarbons in Petroleum, Mineral Oil, and Coal Tar, Analytical Chemistry, 35:952-956 (1963). 
18. Eller, P.M., ed., Mineral Oil Mist, Method 5026, In NIOSH Manual of Analytical Methods, 3rd ed., Vol. 2, National Institute for Occupational Safety and Health, U.S. Department of Health and Fin nan Services, DHHS (NIOSH) Publication No. 84-100 $(1984,1987)$.

19. Hermann, M., et al., Adaptation of the Salmonella/Mammalian Microsome Test to the Determination of the Mutagenic Properties of Mineral Oils, Mutation Research, 77:327-339 (1980).

20. Hermann, M., et al., Correlations of Mutagenic Activity with Polynuclear Aromatic Hydrocarbon Content of Various Mineral Oils, In A. Bjorseth and A.J. Dennis, eds., Chemistry and Biological Effects, Fourth International Symposium, Battelle Press, Columbus, Ohio, pp. 899-916 (1980).

21. Haas, J.M., et al., A Simple Analytical Test and a Formula to Predict the Potential for Dermal Carcinogencicity from Petroleum, American Industrial Hygiene Association Journal, 48:935940 (1987).

22. Blackburn, G.R., et al., Estimation of the Dermal Carcinogenic Activity of Petroleum Fractions Using a Modified Ames Assay, Cell Biology and Toxicology, 1:67-80 (1984).

23. Wagner, W.D., P.G. Wright, and H.E. Stokinger, Inhalation Toxicology of Oil Mists. I. Chronic Effects of White Mineral Oil, American Industrial Hygiene Association Journal, 25:158-168 (1964).

24. Young, J.Y., et al., Field Exposure of Chemical School Students and Cadre to Fog Oil and Hexachloroethane (HC) Smokes, Technical Report 8908, U.S. Army Biomedical Research and Development Laboratory, Fort Detrick, Frederick, Md. (1989).

25. U.S. Environmental Protection Agency Environmental Criteria and Assessments Office, Health Effects Assessment Summary Tables (HEAST), U.S. Environmental Protection Agency, Cincinnati, Ohio (1990).

26. ICF-Clement Associates, Comparative Potency Approach for Estimating the Cancer Risk Associated with Exposure to Mixtures of Polycyclic Aromatic Hydrocarbons, Prepared for the Office of Health and Environmental Assessment, U.S. Environmental Protection Agency, by ICF-Clement Associates, Fairfax, Va., Contract No. 68-02-4403 (1988).

27. American Conference of Governmental Industrial Hygienists (ACGIH), TLVs: Threshold Limit Values and Bi. 'gical Exposure Indices for 1988-1989, Cincinnati, Ohio (1988). 
28. Eller, P.M., ed., Polynuclear Aromatic Hydrocarbons, Method 5515, In NIOSH Manual of Analytical Methods, Third Ed., Vol. 2, National Institute of Occupational Safety and Health, U.S. Department of Health and Human Services, DHHS (NIOSH) Publication No. 84-100 (1984, 1985).

29. Eaton, J.C., and J.Y. Young, Medical Criteria for Respiratory Protection in Smoke: The Effectiveness of the Military Protective Mask, Technical Report 8902, U.S. Army Biomedical Research and Development Laboratory, Fort Detrick, Frederick, Md. (1989). 


\section{Appendix C: Conversion of GPS Positions to Local Coordinates}

\section{C.1 Local/GPS Latitude and Longitude Conversion}

The basic parameters that specify the horizontal position of a point on the Earth are the latitude and longitude of the point. However, the common (geodetic) latitude and longitude are not defined with respect to the actual surface of the Earth, but rather with respect to the surface of a reference ellipsoid of revolution chosen to provide the best possible fit to the actual surface within a well-defined geographic area. A reference ellipsoid combined with a reference positional grid comprises a "datum." Within its area of definition, each datum provides a geodetic reference grid with respect to which all local surveying is done. Historically, many different datums (by conventional usage, the plural of the word datum in this context is datums, not data) are used in different parts of the globe. Because of the manner in which they have been generated, these datums are essentially independent of each other, and latitudes and longitudes with respect to different datums should not be compared at the highest level of accuracy. Examples are the North American Datum 1927 (or NAD 27), used until very recently in the contiguous United States and used for most U.S. Geological Survey (USGS) topographic and hydrographic maps, and the European Datum 1950 (ED 50), used in western Europe.

In contrast to the datums described above, the fundamental datum used in satellite navigation and surveying, the World Geodetic System (WGS) 84 Datum, is defined to provide a good global, rather than local, reference surface. The accurate definition and determination of global geodetic reference systems became possible only after the development of artificial satellites. Because different reference surfaces are used, WGS 84 positions are not identical to those defined with respect to another datum, such as NAD 27, and the differences can correspond to distances on the surface of the Earth of up to a few hundred meters.

A complicating factor is that, in the historical datums, distortions are present in both latitude and longitude, because of the accumulation of errors in the systems of triangulation that are needed to extend the reference grid over a large area. These distortions, which may reach $100 \mathrm{~m}$ or more, were detected by satellite positioning systems, in which the corresponding error accumulation does not occur.

Commercially available GPS receivers generally offer the option of selecting the datum with respect to the computed latitude and longitude that are to be displayed. The computations are done internally with respect to the WGS 84 system, on which the GPS system is fundamentally based, and then the results are converted to the desired datum. If it is known in advance that a comparison of GPS positions with positions defined with respect to a specific datum will be needed, the proper datum may be selected prior to obtaining the positions. 
In other situations, it may be required to convert positions from a local datum to WGS 84 or vice versa. In Reference C.1, the Defense Mapping Agency has provided formulas and data needed for converting positions defined on a large number of local grids used around the world to WGS 84 positions, but not for converting positions from WGS 84 to local grids. The remainder of this section discusses the conversion of positions between WGS 84 and NAD 27 and between WGS 84 and the ED 50.

Reference C.1 provides Multiple Regression Equations (MREs) for the transformation of local NAD 27 or ED 50 positions, defined by local latitude $\phi$ and longitude $\lambda$, to WGS 84 positions, specified by latitude $\phi_{W G S}$ and longitude $\lambda_{\text {WGS }}$. The formulas may be represented generally as follows:

$$
\begin{aligned}
& \Delta \phi^{\prime \prime}=\Delta \phi_{0}+\Phi(U, V) \text { and } \\
& \Delta \lambda^{\prime \prime}=\Delta \lambda_{0}+\Lambda(U, V) .
\end{aligned}
$$

In these equations, $\Delta \phi^{\prime \prime}$ and $\Delta \lambda "$ are defined as the differences, in arc-seconds, betiveen WGS 84 and local latitudes and longitudes:

$$
\begin{aligned}
& \phi_{\mathrm{WGS}}=\phi+\mathrm{f} \Delta \phi^{\prime \prime} \text { and } \\
& \lambda_{\mathrm{WGS}}=\lambda+\mathrm{f} \Delta \lambda ",
\end{aligned}
$$

where $\phi$ and $\lambda$ are given in degrees, and $f=1 / 3,600$ converts arc-seconds to degrees.

In Equations $C .1$ and $C .2, \Delta \phi_{0}$ and $\Delta \lambda_{0}$ are given constants, and $\Phi(U, V)$ and $\Lambda(U, V)$ are given polynomial functions of the variables $U$ and $V$, which are defined by

$$
\begin{aligned}
& U=K\left(\phi-\phi_{0}\right) \text { and } \\
& V=K\left(\lambda-\lambda_{0}\right) .
\end{aligned}
$$

The quantity $\mathrm{K}$ is a scale factor,

$$
K=0.05235988 \text {, }
$$

and the quantities $\phi_{0}$ and $\lambda_{0}$ are reference coordinates specific to each datum. Longitudes are measured positive eastward from Greenwich $\left(0^{\circ}\right.$ to $\left.360^{\circ}\right)$ and latitudes are measured positive $\left(0^{\circ}\right.$ to $\left.90^{\circ}\right)$ in the northern hemisphere and negative $\left(0^{\circ}\right.$ to $\left.-90^{\circ}\right)$ in the southern hemisphere. 
The functions $\Phi(U, V)$ and $\Lambda(U, V)$ may be written in a form that is part linear in $U$ and $V$ and part nonlinear:

$$
\begin{aligned}
& \Phi(\mathrm{U}, \mathrm{V})=\mathrm{aU}+\mathrm{bV}+\Phi_{\mathrm{nl}}(\mathrm{U}, \mathrm{V}) \text { and } \\
& \Lambda(\mathrm{U}, \mathrm{V})=\mathrm{cU}+\mathrm{dV}+\Lambda_{\mathrm{nl}}(\mathrm{U}, \mathrm{V})
\end{aligned}
$$

in which $\Phi_{\mathrm{nl}}$ and $\Lambda_{\mathrm{nl}}$ contain terms of second degree and higher in U and V. Table C.1 lists the values of the parameters and coefficients introduced above for the NAD 27 and ED 50 datums. Table C.2 provides the expressions for the functions $\Phi_{\mathrm{nl}}$ and $\Lambda_{\mathrm{nl}}$ for the transformation from NAD 27 and ED 50 datums to WGS 84. The best (fastest and most accurate) way to evaluate polynomial expressions such as these is to evaluate them in a nested fashion. This method has been indicated for the most part in the manner in which the expressions are shown in the table. The two terms that begin with powers of $U$ and $V$, respectively, should be computed as shown, then the coefficients of the various powers of the product UV should be calculated, and finally the total value of the expression should be computed by calculating the contribution of powers of UV.

The transformation of local coordinates $(\phi, \lambda)$ to WGS 84 coordinates is straightforward. The procedure is to (1) compute the values of the variables $U$ and $V$ by using Equations $C .5$ and C.6, (2) compute $\Phi(\mathrm{U}, \mathrm{V})$ and $\Lambda(\mathrm{U}, \mathrm{V})$ from Equations C.8 and C.9 in combination with the expressions for the nonlinear parts from Table C.2, (3) compute $\Delta \phi "$ and $\Delta \lambda$ " from Equations C.1 and C.2, and finally (4) compute $\phi$ WGS and $\lambda_{W G S}$ by using Equations C. 3 and C.4.

Reference C. 1 does not provide analogous expressions for the conversion from WGS 84 to local coordinates. The approach taken here is to compute the values of $U$ and $V$ at the point in question, and then to compute $\phi$ and $\lambda$ from

$$
\begin{aligned}
& \phi=\phi_{0}+U / K \text { and } \\
& \lambda=\lambda_{0}+V / K
\end{aligned}
$$

which follow from Equations C.5 and C.6. The terms $U$ and $V$ satisfy the equations

$\mathrm{U}=\mathrm{U}_{\mathrm{o}}-\mathrm{Kf}\left[\mathrm{aU}+\mathrm{bV}+\Phi_{\mathrm{nl}}\right]$ and

$V=V_{0}-K f\left[c U+d V+\Lambda_{n l}\right]$

Equation C.12 is derived by equating the two expressions for $\phi$ obtained from Equations TABLE C.1 Linear Transformation Coefficients

C. 3 and C.5, and Equation C.13 is derived

\begin{tabular}{ccl}
\hline & & \\
Parameter & NAD 27 & \multicolumn{1}{l}{ ED 50 } \\
\hline$\phi_{0}$ & $37^{\circ}$ & \multicolumn{1}{l}{$52^{\circ}$} \\
$\lambda_{0}$ & $265^{\circ}$ & $10^{\circ}$ \\
$\Delta \phi_{0}$ & 0.16984 & \multicolumn{1}{l}{-2.65261} \\
$\Delta \lambda_{0}$ & -0.88437 & -4.13447 \\
$a$ & -0.76173 & 2.06392 \\
$b$ & 0.09585 & 0.77921 \\
$c$ & 0.0 & -1.50572 \\
$d$ & 2.05061 & 1.94075 \\
\hline
\end{tabular}


NAD 27 Conversion:

$$
\begin{aligned}
& \Phi_{\mathrm{nl}}=\mathrm{U}^{2}\left[1.09919+\mathrm{U}\left[-4.57801+\mathrm{U}^{2}\left[27.05396+\mathrm{U}^{2}[-59.96555\right.\right.\right. \\
& +\mathrm{U}[-4.76082+49.04320 \mathrm{U}]]]]] \\
& +\mathrm{V}^{3}[0.49831+\mathrm{V}[0.11450+\mathrm{V}[-0.37548+\mathrm{V}[-(0.1419]+\mathrm{V}] 0.07439 \\
& +0.03385 \mathrm{~V}] 1]]] \\
& +(\mathrm{UV})\left[\mathrm { U } \left[-1.13239+\mathrm{U}\left[-0.98399+2.03449 \mathrm{U} \| \mathrm{I}+0.12415 \mathrm{~V}^{2}\right]\right.\right. \\
& +(\mathrm{UV})^{2}[0.73357 \mathrm{~V}]+(\mathrm{UV})^{3}\left[-1.30575 \mathrm{U}^{3}-0.07653 \mathrm{~V}^{6}\right] \\
& +(\mathrm{UV})^{4}\left[0.08646 \mathrm{~V}^{5}\right] \\
& \Lambda_{\mathrm{nl}}=\mathrm{U}^{2}\left[0.26361+\mathrm{U}\left[-1.31974+3.41827 \mathrm{U}^{6}\right]\right] \\
& +\mathrm{V}^{2}\left[0.13374+\mathrm{V}^{2}\left[-0.06004+\mathrm{V}^{2}\left[-0.05183-0.01444 \mathrm{~V}^{3}\right. \text { II] }\right.\right. \\
& +(\mathrm{UV})\left[-0.76804+\mathrm{U}\left[-0.52162+\mathrm{U}^{2}\left|0.30139-0.44507 \mathrm{U}^{4}\right|\right]\right. \\
& +\mathrm{V}[-1.05853+\mathrm{V}[2.17204+\mathrm{V}[1.88585+\mathrm{V}[-0.81162+\mathrm{V}[-(0.96723 \\
& \left.+\mathrm{V}^{2}[0.18882+0.04794 \mathrm{~V} \mid 1111]\right] \\
& +(\mathrm{UV})^{2}[-0.49211]+(\mathrm{UV})^{3}\left[-0.59013 \mathrm{U}^{6}-0.12948 \mathrm{~V}^{2}\right]
\end{aligned}
$$

ED 50 Conversion:

$$
\begin{aligned}
& \Phi_{\mathrm{nl}}=\mathrm{U}^{2}\left[0.26743+\mathrm{U}\left[0.76407+\mathrm{U}\left[0.17197-0.78909 \mathrm{U}^{5}\right]\right]\right]-0.05401 \mathrm{~V}^{8} \\
& +(\mathrm{UV})\left[0.10706+\mathrm{U}\left[-0.95430+1.04974 \mathrm{U}^{2}\right]+0.05283 \mathrm{~V}^{8}\right] \\
& +(\mathrm{UV})^{2}\left[-0.22899 \mathrm{U}^{3}-0.10572 \mathrm{~V}^{5} \mid+\left(\mathrm{UV}^{\prime}\right)^{3}\left[0.02445 \mathrm{~V}^{6}\right]\right. \\
& \Lambda_{\mathrm{nl}}=\mathrm{U}^{2}[-1.37600+\mathrm{U}[-2.31939+\mathrm{U}[-1.70401+\mathrm{U}[7.41956+\mathrm{U}[1.57701 \\
& -3.08344 \text { U }] 1] 11 \\
& +\mathrm{V}^{2}\left[0.30068+\mathrm{V}^{3}\left[-1.97974+0.16438 \mathrm{~V}^{4}\right]\right] \\
& +(\mathrm{UV})\left[1.98425+\mathrm{U}^{5}\left[-14.32516+9.98750 \mathrm{U}^{2}\right]+\mathrm{V}^{2}[-5.48711\right. \\
& +\mathrm{V}[5.92923-1.79701 \mathrm{~V} \text { III } \\
& +(\mathrm{UV})^{2}\left[\mathrm{U}^{5}\left[7.80215-8.25844 \mathrm{U}^{2}\right]+\mathrm{V}[-1.61351+\mathrm{V}[16.85976\right. \\
& \left.-2.26917 \mathrm{~V}^{3} \mathrm{l}\right] \mathrm{l} \\
& +(\mathrm{UV})^{3}\left[-6.52522+5.28734 \mathrm{U}^{5}\right] \\
& +(U V)^{4}\left[4.49096-3.48015 U^{5}+V^{2}\left[-17.45428+0.71041 V^{3}\right]\right] \\
& +(\mathrm{UV})^{5}\left[8.87141 \mathrm{~V}^{2} 1\right.
\end{aligned}
$$


similarly by solving for $\lambda$ from Equations C.4 and C.6. The quantities $U_{0}$ and $V_{o}$ are defined as follows in terms of $\phi$ WGS,$\lambda$ WGS, and known constants:

$$
\begin{aligned}
& \mathrm{U}_{\mathrm{o}}=\mathrm{K}\left[\phi W G S-\phi_{0}-\mathrm{f} \Delta \phi_{\mathrm{o}}\right] \text { and } \\
& \mathrm{V}_{\mathrm{o}}=\mathrm{K}\left[\lambda_{\mathrm{WGS}}-\lambda_{0}-\mathrm{f} \Delta \lambda_{0}\right] .
\end{aligned}
$$

The problem is that both $\Phi_{\mathrm{nl}}$ and $\Lambda_{\mathrm{nl}}$ are themselves nonlinear functions of $\mathrm{U}$ and $\mathrm{V}$, making Equations $C .12$ and $C .13$ complicated to solve. However, $\mathrm{U}^{2}$ and $\mathrm{V}^{2}$ differ from $\mathrm{U}_{0}{ }^{2}$ and $\mathrm{V}_{0}{ }^{2}$ by terms of order $\mathrm{Kf}$, and, therefore, $\Phi_{\mathrm{nl}}\left(\mathrm{U}_{0}, \mathrm{~V}_{0}\right)$ and $\Lambda_{\mathrm{nl}}\left(\mathrm{U}_{0}, \mathrm{~V}_{\mathrm{o}}\right)$ differ from $\Phi_{\mathrm{nl}}(\mathrm{U}, \mathrm{V})$ and $\Lambda_{\mathrm{nl}}(\mathrm{U}, \mathrm{V})$ by a comparable amount. If the nonlinear terms are replaced in Equations C.12 and C. 13 by their values evaluated at the point $\left(U_{0}, V_{0}\right)$, denoted by $\Phi_{\text {nlo }}$ and $\Lambda_{\text {nlo }}$, the error made in the equations is only of order $(\mathrm{Kf})^{2}$. The resulting error in the computed coordinates is then of order $10^{-5}$ arc-seconds, and this error is negligible. If this replacement is made, Equations C. 12 and $\mathrm{C} .13$ become two linear equations (Equations $\mathrm{C} .16$ and $\mathrm{C} .17$ ) in the unknowns $\mathrm{U}$ and $\mathrm{V}$, which can easily be solved:

$$
(1+K f a) U+K f b V=U_{o}-K f \Phi_{\text {nlo }} \text { and }
$$

$K f c U+(1+K f d) V=V_{0}-K f \Lambda_{\text {nlo }}$

The solutions to Equations C.16 and C. 17 may be written in the form

$$
\begin{aligned}
& \mathrm{U}=\left(\mathrm{b}_{1} \mathrm{a}_{22}-\mathrm{b}_{2} \mathrm{a}_{12}\right) / \mathrm{D} \text { and } \\
& \mathrm{V}=\left(\mathrm{b}_{2} \mathrm{a}_{11}-\mathrm{b}_{1} \mathrm{a}_{21}\right) / \mathrm{D}
\end{aligned}
$$

when

$$
\begin{aligned}
D & =a_{11} a_{22}-a_{12} a_{21} \\
b_{1} & =U_{0}-K f \Phi_{n l o} \\
b_{2} & =V_{0}-K f \Lambda_{n l o} \\
a_{11} & =1+K f a \\
a_{12} & =K f b
\end{aligned}
$$




$$
\begin{aligned}
& a_{21}=K f c, \text { and } \\
& a_{22}=1+K f d .
\end{aligned}
$$

Table C. 3 provides numerical values of the parameters $a_{i j}$ and D for the NAD 27 and ED 50 datums. The procedure for converting WGS 84 coordinates to NAD 27 or ED 50 coordinates is as follows: (1) compute $U_{o}$ and $V_{o}$ from Equations C.14 and C.15, (2) compute $\Phi_{\text {nlo }}$ and $\Lambda_{\text {nlo }}$ by using the expressions in Table C.2, (3) compute $b_{1}$ and $b_{2}$ from Equations C.21a and $b$, (4) compute $U$ and $V$ from Equations $C .18$ and C.19, and finally (5) compute $\phi$ and $\lambda$ from Equations C.10 and C. 11 .

To illustrate the conversion process, an example of conversion in each direction is presented. Reference C. 1 gives test cases for converting NAD 27 or ED 50 coordinates to WGS 84 coordinates. The input for the ED 50 test point is as follows:

$$
\begin{aligned}
& \phi=46^{\circ} 41^{\prime} 42.893^{\prime \prime} \text { or } 46.695248055^{\circ} \text { and } \\
& \lambda=13^{\circ} 54^{\prime} 54.088^{\prime \prime} \text { or } 13.915024444^{\circ} \text {. }
\end{aligned}
$$

The computed values of several inte mediate quantities are listed below.

$$
\begin{array}{cc}
\mathrm{U}=-2.777561753 \times 10^{-1} & \Lambda_{\mathrm{nl}}=-1.672514537 \times 10^{-1} \\
\mathrm{~V}=2.049902101 \times 10^{-1} & \Phi=4.281371132 \times 10^{-1} \\
\Phi_{\mathrm{nl}}=-1.460100948 \times 10^{-2} & \Lambda=6.488063248 \times 10^{-1}
\end{array}
$$

TABLE C.3 Parameters for the Conversion of WGS 84 to Local Coordinates

\begin{tabular}{lll}
\hline Parameter & \multicolumn{1}{c}{ NAD 27 } & \multicolumn{1}{c}{ ED 50 } \\
\hline$a_{11}$ & 0.9999889211 & 1.000030019 \\
$a_{12}$ & $1.39408 \times 10^{-6}$ & $1.133315 \times 10^{-5}$ \\
$a_{21}$ & 0.0 & $-2.189981 \times 10^{-5}$ \\
$a_{22}$ & 1.000029825 & 1.000028227 \\
$D$ & 1.000018746 & 1.000058247 \\
\hline
\end{tabular}


The final results for the computation of corrections to $\phi$ and $\lambda$ are

$$
\Delta \phi^{\prime \prime}=-3.080_{7} " \text { and } \Delta \lambda^{\prime \prime}=-3 .+85_{6} ",
$$

in exact agreement with the test case results reported in Reference C.1.

A useful test case for the conversion from WGS to local coordinates is the reverse of the above example. The input for this example is

$$
\begin{aligned}
& \text { WGS }_{\text {W }}=46^{\circ} 41^{\prime} 39.812^{\prime \prime} \text { or } 46.694392222^{\circ} \text { and } \\
& \lambda_{\text {WGS }}=13^{\circ} 54^{\prime} 50.602^{\prime \prime} \text { or } 13.914056111^{\circ} \text {. }
\end{aligned}
$$

The computed values of several intermediate quantities are listed below.

$$
\begin{array}{cl}
\mathrm{U}_{\mathrm{o}}=-2.777624059 \times 10^{-1} & \mathrm{~b}_{1}=-2.777621935 \times 10^{-1} \\
\mathrm{~V}_{\mathrm{o}}=2.049996417 \times 10^{-1} & \mathrm{~b}_{2}=2.050020744 \times 10^{-1} \\
\Phi_{\text {nlo }}=-1.460270400 \times 10^{-2} & \mathrm{U}=-2.777561787 \times 10^{-1} \\
\Lambda_{\text {nlo }}=-1.672598490 \times 10^{-1} & \mathrm{~V}=2.049902054 \times 10^{-1}
\end{array}
$$

The final results are

$$
\begin{aligned}
& \phi=46.695247989^{\circ} \text { or } 46^{\circ} 41^{\prime} 42.893^{\prime \prime} \text { and } \\
& \lambda=13.915024354^{\circ} \text { or } 13^{\circ} 54^{\prime} 54.088^{\prime \prime} \text {, }
\end{aligned}
$$

in agreement with the local coordinates specified in the initial test case. Thus, the two conversion algorithms are each other's inverse at the 0.001 " level of accuracy.

\section{C.2 Computation of Universal Transverse Mercator Coordinates}

The computation of Universal Transverse Mercator (UTM) coordinates from latitude and longitude was done by using formulas given in Reference C.2, and these formulas are given below. A specific ellipsoid, defined by equatorial radius a and flattening $f$, must be used. 
Table C. 4 gives the values of these parameters for three widely used ellipsoids. In most formulas, some form of the eccentricity $e$ is used, instead of the flattening $\mathrm{f}$. The eccentricity is given in terms of the flattening by

$$
e^{2}=2 f-f^{2} .
$$

To calculate the East UTM coordinate $x$ (meters), the North UTM coordinate $y$ (meters), and the local map scale factor $k$ (dimensionless) from a given latitude $\phi$ and longitude $\lambda$, the following equations may be used:
TABLE C.4 Ellipsoid Parameter Values for Commonly Used Datums

\begin{tabular}{|c|c|c|}
\hline Datum & $\begin{array}{c}\text { Equatorial } \\
\text { Radius, a }(\mathrm{m})\end{array}$ & $\begin{array}{c}\text { Flattening, f } \\
\text { (dimensionless) }\end{array}$ \\
\hline WGS $84^{a}$ & $6,378,137$ & $1 / 298.257$ \\
\hline NAD $27^{b}$ & $6,378,206.4$ & $1 / 294.98$ \\
\hline$E D 50^{c}$ & $6,378,388$ & $1 / 297.00$ \\
\hline
\end{tabular}

a Based on the International Union of Geodesy and Cieophysics Geodetic Reference System 80 (GRS 80) ellipsoid.

b Uses the Clarke 1866 ellipsoid.

c Uses the Internatic: : ollipsoid.

$$
\begin{aligned}
x= & x_{R E F}+k_{o} N\left\{A+(1-T+C) A^{3} / 6+\left(5-18 T+T^{2}+72 C-58 e^{\prime 2}\right) A^{5 / 120}\right], \\
y= & y_{R E F}+k_{o}\left\{M-M_{o}+N \tan \phi\left\{A^{2} / 2+\left(5-T+9 C+4 C^{2}\right) A^{4} / 24\right.\right. \\
& \left.\left.+\left(61-58 T+T^{2}+600 C-330 e^{\prime 2}\right) A^{6} / 720\right]\right\}, \text { and } \\
k= & k_{o}\left[1+(1+C) A^{2} / 2+\left(5-4 T+42 C+13 C^{2}-28 e^{\prime 2}\right) A^{4} / 24\right. \\
& +\left(61-148 T+16 T^{2}\right) A^{6} / 720
\end{aligned}
$$

where $k_{0}$ denotes the scale on the central meridian; UTM system adopts the value 0.9996 for $k_{0}$. The quantities $x_{R E F}$ and $y_{R E F}$ are known as the "false Easting" and "false Northing," respectively; in the UTM system, $x_{R E F}$ is assigned the value 500,000$) \mathrm{m}$, and $y_{R E F}$ is zero in the northern hemisphere and $10,000,000 \mathrm{~m}$ in the southern hemisphere. The other quantities appearing in these equations are defined by

$$
\begin{aligned}
\mathrm{e}^{\prime 2} & =\mathrm{e}^{2} /\left(1-\mathrm{e}^{2}\right), \\
\mathrm{N} & =\mathrm{a} /\left(1-\mathrm{e}^{2} \sin ^{2} \phi\right)^{1 / 2}, \\
\mathrm{~T} & =\tan ^{2} \phi, \\
\mathrm{C} & =\mathrm{e}^{\prime 2} \cos ^{2} \phi, \\
\mathrm{A} & =\left(\lambda-\lambda_{0}\right) \cos \phi, \text { with } \lambda \text { and } \lambda_{\mathrm{o}} \text { in radians, and }
\end{aligned}
$$




$$
\begin{aligned}
& M=a\left[\left(1-e^{2} / 4-3 e^{4} / 64-5 e^{6 / 256}-\ldots\right) \phi-\left(3 e^{2} / 8+3 e^{4} / 32\right.\right. \\
& \left.+45 e^{6 / 1024}+\ldots\right) \sin 2 \phi+\left(15 e^{4} / 256\right. \\
& \left.\left.+45 e^{6 / 1024}+\ldots\right) \sin 4 \phi-\left(35 e^{6 / 3072}+\ldots\right) \sin 6 \phi+\ldots\right]
\end{aligned}
$$

where $\phi$ must be given in radians. $M$ is the true distance along the central meridian to latitude $\phi$; $M_{0}$ is the value of $M$ calculated for $\phi=\phi_{0}$, the latitude of the assumed origin. In the UTM system, $\phi_{0}$, and hence $M_{0}$, is zero. At $\phi= \pm 90^{\circ}, x=0, y=k_{0}\left(M-M_{0}\right)$, and $k=k_{0}$.

In Equation C.31, the quantity $\lambda_{\mathrm{o}}$ denotes the longitude of the central meridian assumed for the map. In the UTM system, the globe is divided into 60 zones, each generally $6^{\circ}$ wide in longitude and numbered from 1 to 60 proceeding eastward from the 180th meridian from Greenwich. Thus, Chicago, Illinois, is in UTM zone 16, and the Combat Maneuver Training Center is in UTM zone 32; the Greenwich meridian itself forms the boundary between zones 30 and 31 . The value of $\lambda_{0}$ for any given zone is the longitude of the central meridian for that zone.

To compute $\phi$ and $\lambda$ (in radians) from $x$ and $y$, the following equations may be used:

$$
\begin{aligned}
\phi=\phi_{1} & -\left(N_{1} \tan \phi_{1} / R_{1}\right)\left[D^{2} / 2-\left(5+3 T_{1}+10 C_{1}-4 C_{1}^{2}-9 e^{\prime 2}\right) D^{4} / 24\right. \\
& \left.+\left(61+90 T_{1}+298 C_{1}+45 T_{1}^{2}-252 e^{2}-3 C_{1}^{2}\right) D^{6} / 720\right] \text { and } \\
\lambda=\lambda_{0} & +\left[D-\left(1+2 T_{1}+C_{1}\right) D^{3} / 6+\left(5-2 C_{1}+28 T_{1}-3 C_{1}^{2}+8 e^{\prime 2}\right.\right. \\
& \left.\left.+24 T_{1}^{2}\right) D^{5} / 120\right] / \cos \phi_{1},
\end{aligned}
$$

where

$$
\begin{aligned}
& \phi_{1}=\mu+\left(3 \mathrm{e}_{1} / 2-27 \mathrm{e}_{1}^{2} / 32+\ldots\right) \sin 2 \mu+\left(21 \mathrm{e}_{1}^{2} / 16\right. \\
& \left.-55 \mathrm{e}_{1}{ }^{4} / 32+\ldots\right) \sin 4 \mu+\left(151 \mathrm{e}_{1}^{3 / 96}+\ldots\right) \sin 6 \mu \\
& +\left(1097 \mathrm{e}_{1}{ }^{4 / 512}-\ldots\right) \sin 8 \mu+\ldots, \\
& e_{1}=\left[1-\left(1-e^{2}\right)^{1 / 2}\right] /\left[1+\left(1-e^{2}\right)^{1 / 2}\right] \\
& \mu=M /\left[a\left(1-e^{2} / 4-3 e^{4} / 64-5 e^{6 / 256}-\ldots\right)\right], \\
& M=M_{0}+\left(y-y_{R E F}\right) / k_{0} \text {, } \\
& \mathrm{C}_{1}=\mathrm{e}^{\prime 2} \cos 2 \phi_{1}, \\
& T_{1}=\tan ^{2} \phi_{1}
\end{aligned}
$$




$$
\begin{aligned}
& N_{1}=a /\left(1-e^{2} \sin ^{2} \dot{\phi}_{1}\right)^{1 / 2} \\
& R_{1}=a\left(1-e^{2}\right) /\left(1-e^{2} \sin ^{2} \phi_{1}\right)^{3 / 2}, \text { and } \\
& D=\left(x-x_{R E F}\right) /\left(N_{1} k_{0}\right)
\end{aligned}
$$

\section{C.3 References}

C. 1 Defense Mapping Agency (DMA), 1987, Department of Defense World Geodetic System 1984, Its Definition and Relationships with Locai' Geodetic Systems, DMA Technical Report No. 8350.2, Washington, D.C., NTIS Reference AD/A188 815.

C.2 Snyder, J.P., 1987, Map Projections - A Working Manual, U.S. Geological Survey Professional Paper No. 1395, U.S. Gover-ment Printing Office, Washington, D.C. 


\section{Appendix D: Data, Sample, and Document Management}

This Appendix contains the text of Section 3 of the Sampling and Analysis Plan, dealing with data, sample, and clocument management. This discussion presents the procedures followed during the field investigation done as part of this study.

\section{D.1 Data Management}

Sources of data relevant to the interpretation of the sampling and analysis results and to the assessment of any potential contamination problems include, among others, the field logbook, which will contain information regarding the sample collection process, and the results from the analysis at ANL of the collected environmental samples. Summaries of all relevant data will be prepared in a suitable format and provided to the principal investigator. A printed copy will be appended to the report prepared for the sponsor.

\section{D.2 Sample and Document Management}

This section describes the sample and document management procedures that will be implemented in order 11 ) ensure the authenticity of the information generated and (2) facilitate the interpretation of the särping and analysis results.

\section{D.2.1 General Considerations}

The field logbook, sample labels, and sample tags will be completed by using waterproof ink. If weather conditions preclude the use of ink, a pencil may be used, but the reason for its use must bc noted in the logbook. If an error is made on any field document (which designation includes the documents just listed), a correction will be made by drawing a single line through the error and entering the correct information. All corrections must be initialed and dated. Should a field document become damaged, lost, or destroyed, the serial number and disposition of the document must be recorded. Field documents that are voided must not be discarded; they must be maintained in the project files for accountability.

\section{D.2.2 Sample Documentation and Control}

Sample Identification Numbers. Sample identification (ID) numbers will be assigned to each physical sample collected. The sample ID must be (1) unique (so that the sample can be distinguished from other similar samples) and (2) traceable throughout the process. To meet these 
two requirements, the sample ID will contain, in 12 character coded form, the information shown in Table D.1. In this investigation, the Army facility will always be the Hohenfels Training Area (code HTA). The sampling location codes will correspond to approximate grid reference numbers. The sample type code corresponds to the different types of sample that will be collected: $\mathrm{S}$, surface-soil samples; V, vegetation samples; R, runoff sediment samples; and $\mathrm{N}$, neat fog oil samples. For example, the sample ID number HTA015603S01 would indicate the following:

- The Army facility at which the sample was collected was the Hohenfels Training Area, Gernany.

- The sampling point (location) within HTA was at approximate grid reference 015603.

- The sample was a surface-soil sample.

- The sample was the first surface-soil sample collected at that point.

Field Logbooks. A field logbook will be used to (1) record the activities of the sampling team in order to be able to reconstruct any given sampling event at a later date and (2) record field observations and quantitative information associated with each physical sample taken. The field logbook will clearly display the title Field Logbook in addition to (1) the field logbook number (two-digit numeric), (2) the name of the sampling organization (Reclamation Engineering and Geosciences Section, Energy Systems Division, ANL), (3) the name of the project (Terrestrial and Aquatic Investigations), (4) the name of the activity (Preliminary Soil Contamination Survey), (5) the Army facility being sampled (Hohenfels Training Area, Germany), and (6) the document code (C; see Table.D.4). Each field logbook will be bound, with consecutively numbered pages.

The field logbook contains a record of the sampling team's activities. Specifically, the field logbook shall contain, on each page, (1) the signatures of the sampling team members and (2) the date. The logbook shall contain a chronological narrative of the sampling team's activities

TABLE D.1 Sample ID Number Information Codes

\begin{tabular}{|c|c|c|c|}
\hline Character(s) & Definition & $\begin{array}{c}\text { Code } \\
\text { Characteristic }\end{array}$ & Choices \\
\hline $\begin{array}{l}1,2, \text { and } 3 \\
4,5, \text { and } 6 \\
7,8 \text {, and } 9 \\
10 \\
11 \text { and } 12\end{array}$ & $\begin{array}{l}\text { Army facility } \\
\text { East grid reference } \\
\text { North grid reference } \\
\text { Sample type } \\
\text { Sequential sample number }\end{array}$ & $\begin{array}{l}\text { Alphabetic } \\
\text { Numeric } \\
\text { Numeric } \\
\text { Alphabetic } \\
\text { Numeric }\end{array}$ & $\begin{array}{l}\text { HTA only } \\
950-999 \text { or } 000-149 \\
520-689 \\
\text { S, V, R, or N } \\
00-99\end{array}$ \\
\hline
\end{tabular}


throughout the day, including times and locations of all events noted. Descriptions of any general problems encountered should be recorded, as should the names and telephone numbers of any base personnel contacted for permits, logistical support, security, and technical or other information. The general meteorological conditions at the site should be recorded throughout the day, including the wind direction and at least a qualitative description of the wind speed (e.g., calm, steady, gusty). The occurrence of any rainfall should be recorded, as should a general assessment of soil moisture.

The field logbook also contains specific information about each physical sample taken. In particular, for each sample, the field logbook should contain the following information: (1) the sample ID number; (2) for clarity, the sample location number, sequence number, and type of sample, explicitly written out; (3) the time at which the sample was taken (local time, daylight savings, or standard time being explicitly noted, expressed in 24-h clock notation); (4) any relevant field observations, including problems encountered in collecting the sample or any noteworthy characteristics of the sample, such as color or odor; (5) a description of any deviations from established sampling procedures, including the reasons for the changes; and (6) any fie: 1 equipment decontamination that was carned out, including a description of the reasons for doing it and a description of, or reference to, the method used.

At the end of each day, the Quality Assurance Coordinator shall inspect the field logbook entries for that day for accuracy and completeness and, following the inspection, shall sign and date each page checked.

Sample Labels. The purpose of the sample label is to maintain sample identity. The sample label will be completed by a sampling team member to be designated by the Field Sampling Team Leader. The label will be affixed directly to the sampling container. Table D.2 lists the minimum amount of information that will appear on each sample label.

Sample Tags. Sample tags are normally used to (1) help maintain sample identity and (2) identify any hazards associated with the sample that would require special handling procedures. For the types of samples being collected in this study, no chemical or radiological hazards are anticipated. The sample tag will be completed by someone present at the actual sample collection and will show the information given in Table D.3.

Chain-of-Custody Record. It is necessary to demonstrate that a sample is the same sample that was collected at the site and that it has not been altered since collection. A written record is kept for this purpose and unambiguously shows that the sample was in someone's "custody" every step of the way. A sample is in someone's custody if

- It is in one's actual physical possession; or

- It is in one's sight, after being in one's physical possession; or 
TABLE D.2 Sample Label Information

\begin{tabular}{ll}
\hline \multicolumn{1}{c}{ Item } & \multicolumn{1}{c}{ Description } \\
\hline Site name & $\begin{array}{l}\text { The general name of the site at which the sample was } \\
\text { collected; for example, Sampling Area No. 1. } \\
\text { The date (dd/mmm/yy) on which the sample was collected; } \\
\text { for example, 27/SEP/90. }\end{array}$ \\
Date & $\begin{array}{l}\text { The time (based on a 24-h clock) at which the sample was } \\
\text { collected; for example, 0930 or 1445. }\end{array}$ \\
Time & $\begin{array}{l}\text { None required. } \\
\text { Preservative }\end{array}$ \\
Analysis & $\begin{array}{l}\text { The analysis that will be performed by the Analytical } \\
\text { Chemistry Laboratory at ANL. Because the analyses will } \\
\text { differ somewhat from standardized USFPA analyses, the } \\
\text { word "SPECIAL" should be written }\end{array}$ \\
Sample ID number & $\begin{array}{l}\text { The ID number assigned to the sample as described in } \\
\text { Table D.1. }\end{array}$ \\
Sampler initials & \begin{tabular}{l} 
The initials of the person collecting the sample. \\
\hline
\end{tabular}
\end{tabular}

TABLE D.3 Sample Tag Information

Item Description

Sample ID number

Date

Recorded by (initials)

Remarks
The ID number of the sample.

The date (dd/mmm/yy) of collection (for example, 27/SEP/90).

The initials of the person who prepared the sample tag.

Any additional information that is distinctive for the given sample and that would be of use to the analyst. 
- It is in one's physical possession and then locked up so that no one can tamper with it; or

- It is kept in a secure area, restricted to authorized personnel only.

A chain-of-custody record for each sample collected will be initiated by the person collecting the samples. These samples will be transported back to ANL in the custody of a member of the sampling team. Custody seals will be used as appropriate. The samples will be turned directly over to Analytical Chemistry Laboratory personnel upon return to ANL, and the chain-ofcustody records appropriately completed. Because of the nature of the on-site sampling and analysis procedures, froper custody will be maintained simply by having one member of the sampling team turn the sample over to the analyst for immediate analysis. In all cases, the sample will be in the direct physical possession of authorized team members from the time of collection to the time of analysis.

Document Control. The objective of document control is to ensure that all project documents used by the sampling and analysis team are accounted for when a project is completed. Document control includes the use of (1) serialized documents, (2) a document inventory, and (3) a document filing system. The Quality Assurance Coordinator will serve as the document control coordinator, who will oversee and coordinate these items. The principal documents used by the sampling and analysis team are listed in Table D.4.

Sample Tags and Chain-of-Custody Records will have preprinted serial numbers. All issued numbers will be appropriately accounted for by the document control coordinator. Should a Sample Tag or Chain-of-Custody Record be damaged, lost, or destroyed before use, the serial number and disposition of the document must be recorded. Sample Tags and Chain-of-Custody

TABLE D.4 Documents Used by the Sampling and Analysis Team

\begin{tabular}{ll} 
Code & \multicolumn{1}{c}{ Document } \\
\hline & \\
A & Sampling and Analysis Plan \\
B & Health and Safety Plan \\
C & Field Logbooks \\
D & Sample Tags \\
E & Chain-of-Custody Forms \\
F & Correspondence \\
G & Report Notes, Calculations, otc. \\
H & Miscellaneous Photographs, Maps, Drawings, etc. \\
I & Sampling and Analysis Repurt(s) \\
&
\end{tabular}


Records that are voided must be maintained in the files. Other documents used in conducting a project (e.g., field and laboratory logbooks) must be coded with the appropriate document code shown in Table D.4.

The document control coordinator shall be responsible for keeping an inventory of all documents relating to this investigation.

Project files for each site from which samples are collected will be maintained by the principal investigator or his desigrated alternate. At a minimum, the project file will contain all of the original documents listed in Table D.4. 


\section{Appendix E: Analytical Procedures}

\section{E.1 Introduction}

This report presents the analytical results from soil and plant samples obtained at the CMTC, rishenfels, Germany. Thirty-three soil samples and twenty-seven plant samples were extracted in organic solvent by sonication. Each concentrated extract was analyzed by gas chromatography/flame ionization detection (GC/FID). See Table E.1 for a sequential list of the GC runs made and Table E. 2 for a summary of the sample preparation timetable. All extractions and analyses were performed by the Argonne Analytical Chemistry Laboratory (ACL).

In this exploratory study, the major component of interest is fog oil, a petroleum product used to create an artificial battlefield fog. The secondary component of interest is 2-chlorobenzaldehyde (or ortho-chlorobenzaldehyde, OCB), a degradation product of CS, used in training exercises. No certified method or protocol exists for the analysis of environmental samples that may contain these compounds. Analytical procedures were developed based on protocols used in methods certified by the U.S. EPA. The procedures included the extraction of a matrix spike and matrix spike duplicate to determine extraction efficiency, preparation of fog oil standards, and determination of a linear calibration curve prior to sample analysis. In addition, a fog oil standard was analyzed at the beginning and end of each analytical sequence and after every ten samples so that the percent relative standard deviation (\%RSD) and percent difference (\%D) could be established.

Because fog oil elutes from the gas chromatographic column as a broad, unresolved envelope, the entire area under the envelope was used for quantification. Samples were screened for the presence of 2-chlorobenzaldehyde; derivatization was not performed.

Complex chromatograms for both soil and plant samples required the application of ratio and subtraction techniques to the data. On the basis of the results obtained, no fog oil or 2-chlorohenzaldehyde was detected in the soil or plant samples.

The minimum quantity of fog oil detected by the instrument, on the basis of $100 \%$ extraction efficiency of a $30 \mathrm{~g}$ soil sample, is $5 \mathrm{ppm}$. The limit of quantification of fog oil, on the basis of the minimum quantity detected by the instrument and adjusted for the matrix spike and matrix spike duplicate recovery mean of $57 \%$, is $11 \mathrm{ppm}$. 
TABLE E.1 CMTC GC/FID Analyses

\begin{tabular}{|c|c|c|c|c|}
\hline $\begin{array}{c}\text { Data } \\
\text { File No. }\end{array}$ & $\begin{array}{c}\text { Sample } \\
\text { Description }\end{array}$ & $\begin{array}{l}\text { Sample ID } \\
\text { Number }\end{array}$ & $\begin{array}{c}\text { Extract } \\
\text { Color }\end{array}$ & $\begin{array}{l}\text { Percent } \\
\text { Moisture }\end{array}$ \\
\hline FDR10 & Calibration standard & - & clear & - \\
\hline FDR11 & Hexane & - & - & - \\
\hline FDR12 & Fog oil $(0.576 n g / \mu L)$ & - & clear & - \\
\hline FDR13 & Fog oil $(5.76 \mathrm{ng} / \mu \mathrm{L})$ & - & clear & - \\
\hline FDR14 & Fog oil $(11.52 n g / \mu L)$ & - & clear & - \\
\hline FDR15 & Fog oil $(28.8 n g / \mu L)$ & - & clear & 一 \\
\hline FDR16 & Fog oil $(57.6 n g / \mu L)$ & - & clear & - \\
\hline FDR17 & Fog oil $(115.2 \mathrm{ng} / \mu \mathrm{L})$ & - & clear & - \\
\hline FDR18 & Fog oil $(288 n g / \mu L)$ & - & clear & - \\
\hline FDR19 & Fog oil (576 $n g / \mu L)$ & - & clear & - \\
\hline FDR20 & Hexane & - & - & - \\
\hline FDR21 & Calibration standard & - & clear & - \\
\hline FDR22 & Hexane & - & - & - \\
\hline FDR23 & Hexaาe & 一 & - & - \\
\hline FDF 24 & Calibration standard & - & clear & - \\
\hline FDR25 & Hexane & 一 & - & - \\
\hline FDR26 & Fog oil $(115.2 \mathrm{ng} / \mu \mathrm{L})$ & - & clear & - \\
\hline FDR27 & Hexane & - & - & - \\
\hline FDR28 & $91-0206 \mathrm{Na}_{2} \mathrm{SO}_{4}$ blank (soil) & - & clear & - \\
\hline FDR29 & $91-0206 \mathrm{Na}_{2} \mathrm{SO}_{4}$ blank (soil) & - & clear & - \\
\hline FDR30 & 91-0206 NBS Soil blank & - & clear & 2.10 \\
\hline FDR31 & $90-1120 \mathrm{Na}_{2} \mathrm{SO}_{4}$ blank (soil) & - & clear & - \\
\hline FDR32 & $91.0206 \mathrm{MS}$ & - & clear & 2.05 \\
\hline FDR33 & 91-0206 MSD & - & clear & 2.10 \\
\hline FDR34 & Hexane & - & - & - \\
\hline FDR35 & 91-8014-01 Soil & HTA016616S01 & med. yell.-gr. & 24.11 \\
\hline FDR36 & $91-8014-02$ Soil & HTA016616SO2 & med. yell.-gr. & 23.31 \\
\hline FDR37 & 91.8014 .03 Soil & HTA018597SO1 & med. yell.-gr. & 23.73 \\
\hline FDR38 & $91-8014-04$ Soil & HTA019606SO1 & med. yell.-gr. & 22.75 \\
\hline FDR39 & $91-8014-05$ Soil & HTA019606SO2 & med. yell.-gr. & 21.01 \\
\hline FDR40 & Hexane & - & - & - \\
\hline FDR41 & Calibration standard & - & - & - \\
\hline FDR42 & 91-8014-06 Sull & HTA019606SO3 & med. yell.-gr. & 19.16 \\
\hline FDR43 & 91-8014-07 Soil & HTA020603RO1 & pale yell. & 18.48 \\
\hline FDR44 & 91-8014-08 Soil & HTA020608RO1 & clear & 42.78 \\
\hline FDR45 & 91-8014-09 Soil & HTA021610SO1 & deep yell.-gr. & 25.28 \\
\hline FDR46 & $91-8014-10$ Soil & HTA023604SO1 & deep yell.-gr. & 17.96 \\
\hline FDR47 & Hexane & - & - & - \\
\hline FDR48 & $91-8014-11$ Soil & HTA033606SO1 & med. yell.-gr. & 11.70 \\
\hline FDR49 & $91-8014-12$ Soil & HTA036605RO1 & deep gr. & 7.73 \\
\hline FDR50 & Hexane & - & - & - \\
\hline
\end{tabular}


TABLE E.1 (Cont.)

\begin{tabular}{|c|c|c|c|c|}
\hline $\begin{array}{l}\text { Data } \\
\text { File No. }\end{array}$ & $\begin{array}{c}\text { Sample } \\
\text { Description }\end{array}$ & $\begin{array}{c}\text { Sample ID } \\
\text { Number }\end{array}$ & $\begin{array}{c}\text { Extract } \\
\text { Color }\end{array}$ & $\begin{array}{l}\text { Percent } \\
\text { Moisture }\end{array}$ \\
\hline FDR51 & $\begin{array}{l}91-8014-13 \text { Soil } \\
\text { Hexane }\end{array}$ & HTA036605RO2 & deep gr.-yell. & $\begin{array}{l}7.39 \\
-\end{array}$ \\
\hline $\begin{array}{l}\text { FDR52 } \\
\text { FDR53 }\end{array}$ & $\begin{array}{l}\text { Uexane } \\
91-8014-14 \text { Soil }\end{array}$ & HTA037606SO 1 & med. yell. gr. & 10.12 \\
\hline $\begin{array}{l}\text { FDR53 } \\
\text { FDR54 }\end{array}$ & $\begin{array}{ll}91-8014-14 & \text { Soil } \\
91-8014-15 & \text { Soil }\end{array}$ & HTA038601SO1 & med. yell.-gr. & $\begin{array}{l}10.12 \\
16.43\end{array}$ \\
\hline $\begin{array}{l}\text { FDR54 } \\
\text { FDR55 }\end{array}$ & $\begin{array}{l}91-8014-15 \text { Soil } \\
\text { Hexane }\end{array}$ & - & - & $\begin{array}{c}16.43 \\
-\end{array}$ \\
\hline $\begin{array}{l}\text { FDR55 } \\
\text { FDR56 }\end{array}$ & Calibration standard & - & - & - \\
\hline $\begin{array}{l}\text { FDR56 } \\
\text { FDR57 }\end{array}$ & 91-8014-16 Soil & HTA043597RO1 & med. gr.-yell. & $4 \overline{3.99}$ \\
\hline $\begin{array}{l}\text { FDR57 } \\
\text { FDR58 }\end{array}$ & $91-8014-17$ Soil & HTA056593SO 1 & med. yell. & $\begin{array}{l}43.99 \\
24.61\end{array}$ \\
\hline FDR59 & $91-8014-18$ Soil & HTA056593SO2 & & 21.20 \\
\hline FDR60 & 91-8014-19 Soil & HTA056603SO 1 & deep yell.-gr. & 17.14 \\
\hline FDR61 & S1-8014-20 Soil & HTA056625RO1 & clear & 37.13 \\
\hline FDR62 & Hexane & - & - & - \\
\hline FDR63 & Hexane & - & - & - \\
\hline FDR64 & 91-8015-01 Soil & HTA059601SO1 & med. yell. & 24.55 \\
\hline FDR65 & 91-8015-02 Soil & HTA059601SO2 & deep yell.-gr. & 23.74 \\
\hline FDR66 & $91-8015-03$ Soil & HTA061596SO1 & pale yell. & 23.26 \\
\hline FDR67 & $91-8015-04$ Soil & HTA061596SO2 & very pale yell. & 20.79 \\
\hline FDR68 & $91-8015-05$ Soil & HTA062592RO1 & very pale yell. & 25.39 \\
\hline FDR69 & Hexane & - & - & - \\
\hline FDR70 & Calibration standard & - & - & - \\
\hline FDR71 & $91-8015-06$ Soil & HTA065585RO1 & pale yell. & 18.60 \\
\hline FDR72 & 91-8015-07 Soil & HTA066598SO1 & med. yell.-gr. & 14.52 \\
\hline FDR73 & 91-8015-08 Soil & HTA073624RO1 & clear & 27.71 \\
\hline FDR74 & 91-8015-09 Soil & HTA096600RO1 & pale yell. & 37.05 \\
\hline FDR75 & $91-8015-10$ Soil & HTA977673RO1 & pale yell. & 31.86 \\
\hline FRD76 & $91-8015-11$ Soil & HTA979679SO1 & med. yell. & 25.48 \\
\hline FDR77 & 91-8015-12 Soil & HTA979682SO1 & med. yell. & 31.85 \\
\hline FDR78 & $91-8015-13$ Soil & HTA987671SO1 & med. yell. & 28.98 \\
\hline FDR79 & Hexane & - & - & - \\
\hline FDR80 & Calibration standard & - & - & - \\
\hline FDR105 & Hexane & - & - & - \\
\hline FDR106 & Calibration standard & - & - & - \\
\hline FDR107 & Hexane & - & - & - \\
\hline FDR108 & Calibration standard & - & - & - \\
\hline FDR109 & Hexane & - & - & - \\
\hline FDR110 & Calibration standard & - & - & - \\
\hline FDR111 & Fog oil (115.2 $\mathrm{ng} / \mu \mathrm{L})$ & - & - & - \\
\hline FDR112 & Hexane & - & - & - \\
\hline FDR 113 & $90-1219 \mathrm{Na}_{2} \mathrm{SO}_{4}$ blank (plant) & 一 & - & - \\
\hline FDR 114 & $90-1220 \mathrm{Na}_{2} \mathrm{SO}_{4}$ blank (plant) & - & - & - \\
\hline FDR115 & Hexane & - & - & - \\
\hline FDR116 & 91-8017-01 Plant & HTA016616VO1 & very pale yell. & - \\
\hline FDP117 & $91-8017-02$ Plant & HTA018597VO1 & clear & - \\
\hline
\end{tabular}


TABLE E.1 (Cont.)

\begin{tabular}{|c|c|c|c|c|c|}
\hline $\begin{array}{l}\text { Data } \\
\text { File No. }\end{array}$ & \multicolumn{2}{|c|}{$\begin{array}{c}\text { Sample } \\
\text { Desrription }\end{array}$} & \multirow{2}{*}{$\begin{array}{c}\begin{array}{c}\text { Sample ID } \\
\text { Number }\end{array} \\
\text { HTA.019606VO1 }\end{array}$} & \multirow{2}{*}{$\begin{array}{c}\begin{array}{c}\text { Extract } \\
\text { Color }\end{array} \\
\text { clear }\end{array}$} & \multirow{2}{*}{$\begin{array}{c}\text { Percent } \\
\text { Moisture } \\
-\end{array}$} \\
\hline FDR118 & $91-8017-03$ & Plant & & & \\
\hline FDR119 & $91-8017.04$ & Plant & HTA021610VO1 & deep yell.-gr. & - \\
\hline FDR120 & Hexane & & - & - & - \\
\hline FDR121 & $91-8017-05$ & Plant & HTA021610VO2 & pale yell. & - \\
\hline FDR122 & $91-8017-06$ & Plant & HTA023604VO1 & pale yell. & - \\
\hline FDR123 & $91-8017-07$ & Plant & HTA023604VO2 & pale yell. & - \\
\hline FDR124 & $91-8017-08$ & Plant & HTA033606VO1 & deep yell. & - \\
\hline FDR125 & Hexane & & - & - & - \\
\hline FDR126 & $91-8017-09$ & Plant & HTA037606VO1 & doep yell. & - \\
\hline FDR127 & Hexane & & - & - & - \\
\hline FDR128 & $91-8017-10$ & Plant & HTA037606VO2 & deep yell. & - \\
\hline FDR129 & Hexane & & - & - & - \\
\hline FDR130 & Calibration $s$ & standard & - & - & - \\
\hline FDR131 & $91-8017-11$ & Plant & HTA038601VO1 & deep yell. & - \\
\hline FDR132 & Hexane & & - & - & - \\
\hline FDR133 & $91-8017-12$ & Plant & HTA056593VO1 & deep yell. & - \\
\hline FDR134 & Hexane & & - & - & - \\
\hline FDR135 & $91-8017 \cdot 13$ & Plant & HTA056593VO2 & deep yell. & - \\
\hline FDR136 & Hexane & & - & - & - \\
\hline FDR137 & $91-8017-14$ & Plant & HTA056593VO3 & deep yell. & - \\
\hline FDR138 & Hexane & & - & - & - \\
\hline FDR139 & $91-8017-15$ & Plant & HTA056593VO4 & deep yell. & - \\
\hline FDR140 & Hexane & & - & - & - \\
\hline FDR141 & $91-8017-16$ & Plant & HTA056601VO1 & deep yell. & - \\
\hline FDR142 & Hexane & & - & - & - \\
\hline FDR143 & $91-8017-17$ & Plant & HTA059601VO1 & deep yell. & - \\
\hline FDR144 & Hexane & & - & - & - \\
\hline FDR145 & $91-8017-18$ & Plant & HTA059601VO2 & deep yell. & - \\
\hline FDR146 & Hexane & & - & - & - \\
\hline FDR147 & $91-8017-19$ & Plant & HTA059601VO3 & deep yell. & - \\
\hline FDR148 & Hexane & & - & - & - \\
\hline FDR149 & $91-8017-20$ & Piant & HTA061596VO1 & deep yell. & - \\
\hline FDR150 & Hexane & & - & - & - \\
\hline FDA151 & Calibration & standard & - & - & - \\
\hline FDR152 & Hexane & & - & - & - \\
\hline FDR153 & Calibration : & standard & - & - & - \\
\hline FDR154 & Hexane & & - & - & - \\
\hline FDR155 & $91-8018-01$ & Plant & HTA061596VO2 & deep yell. & - \\
\hline FDR156 & Hexane & & - & - & - \\
\hline FDP157 & $91-8018-02$ & Plant & HTA066598VO1 & deэp yell. & - \\
\hline FDR158 & Hexane & & - & - & - \\
\hline FDR159 & 91.8018 .03 & Plant & HTA066598VO2 & deep yell. & 一 \\
\hline FDR160 & Hexane & & - & - & - \\
\hline $\begin{array}{l}\text { FDR161 } \\
\text { FDR162 }\end{array}$ & $\begin{array}{l}91-8018-04 \\
\text { Hexane }\end{array}$ & Piant & HTA979679VO1 & deep yell. & - \\
\hline 4162 & Hexane & & - & - & - \\
\hline
\end{tabular}


TABLE E.1 (Cont.)

\begin{tabular}{|c|c|c|c|c|}
\hline $\begin{array}{l}\text { Data } \\
\text { File No. }\end{array}$ & $\begin{array}{c}\text { Sample } \\
\text { Description }\end{array}$ & $\begin{array}{l}\text { Sample ID } \\
\text { Number }\end{array}$ & $\begin{array}{c}\text { Extract } \\
\text { Color }\end{array}$ & $\begin{array}{l}\text { Percent } \\
\text { Moisture }\end{array}$ \\
\hline FDR163 & 91.8018.05 Plant & HTA979682VO1 & deep yell. & - \\
\hline FDR164 & Haxane & - & - & - \\
\hline FDR165 & 91-8018-06 Plant & HTA979682VO2 & deep yell. & - \\
\hline FDR166 & Hexane & - & - & - \\
\hline FDR167 & 91-8018-07 Plant & HTA987671VD1 & deep yell. & - \\
\hline FDR168 & Hexane & - & - & - \\
\hline FDR169 & Calibration standard & - & - & - \\
\hline FDR170 & Calibration standard & - & - & - \\
\hline FDR171 & Hexane & - & - & - \\
\hline
\end{tabular}


TABLE E.2 Sample Handling Chronology

\begin{tabular}{|c|c|c|c|c|}
\hline \multirow[b]{2}{*}{$\begin{array}{c}\text { ACL Internal } \\
\text { Sample Number }\end{array}$} & \multirow[b]{2}{*}{$\begin{array}{l}\text { Sample } \\
\text { Number }\end{array}$} & \multicolumn{3}{|c|}{ Handling Operation Dates } \\
\hline & & Extraction & Concentration & Analysis \\
\hline $91-8014-01$ & HTA016616SO 1 & $11-27.90$ & $12.06 \cdot 90$ & $03 \cdot 12 \cdot 91$ \\
\hline $91-8014-02$ & HTA016616SO2 & $11-21.90$ & $12-06-90$ & $03-12-91$ \\
\hline 91.8014 .03 & HTA018597SO1 & $11-27-90$ & $11-29-90$ & $03-12.91$ \\
\hline $91.8014-04$ & HTA019606SO1 & $11-27-90$ & $12-06-90$ & $03-12-91$ \\
\hline $91-8014-05$ & HTA019606SO2 & $11-21-90$ & $12.06-90$ & $03-12-91$ \\
\hline $91-8014-06$ & HTA019606SO3 & $11-21-90$ & $12.06-90$ & $03-12-91$ \\
\hline $91-8014-07$ & HTA020603RO1 & $11 \cdot 21-90$ & $11-28-90$ & $03-12 \cdot 91$ \\
\hline $91-8014-08$ & HTA020608RO1 & $11-21-90$ & $11-29-90$ & $03-12 \cdot 91$ \\
\hline 91.8 & HTA021610SO1 & $11-21 \cdot 90$ & $12-06-90$ & $03-12.91$ \\
\hline $14-10$ & HTA023604501 & $11-27-90$ & $11.29-90$ & 03 \\
\hline $91-8014-11$ & HTA033606SO1 & $11.21-90$ & $11-28-90$ & 03 \\
\hline $91-8014-12$ & HTA036605RO1 & $11-27-90$ & $12 \cdot 07-90$ & $03-$ \\
\hline $91-8014-13$ & HTA036605RO2 & $11-27 \cdot 90$ & $12.07-90$ & 03 - \\
\hline $91-8014-14$ & HTA037606SO1 & $11-28-90$ & 12.07 .90 & $03-$ \\
\hline $91-8014-15$ & HTA038601SO1 & $11-27-90$ & $12-07-90$ & $03-12 \cdot 91$ \\
\hline $91-8014-16$ & HTA043597RO1 & $11-28-90$ & $12-13-90$ & 03.13 .91 \\
\hline $91-8014-17$ & HTA056593SO1 & 11.21 .90 & $11-28.90$ & $03-13-91$ \\
\hline $91-8014-18$ & HTA056593SO2 & $11-21-90$ & $12.13-90$ & $03-13-91$ \\
\hline $91-8014-19$ & HTA056603SO1 & 11.21 .90 & $11-29-90$ & $03-13-91$ \\
\hline $91-8014-20$ & HTA056625RO1 & 11.21 .90 & $11-28-90$ & $03-13-91$ \\
\hline $91-8015-01$ & HTA059601SO1 & $11-21.90$ & 12.13 .90 & $03-13-91$ \\
\hline $91-8015-02$ & HTA059601SO2 & $11-21.90$ & $11-29-90$ & $03-13-91$ \\
\hline $91-8015-03$ & HTA061596SO1 & $11-21.90$ & $11-28.90$ & $03-13-91$ \\
\hline $91-8015.04$ & HTA061596SO2 & $11.21-90$ & $12-13-90$ & $03-13-91$ \\
\hline $91-8015-05$ & HTA062592RO1 & $11-21-90$ & $11-28-90$ & $03-13-91$ \\
\hline $91-8015-06$ & HTA065585RO1 & $11-21-90$ & $12 \cdot 13-90$ & $03-13-91$ \\
\hline $91-8015-07$ & HTA066598SO1 & $11-21-90$ & 11.29 .90 & $03-13-91$ \\
\hline $91-8015-08$ & HTA073624RO1 & $11-21-90$ & $12 \cdot 13 \cdot 90$ & $03-13-91$ \\
\hline $91-8015-09$ & HTA096600RO1 & $11.27-90$ & $11 \cdot 29 \cdot 90$ & $03-13.91$ \\
\hline $91-8015-10$ & HTA977673RO1 & $11 \cdot 27 \cdot 90$ & $11-29-90$ & $03-13-91$ \\
\hline $91-8015-11$ & HTA979679SO1 & 11.27 .90 & $11-29.90$ & $03-13-91$ \\
\hline $91-8015-12$ & HTA979682SO1 & 11.21 .90 & $12 \cdot 13.90$ & $03-13-91$ \\
\hline $91-8015-13$ & HTA987671SO1 & $11-21-90$ & $11-29-90$ & $03-13-91$ \\
\hline 91.8017 .01 & HTA016616VO1 & $12-18-90$ & $01-04-91$ & $03-15-91$ \\
\hline $91-8017.02$ & HTA018597VO1 & $12-18-90$ & 01.04 .91 & $03-15-91$ \\
\hline $31-8017-03$ & HTA019606VO1 & $12-18-90$ & $01.04-91$ & $03-15-91$ \\
\hline 91.8017 .04 & HTA021610VO1 & $12 \cdot 18 \cdot 90$ & $01-04-91$ & $03-15-91$ \\
\hline 91.8047 .05 & HTA021610VO2 & $12 \cdot 18-90$ & 01.04 .91 & $03-16-91$ \\
\hline $91-8017-06$ & HTA023604VO1 & $12 \cdot 18-90$ & 01.04 .91 & $03-16-9$ \\
\hline $91-8017-07$ & HTA023604VO2 & $12-18-90$ & $01.04-91$ & 03.16 .91 \\
\hline $91-8017-08$ & HTA033606VO1 & $12-19-90$ & $01-08-91$ & $03-16-91$ \\
\hline $91-8017-09$ & HTA037606VO1 & $12.19-90$ & $01-08-91$ & $03-16-91$ \\
\hline $91-8017-10$ & HTA037606VO2 & $12 \cdot 19-90$ & $01-08.91$ & $03-16 \cdot 91$ \\
\hline $91-8017-11$ & HTA038601VO1 & $12-20-90$ & $01-08-91$ & $03-16 \cdot 91$ \\
\hline
\end{tabular}


TABLE E.2 (Cont.)

\begin{tabular}{|c|c|c|c|c|}
\hline \multirow[b]{2}{*}{$\begin{array}{c}\text { ACL Internal } \\
\text { Sample Number }\end{array}$} & \multirow[b]{2}{*}{$\begin{array}{l}\text { Sample } \\
\text { Number }\end{array}$} & \multicolumn{3}{|c|}{ Handling Operation Dates } \\
\hline & & Extraction & Concentration & Analysis \\
\hline $91-8017-12$ & HTA056593VOT & $12 \cdot 20-90$ & $01-08-91$ & $03-16-91$ \\
\hline $91-8017-13$ & HTA056593VO2 & $12 \cdot 20-90$ & $01-08-91$ & $03-16-91$ \\
\hline $91-8017-14$ & HTA056593VO2 & $01-03-91$ & $01-09-91$ & $03-16-91$ \\
\hline $91-8017-15$ & HTA056593VO4 & $01.03-91$ & $01-09-91$ & $03 \cdot 16-91$ \\
\hline $91-8017 \cdot 16$ & HTA056601VO1 & $12-21-90$ & $01.09-91$ & $03-16-91$ \\
\hline $91-8017-17$ & HTA059601VO1 & $12 \cdot 21-90$ & $01-09-91$ & $03-16-91$ \\
\hline $91-8017-18$ & HTA059601VO2 & $12-21-90$ & $01-09-91$ & $03-16 \cdot 91$ \\
\hline $91-8017-19$ & HTA059601VO3 & $12-21-90$ & $01-09-91$ & $03-16-91$ \\
\hline $91-8017-20$ & HTA061596VO1 & $12 \cdot 21 \cdot 90$ & $01-15-91$ & $03.16 \cdot 91$ \\
\hline $91-8018.01$ & HTA061596VO2 & $12-21-90$ & $01-15-91$ & $03-16-91$ \\
\hline $91-8018.02$ & HTA066598VO1 & $01.03-91$ & $01-15-91$ & $03-17-91$ \\
\hline 91.8018 .03 & HTA066598VO2 & $12 \cdot 21-90$ & $01-15-91$ & $03-17-91$ \\
\hline 91.8018 .04 & HTA979679VO1 & $01-03-91$ & $01-15-91$ & $03-17-91$ \\
\hline 91.8018 .05 & HTA979682VO1 & $01-03-91$ & $01-15-91$ & $03-17-91$ \\
\hline $91-8018-06$ & HTA979682VO2 & 01.03 .91 & $01-\ldots .9-91$ & $03-17-91$ \\
\hline $91-8018-07$ & HTA987671VO1 & $01-03-91$ & $01-23-91$ & $03-17$ \\
\hline
\end{tabular}

\section{E.2 Experimental Procedures}

\section{E.2.1 Sample Receipt}

Thirty-three soil samples and 27 plant samples were received on October 2, 1990, and stored at $4^{\circ} \mathrm{C}\left( \pm 2^{\circ} \mathrm{C}\right)$. Because the permit required by the U.S. Department of Agriculture (USDA) for the importation of foreign soil samples was delayed, the samples could not be processed further until the permit was finally obtained on November 19, 1990.

\section{E.2.2 Sample Preparation}

Sample preparation was initiated on November 20,1990. The analytical method used for the determination of fog oil in the samples was based on the U.S. EPA Contract Laboratory Program Statement of Work (SOW) No. 2/88, including Revisions $9 / 88$ and 4/89. This SOW provides techniques to identify and measure semivolatile organic compounds from soil. Both the major component of interest, fog oil, and the secondary component of interest, 2-chlorobenzaldehyde, are classified as semivolatile compounds and are amenable to analysis by 
extraction of the soil and plant samples with an organic solvent. Derivatization was not performed as part of the analysis of samples for the presence of 2-chlorobenzaldehyde.

Soil Samples. Thirty-three soil samples were prepared for analysis by means of the following procedure. A $30-\mathrm{g}$ aliquot of sample soil was placed in a 400 -mL beaker. The sample was weighed by using a Mettler PT 320 balance. The weight was :ecorded in the Semivolatile Sample Preparation logbook II. The range for soil-sample weights was from 29.550 to $30.578 \mathrm{~g}$. Approximately $30 \mathrm{~g}$ of sodium sulfate was added to the beaker of soil. The sodium sulfate had previously been extracted with hexane and acetone. An internal standard consisting of $0.1 \mathrm{mg} / \mathrm{L}$ $\mathrm{n}$-octacosane in hexane was prepared, and $1 \mathrm{~mL}$ was added to each beaker. The internal standard was not recoverable at this concentration using the described extraction procedure. The soils were extracted by adding $100 \mathrm{~mL}$ of $1: 1$ methylene chloride-acetone to each beaker. The beakers were covered with aluminum foil and stored at $4^{\circ} \mathrm{C}\left( \pm 2^{\circ} \mathrm{C}\right)$ overnight.

The soil samples were sonicated by using a Heat Systems-Ultrasonics, Inc., Model 375 sonic cell disruptor. The following procedure was used. The bottom surface of the tip of the 3/4-in. disruptor horn was placed $1 / 2$ in. below the surface of the solvent, but above the sediment layer. The unit pulsing capability is $375 \mathrm{~W}$. The output control knob setting was 10, mode switch setting was on pulse, and percent duty cycle knob setting was on $50 \%$. The sample was sonicated for $3 \mathrm{~min}$. The solvent extract was decanted and filtered through Whatman \#41 filter paper in a Buchner funnel using vacuum filtration. The procedure was repeated twice with two additional $100-\mathrm{mL}$ portions of 1:1 methylene chloride-acetone. On the final sonication, the entire sample was poured into the Buchner funnel and rinsed with 1:1 methylene chloride-acetone.

Concentration of the soil samples was performed by using the following procedure. The extract was transferred to a Kuderna-Danish (K-D) concentrator consisting of a 10 -mL concentrator tube and a 500-mL evaporating flask. The flask was immersed in a hot-water bath, and the extract was concentrated until the apparent volume was $1 \mathrm{~mL}$. The apparatus was allowed to drain and cool for $10 \mathrm{~min}$. The volume was brought to $10 \mathrm{~mL}$ with hexane, and the extract transferred to Teflon ${ }^{\mathrm{TM}}$-sealed centrifuge tubes. The extract was stored at $4^{\circ} \mathrm{C}\left( \pm 2^{\circ} \mathrm{C}\right)$ until gas chromatographic analysis was performed.

Plant Samples. Twenty-seven samples were received, each consisting of a heterogeneous mix of undefined tree, bush and plant leaves, grass, moss, and twigs. These samples were designated "plant" samples and were extracted by using the following procedure. The entire contents of the plant-sample container was placed in a $400-\mathrm{mL}$ beaker and weighed by means of a Mettler PT 320 balance. The weight was recorded in the Semivolatile Sample Preparation logbook II. The range for the plant samples was from 7.508 to $30.503 \mathrm{~g}$. The plant sample was crushed and approximately $30 \mathrm{~g}$ of sodium sulfate was added to the beaker. The sodium sulfate had previously been extracted with hexane and acetone. An internal standard consisting of $0.1 \mathrm{mg} / \mathrm{L} \mathrm{n}$-octacosane in hexane was prepared, and $1 \mathrm{~mL}$ was added to each beaker. The internal standard was not recoverable at this concentration by using this extraction procedure. The plants were extracted by adding $200 \mathrm{~mL}$ of hexane to each beaker. 
The same sonication method as described above was used for the plant samples, except that the sonication was repeated with two $200-\mathrm{mL}$ portions of hexane. The same concentration procedure described above was used for the plant samples.

\section{E.2.3 Gas Chromatograph Operating Conditions}

The samples were analyzed by using a Hewlett-Packard 5990 gas chromatograph with a flame ionization detector equipped with a $\mathrm{J} \& \mathrm{~W}$ DB5, $30 \mathrm{~m} \times 0.32-\mathrm{mm}$ ID, $0.25-\mu \mathrm{m}$ film thickness, capillary column. The autosampler system delivered a $3-\mu \mathrm{L}$ splitless injection. Injector temperature was $270^{\circ} \mathrm{C}$, and detector temperature was $290^{\circ} \mathrm{C}$. The temperature program was $100^{\circ} \mathrm{C}$ for $2 \mathrm{~min}$, then increased to $120^{\circ} \mathrm{C}$ at $5^{\circ} \mathrm{C} / \mathrm{min}$, then a final increase from $120^{\circ} \mathrm{C}$ to $320^{\circ} \mathrm{C}$ at $12^{\circ} \mathrm{C} / \mathrm{min}$, and held at $320^{\circ} \mathrm{C}$ for $10 \mathrm{~min}$. Other operating conditions were as follows:

$\begin{array}{llll}\text { Injector temperature: } & 270^{\circ} \mathrm{C} & \text { Final temperature: } & 320^{\circ} \mathrm{C} \\ \text { Detector temperature: } & 290^{\circ} \mathrm{C} & \text { Ramp rate } 2: & 12^{\circ} \mathrm{C} / \mathrm{min} \\ \text { Initial temperature: } & 100^{\circ} \mathrm{C} & \text { Final time: } & 10 \mathrm{~min} \\ \text { Initial time: } & 2 \mathrm{~min} & \text { Total run time: } & 35 \mathrm{~min}\end{array}$

Temperature at end of first ramp: $\quad 120^{\circ} \mathrm{C}$

Ramp rate 1: $\quad 5^{\circ} \mathrm{C} / \mathrm{min}$

The carrier gas was helium at a linear velocity of $19 \mathrm{~cm} / \mathrm{s}$. Hydrogen, air, and make-up gas flow were set to Hewlett-Packard specifications.

\section{E.3 Analytical Results for the Environmental Samples}

Fog oil is a complex hydrocarbon mixture that could not be chromatographically resolved with the gas chromatographic system used. Both soil and plant samples yielded complex chromatograms that required the use of two specialized data-handling techniques to evaluate for the presence of fog oil, which ciutes as an unresolved envelope (see Figure E.1 at the end of Appendix E). Many of the soil and plant chromatograms displayed poor resolution in the region of interest, and simple comparison was not definitive. Therefore, Nelson Analytical Software 2600 Series Chromatography Data System, Rev. 5.0, ratio and subtraction techniques were used for data analysis. 
The ratio technique calculates a point-by-point ratio of the sample to a solvent blank immediately preceding the sample injection. Where a solvent injection did not occur just before the sample injection, the closest preceding solvent blank injection was used. This technique may be used to cancel baseline drift and eliminate its resemblance to the fog oil elution pattern. The subtraction technique calculates point-by-point differences in two chromatograms. The sample chromatographic peaks are reduced in size as chromatograms of increasing fog oil concentrations are subtracted from it. If fog oil is not present in the sample, the baseline takes on a "bowl" effect. If tog oil is present in the sample, the eventual result will be a straight baseline. The linearity calibration standard chromatograms of increasing concentrations were subtracted in all cases where this technique was applied.

No fog oil was detected in any of the environmental samples run, even with the use of these data processing techniques. The 2-chlorobenzaldehyde elutes at a retention time of $1.87 \mathrm{~min}$ on the chromatogram. None was detected in any environmental samples.

The GC/FID chromatograms for all soil and sediment samples and for a representative set of vegetation samples are shown in Figures E.2-E.42, which appear at the end of Appendix E.

\section{E.4 Quality Assurance/Quality Control}

\section{E.4.1 Matrix Spike and Matrix Splke Duplicate}

Calculations and Results. A soil matrix spike (MS) sample and a soil matrix spike duplicate (MSD) sample were extracted to determine the efficiency of the extraction technique. The recovery $\mathrm{R}(\mathrm{MS}, \mathrm{MSD})$ was calculated by using Equation E.1:

$$
\mathrm{R}(\mathrm{MS}, \mathrm{MSD})(\mu \mathrm{g} / \mathrm{g})=\frac{[\mathrm{A}(\mathrm{MS}, \mathrm{MSD})](\mathrm{Is})(\mathrm{Vt})}{(\mathrm{Astd})(\mathrm{Vi})(\mathrm{Ws})(\mathrm{M})}
$$

where

$\mathrm{A}(\mathrm{MS}, \mathrm{MSD})=$ peak area count for the matrix spike or matrix spike duplicate,

$$
\begin{aligned}
\text { Astd } & =\text { standard peak area count, } \\
\text { Is } & =\text { amount of standard injected }(\mu \mathrm{g}), \\
\mathrm{Vi} & =\text { volume of extract injected }(\mu \mathrm{L}),
\end{aligned}
$$




$$
\begin{aligned}
V t & =\text { volume of total extract }(\mu \mathrm{L}) \\
W s & =\text { weight of sample extracted }(g), \text { and } \\
M & =(100-\text { percent moisture }) / 100
\end{aligned}
$$

The percent recovery (\%R) was calculated using Equation E.2:

$$
\% \mathrm{R}=[\mathrm{R}(\mathrm{MS}, \mathrm{MSD}) / \mathrm{R}(\mathrm{MSS})] \times 100 \%
$$

where

$$
\begin{aligned}
\mathrm{R}(\mathrm{MS}, \mathrm{MSD})= & \text { recovery }(\mu \mathrm{g} / \mathrm{g}) \text { calculated from Equation } \mathrm{E} .1 \text { for the matrix spike } \\
& \text { or matrix spike duplicate and } \\
\mathrm{R}(\mathrm{MSS})= & 98.72 \mu \mathrm{g} / \mathrm{g}=\text { recovery based on the addition of } 1 \mathrm{~mL} \text { of matrix } \\
& \begin{array}{l}
\text { spike solution }(2.97 \mathrm{mg} / \mathrm{mL}) \text { to the } \mathrm{MS} \text { and } \mathrm{MSD} 30-\mathrm{g} \text { soil } \\
\text { samples. }
\end{array}
\end{aligned}
$$

Percent recoveries were found to be $59 \%$ for the matrix spike and 55\% for the matrix spike duplicate. The acceptable percent recoveries for the MS and MSD by means of the EPA method are between $31 \%$ and $137 \%$, on the basis of the nonpolar hydrocarbon acenapthene.

The relative percent difference (\%RPD) was 9\%, as calculated by using Equation E.3:

$$
\% \mathrm{RPD}=\frac{(\mathrm{S} 1-\mathrm{S} 2)}{(\mathrm{S} 1+\mathrm{S} 2) / 2} \times 100 \%
$$

where

$$
\begin{aligned}
& S 1=\text { MS recovery }(\mu \mathrm{g} / \mathrm{g}) \text { and } \\
& \text { S2 }=\text { MSD recovery }(\mu \mathrm{g} / \mathrm{g}) \text {. }
\end{aligned}
$$

The acceptable EPA maximum value of \%RPD for MS and MSD is 19\%, again on the basis of acenapthene.

The experimental accuracy and precision of the MS and MSD data by using the autosampler splitless injection technique is presented in Table E.3. The percent relative standard deviation 
(\%RSD) for the MS and MSD ranges from 1 to $6 \%$. The acceptable EPA-method value for the initial \% RSD is any value less than $30 \%$.

MS and MSD Sample Preparation. Matrix spike and matrix spike duplicate samples were prepared on February 6, 1991, in accordance with a National Bureau of Standards (NBS) soil standard. The MS and MSD samples consisted of soil that had been spiked with a known quantity of fog oil. The samples were subjected on February 6,1991, to the entire analytical procedure in order to determine the matrix effect upon the analytical methodology by measuring the recovery of fog oil. The MSD result also indicates the precision of the analytical method.

Two 30-g standard soil samples (U.S. Army THAMA SARM Repository USATHAMA Standard Soil Lot \# DAA05-81-M-A284) were weighed in two separate 4())-mL beakers by using a Mettler H31 analytical balance. Thirty grams of sodium sulfate that had previously been extracted with hexane and acetone was added to each beaker of soil. A $1-\mathrm{mL}$ aliquot of fog oil matrix spiking solution $(2.97 \mathrm{mg} / \mathrm{mL})$ was delivered by volumetric pipette to each beaker of soil/sodium sulfate. A volume of $100 \mathrm{~mL}$ of $1: 1$ methylene chloride-acetone was added to each beaker.

The MS and MSD samples were sonicated and concentrated by using the same methods as those described for the soil samples.

Contamination Peak. The matrix spike chromatogram contained a peak at 19.64 min that was not noted in the matrix spike duplicate or the soil blank. The peak area of 7,575,370 counts at $19.64 \mathrm{~min}$ was subtracted from the total peak area of $24,135,380$ counts of the matrix spike chromatogram. The resulting area of $16,560,000$ counts was used to calculate the $59 \%$ recovery (Equation E.1). The peak was also detected in the method/reagent blanks discussed in Section E.4.2.

TABLE E.3 Matrix Spike and Matrix Spike Duplicate Comparison

\begin{tabular}{|c|c|c|c|c|c|}
\hline \multirow{2}{*}{$\begin{array}{l}\text { Retention } \\
\text { Time (min) }\end{array}$} & \multicolumn{2}{|c|}{ Sample Areas } & \multirow[b]{2}{*}{ Mean } & \multirow{2}{*}{$\begin{array}{l}\text { Deviation } \\
\text { from Mean }\end{array}$} & \multirow{2}{*}{$\begin{array}{c}\text { Relative } \\
\text { Standard } \\
\text { Deviation } \\
(\%)\end{array}$} \\
\hline & $\# 1$ & $\# 2$ & & & \\
\hline 6.335 & 5113 & 5010 & 5061 & 73 & 2 \\
\hline 7.275 & 20311 & 20048 & 20179 & 186 & 1 \\
\hline 19.635 & 16560000 & 15181223 & 15870600 & 974943 & 6 \\
\hline
\end{tabular}




\section{E.4.2 Laboratory Blanks}

Soil Blank. Preparation of the standard soil blank was performed on February 6, 1991, by using the NBS soil standard described above. The soil blank contained an aliquot of standard soil plus all other reagents and solvents used in the sample preparation method. Analysis of the soil blank provided data for assessing the level of background generated by the soil matrix. Soil blank sample preparation, sonication, and concentration was performed by using the same procedures as for the soil samples.

Method/Reagent Blanks. Preparation of the method/reagent blanks was performed at the time of sample extraction on November 20 and December 19-20, 1990, and February 6, 1991. The blanks contained all reagents and solvents used in the sample preparation method to assess the level of background generated from this portion of the analytical procedure. Chromatographic peaks were noted at retention times of $14.01,18.55$ and $19.59 \mathrm{~min}$.

Method/reagent blank preparation, sonication, and concentration were performed by using the same procedures as for the soil samples, except that a $60 \mathrm{~g}$ aliquot of sodium sulfate was used.

\section{E.4.3 Standards}

Linearity and Calibration Factors. A series of eight fog oil standards was prepared at concentrations of $0.576,5.76,11.52,28.8,57.6,115.2,288$, and $576 \mathrm{ng} / \mu \mathrm{L}$. The standards were analyzed by means of GC, and the peak area response for each concentration was compared with the amount of standard injected, as shown in Table E.4. The resulting calibration factors were plotted, and a detector response range was determined. The $11.52 \mathrm{ng} / \mu \mathrm{L}$ standard was the minimum detected. Fog oil is a complex hydrocarbon mixture that cannot be chromatographically resolved and that elutes as an unresolved envelope. The entire envelope was integrated as a single peak. A typical chromatogram is shown in Figure E.1.

Calibration Standards. A calibration standard was prepared containing 2-chlorobenzaldehyde $(57.36 \mathrm{ng} / \mu \mathrm{L})$ and fog oil $(115.2 \mathrm{ng} / \mu \mathrm{L})$, as well as the internal standards, n-entadecane $(31.2 \mathrm{ng} / \mu \mathrm{L})$ and $\mathrm{n}$-triacontane $(33.8 \mathrm{ng} / \mu \mathrm{L})$. The retention times for the standard components are listed in Table E.5.

The standard was analyzed at the beginning, after every 10 samples, and at the end of every analysis sequence. In addition, five standards containing only fog oil $(115.2 \mathrm{ng} / \mu \mathrm{L})$ were analyzed. The results are presented in Table E.6. 
TABLE E.4 Linearity Calibration Factors

\begin{tabular}{crcc}
\hline $\begin{array}{c}\text { Concentration } \\
\text { (ng/uL) }\end{array}$ & $\begin{array}{c}\text { Peak Area } \\
\left(10^{3} \text { units) }\right.\end{array}$ & $\begin{array}{c}\text { Amount } \\
\text { Injected (ng) }\end{array}$ & $\begin{array}{c}\text { Calibration Factor } \\
\left(10^{3} \text { units/ng) }\right.\end{array}$ \\
\hline & & & \\
0.576 & 0 & 1.728 & 0 \\
5.76 & 0 & 17.28 & 0 \\
11.52 & 730 & 34.56 & 21.1 \\
28.8 & 2,079 & 86.4 & 24.0 \\
57.6 & 4,686 & 172.8 & 27.1 \\
115.2 & 10,342 & 345.6 & 29.9 \\
288 & 28,218 & 864 & 32.6 \\
576 & 61,005 & 1728 & 35.3 \\
\hline
\end{tabular}

a Area is measured in arbitrary units.

TABLE E.5 Calibration Standard Retention Times

\begin{tabular}{lcc}
\hline \multicolumn{1}{c}{ Substance } & $\begin{array}{c}\text { Concentration } \\
(\mathrm{ng} / \mu \mathrm{L})\end{array}$ & $\begin{array}{c}\text { Retention Time } \\
(\mathrm{min})\end{array}$ \\
\hline Fog oil & 115.2 & $\begin{array}{c}16.25 \text { at maximum, } \\
\text { range }=10-24 \mathrm{~min}\end{array}$ \\
n-Triacontane & 33.8 & 22.37 \\
n-Pentadecane & 31.2 & 7.1 \\
2-chlorobenzaldehyde & 57.4 & 1.87 \\
\hline
\end{tabular}

Soil Calibration Standard Comparison. The fog oil peak areas of the calibration standards analyzed during the soil-sample sequence were evaluated for method precision. Calibration factors, the standard deviation of the remaining soil standards on the basis of the mean of the initial three calibration factors, and the percent relative standard deviation were calculated. Standard comparison for soil samples showed a percent difference $(\% D)$ ranging from 7 to $21 \%$. The acceptable EPA method value for \%D is $25 \%$.

The fog oil calibration factors $\left(\mathrm{CF}_{\mathrm{i}}\right)$ for the three initial standards analyzed during the soil sample sequence (FDR10, FDR 17, and FDR21) were calculated by using Equation E.4:

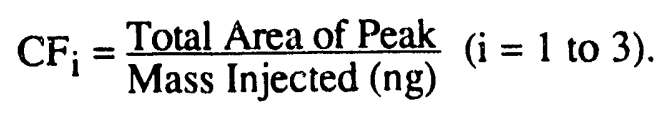


TABLE E.6 Calibration Standard Runs

\begin{tabular}{|c|c|c|}
\hline File Number & $\begin{array}{l}\text { Fog Oil } \\
\text { Peak Area } \\
\left(10^{5} \text { units }\right)\end{array}$ & $\begin{array}{c}\text { 2-chlorobenzaldehyde } \\
\text { Peak Area } \\
\text { (106 units) }\end{array}$ \\
\hline
\end{tabular}

Soil Sequence:

$\begin{array}{lrl}\text { FDR10 } & 13.3 & 1.5 \\ \text { FDR17 } & 10.8 & \mathrm{a} \\ \text { FDR21 } & 13.6 & 1.5 \\ \text { FDR24 } & 13.5 & 1.5 \\ \text { FDR26 } & 10.7 & \mathrm{a} \\ \text { FDR41 } & 14.4 & 1.5 \\ \text { FDR56 } & 13.9 & 1.5 \\ \text { FDR70 } & 10.6 & 1.3 \\ \text { FDR80 } & 9.9 & 1.5 \\ \text { FDR83 } & 9.9 & \mathrm{a} \\ \text { FDR84 } & 10.6 & \mathrm{a} \\ \text { FDR86 } & 10.7 & \mathrm{a}\end{array}$

Plant Sequence:

$\begin{array}{lll}\text { FDR106 } & 6.7 & 1.2 \\ \text { FDR108 } & 7.9 & 1.2 \\ \text { FDR110 } & 9.4 & 1.4 \\ \text { FDR111 } & 7.3 & \mathrm{a} \\ \text { FDR130 } & 7.0 & 1.2 \\ \text { FDR151 } & 7.0 & 1.2 \\ \text { FDR153 } & 7.1 & 1.2 \\ \text { FDR169 } & 7.2 & 1.2 \\ \text { FDR170 } & 7.2 & 1.2\end{array}$

a Standard did not contain 2-chlorobenzaldehyde 
The mean $\left(\mathrm{M}_{\mathrm{CF}}\right)$ and standard deviation $\left(\mathrm{SD}_{\mathrm{CF}}\right)$ of the three initial fog oil soil calibration factors were calculated by using Equations E.5 and E.6:

$$
\begin{aligned}
& \mathrm{M}_{\mathrm{CF}}=(1 / 3) \sum_{\mathrm{i}=1}^{3} \mathrm{CF} \text { and } \\
& {\left[\mathrm{SD}_{\mathrm{CF}}\right]^{2}=(1 / 2) \sum_{\mathrm{i}=1}^{3}\left[\mathrm{CF}_{\mathrm{i}}-\mathrm{M}_{\mathrm{CF}}\right]^{2}}
\end{aligned}
$$

The mean and standard deviation calculated in this way are

$$
\begin{aligned}
& \left.\mathrm{M}_{\mathrm{CF}}=36\left(10^{3} \text { area units/[ng/ } / \mathrm{LL}\right]\right) \text { and } \\
& \mathrm{SD}_{\mathrm{CF}}=4.4\left(10^{3} \text { area units/[ng/ } / \mathrm{L} \mid\right) \text {. }
\end{aligned}
$$

The percent relative standard deviation (\%RSD) of the three initial soil calibration factors was calculated as the value $\mathrm{SD}_{\mathrm{CF}} / \mathrm{M}_{\mathrm{CF}} \times 100 \%$ and has a value of $12 \%$. The acceptable EPA value is less than $30 \%$. The result describes the precision of the analytical results.

The calibration factors for each of the continuing standards $\left(\mathrm{CF}_{\mathrm{c}}\right)$ analyzed during the soil sequence were calculated as $\mathrm{CF}_{\mathrm{c}}=$ total area of peak/mass injected (ng), and the soil mean, $\mathrm{M}_{\mathrm{CF}}$, was used in calculating the percentage difference $(\% \mathrm{D})$ for the remaining soil standards:

$$
\% \mathrm{D}=\left[\left(\mathrm{M}_{\mathrm{CF}}-\mathrm{CFc}\right) / \mathrm{M}_{\mathrm{CF}}\right] \times 100 \%
$$

In each run, the mass of fog oil injected is $345.6 \mathrm{ng}$, on the basis of the injection of $3 \mu \mathrm{L}$ of a $115.2 \mathrm{ng} / \mu \mathrm{L}$ solution. The results are presented in Table E. 7 and range from 7 to $21 \%$. The acceptable EPA method value is less than $25 \%$.

Plant Calibration Standard Comparison. The fog oil peak areas of the calibration standards analyzed during the plant sample sequence were evaluated for method precision by using the same procedure as described above for the soil standards. Comparison of the plant calibration standards by using the plant mean reveals a percent difference range of $8-10 \%$. The acceptable EPA method value for $\% \mathrm{D}$ is less than $25 \%$.

The mean $\left(\mathrm{M}_{\mathrm{CF}}\right.$ ), the corresponding standard deviation (SD), and the percent relative deviation (\%RSD) of the four initial plant calibration factors were calculated as described above, and the values are $23\left(10^{3}\right.$ area units/[ng/ $\left.\left./ \mathrm{LL}\right]\right), 3.3\left(10^{3}\right.$ area units/[ng/ $\left.\left./ \mu \mathrm{L}\right]\right)$, and $15 \%$, respectively. The acceptable EPA method value for the percent relative deviation is less than $30 \%$. 
TABLE E.7 Percentage Differences in Soil Analysis

Sequence Calibration Factors

\begin{tabular}{lccc}
\hline $\begin{array}{c}\text { File } \\
\text { Number }\end{array}$ & $\begin{array}{c}\text { Fog Oil } \\
\text { Peak Area } \\
\left(10^{6} \text { units }\right)\end{array}$ & $\begin{array}{c}\text { CFc } \\
\left(10^{4} \text { units/ng }\right)\end{array}$ & $\begin{array}{c}\text { Percentage } \\
\text { Difference } \\
(\%)\end{array}$ \\
\hline & & & \\
FDR24 & 13.5 & 3.9 & 7 \\
FDR26 & 10.7 & 3.1 & 15 \\
FDR41 & 14.4 & 4.2 & 15 \\
FDR56 & 13.9 & 4.0 & 11 \\
FDR70 & 10.6 & 3.1 & 16 \\
FDR80 & 9.9 & 2.9 & 21 \\
FDR83 & 9.9 & 2.9 & 21 \\
FDR84 & 10.6 & 3.1 & 15 \\
FDR86 & 10.7 & 3.1 & 15 \\
\end{tabular}

The calibration factors for each of the continuing standards (CFc) analyzed during the plant analysis sequence and the percent difference $(\% \mathrm{D})$ for the remaining plant standards were calculated. The percentage deviation values range from 8 to $10 \%$; EPA acceptable values are less than $25 \%$.

\section{E.4.4 Limit of Detection}

Fog Oil. The minimum quantity detected (MQD) in soil by the instrument on the basis of $100 \%$ extraction efficiency is $5 \mathrm{ppm}$. This value represents a comparison of the fog oil peak area at first detector response to the least area response of the calibration standards, the volume and amount of fog oil injected, the soil sample aliquot weight and final extract volume, and an adjustment factor for the soil percent moisture as shown in Equation E.8:

$$
\operatorname{MQDs}(\mu \mathrm{g} / \mathrm{g})=\frac{(\mathrm{Ax})(\mathrm{Is})(\mathrm{Vt})}{(\mathrm{As})(\mathrm{Vi})(\mathrm{Ws})(\mathrm{M})}
$$

where

$$
\begin{aligned}
& \text { Ax }=\text { peak area count first detector response, } \\
& \text { As = peak area count least area response, } \\
& \text { Is }=\text { amount of standard injected }(\mu \mathrm{g}),
\end{aligned}
$$




$$
\begin{aligned}
V i & =\text { volume of extract injected }(\mu \mathrm{L}), \\
V t & =\text { volume of total extract }(\mu \mathrm{L}), \\
W s & =\text { weight of sample extracted }(g), \text { and } \\
M & =(100-\text { percent moisture }) / 100 .
\end{aligned}
$$

The fog oil peak area of 730,204 counts for standard FDR $14(11.52 \mathrm{ng} / \mu \mathrm{L})$ represents the value at first detector response. This value is compared with the fog oil peak area of $6,707,900$ counts for standard FDR $106(115.2 \mathrm{ng} / \mu \mathrm{L})$ representing the least standard fog oil area count. The injection volume was $3 \mu \mathrm{L}$, and the amount injected was $0.345 \mu \mathrm{g}$. A $30 \mathrm{~g}$ soil aliquot was extracted, and the final extract volume was $10 \mathrm{~mL}$. The percent moisture factor was 0.7667 based on $23.33 \%$ average moisture for all soil samples.

2-chlorobenzaldehyde. The minimum concentration detectable in soil, on the basis of $100 \%$ extraction efficiency of a $30 \mathrm{~g}$ soil sample, is $19 \mathrm{ppm}$. This value represents a comparison of the 2-chlorobenzaldehyde peak area of the first calibration standard to the least area response of the calibration standards and included the additional soil extraction factors described in Equation E.8. The samples were screened for the presence of 2-chlorobenzaldehyde, and therefore, no calibration curve or derivation was performed. The 2-chlorobenzaldehyde peak area of $1,546,071$ counts for standard FDR $10(57.36 \mathrm{ng} / \mu \mathrm{L})$ represents the value for the first calibration standard area and is used for the value of $\mathrm{Ax}$ in Equation E.8. This value is compared with the peak area of 1,160,534 counts for standard FDR $153(57.36 \mathrm{ng} / \mu \mathrm{L})$ representing the least standard 2-chlorobenzaldehyde area count. The injection volume was $3 \mu \mathrm{L}$, and the amount injected was $0.172 \mu \mathrm{g}$. A $30-\mathrm{g}$ soil aliquot was extracted, and the final extract volume was $10 \mathrm{~mL}$. The percent moisture factor, $\mathrm{M}$, was 0.7667 on the basis of $23.33 \%$ average moisture for all soil samples.

Fog Oil Limit of Quantification ( $L O Q)$. The fog oil limit of quantification is $11 \mathrm{ppm}$ on the basis of the MS and MSD recovery mean of $57 \%$. This value reflects the minimum quantity detected by the instrument divided by a factor reflecting the fog oil extraction efficiency mean of 57\%. Equation E.9 illustrates the calculation:

$$
\text { LOQ }(\mu \mathrm{g} / \mathrm{g})=\mathrm{MQD} / \mathrm{EEF} \text {, }
$$

where

$$
\text { MQDs = minimum quantity detected for soil and }
$$

$$
\mathrm{EEF}=\text { mean percentage extraction efficiency/100. }
$$




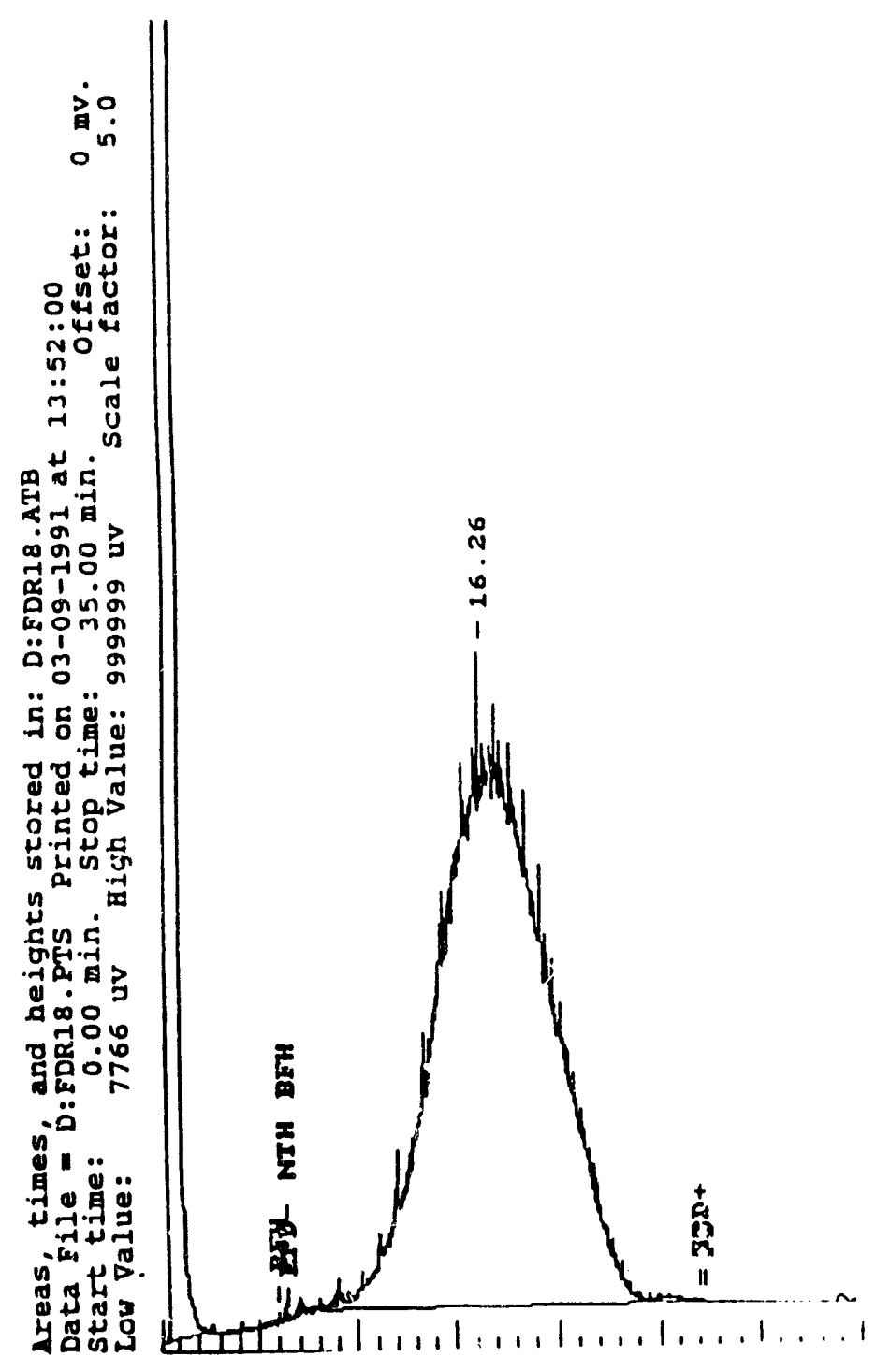

FIGURE E.1 GC/FID Chromatogram of Fog Oil in Hexane 


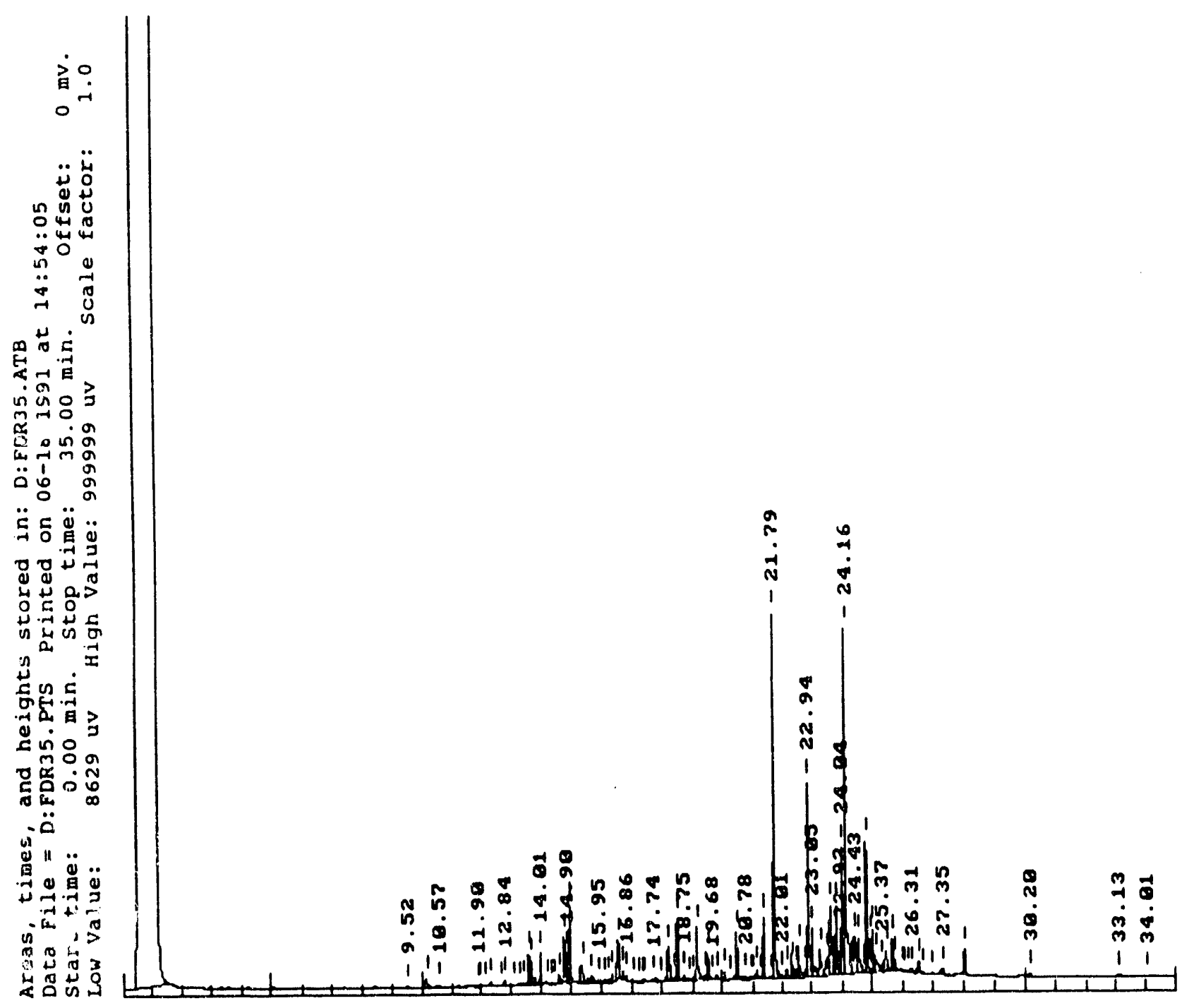

FIGURE E.2 GC/FID Chrcmatogram of Sample HTA016616S01 


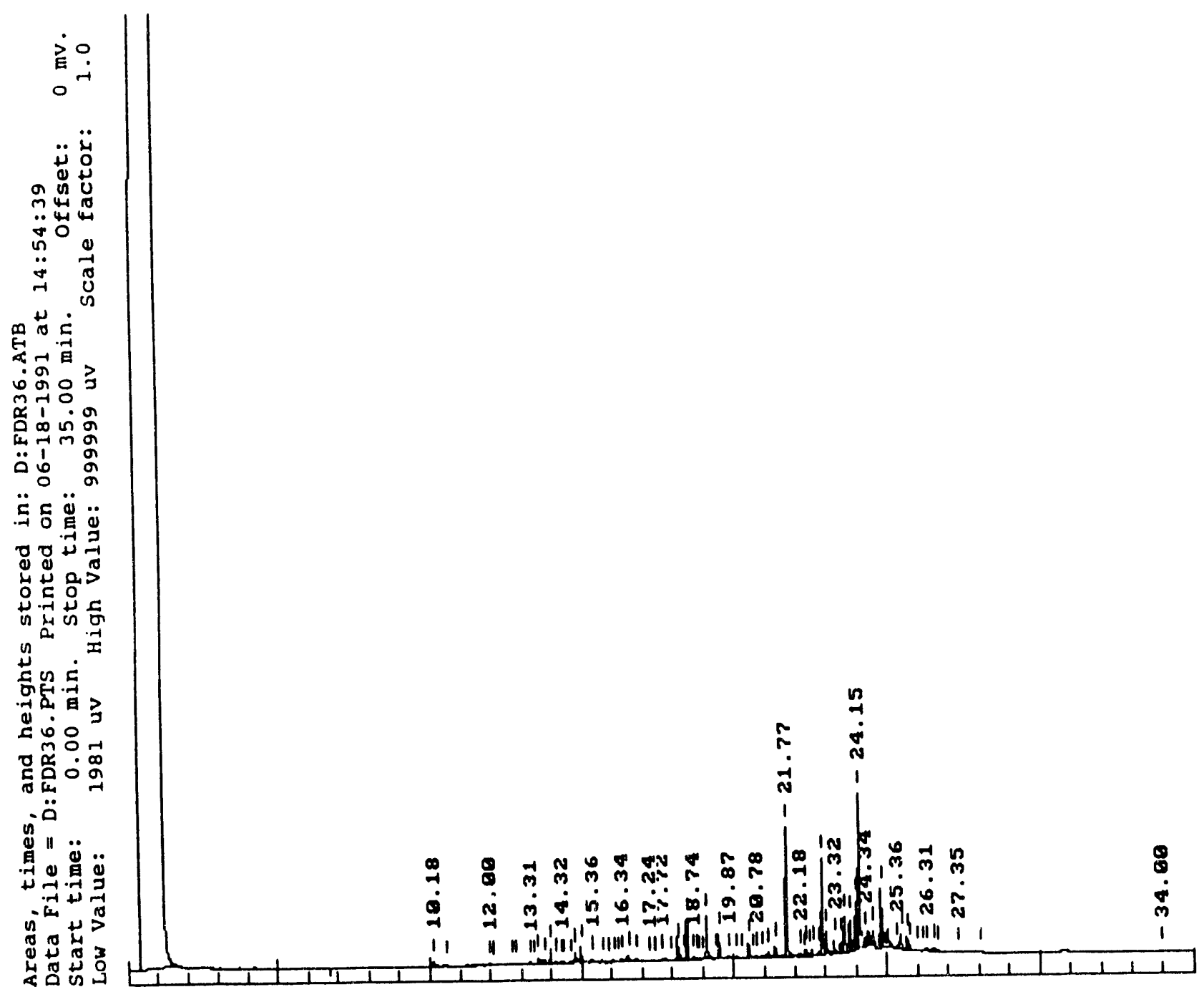

FIGURE E.3 GC/FID Chromatogram of Sample HTA016616S02 


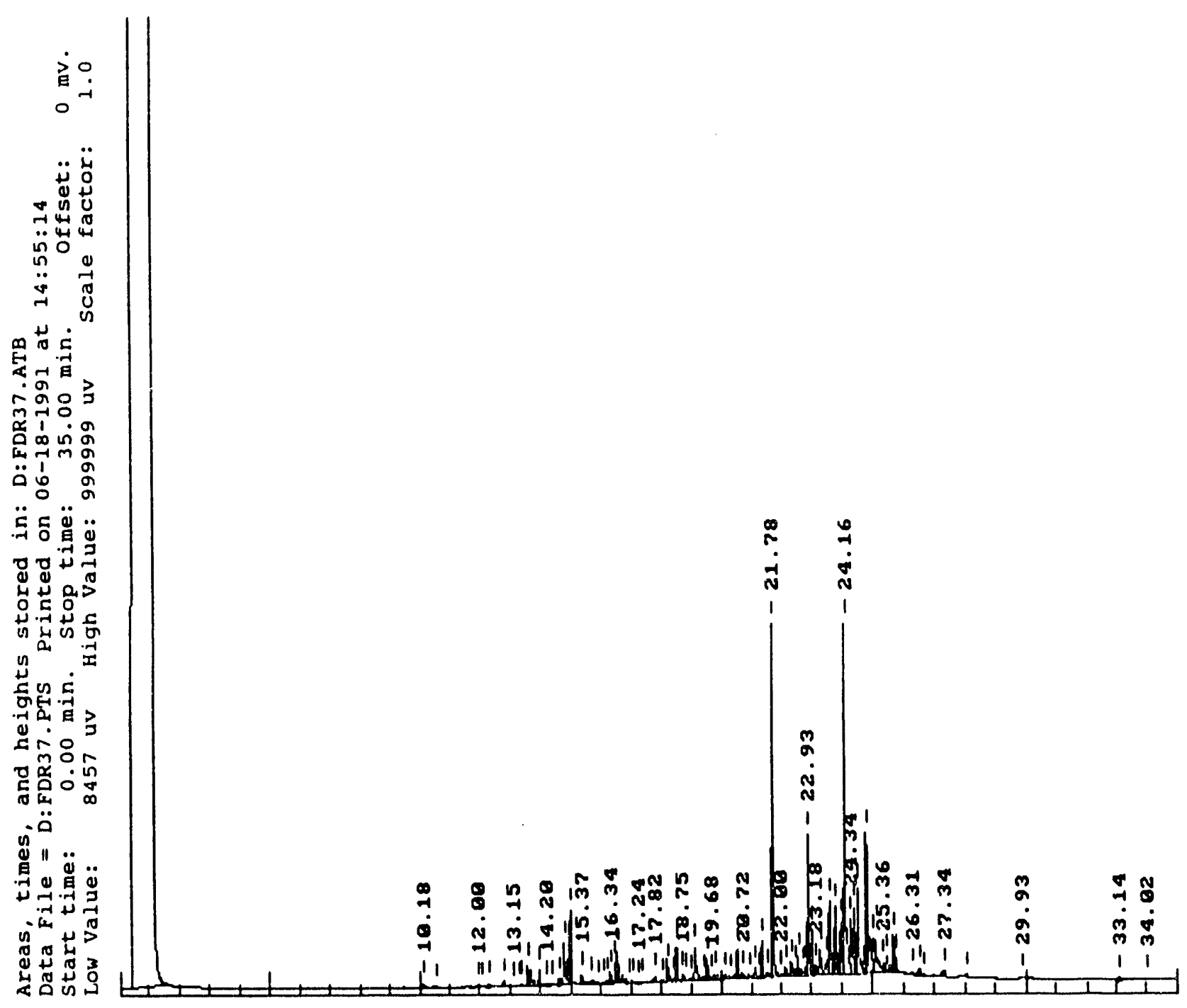

FIGURE E.4 GC/FID Chromatogram of Sample HTA018597S01 


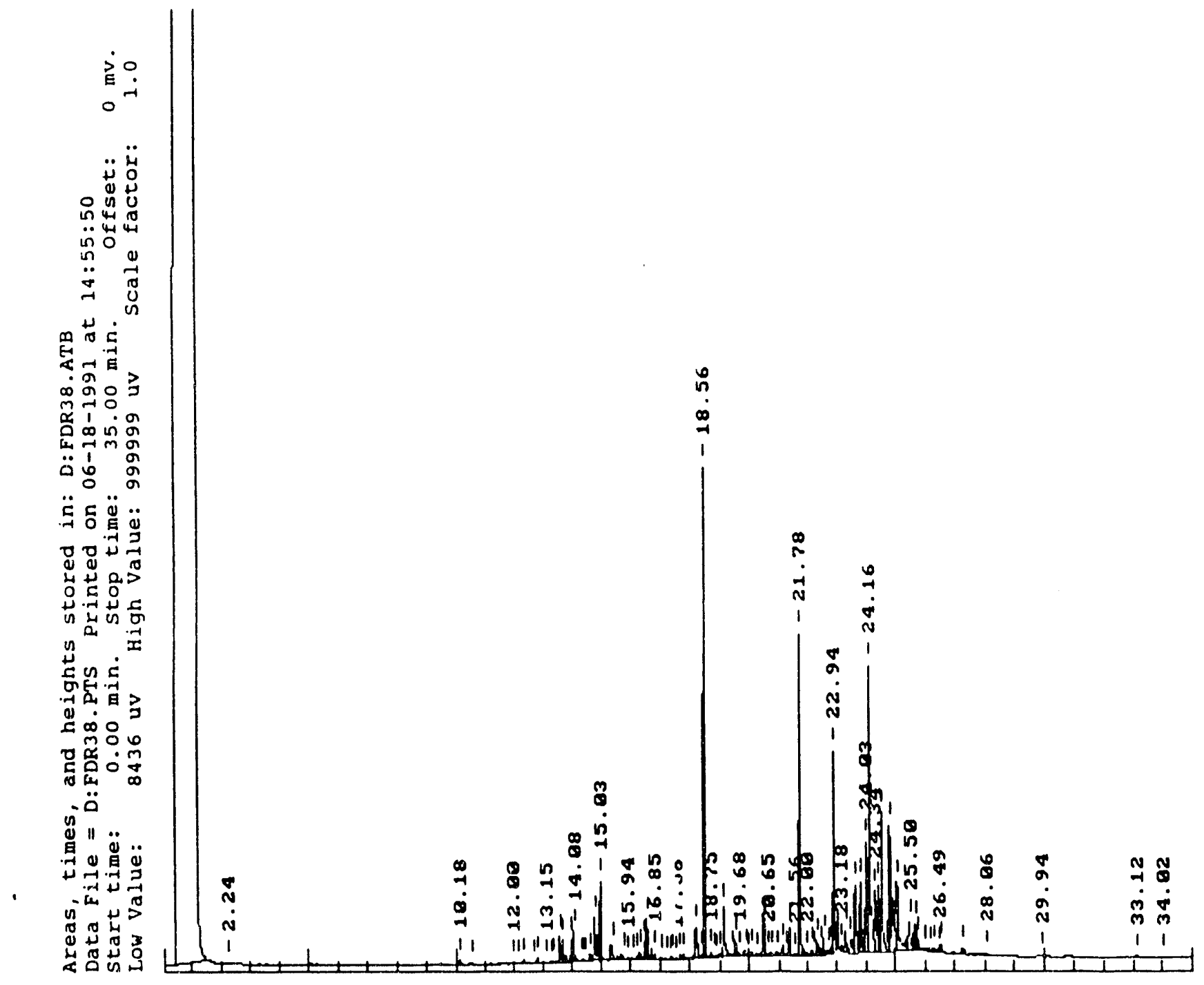

FIGURE E.5 GC/FID Chromatogram of Sample HTA019606S01 


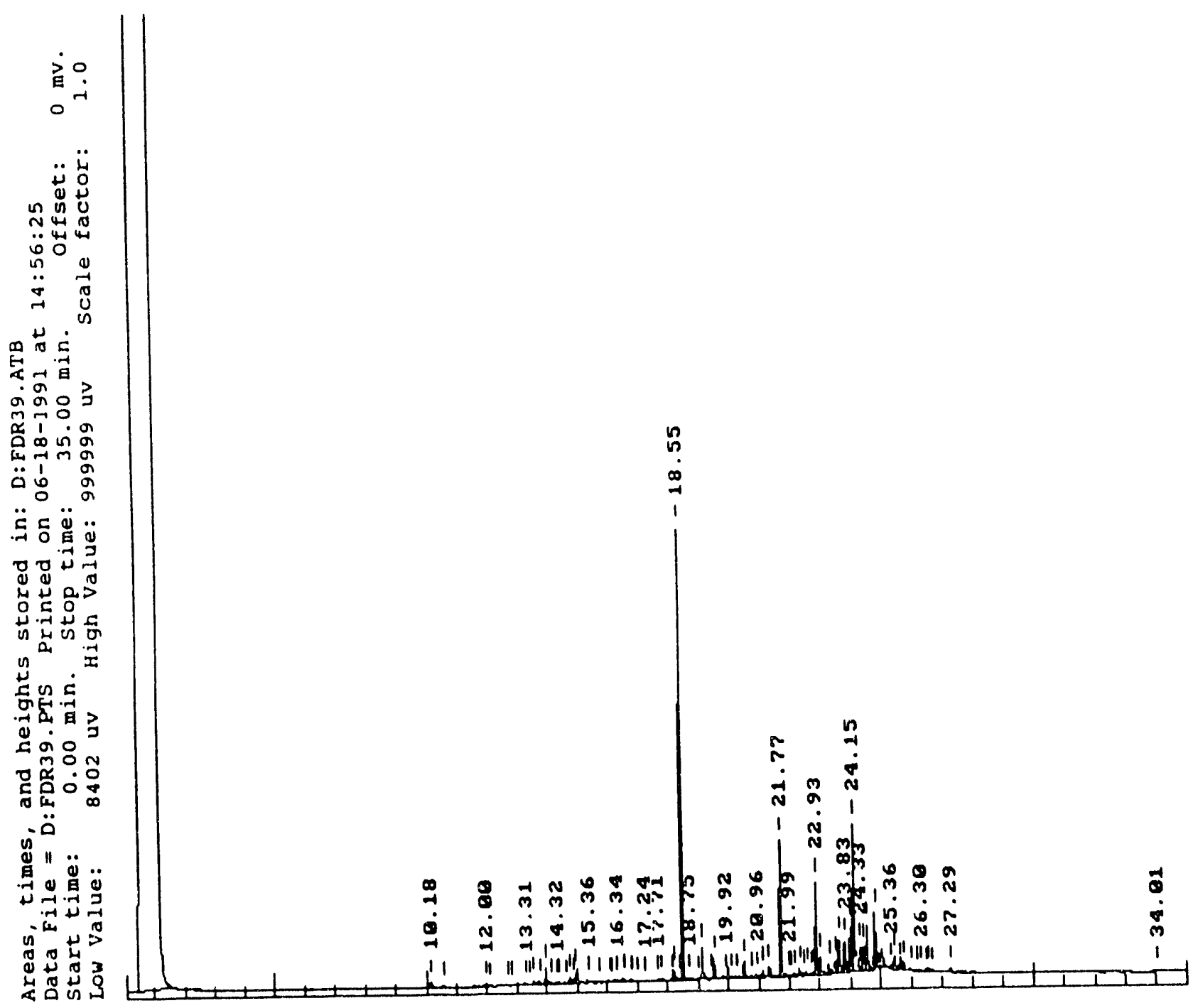

FIGURE E.6 GC/FID Chromatogram of Sample HTA019606S02. 


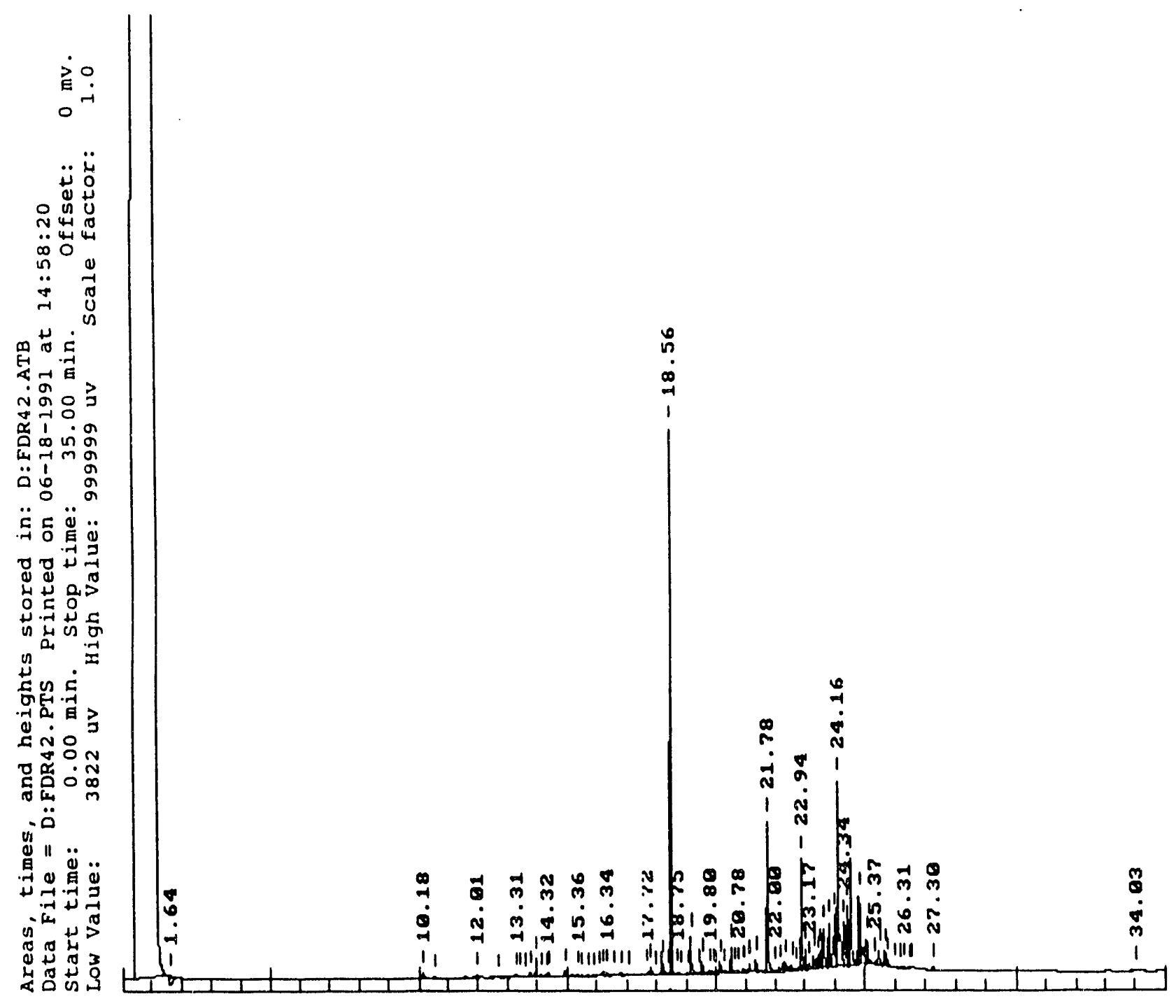

FIGURE E.7 GC/FID Chromatogram of Sample HTA019606S03 


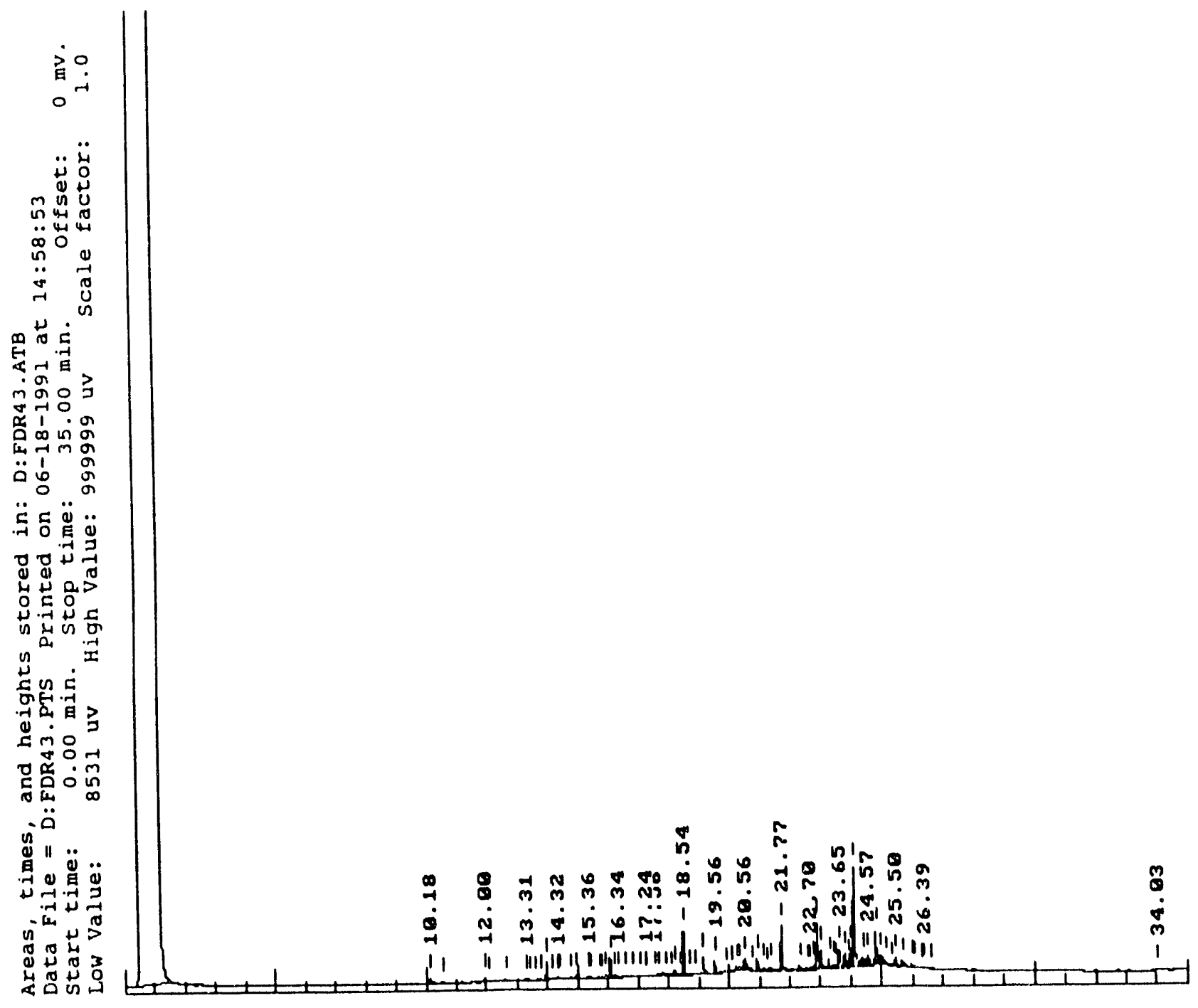

FIGURE E.8 GC/FID Chromatogram of Sample HTA020603R01 


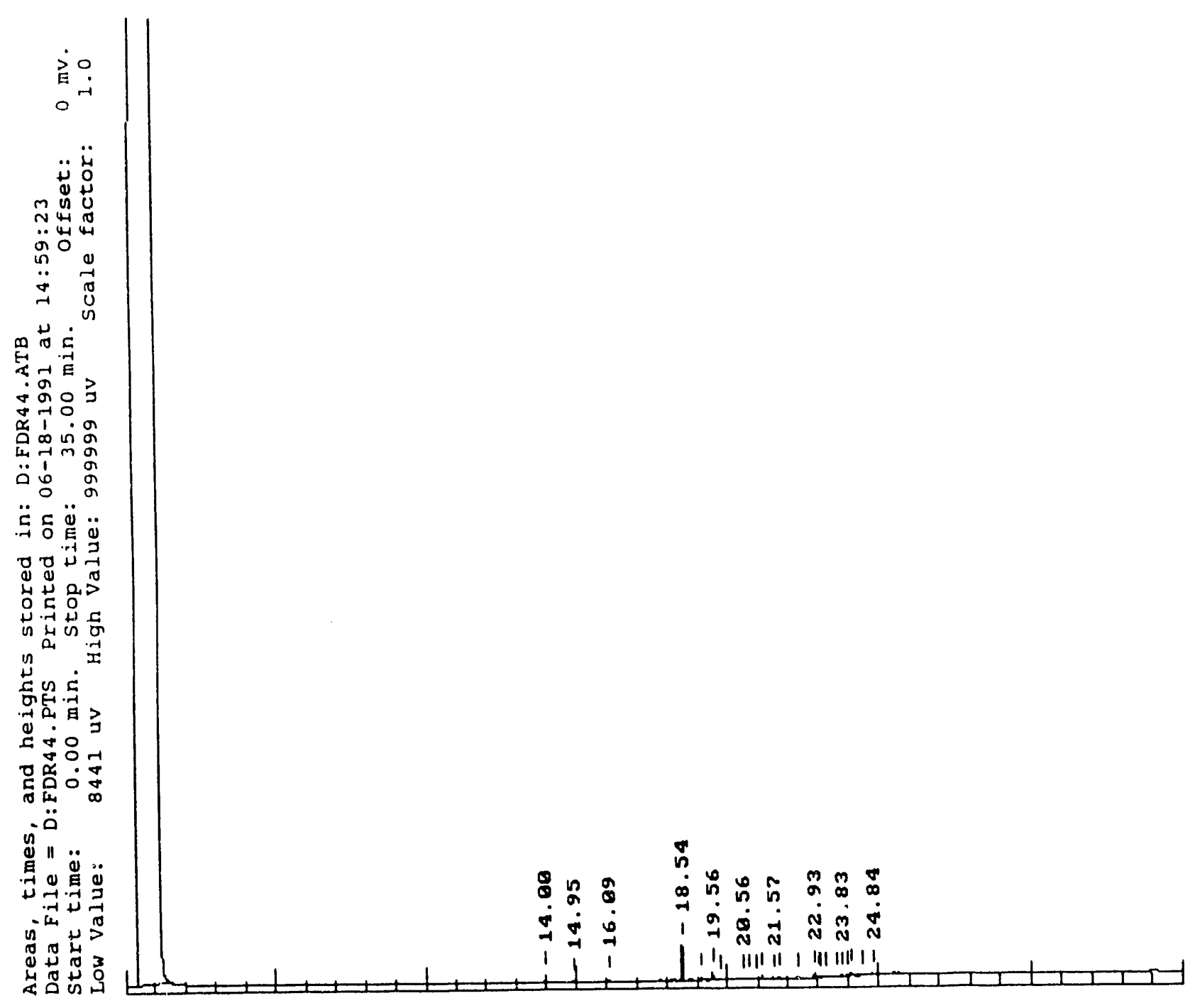

FIGURE E.9 GC/FID Chromatogram of Sample HTA.020608R01 


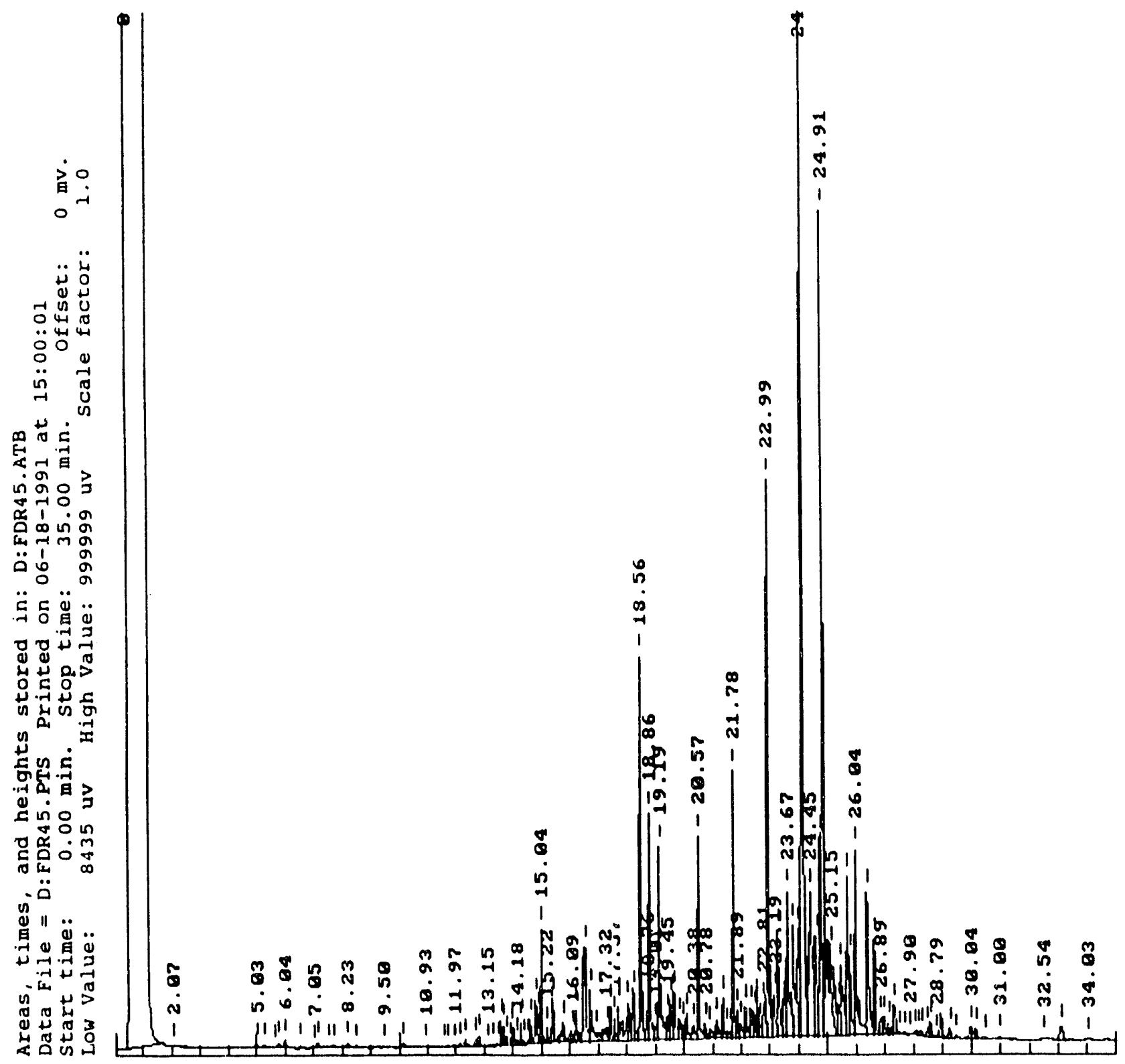

FIGURE E.10 GC/FID Chromatogram of Sample HTA021610S01 


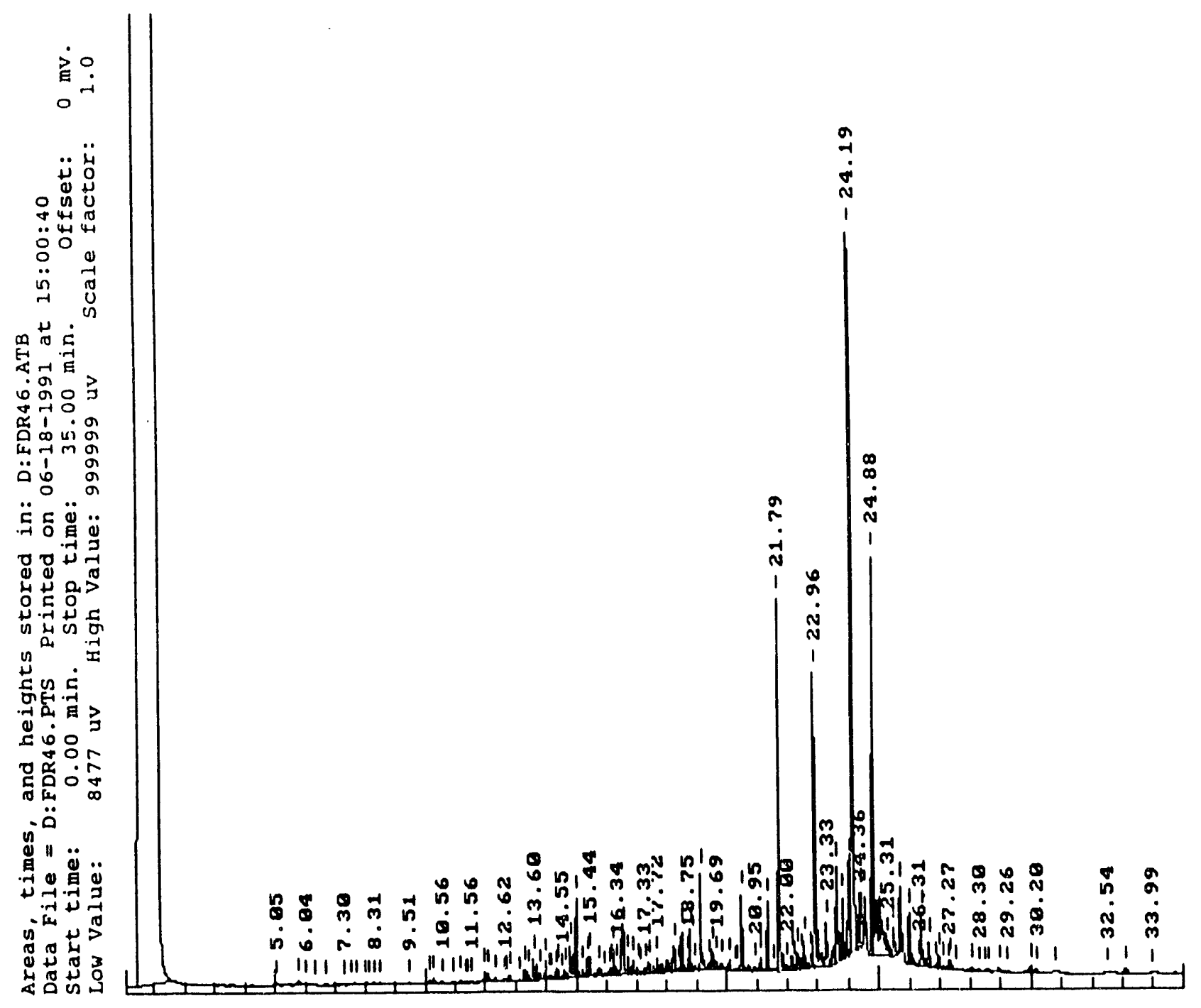

FIGURE E.11 GC/FID Chromatogram of Sample HTA023604S01 


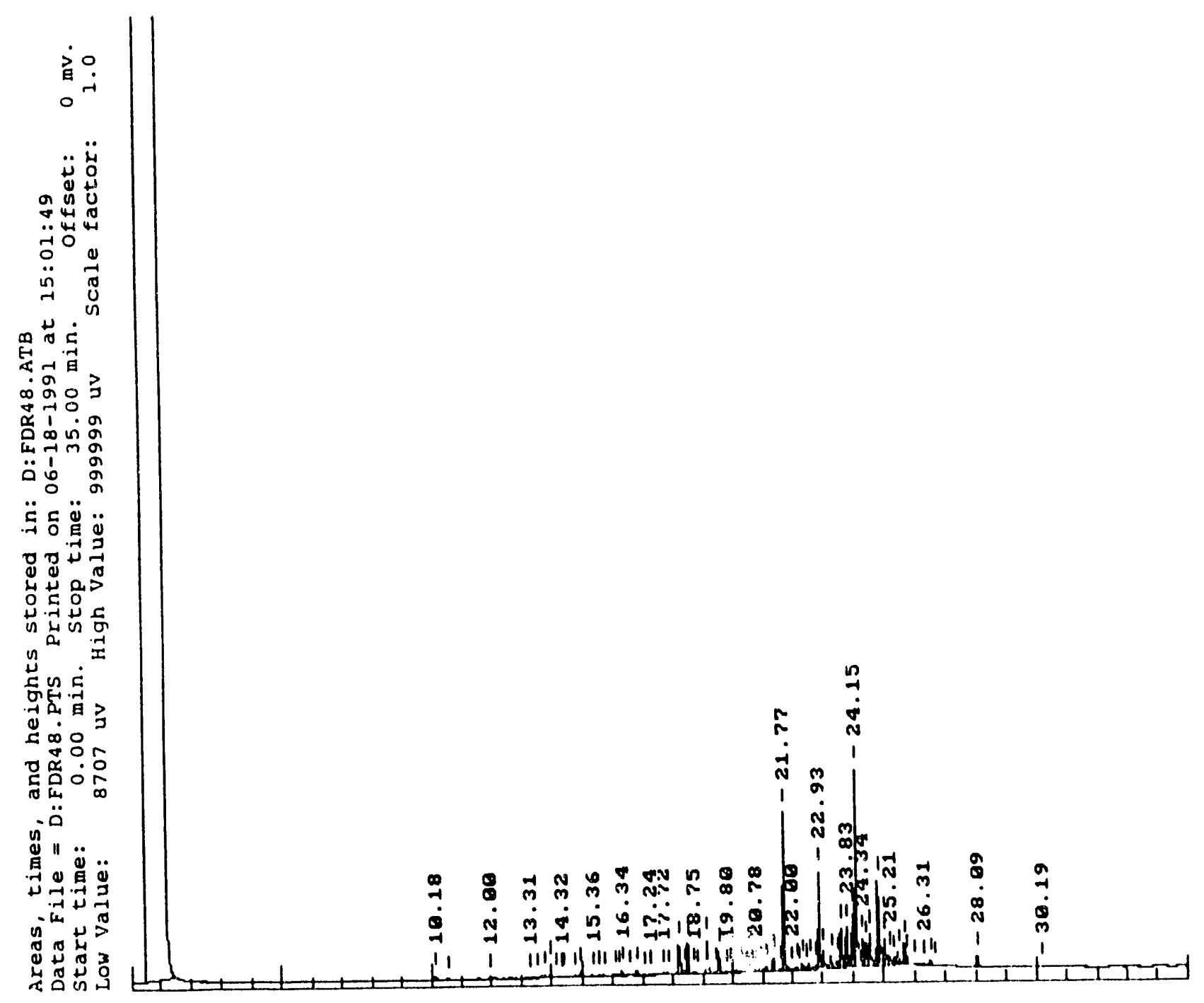

FIGURE E.12 GC/FID Chromatogram of Sample HTA033606S01 


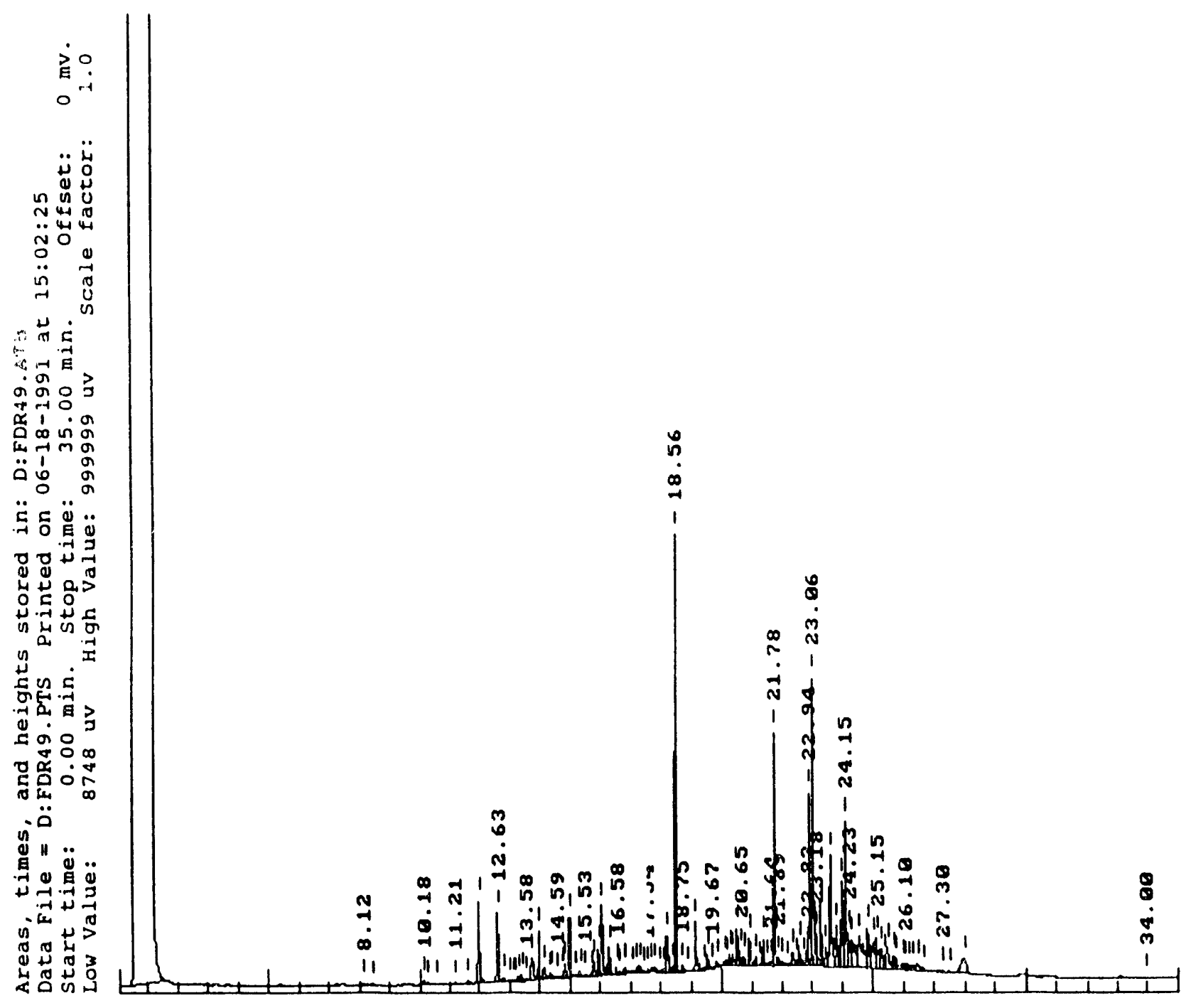

FIGURE E.13 GC/FID Chromatogram of Sample HTA036605R01 


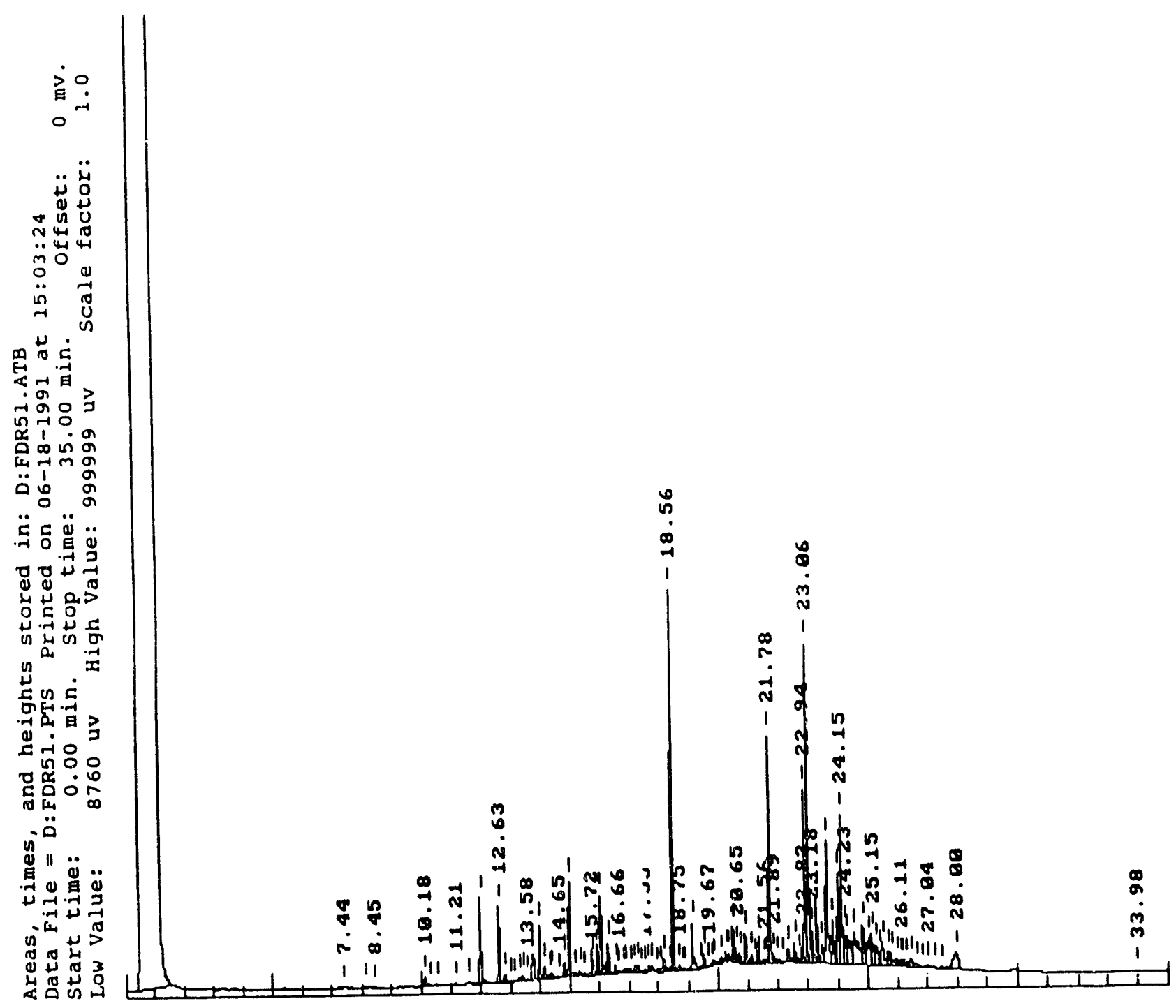

FIGURE E.14 GC/FID Chromatogram of Sample HTA036605R02 


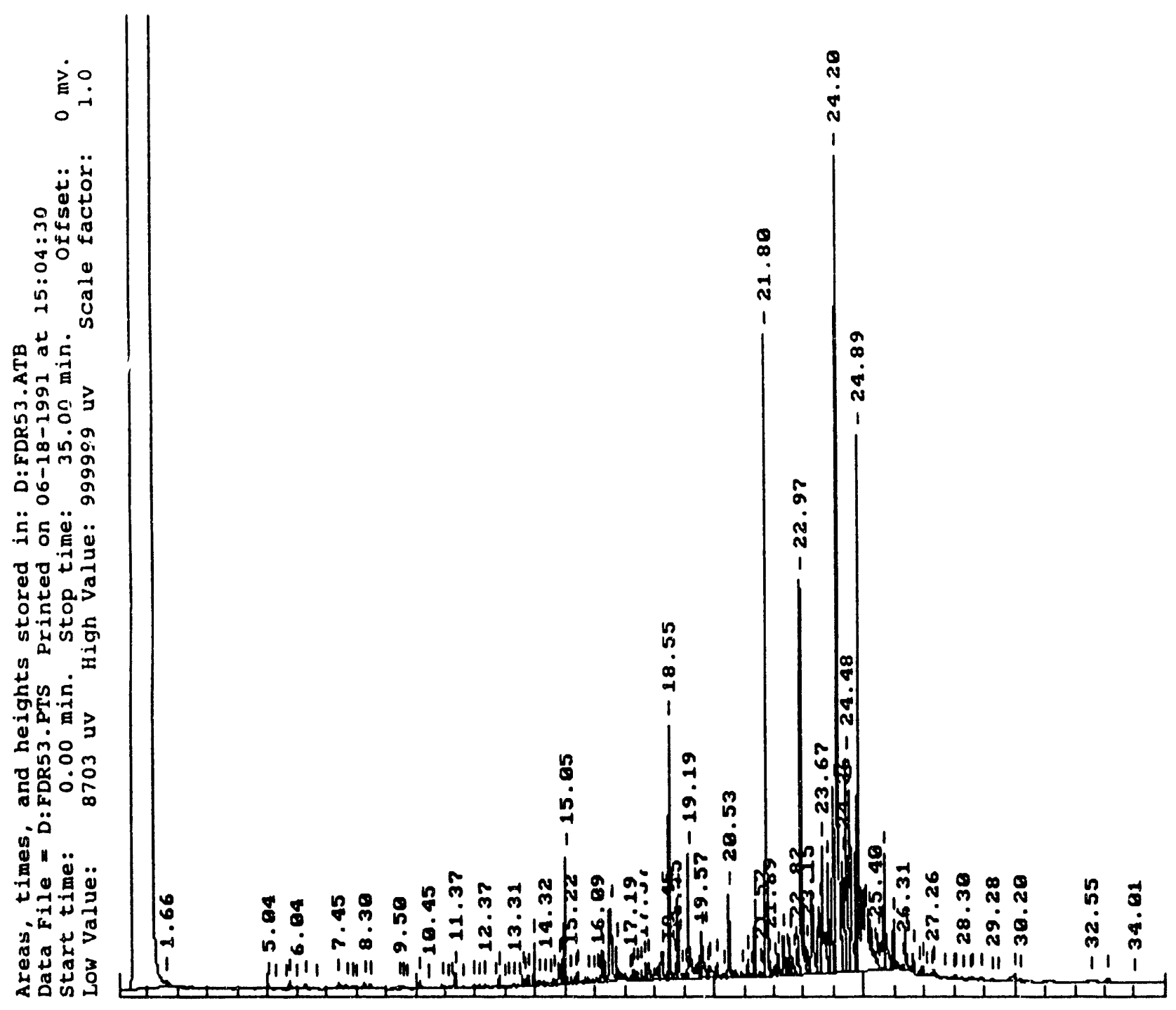

FIGURE E.15 GC/FID Chromatogram of Sample HTA037606S01 


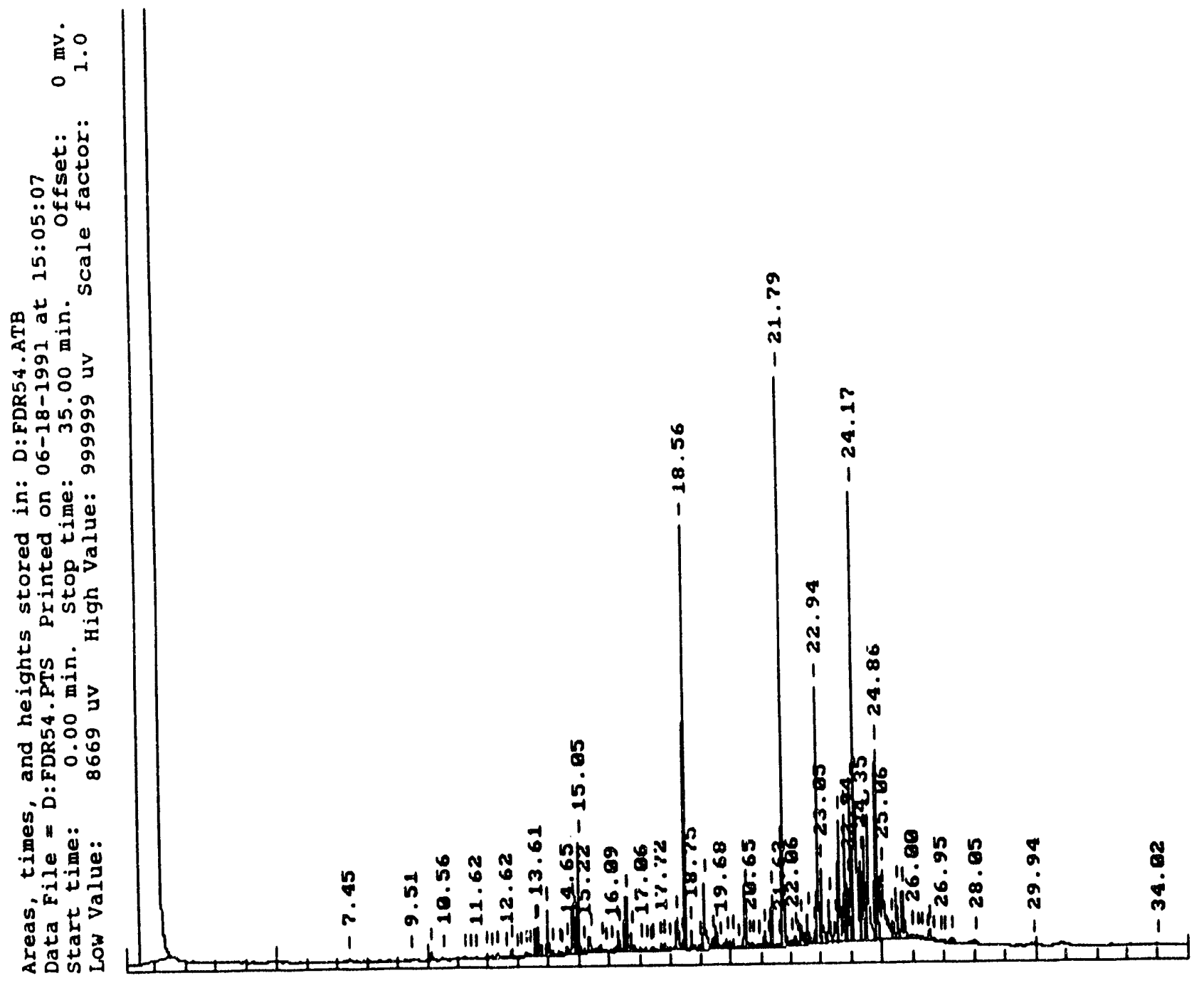

FIGURE E.16 GC/FID Chromatogram of Sample HTA038601S01 


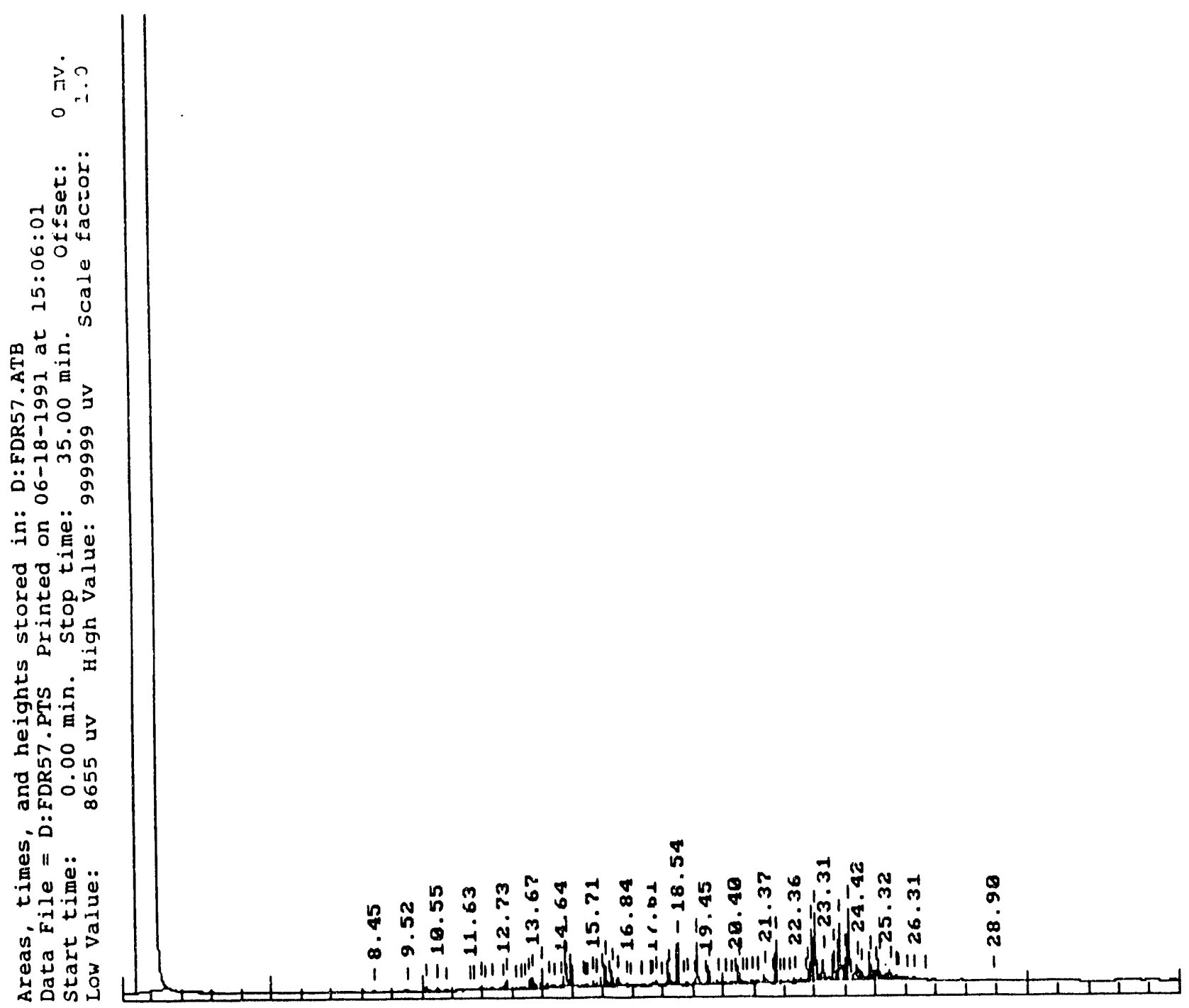

FIGURE E.17 GC/FID Chromatogram of Sample HTA043597R01 


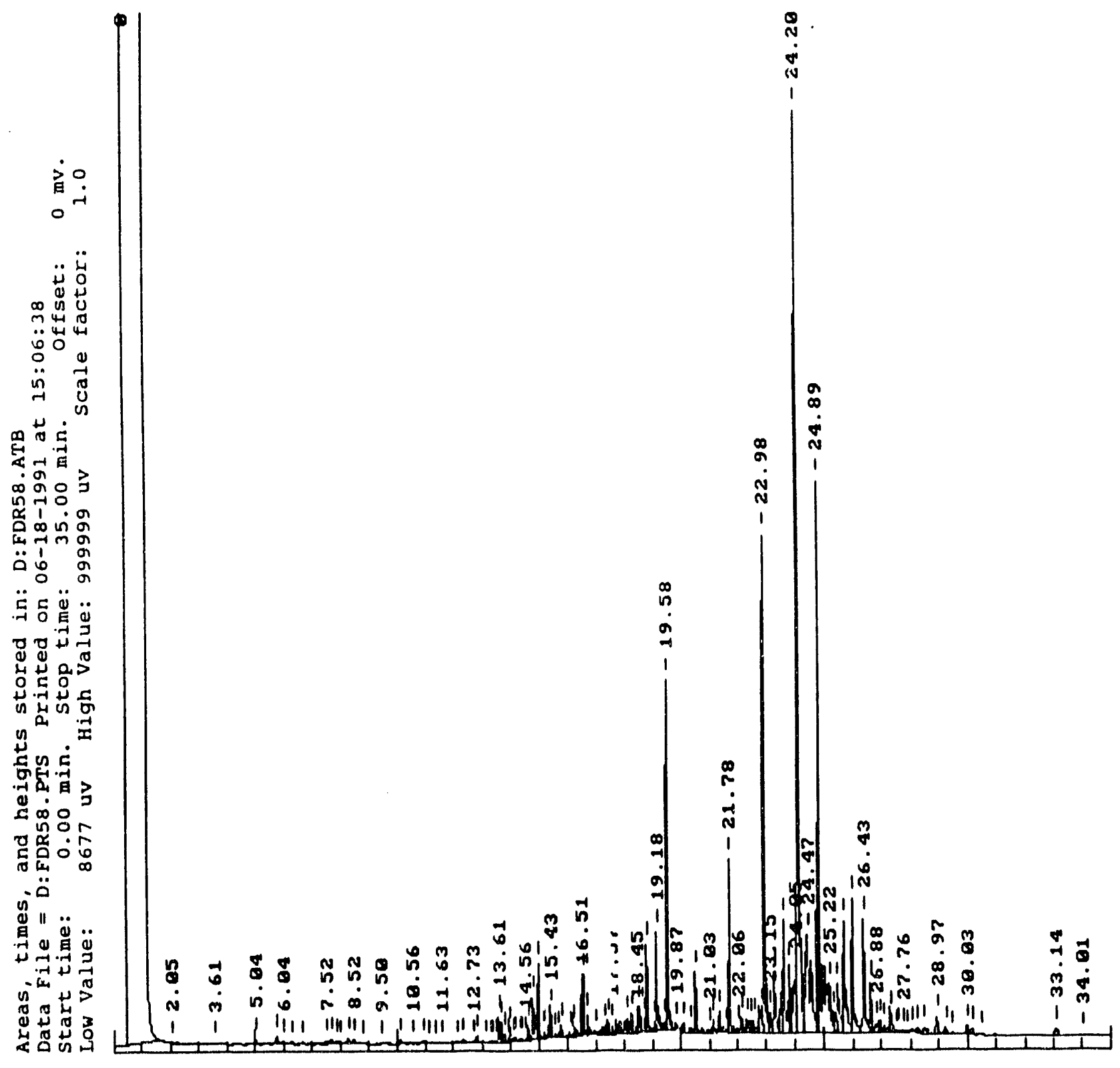

FIGURE E.18 GC/FID Chromatogram of Sample HTA056593S01 


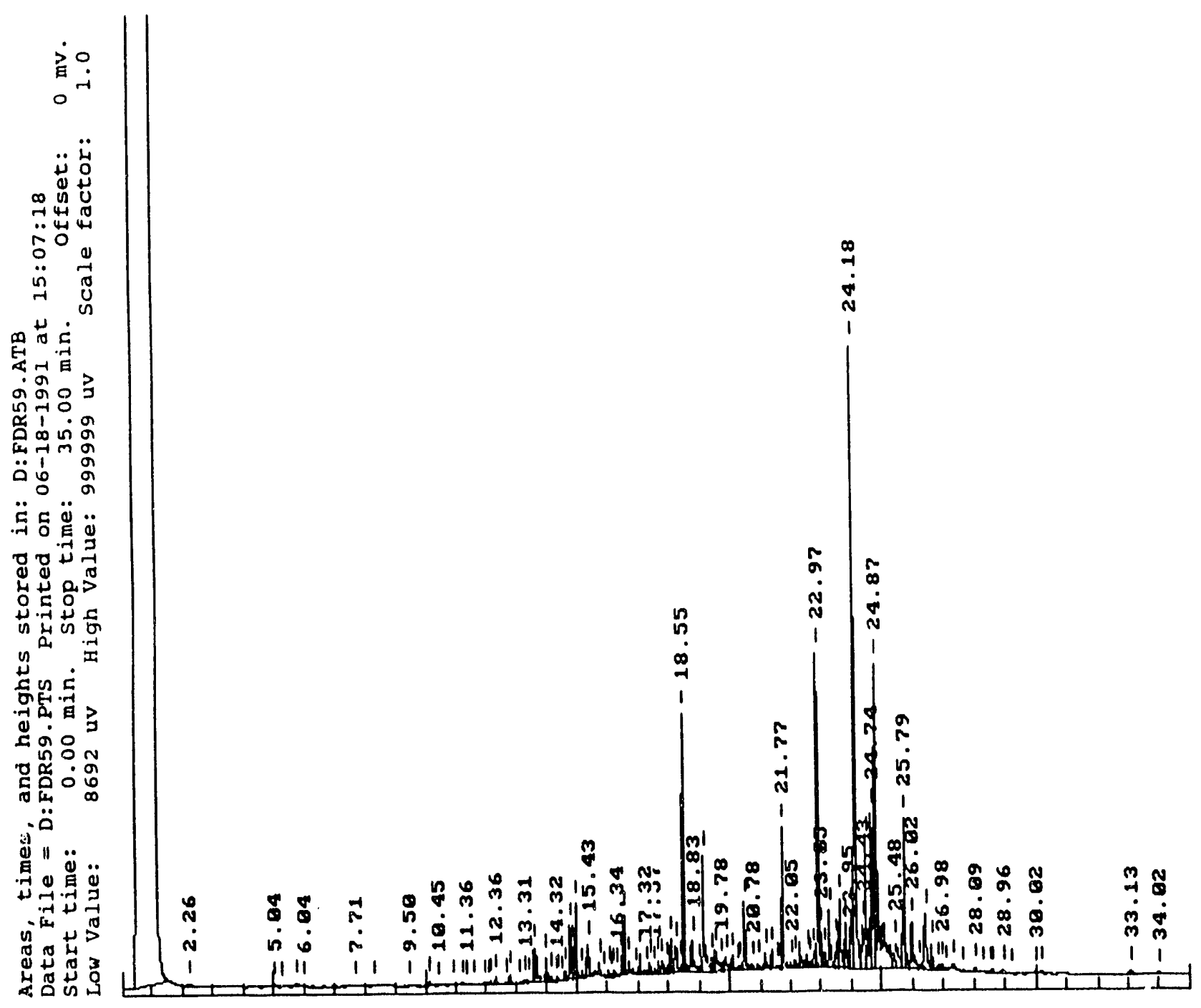

FIGURE E.19 GC/FID Chromatogram of Sample HTA056593S02 


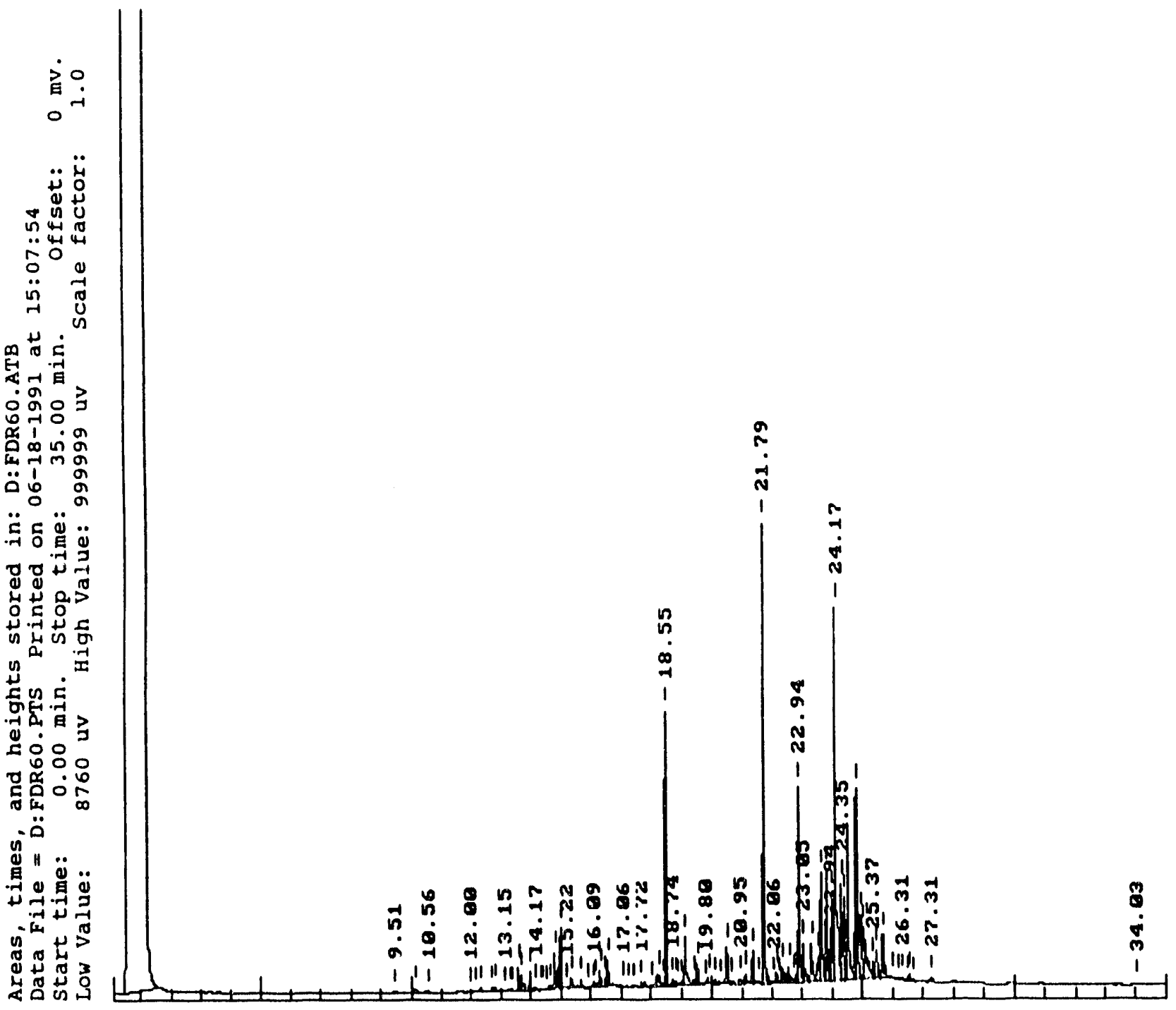

FIGURE E.20 GC/FID Chromatogram of Sample HTA056603S01 


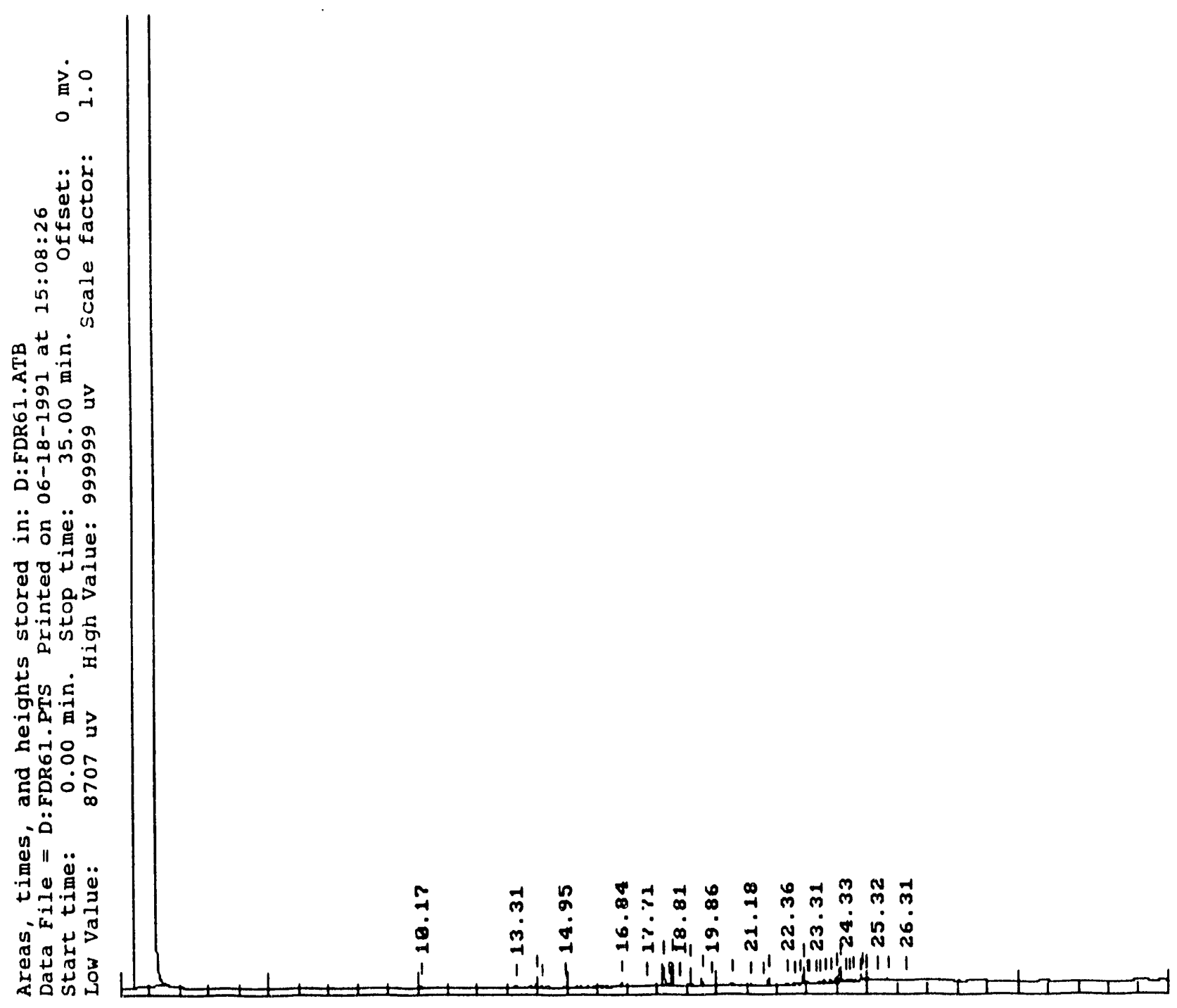

FIGURE E.21 GC/FID Chromatogram of Sample HTA056625R01 


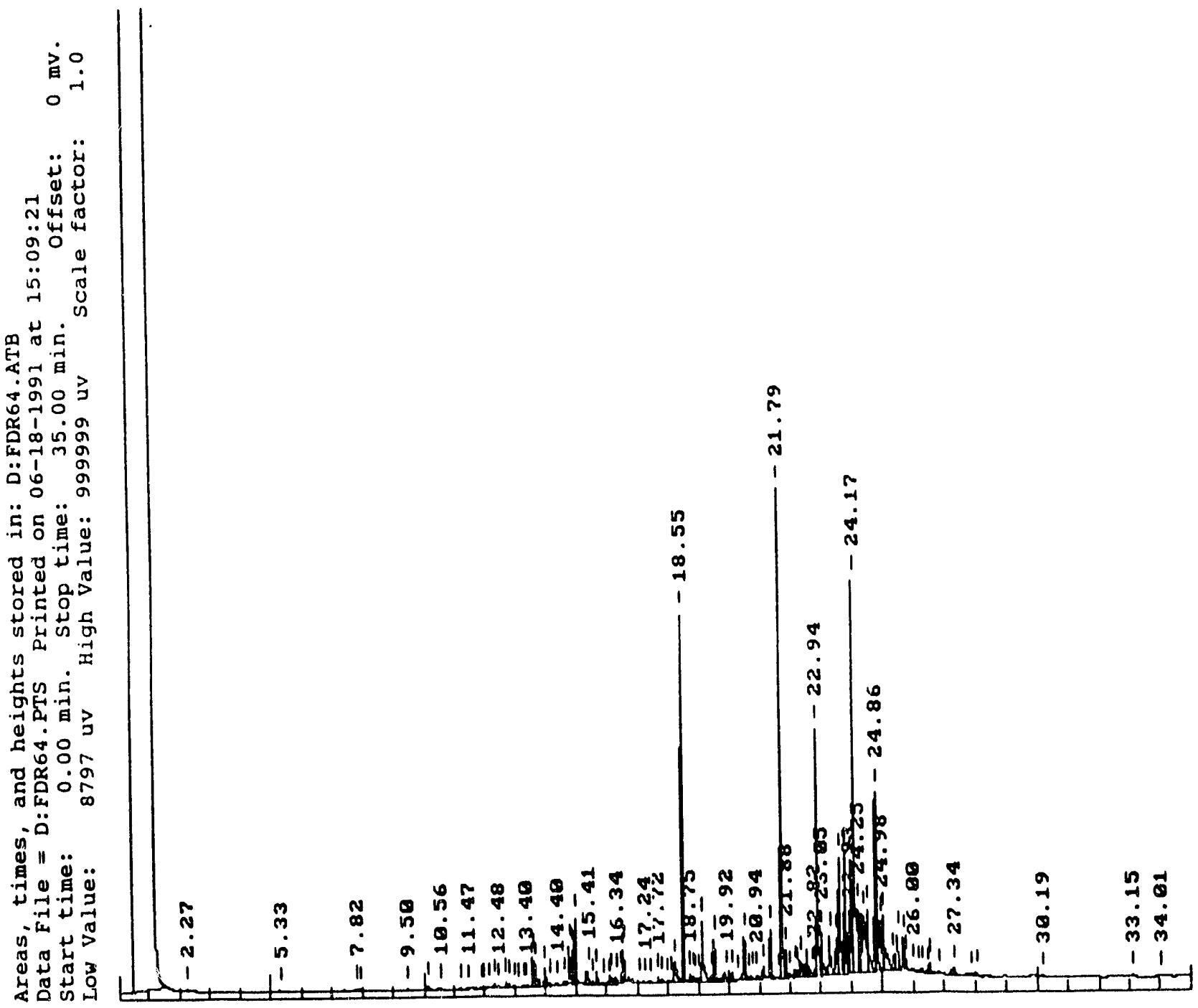

FIGURE E.22 GC/FID Chromatogram of Sample HTA059601S01 


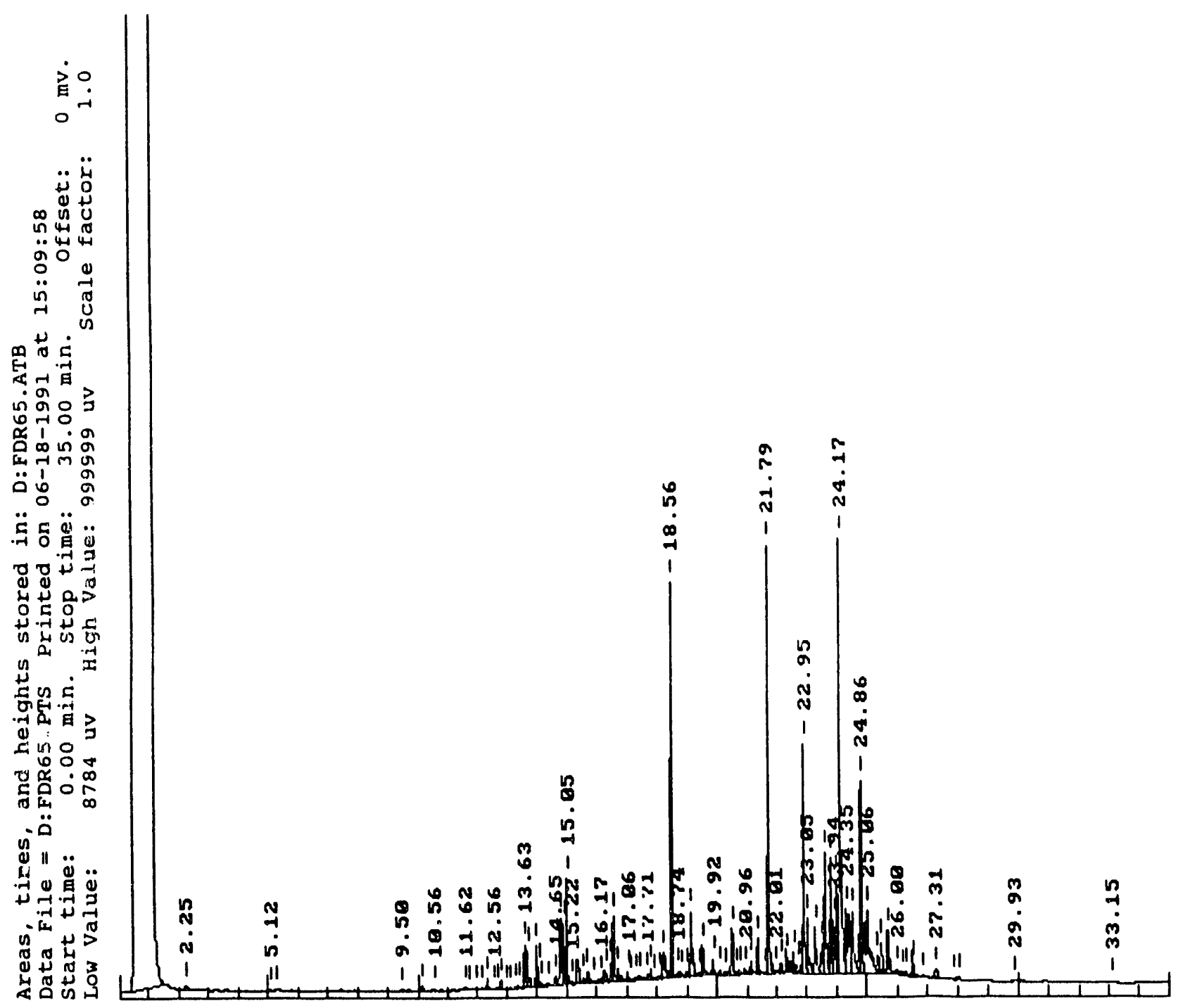

FIGURE E.23 GC/FID Chromatogram of Sample HTA059601S02 


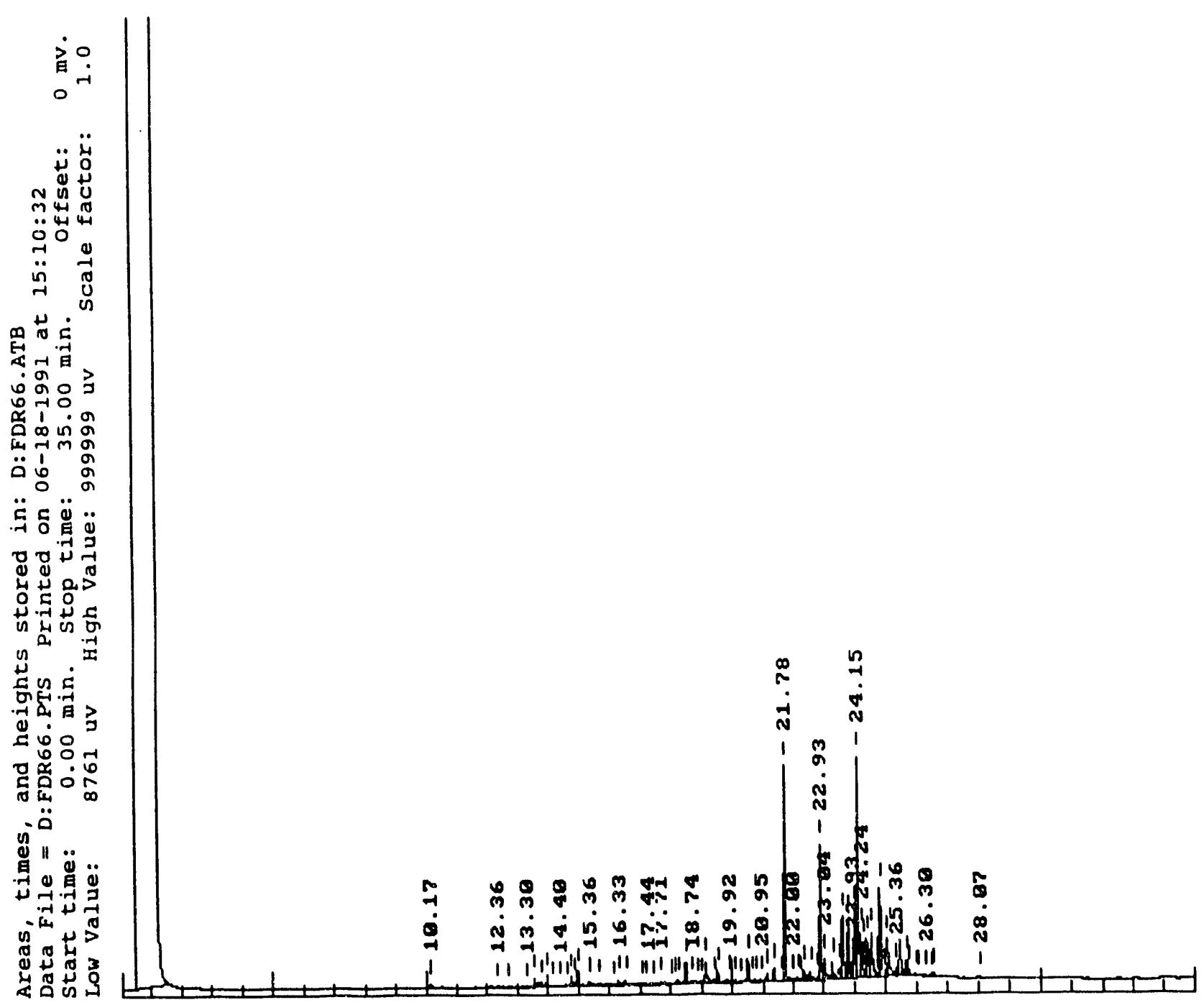

FIGURE E.24 GC/FID Chromatogram of Sample HTA061596S01 


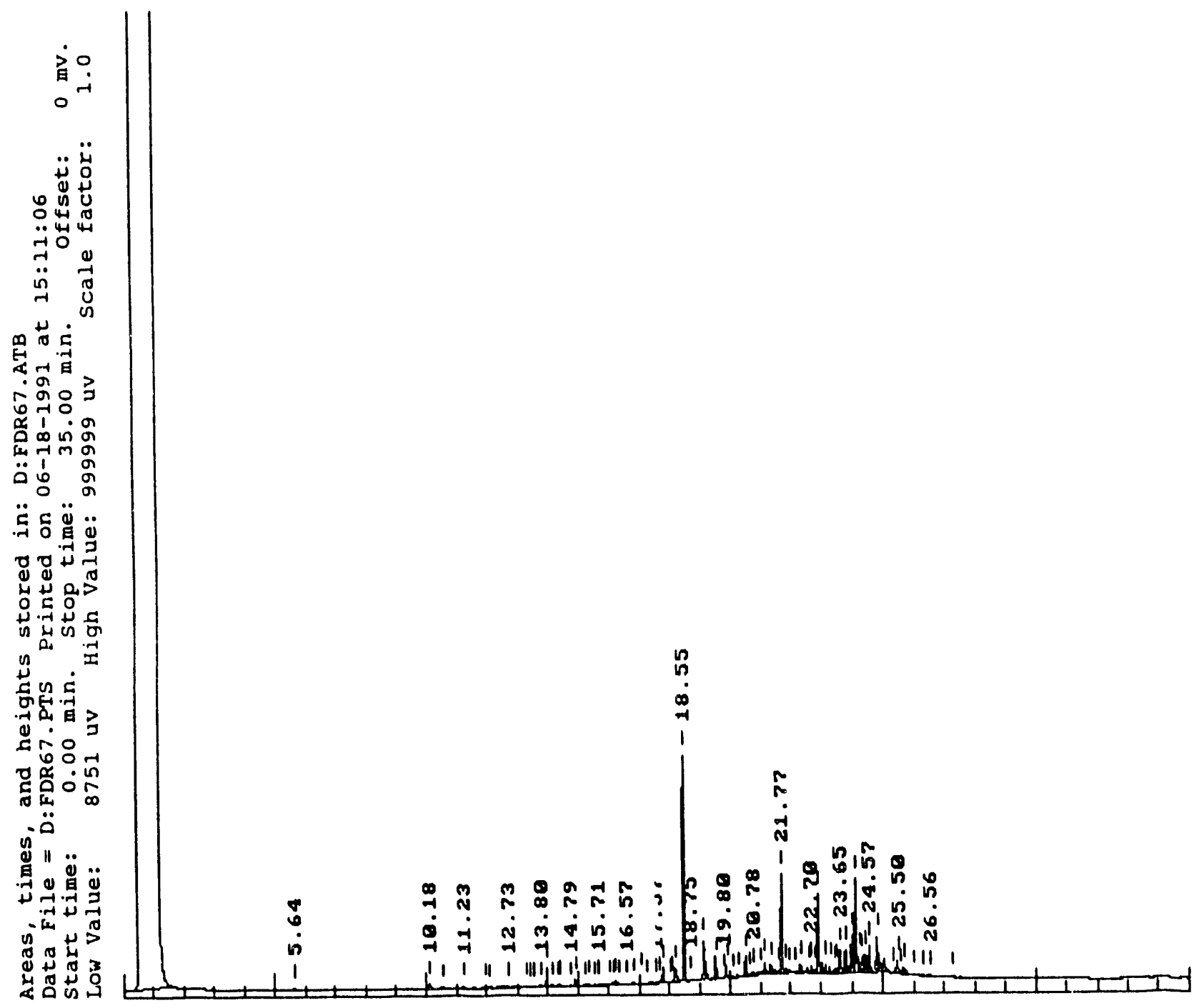

FIGURE E.25 GC/FID Chromatogram of Sample HTA061596S02 


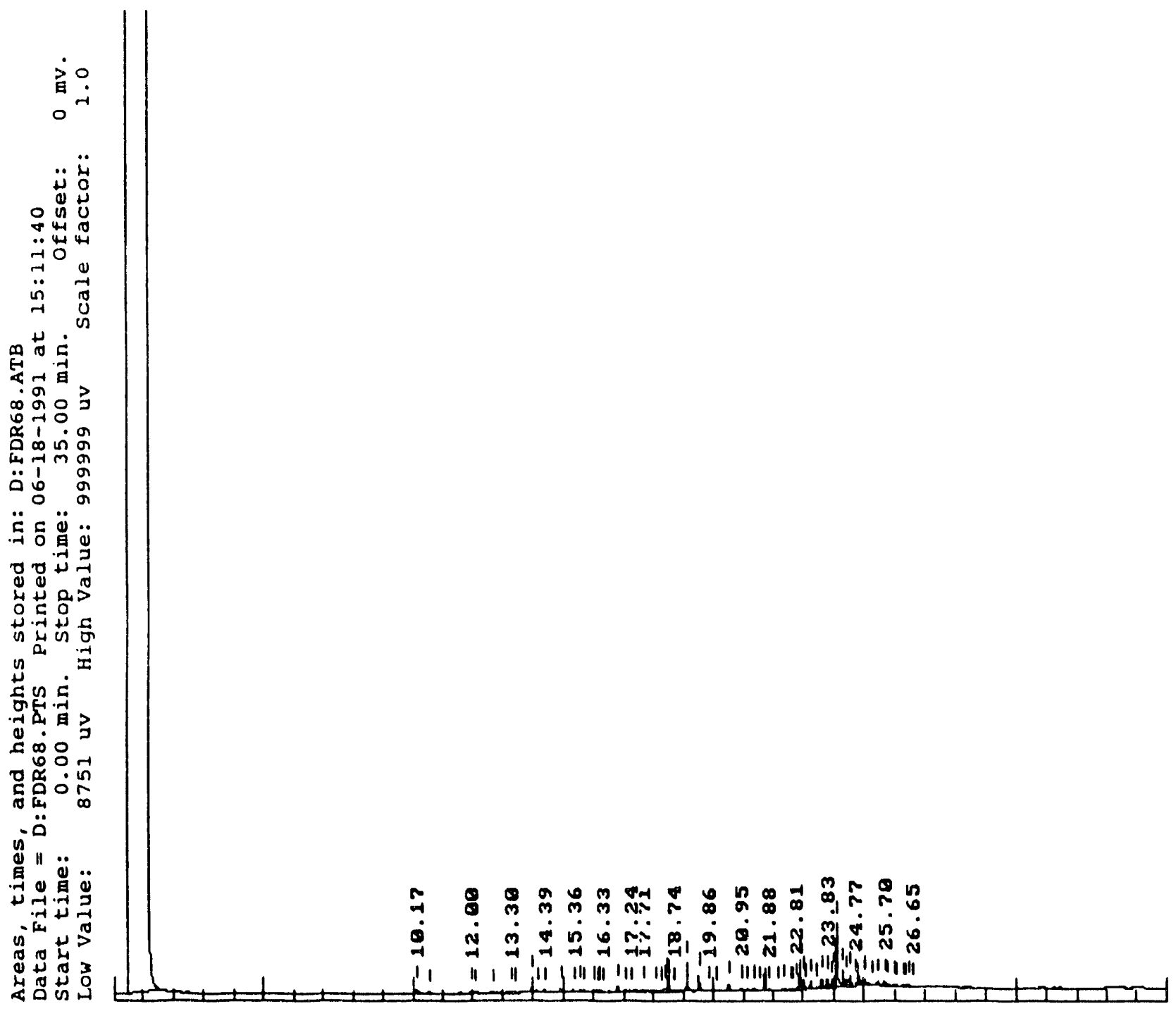

FIGURE E.26 GC/FID Chromatogram of Sample HTA062592R01 


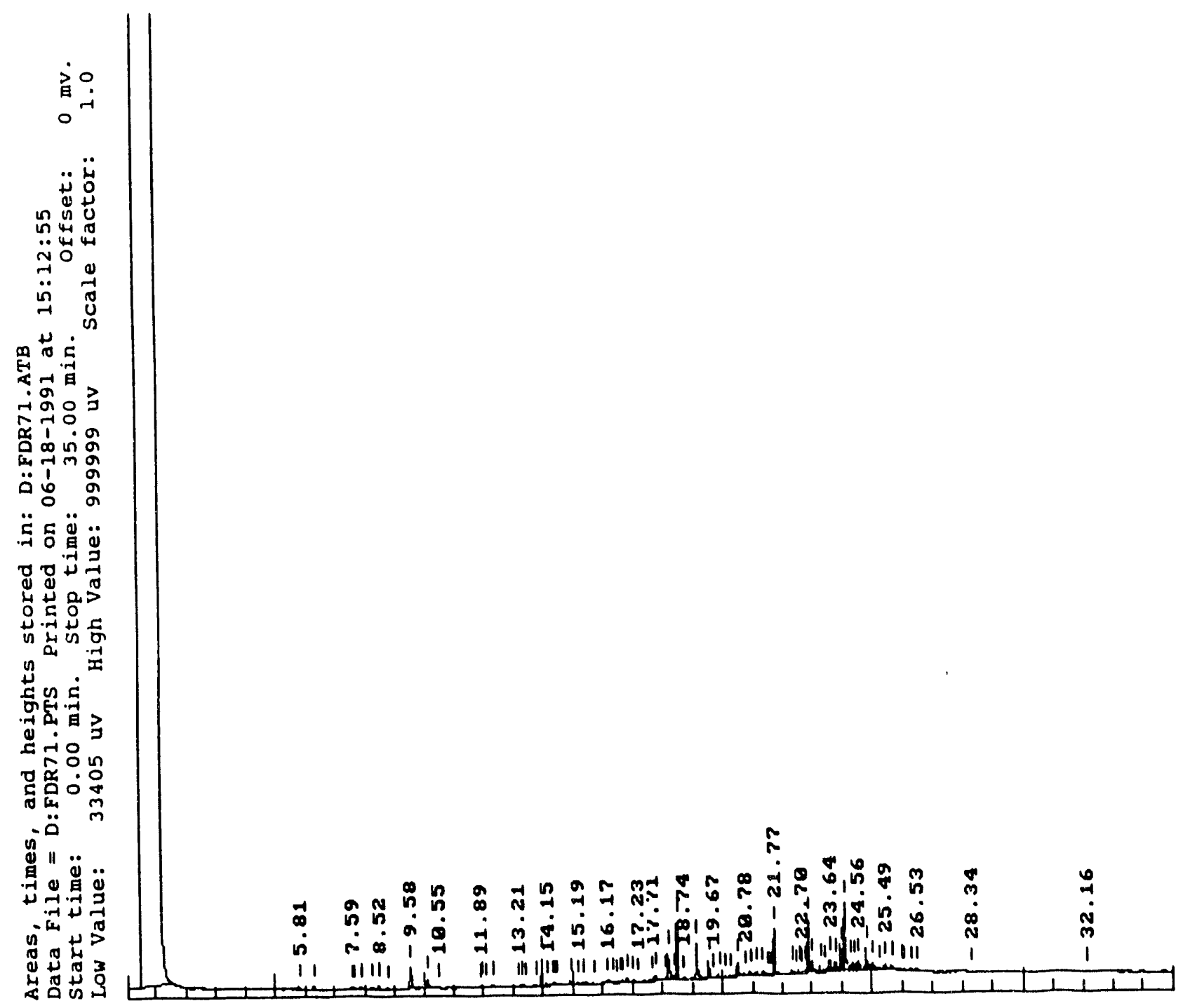

FIGURE E.27 GC/FID Chromatogram of Sample HTA065585R01 


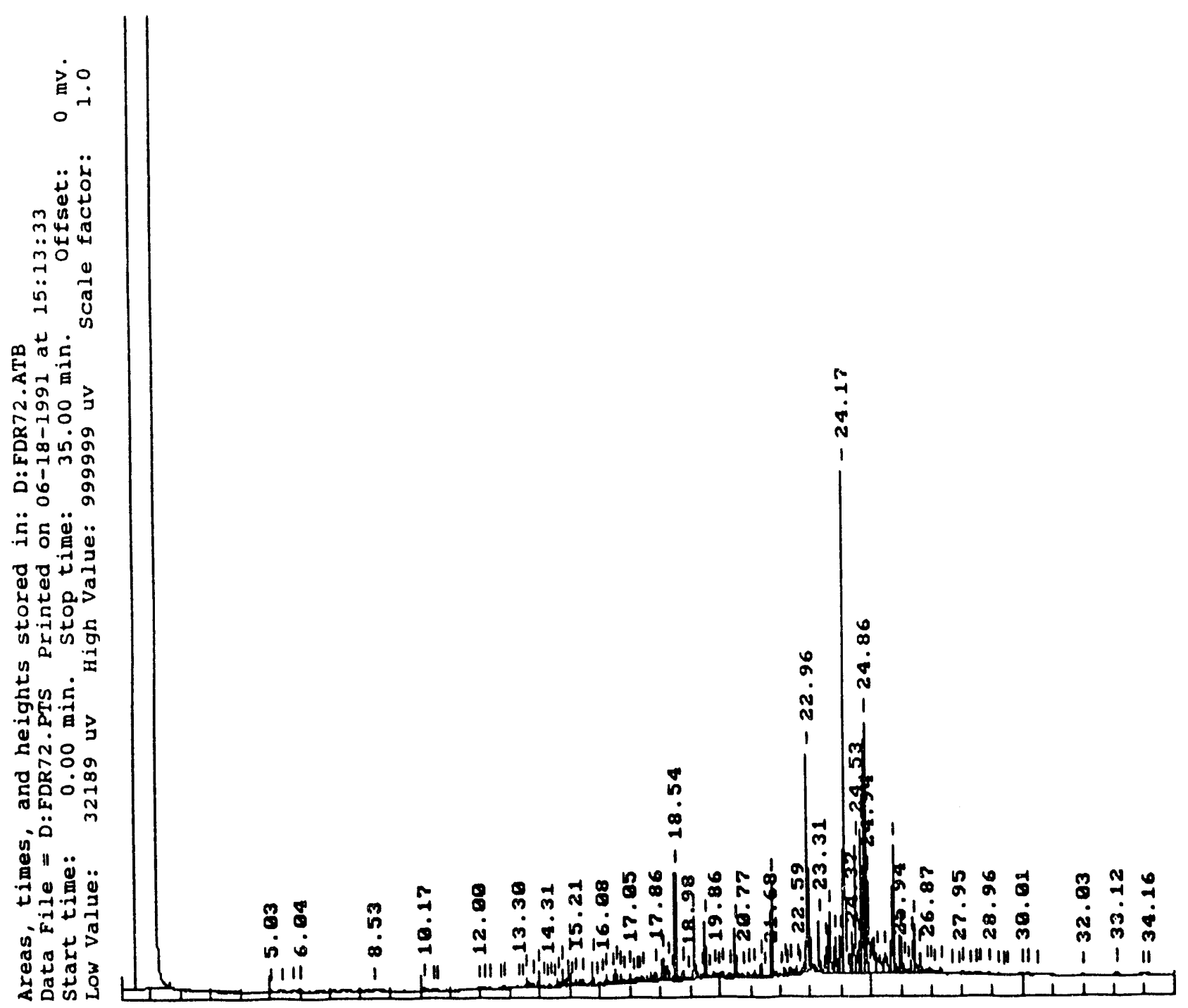

FIGURE E.28 GC/FID Chromatogram of Sample HTA065598S01 


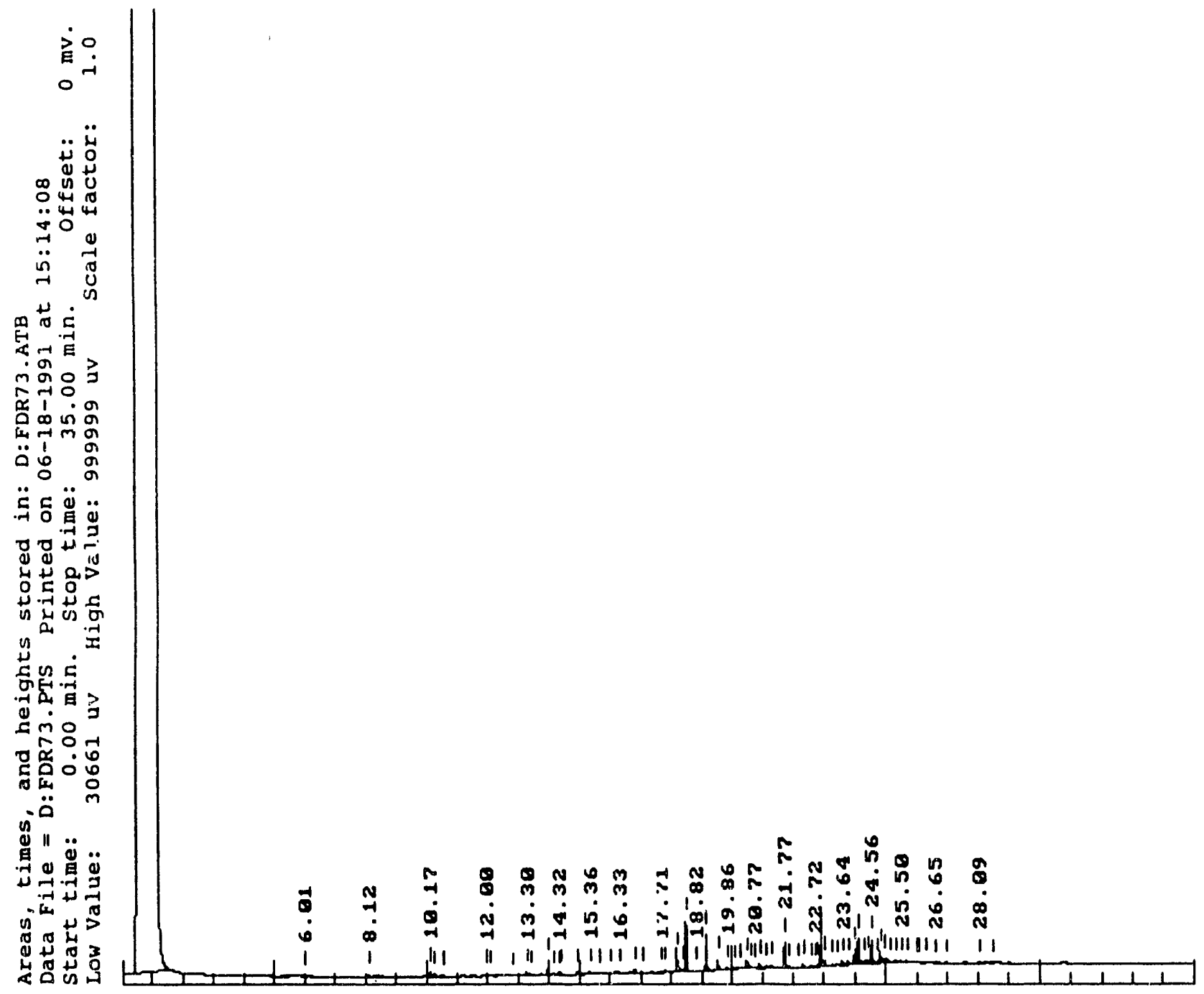

FIGURE E.29 GC/FID Chromatogram of Sample HTA073624R01 


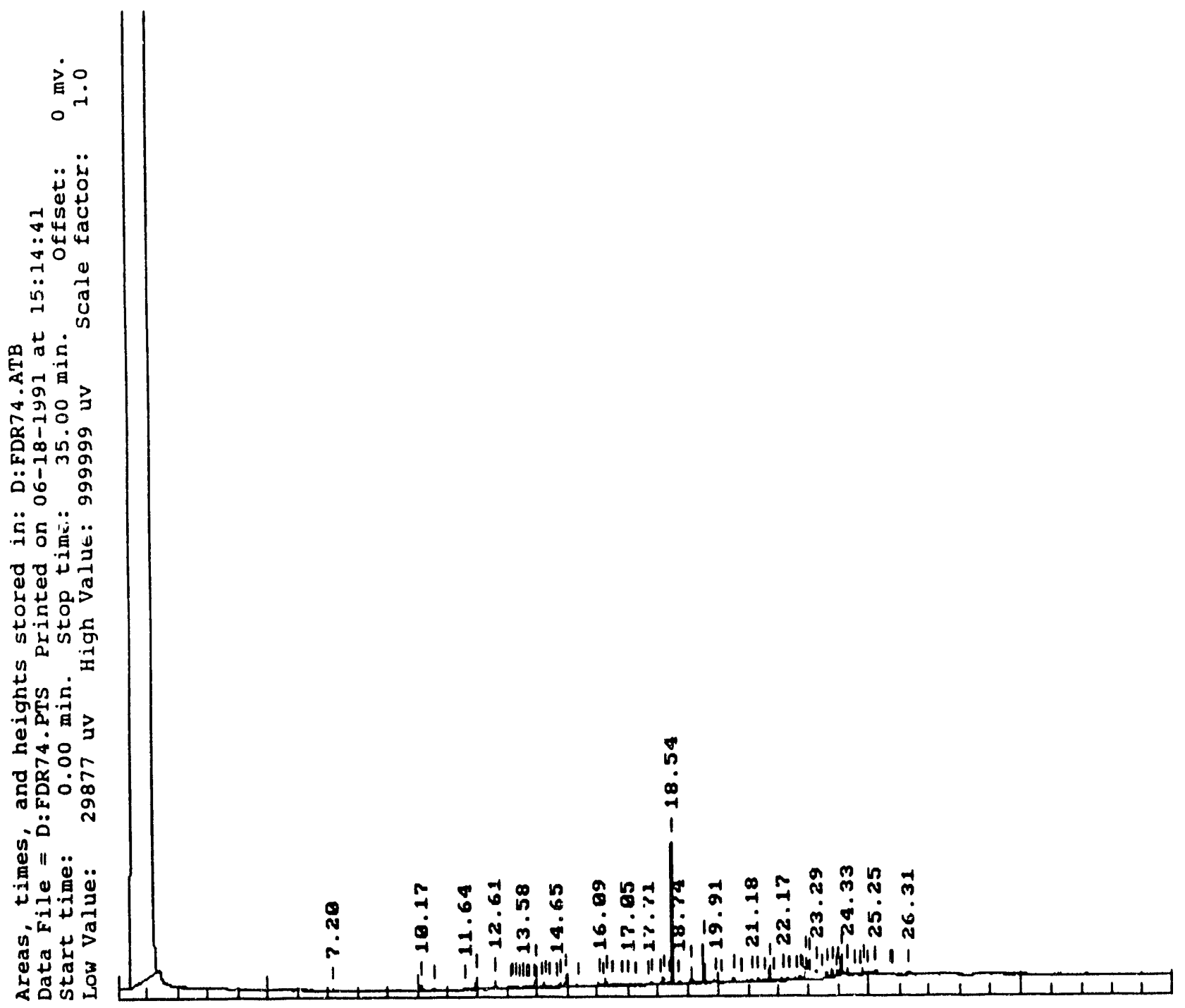

FIGURE E.30 GC/FID Chromatogram of Sample HTA096600R01 


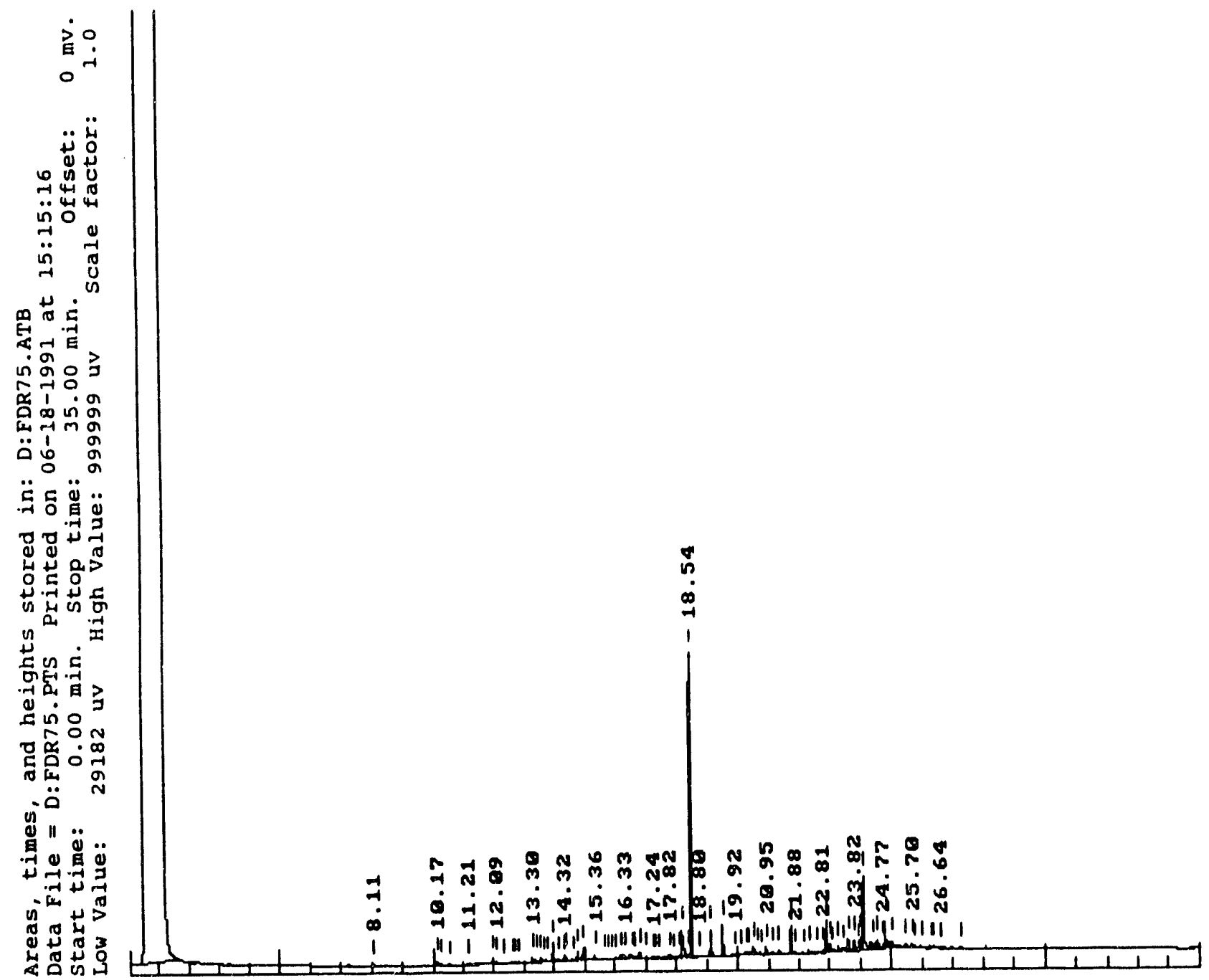

FIGURE E.31 GC/FID Chromatogram of Sample HTA977673R01 


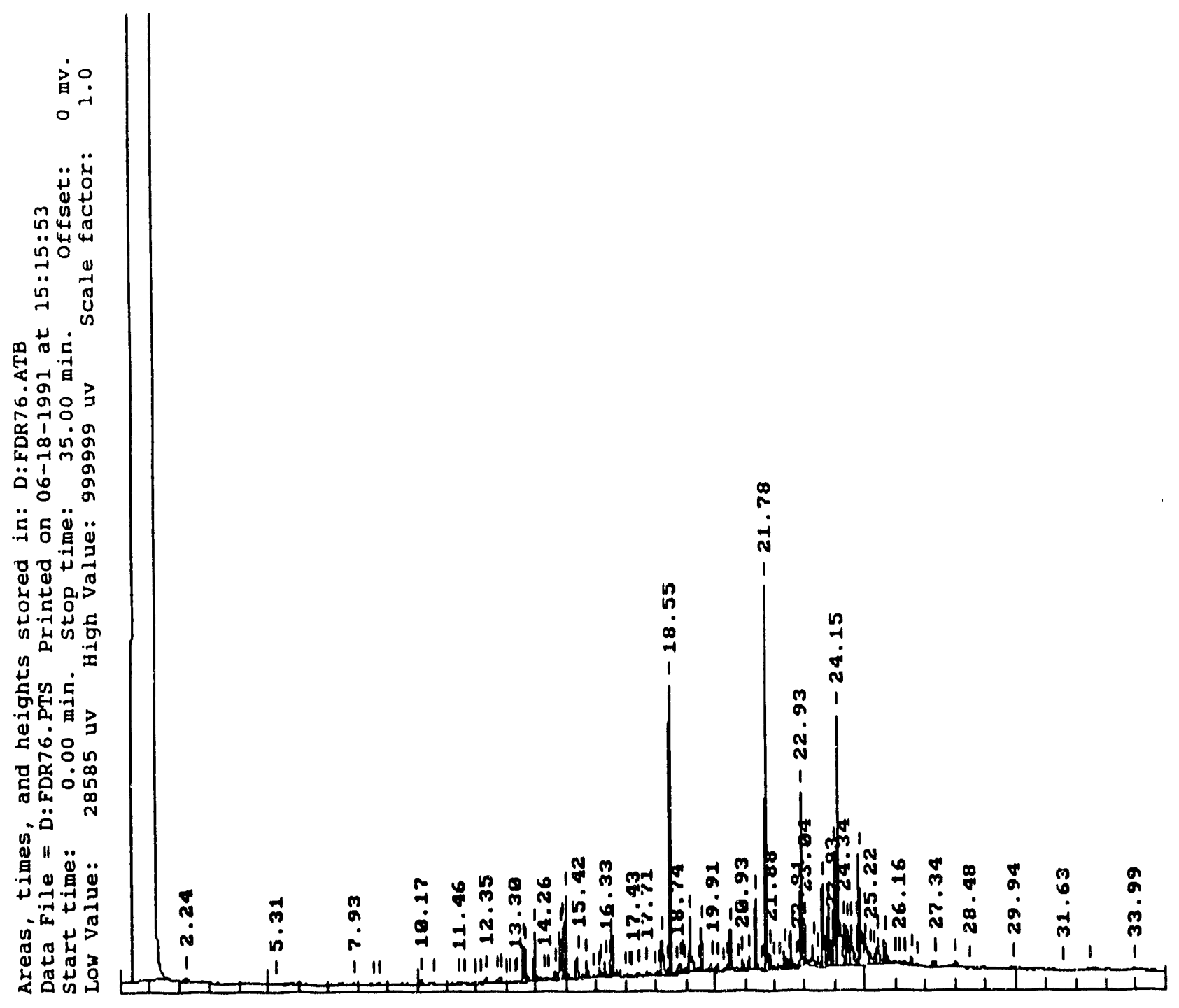

FIGURE E.32 GC/FID Chromatogram of Sample HTA979679S01 


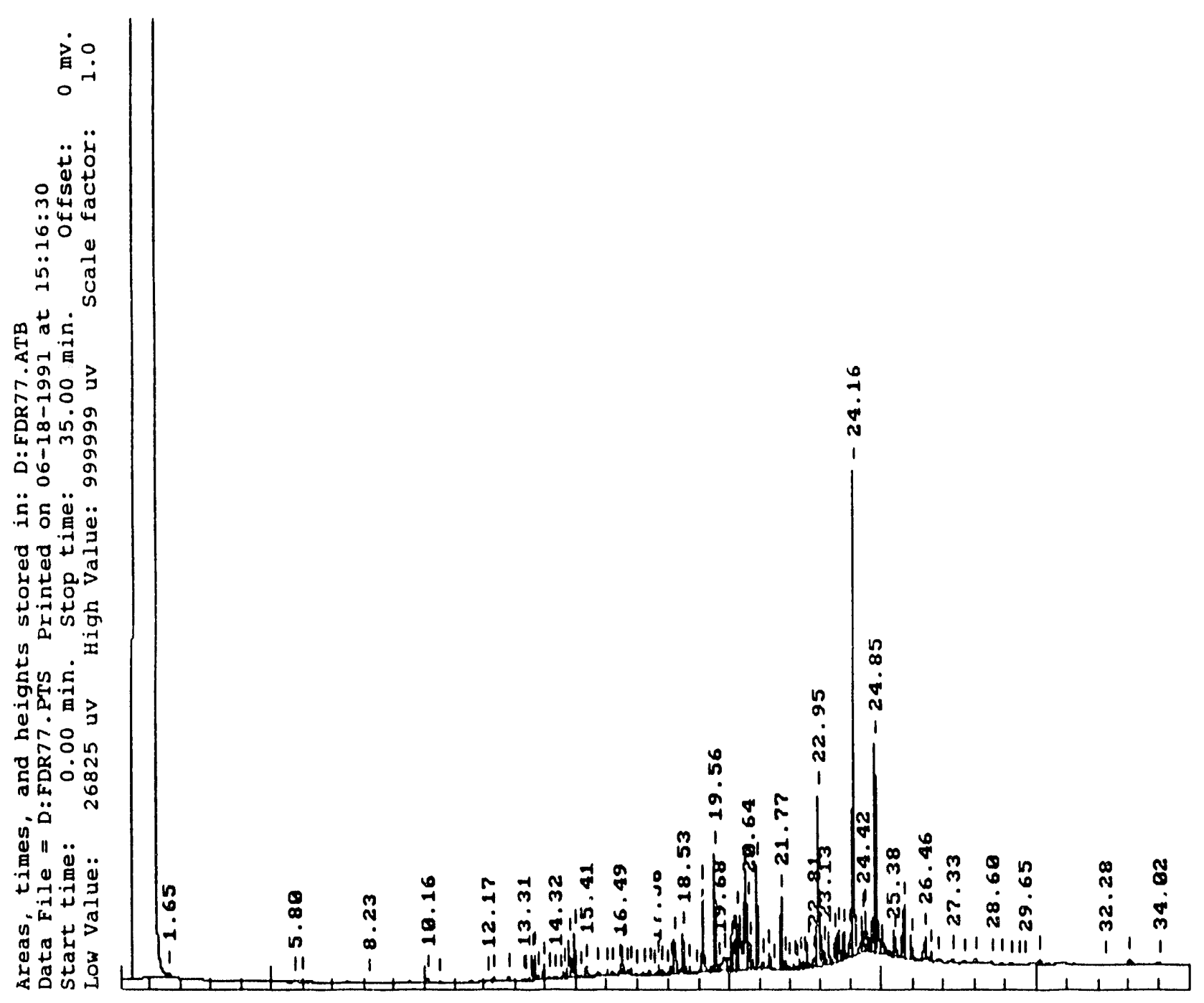

FIGURE E.33 GC/FID Chromatogram of Sample HTA979682S01 


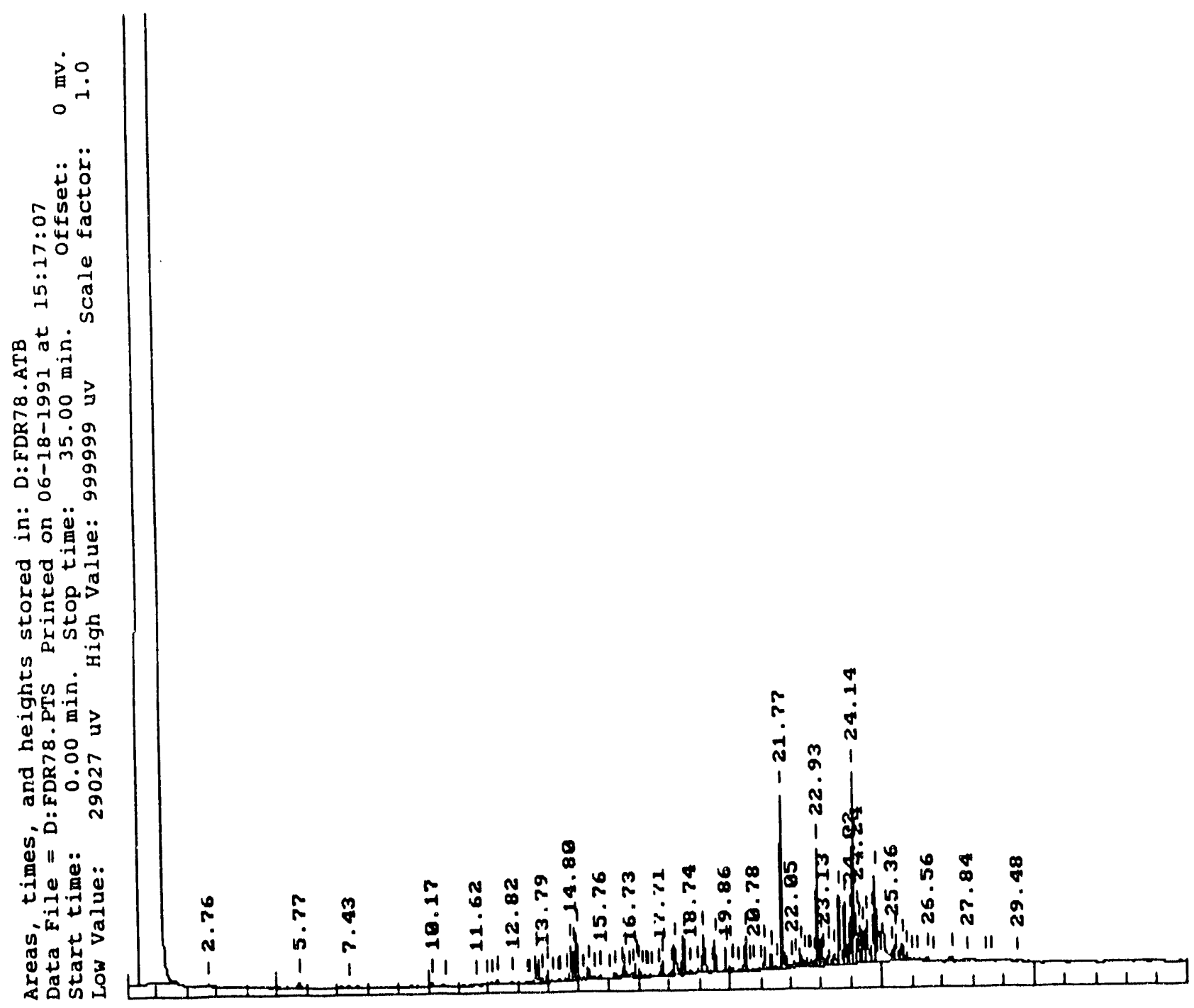

FIGURE E.34 GC/FID Chromatogram of Sample HTA987671S01 


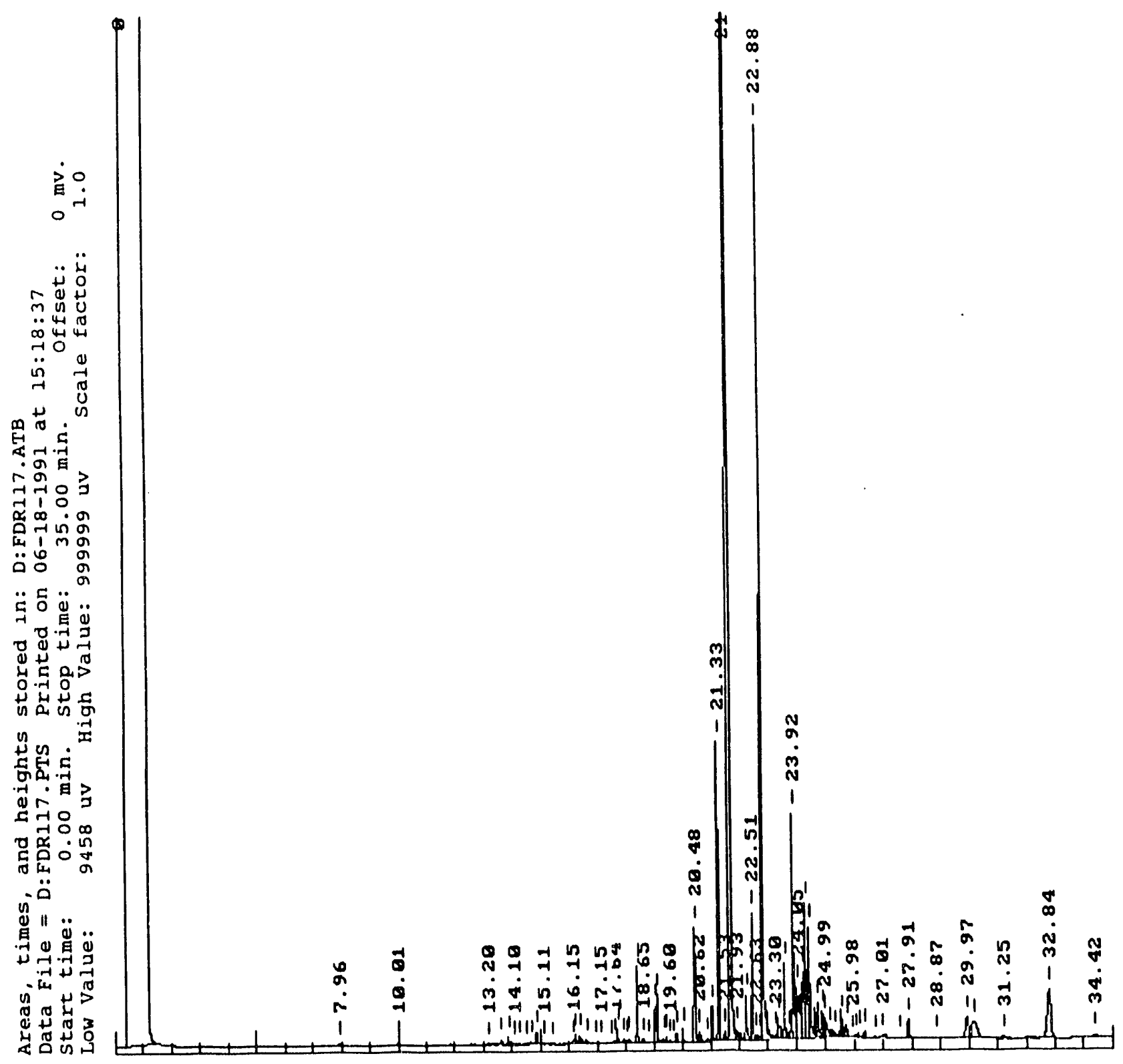

FIGURE E.35 GC/FID Chromatogram of Sample HTA018597V01 


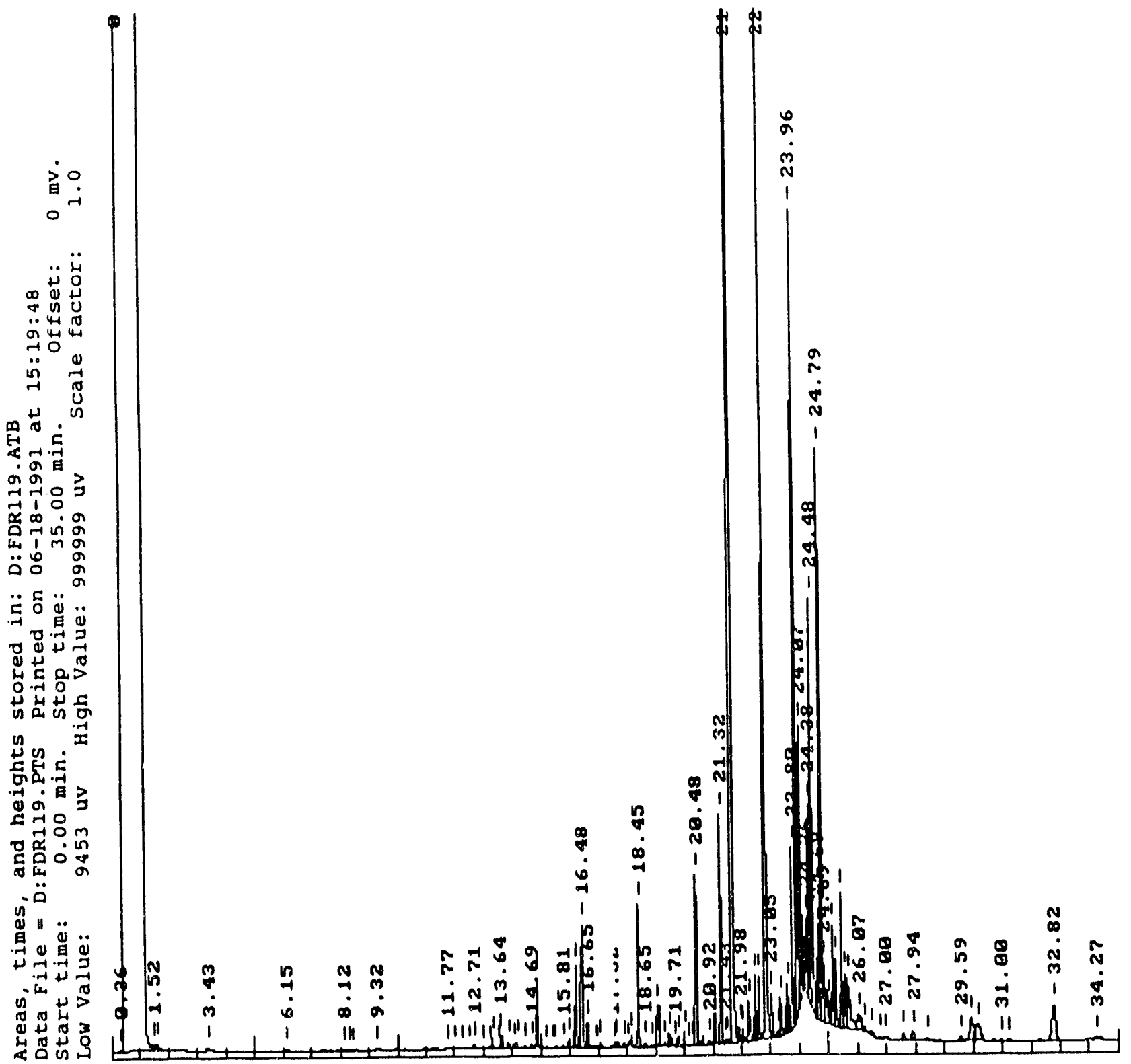

FIGURE E.36 GC/FID Chromatogram of Sample HTA021610V01 


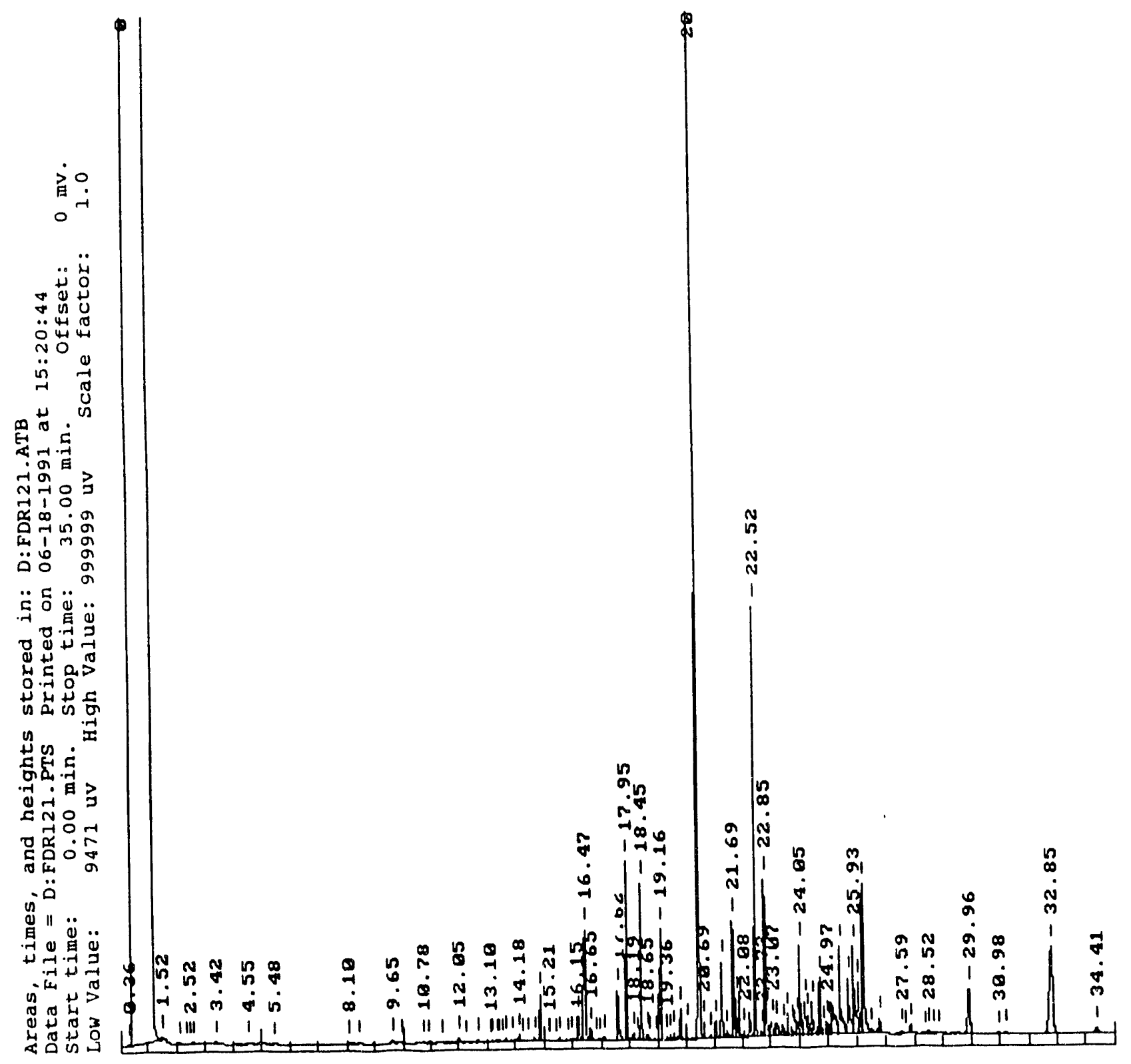

FIGURE E.37 GC/FID Chromatogram of Sample HTA021610V02 


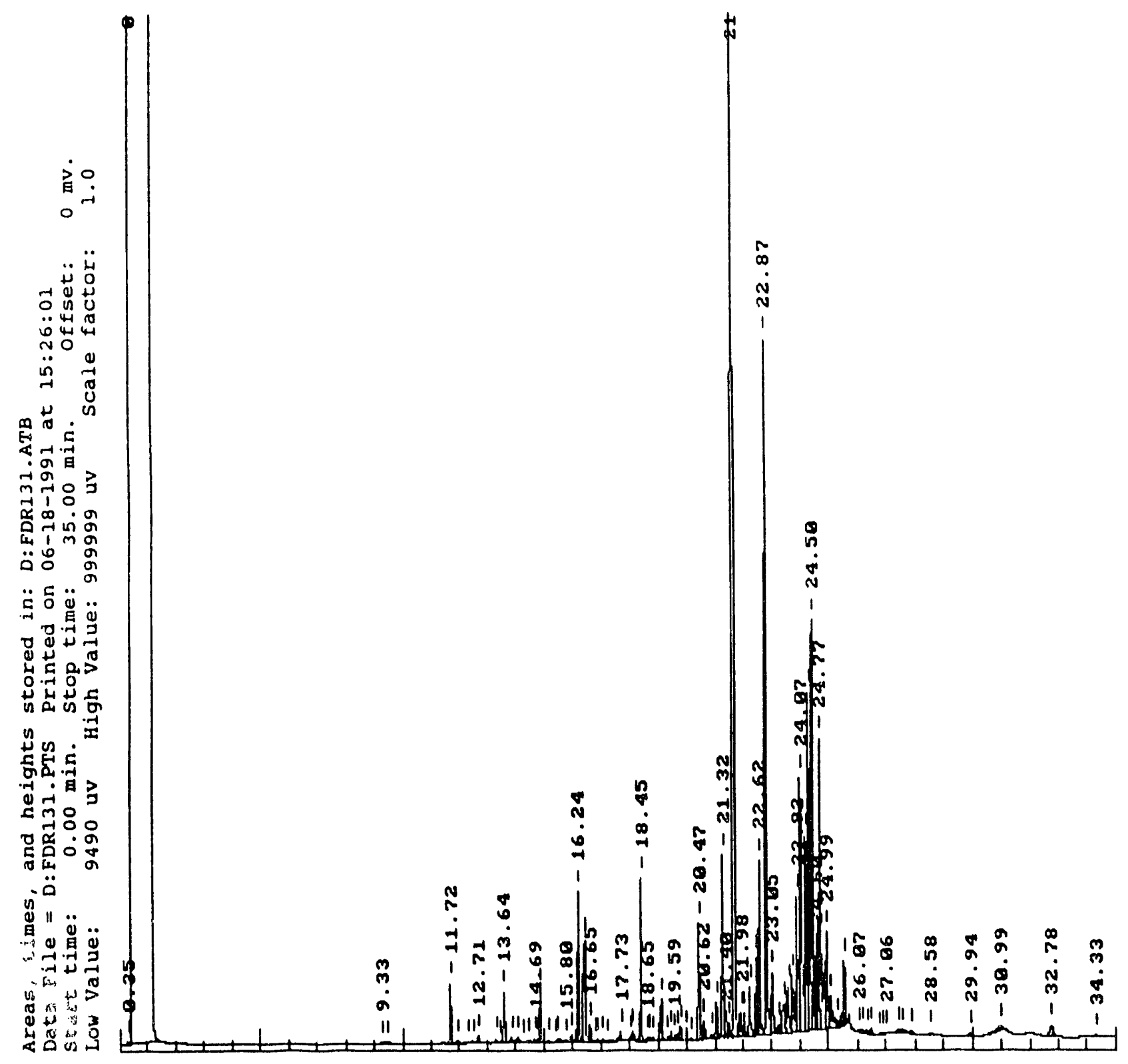

FIGURE E.38 GC/FID Chromatogram of Sample HTA038601V01 

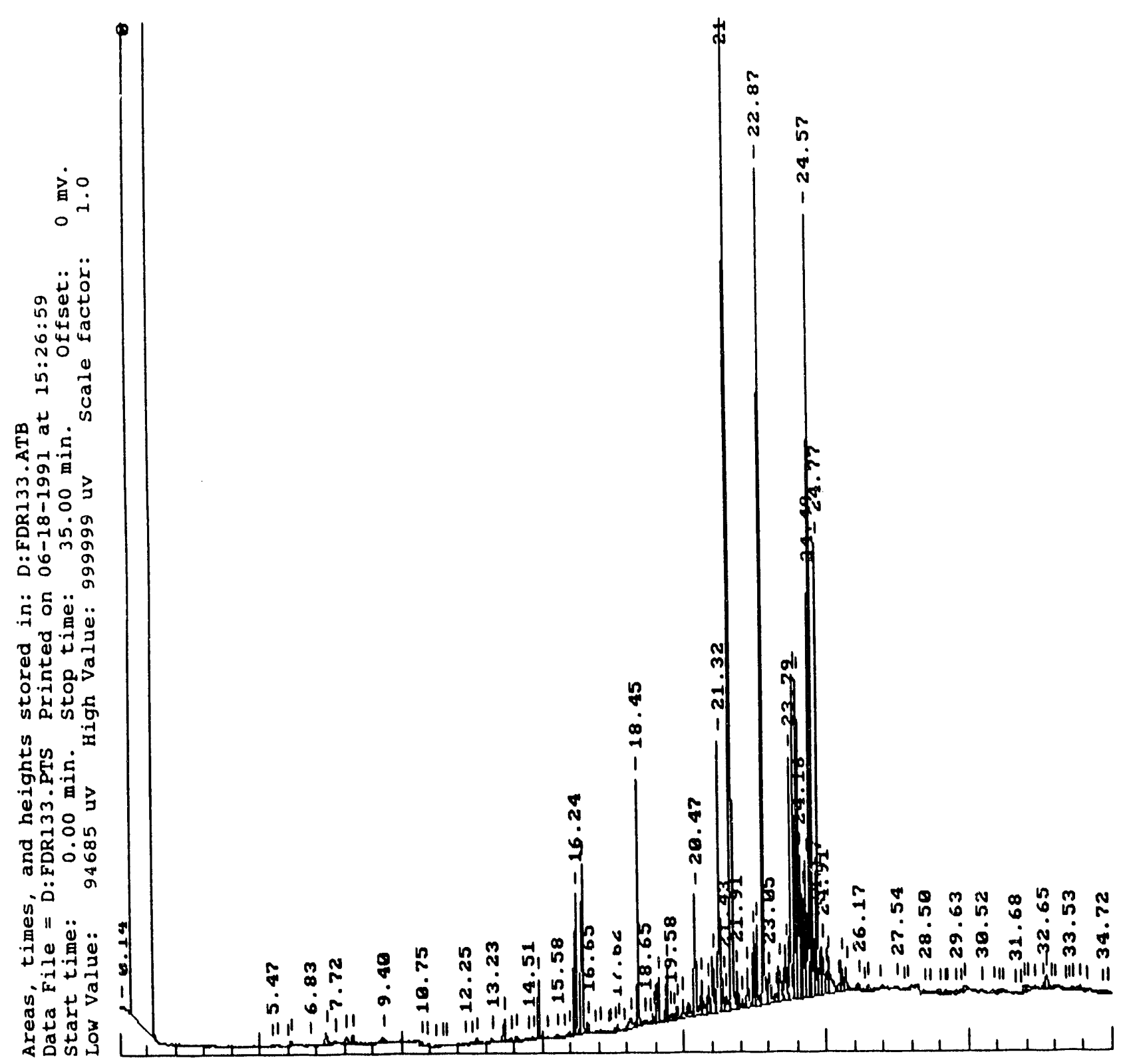

FIGURE E.39 GC/FID Chromatogram of Sample HTA056593V01 

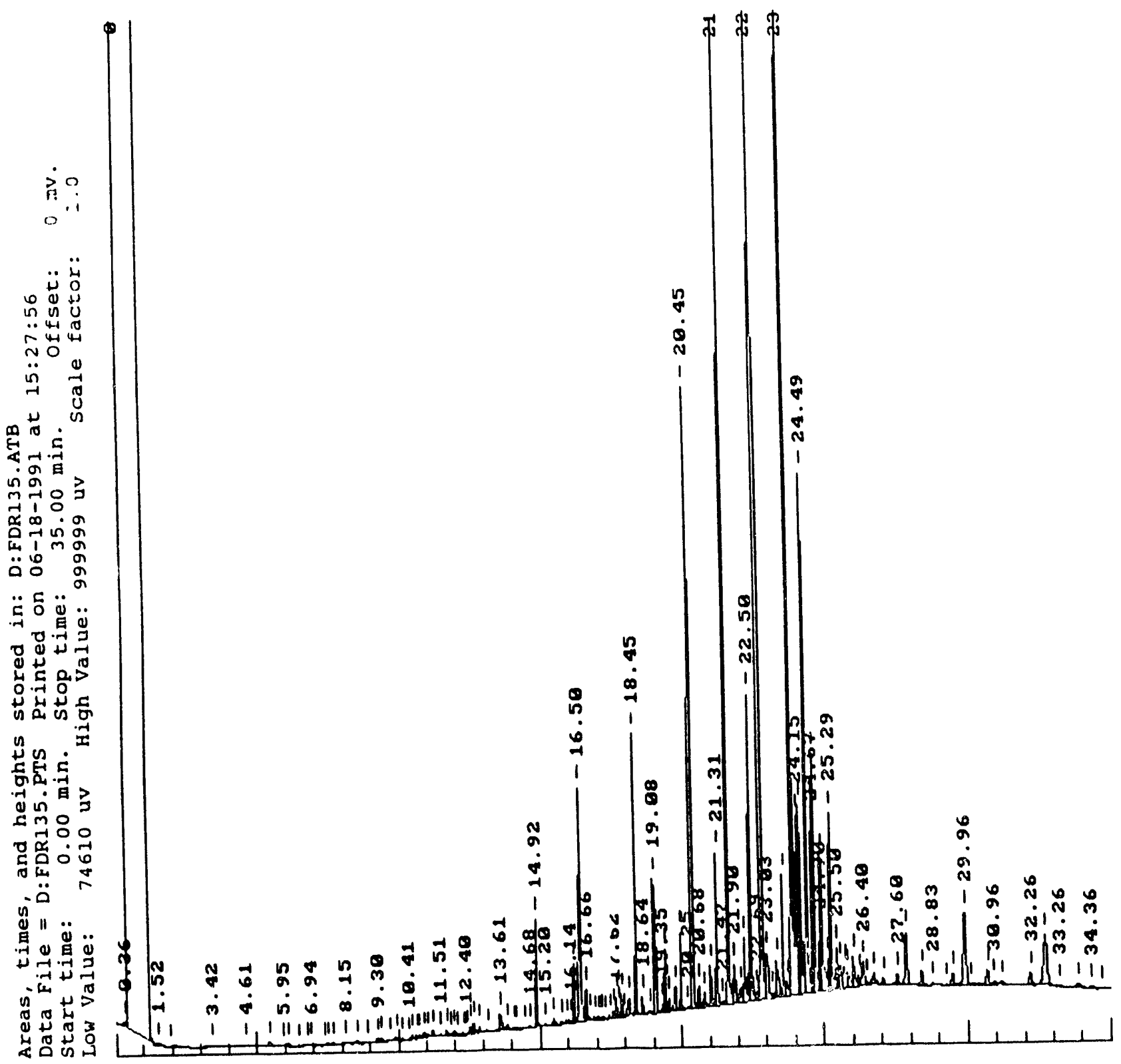

FIGURE E.40 GC/FID Chromatogram of Sample HTA056593V02 

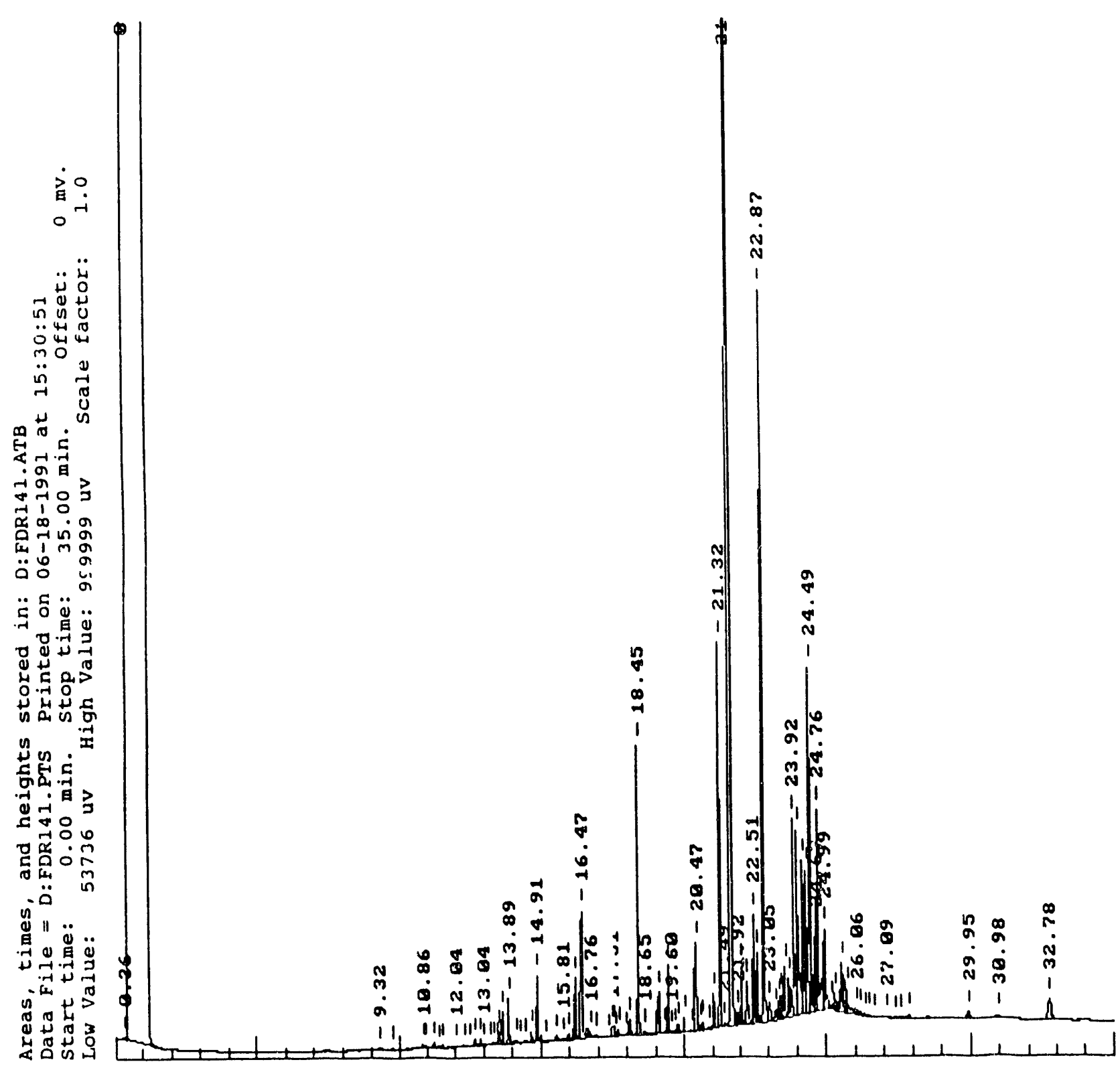

FIGURE E.41 GC/FID Chromatogram of Sample HTA056603V01 


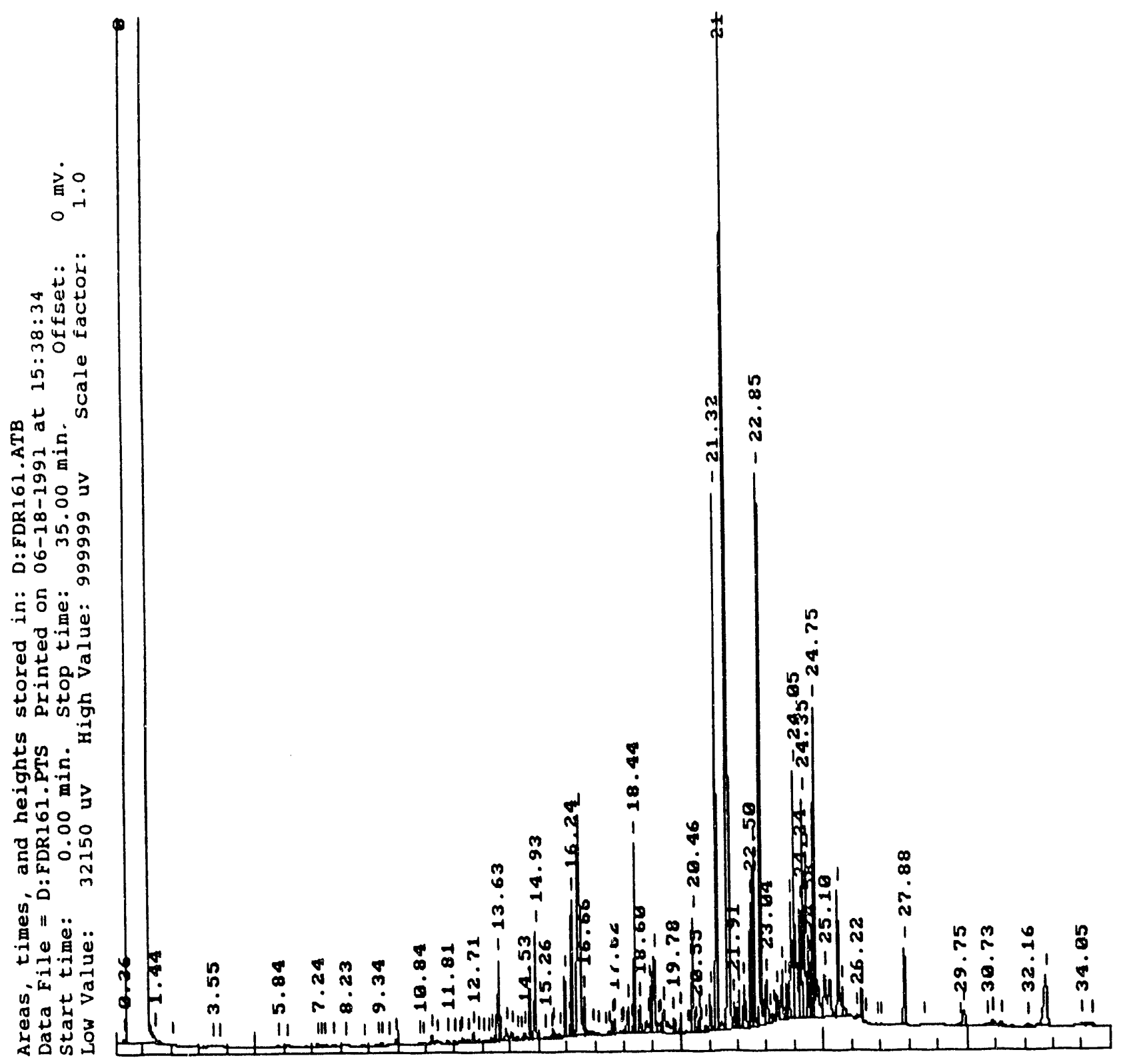

FIGURE E.42 GC/FID Chromatogram of Sample HTA979679V01 


\section{Appendix F: Target List for U.S. Environmental Protection Agency Semivolatile Priority Pollutants}

This Appendix provides a list of the 64 chemical compounds that are categorized as semivolatile priority pollutants by the U.S. Environmental Protection Agency. These compounds are judged to present a potential hazard because of their toxicity and because they may be found at various types of hazardous waste sites in the United States. 
TABLE F.1 EPA Semivolatile Priority Pollutants ${ }^{a}$

Phenol

2-Chlorophenol

1,4-Dichlorobenzene

2-Methylphenol

4-Methylphenol

Hexachloroethane

Isophorone

2,4-Dimethylphenol

2,4-Dichlorophenol

Naphthalene

Hexachlorobutadierie

2-Methylnaphthalene

2,4,6-Trichlorophenol

2-Chloronaphthalene

Dimethylphthalate

2,6-Dinitrotoluene

Acenaphthene

4-Nitrophenol

2,4-Dinitrotoluene

4-Chlorophenyl-phenylether

4-Nitroaniline

$\mathrm{N}$-Nitrosodiphenylamine

Hexachlorobenzene

Phenanthrene

Carbazole

Fluoranthene

Butylbenzylphthalate

Benzo(a)anthracene

bis(2-Ethylhexyl)phthalate

Benzo(b)fluorznthene

Benzo(a)pyrene

Dibenz(a,h)anthracene bis (2.Chloroethyl) ether

1.3-Dichlorobenzene

1,2-Dichlorobenzene

2,2'-oxybis (1-Chloropropane) ${ }^{b}$

N-Nitroso-di-n-propylamine

Nitrobenzene

2-Nitrophenol

bis (2-Chloroethoxy) methane

1,2,4-Trichlorobenzene

4-Chloroaniline

4-Chloro-3-methylphenol

Hexachlorocyclopentadiene

2,4,5-Trichorophenol

2-Nitroaniline

Acenaphthylene

3-Nitroaniline

2,4-Dinitrophenol

Dibenzofuran

Diethylphthalate

Fluorene

4,6-Dinitro-2-methylphenol

4-Bromophenyl-phenylether

Pentachlorophenol

Anthracene

Di-n-butylphthalate

Pyrene

3,3'-Dichlorobenzidine

Chrysene

Di-n-octylphthalate

Benzo(k)fluoranthene

Indeno(1,2,3-cd)pyrene

Benzo $(g, h, i)$ perylene

a EPA Contract Laboratory Program Staiement of Work for Organics Analysis, Multimedia, Multiconcentration, Document Number OLM01.0

b Formerly known by the name bis(2-chloroisopropyl)ether. 

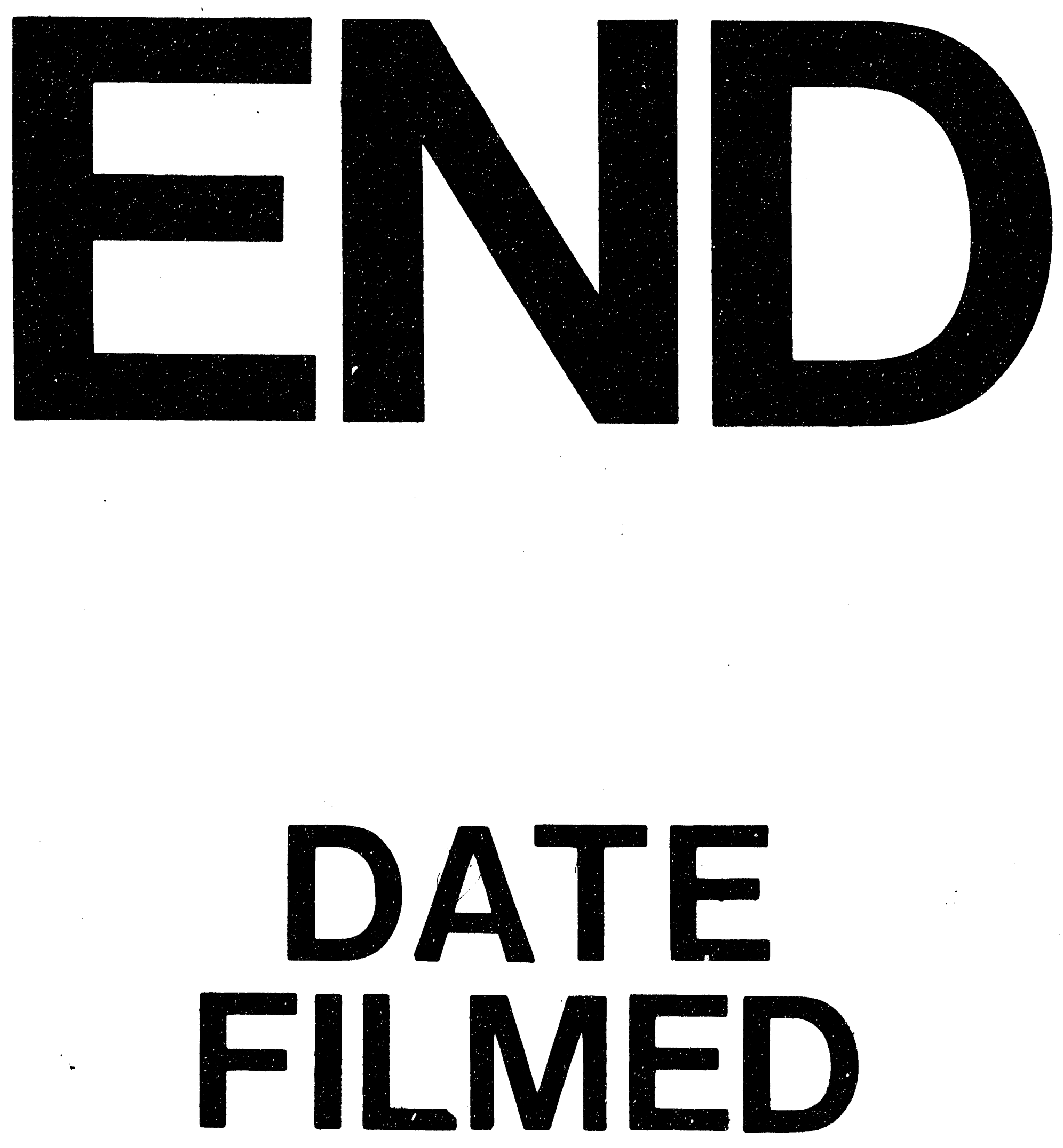

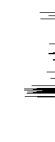

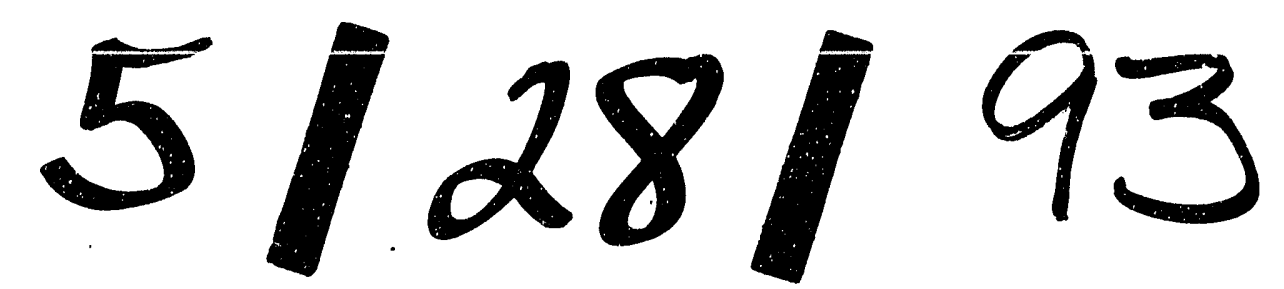




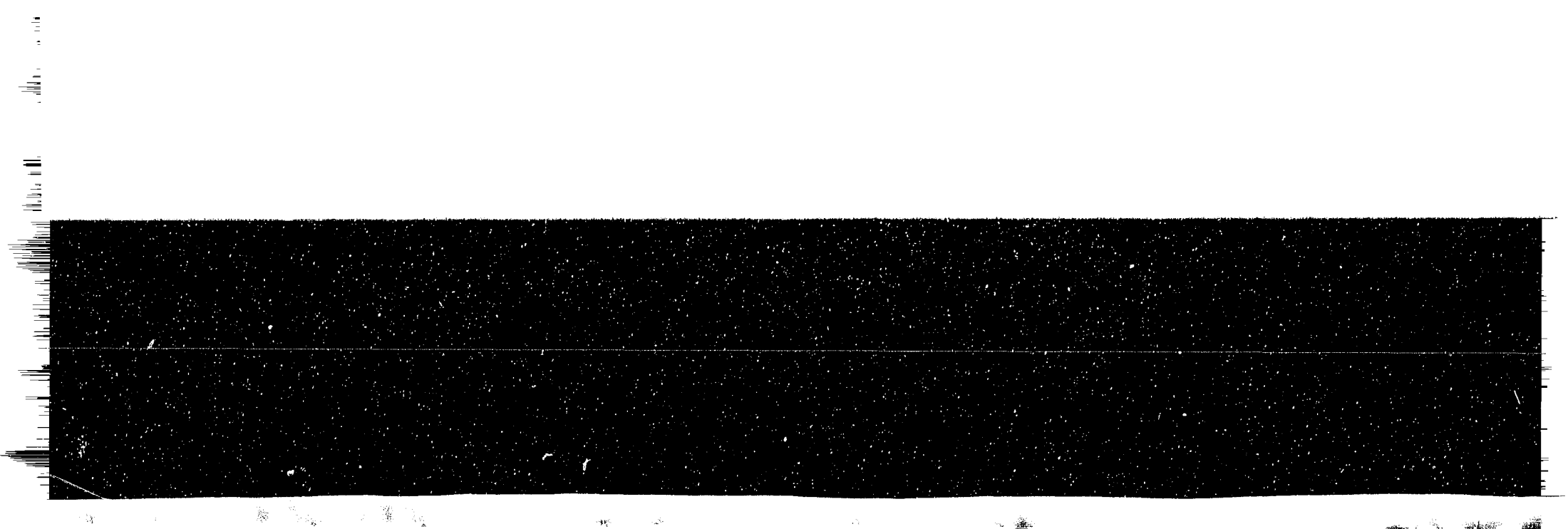

